\title{
Australian Transnational Vocational Education and Training Provisions: Sustainability, Quality, and Relevance
}

A thesis submitted in fulfilment of the requirements of the degree of

\author{
Doctor of Education \\ by \\ Louise Elisabeth King \\ Master of Arts in Public Sector Leadership \\ Graduate Certificate in Management \\ Graduate Certificate in Adult Education in Community \\ Bachelor of Arts - Social Welfare
}

from

School of Education and Professional Studies (Brisbane, Mt Gravatt)

Faculty of Education

Griffith University

7 March 2019 


\section{Abstract}

In an era of globalisation and economic competitiveness, Australia plays a major role in assisting other countries' governments to build their workforce through the provision of vocational education programs. This is referred to as transnational education. It encompasses any educational service or product offered by an educational institution based in one country to students in another. The advantages of the provision of these programs include expanding opportunities for governments and individuals to access relevant and quality vocational education in their own country. However, the capacity of Australian educational providers to meet the diverse needs of this market is hampered by its own national regulations. The mandatory requirements for the implementation of the Australian national vocational education curricula -- known as Training Packages -- which are tied to national industry standards, restrict these provisions and frequently render them irrelevant to the needs and circumstances of other countries. Therefore, questions emerge about the sustainability of pursuing an approach to transnational education that expects and requires teachers to maintain these standards in a country for which the curriculum was not designed.

To understand how teachers negotiate the needs and interests of transnational students and their sponsors amongst the imperatives of national curricula, a tentative analytical framework was synthesised from a review of relevant literature. This framework of curriculum conceptions was used as the basis for comprehending what constitutes an extensive account of curriculum in Australian transnational vocational education and training (VET). To understand further the key factors associated with teachers developing, adapting, and enacting Training Packages in another country, a phenomenological approach was used to collect and analyse data. The informants included 13 Australian and expatriate teachers who taught in transnational VET programs across nine countries. The findings contribute to an explanation of the complexity of factors that influenced these teachers' enactment of the curriculum and how they engaged in decision-making, problemsolving, and curriculum formation to overcome the constraints associated with implementation. The aim of using a phenomenological approach was to foster an understanding of curriculum transformation in Australian transnational VET through the experiences and perspectives of teachers directly involved in the process. It is contended that their views are essential in seeking to understand the relevance, quality, and sustainability of Australia's approach to transnational VET. 
The findings show that five situational factors had the most influence on these teachers' ability to maintain Australian curriculum standards in another country: (a) information, (b) resource, (c) material, (d) institutional, and (e) student readiness. These factors were manifested quite differently across national and cultural contexts. Thus, teachers faced different forms of dissonance between the intentions of the curriculum and what was understood and supported by stakeholders in each situation. As a consequence of these situational factors, and within their scope of decision-making, teachers took on the role of developers in the enactment of the curriculum, informed by three distinct phases: (a) assessment, (b) deliberation, and (c) curriculum remaking. Teachers reported engaging in these phases to resolve the tension between the expectation to maintain Australian standards and meeting their students' needs. In the process, they recontextualised their ideas of curriculum quality when they came to the realisation that they could not enact an Australian VET curriculum in another country with fidelity as such enactment was, by varying degrees, impracticable, irrelevant, and unenforceable. Consequently, through their deliberations, these teachers became the curriculum-makers. They remade the curriculum to increase its relevance, learnability, and attainability for students through its enactment. The outcomes of these strategies were shown to be not always consistent with the intentions of the curriculum. Moreover, the quality and relevance of the materials they developed was, in many instances, hampered by a lack of local knowledge.

These findings suggest that there is a need for supporting an extended scope of the teachers' role in negotiating with local stakeholders to develop a relevant curriculum and its measures of quality in context. The provision of customised professional development, along with material support and implementation guidelines, is also essential if such teachers are to fulfil this role. Additionally, closer monitoring of curriculum implementation by the Australian regulator would not only hold teachers accountable to, but would also legitimise, the decisions they make in another country. Such efforts may well strengthen the relevance, quality, and sustainability of these transnational educational provisions and also make transparent the worth of Australian VET qualifications obtained by students internationally. 


\section{Candidate's Statement}

I certify that this dissertation, titled Australian Transnational Vocational Education and Training Provisions: Sustainability, Quality, and Relevance, submitted for the degree of Doctor of Education, is my own work. This work has not previously been submitted for a degree or diploma in any university. To the best of my knowledge and belief, the thesis contains no material previously published or written by another person except where due reference is made in the thesis itself.

Signed:

Louise Elisabeth King

Dated: 7 March 2019 
Table of Contents

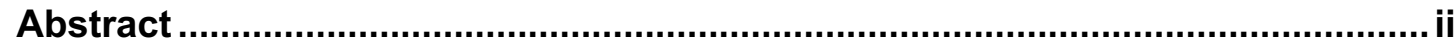

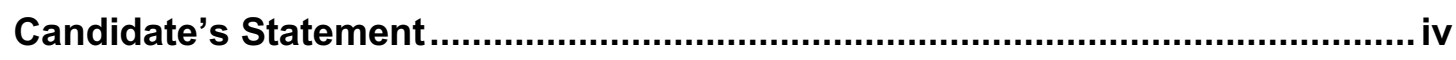

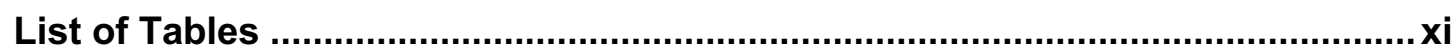

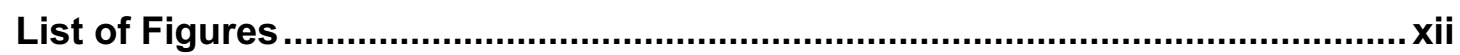

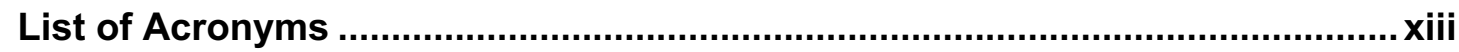

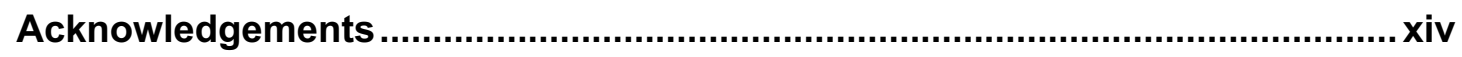

Chapter 1 Australian transnational vocational education and training: An

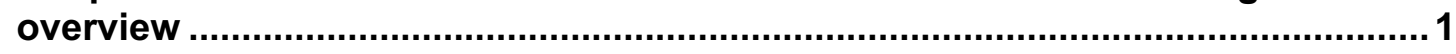

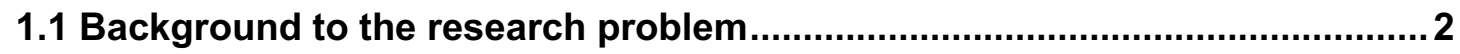

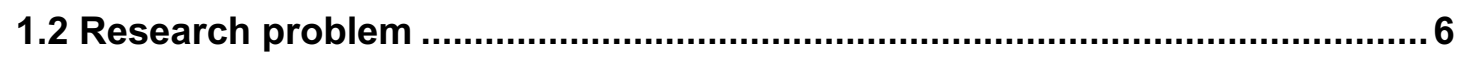

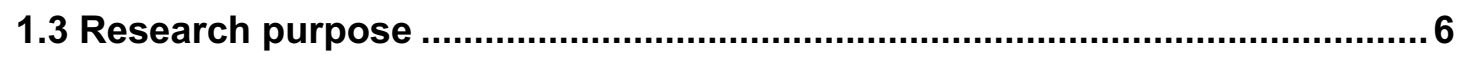

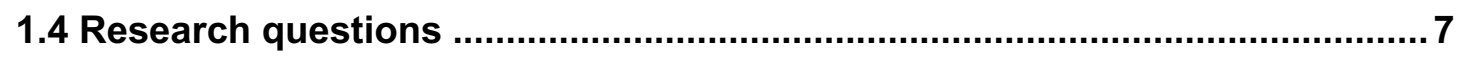

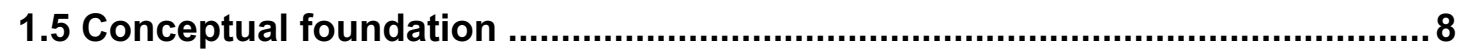

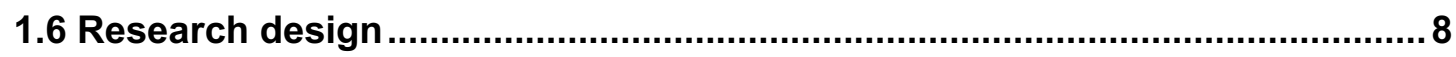

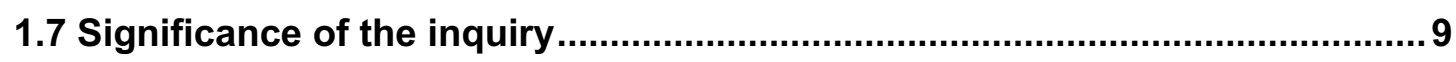

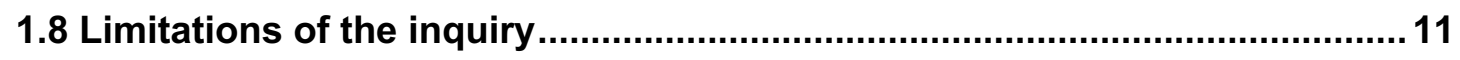

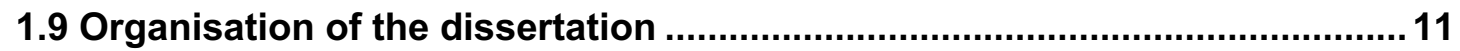

Chapter 2 The quality, relevance, and sustainability of Australian transnational

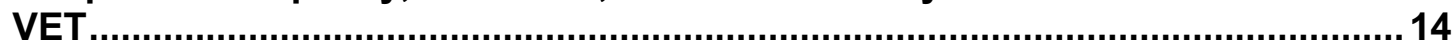

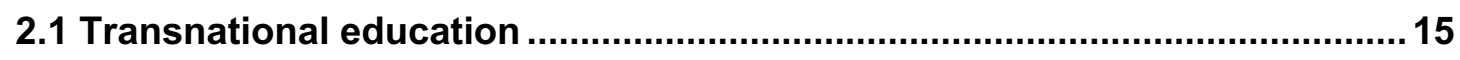

2.1.1 Transnational education and the global market .................................. 16

2.1.2 Transnational education in the context of globalisation ............................. 18

2.1.3 Quality and relevance of transnational education ................................ 21

2.1.4 Sustainability of transnational education .......................................... 24

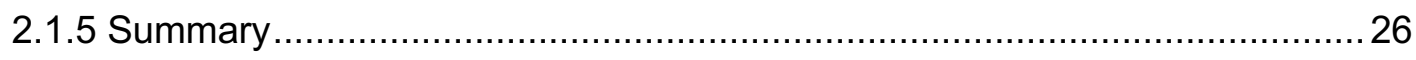

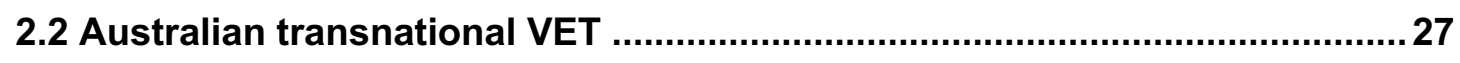

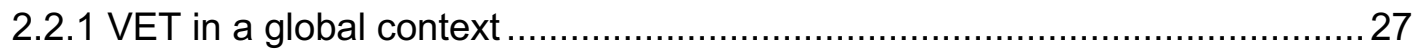


2.2.3 Australia's approach to the provision of transnational VET ......................... 30

2.2.4 Australian transnational VET: An overview ............................................... 31

2.2.5 Relevance and quality of Australian transnational VET ........................... 35

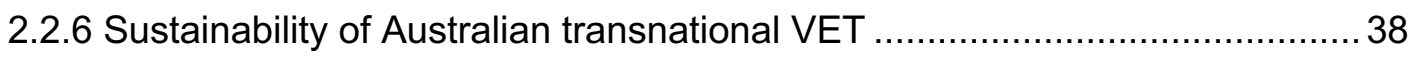

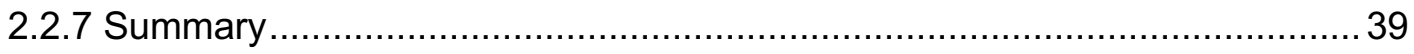

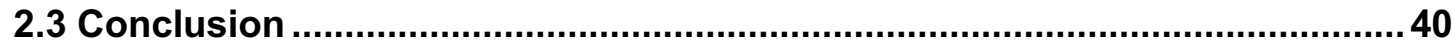

Chapter 3 Training packages: Implementing the curriculum in Australian

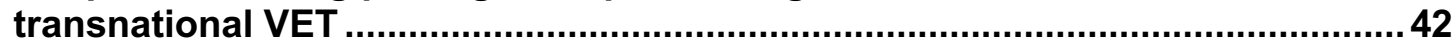

3.1 Conceptualising curriculum for Australian transnational VET .....................44

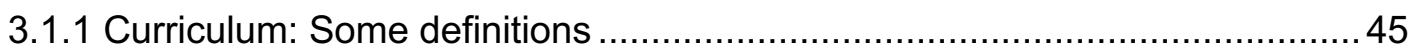

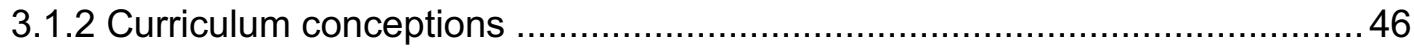

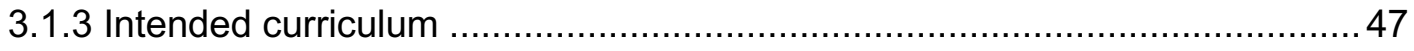

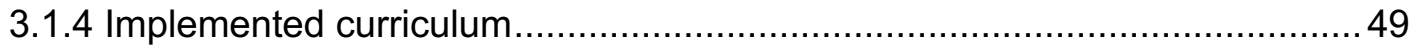

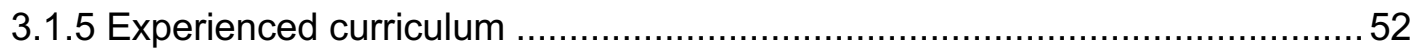

3.1.6 Relationship amongst curricula conceptions..................................... 54

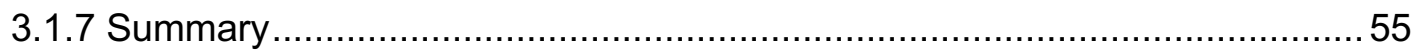

3.2 Curriculum conceptions in Australian transnational VET ............................55

3.2.1 The intended curriculum in Australian transnational VET ...........................55

3.2.2 Implementation of the curriculum in Australian transnational VET ..............60 60

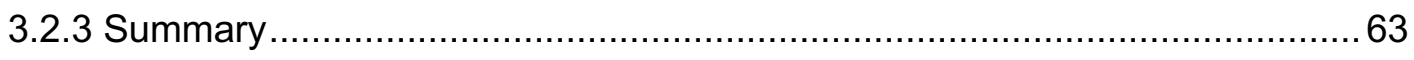

3.3 Role of the teacher in Training Package implementation in Australian

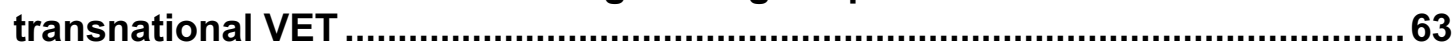

3.3.1 Teacher decision-making and problem-solving in Training Package implementation in Australian transnational VET

3.3.2 Curriculum-making for Australian transnational VET ............................... 70

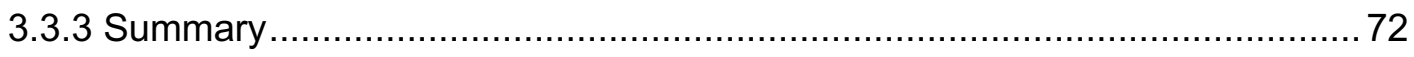

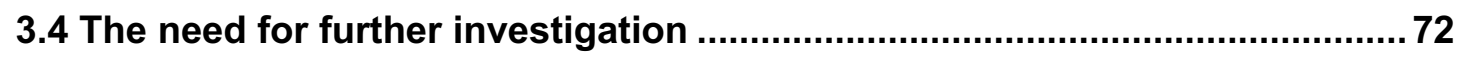


Chapter 4 Investigating the experiences of teachers' enactment of the curriculum in Australian transnational VET.

4.1 Research orientation and approach ........................................................ 75

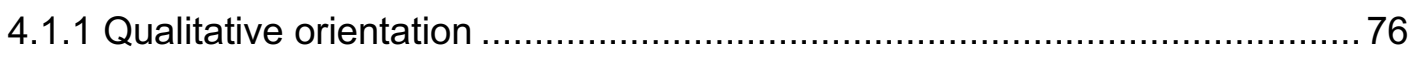

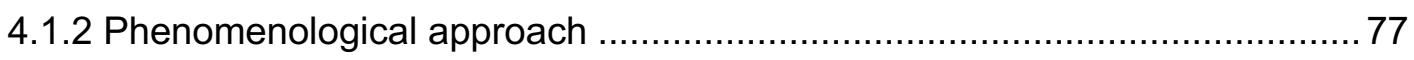

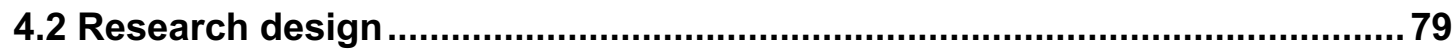

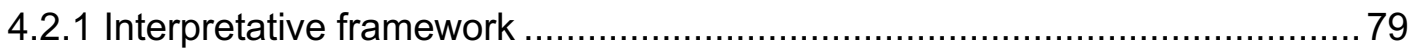

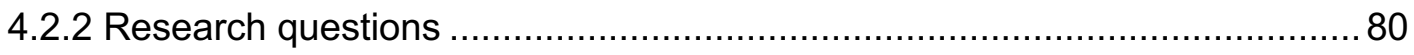

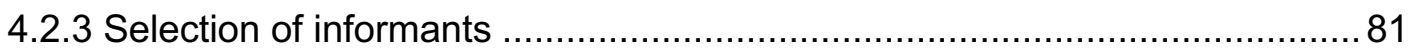

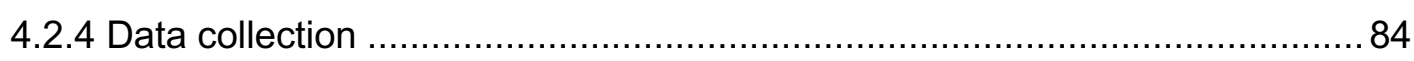

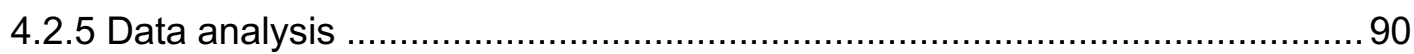

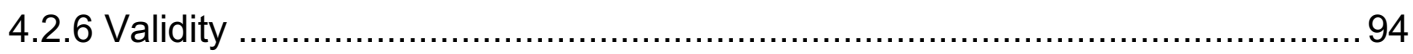

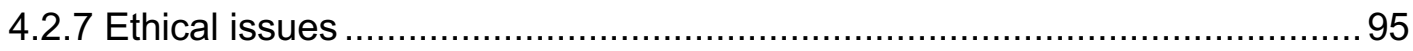

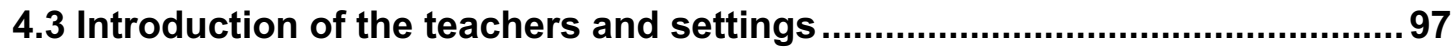

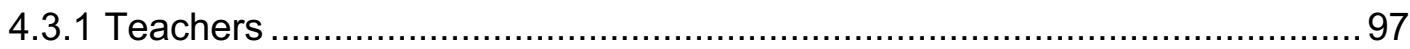

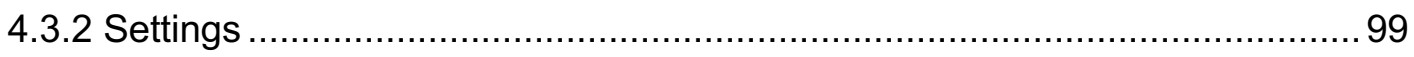

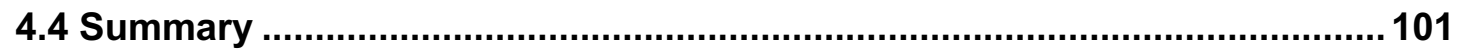

Chapter 5 The influence of situational factors on curriculum implementation in Australian transnational VET ......................................................................... 102

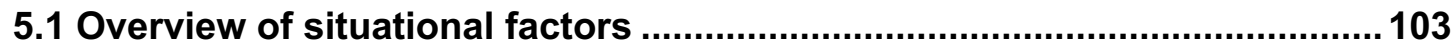

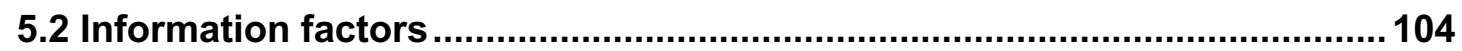

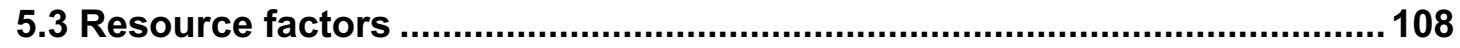

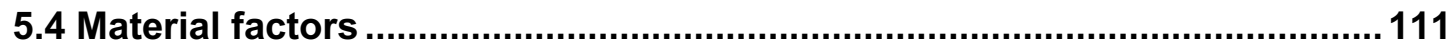

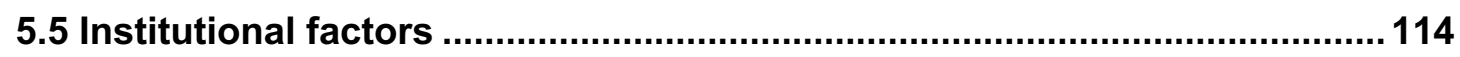

5.6 Student readiness factors ...................................................................... 118

5.6.1 Student goals and interest ................................................................ 119

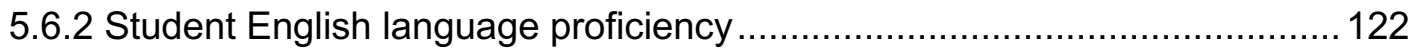

5.6.3 Student prior knowledge and abilities .............................................. 124 
5.6.5 Combination of student readiness factors............................................ 128

5.7 Teachers' experience of situational factors............................................128

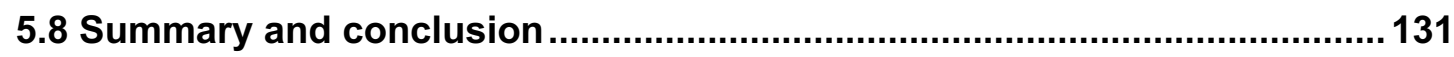

Chapter 6 The influence of situational factors on teacher decision-making and problem-solving in Australian transnational VET ...........................................133

6.1 Teacher decision-making and problem-solving ...................................... 133

6.2 A reactive approach to decision-making and problem-solving ..................135

6.3 A practical approach to decision-making and problem-solving .................137

6.4 An interactive approach to decision-making and problem-solving ............140

6.5 Subjective approach to decision-making and problem-solving ................ 144

6.6 Experience of teacher decision-making and problem-solving ................... 148

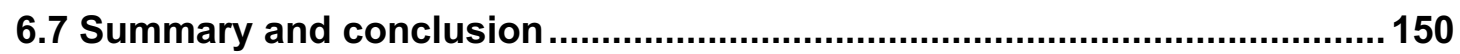

Chapter 7 Curriculum remaking in Australian transnational VET ...................152

7.1 Overview of curriculum remaking........................................................... 153

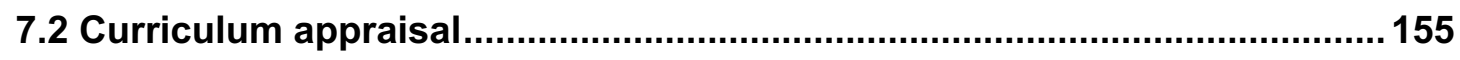

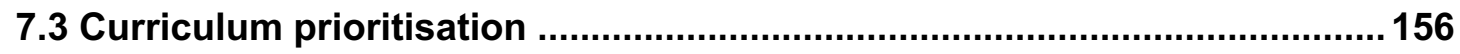

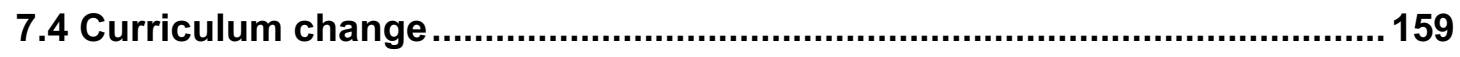

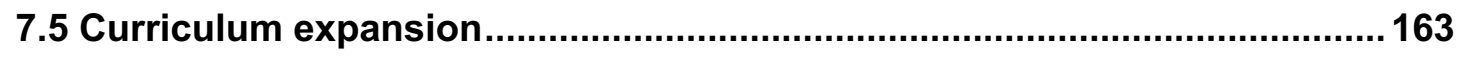

7.6 Curriculum design and experimentation................................................. 167

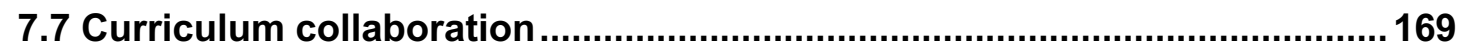

7.8 Teachers' experience and role as adaptive curriculum-makers ................. 172

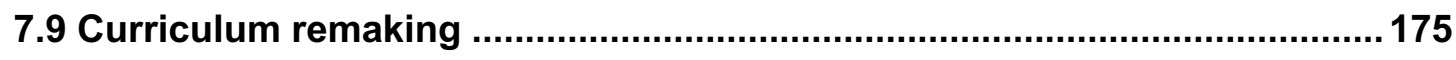

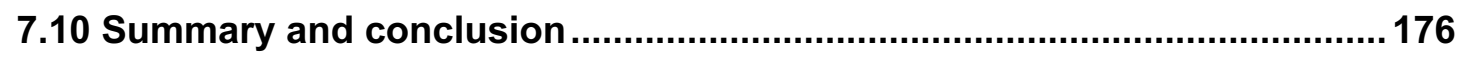

Chapter 8 Conceptualising curriculum implementation in Australian transnational VET: Implications for quality, relevance, and sustainability of provision ........................................................................................................ 179

8.1 Conceptualising curriculum implementation in Australian transnational VET 


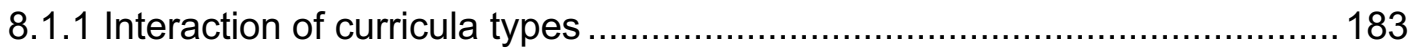

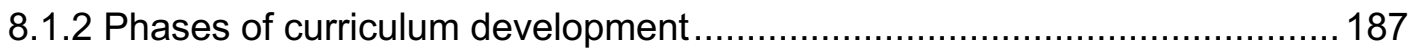

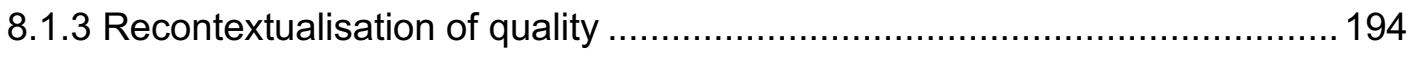

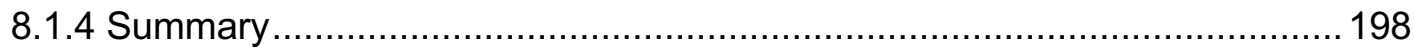

8.2 A sustainable approach to Australian transnational VET provision .......... 199

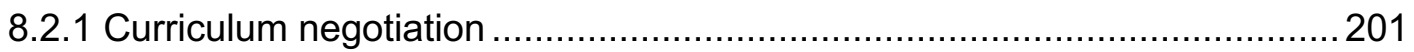

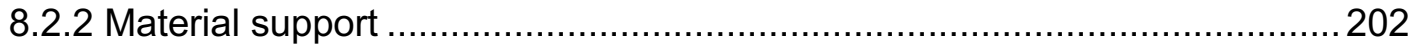

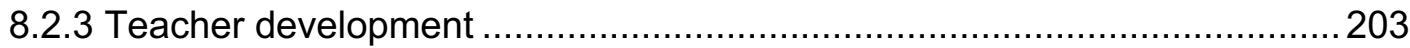

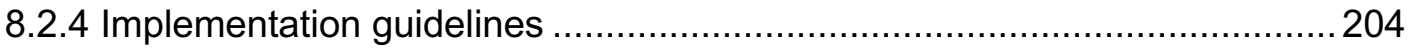

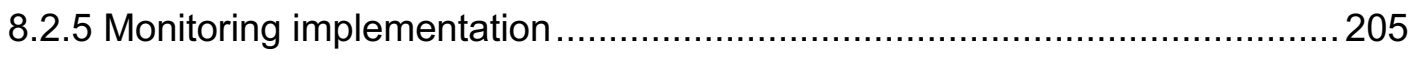

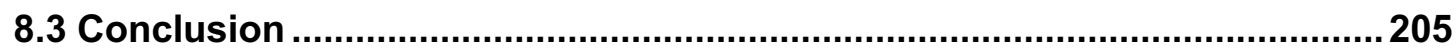

Chapter 9 Transnational vocational education: Conclusions and contributions

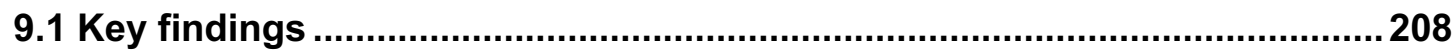

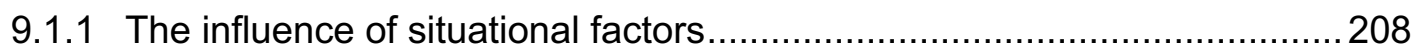

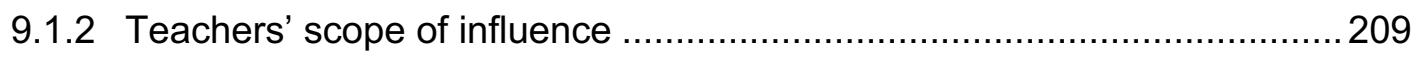

9.1.3 Teachers as adaptive curriculum-makers ......................................... 210

9.1.4 Curriculum development as a framework for teacher decision-making in enactment

9.1.5 The limitations of the intended curriculum of Training Packages in transnational vocational education

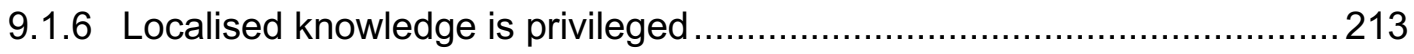

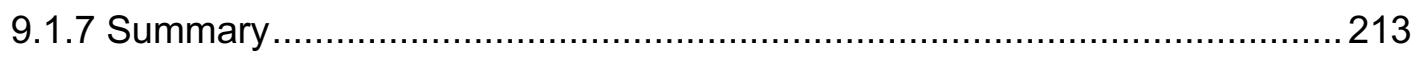

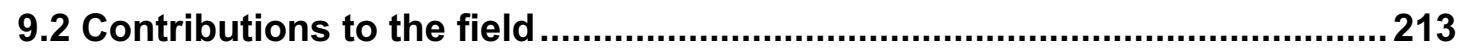

9.2.1 Identifying factors shaping the enacted curriculum in Australian transnational VET

9.2.2 Conceptualising the tension between the intended and enacted curricula in Australian transnational VET

9.2.3 Recognising the role that teachers play as curriculum-makers in Australian transnational VET 
9.2.4 Identifying strategies for improving the relevance, quality, and sustainability of Australian transnational VET .................................................................. 216

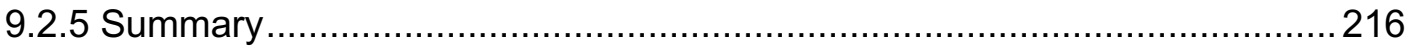

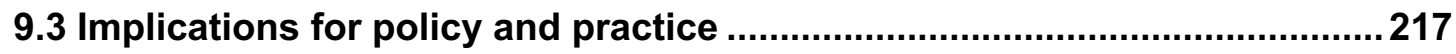

9.3.1 Australian transnational VET policy reappraisal..................................217

9.3.2 Support for an extended scope of role for transnational teachers .............218

9.3.3 Provision of specific forms of professional development for transnational

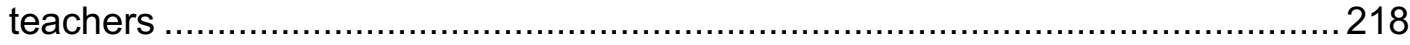

9.3.4 Improvement of Training Packages for international implementation .........219

9.3.5 Effective and regular monitoring by Australian stakeholders .................... 219

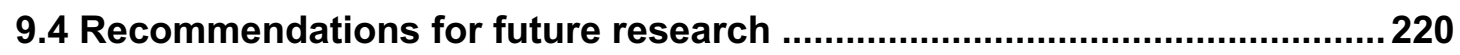

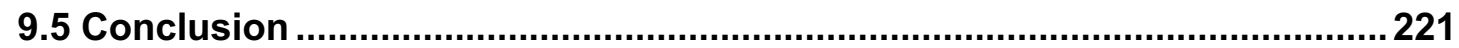

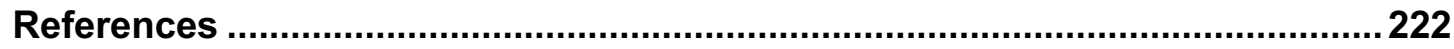

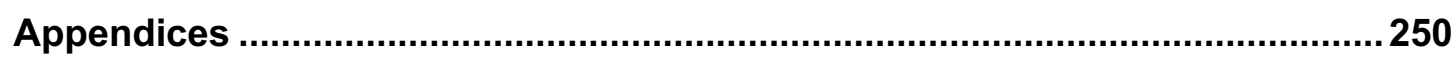

Appendix A: Participant recruitment advertisement....................................... 250

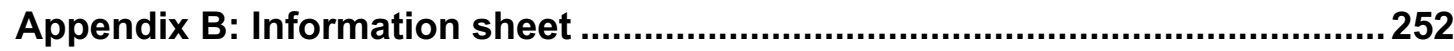

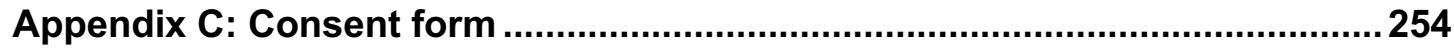

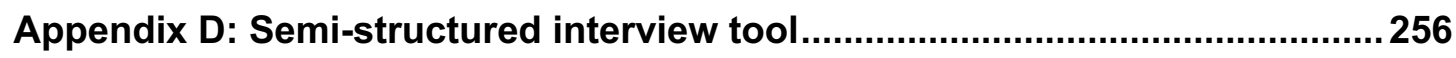

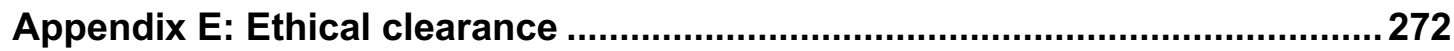




\section{List of Tables}

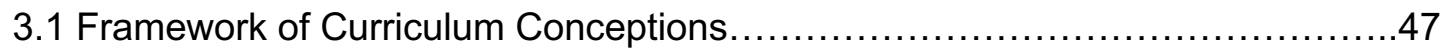

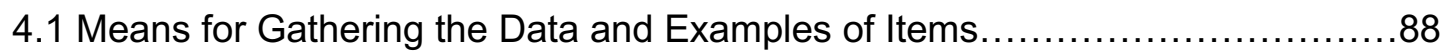

4.2 Partial Example of Themes and Supporting Statements for One Informant......91

4.3 Example of Collation of Quantitative Data.................................. 92

4.4 Teacher Demographics, Qualifications, Expertise, and Experience..............97

4.5 Country, Teaching Environment, Student Cohort, Type of Arrangement for

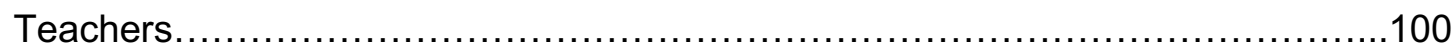

5.1 Factors Rated by Teachers as an Enabling or Constraining Influence on

Curriculum Implementation...................................................104

5.2 Factors, Role, and Influence of Teachers' Enactment of Curriculum.............129

6.1 Summary of Teachers' Decision-Making and Problem-Solving Approaches....134

7.1 Common Curriculum Remaking Strategies Utilised by Teachers................154

8.1 Curriculum Conceptions, Description, and Influence.........................184

8.2 Three Phases of Curriculum Development Undertaken by Teachers.............189

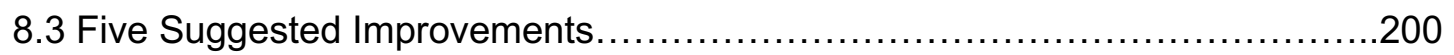




\section{List of Figures}

8.1 Situational model of curriculum implementation.

8.2 Curriculum development as a framework for teacher decision-making and problem-solving. 188

8.3 Teachers' recontextualisation of quality. 194 


\section{List of Acronyms}

ACPET Australian Council for Private Education and Training

AEI Australian Education International

ASQA Australian Skills Quality Authority

AVETRA Australasian Vocational Education and Training Research Association

CTE Career and Technical Education

EU European Union

FET Further Education and Training

GATS General Agreement on Trade in Services

NCVER National Centre for Vocational Education Research

OECD Organisation for Economic Co-operation and Development

PNG Papua New Guinea

TAE Training Assessment and Education

TVET Technical and Vocational Education and Training

UAE United Arab Emirates

UK United Kingdom

USA United States of America

VET Vocational Education and Training

VTE Vocational and Technical Education

VTET Vocational and Technical Education and Training

WTO World Trade Organisation 


\section{Acknowledgements}

I would like to express my gratitude to my principal supervisor, Professor Stephen Billett. He has been generous with his time, knowledge, and experience, and has provided me with invaluable and insightful feedback. His support in facing the many unexpected challenges that come with writing a thesis such as this has been unstinting and is greatly appreciated. I would also like to thank my associate supervisors, Associate Professor Sue Thomas and Associate Professor Sarojni Choy. Additionally, I wish to acknowledge the editing work of Elizabeth Stevens.

I would also like to express my gratitude to the teachers, the informants of this study, who gave their time, experience, and stories and, in doing so, provided me with invaluable data. Their commitment to their students and to the principles of education was an inspiration to me.

Lastly, I would like to thank my family who have provided me with endless love, support, and encouragement and have always believed in my ability to achieve whatever I set my mind to, including this dissertation. 


\section{Chapter 1}

\section{Australian transnational vocational education and training: An overview}

Many countries across the world are seeking to build the capacity of their workforce through improved vocational education and training (VET) provisions. An increasing number of these countries are meeting this goal through the importation of curriculum products and the engagement of teachers with the expertise to enact them. This phenomenon, more broadly referred to as transnational education, typically features the export of educational programs that have been developed by countries with effective vocational education systems to other countries. In recent years, many Australian vocational educational institutions have become active participants in this global market. While these provisions have the advantage of expanding opportunities for governments and individuals to access vocational education and training in their own country, they also generate unique challenges in their implementation, and for those who implement them: VET teachers. Indeed, personal experience has shown that it is seldom possible to merely replicate or introduce a curriculum that has been successful in one country and implement it in another without adapting it to suit the local context. This is more likely to be true when there are significant cultural, societal, and institutional differences between the country that developed the curriculum and the one in which it is to be applied.

Australia's reputation for relevance and quality in transnational VET is linked to the teachers' enactment of the curriculum (Tran \& Dempsey, 2017). Yet, little is known about the experiences of teachers whose role it is to negotiate between the imperatives of national curriculum standardisation and the needs and interests of students and their sponsors in different cultural and institutional contexts, internationally. This is regrettable given that the number and scope of such provisions have expanded significantly over the last decade. However, serving overseas markets has drawn the attention of regulators concerned with protecting Australia's reputation for international education. Consequently, at a time when demand for VET in the international market is growing, Australian education and training institutions are beset by government regulations to provide their programs and secure outcomes to the same standard offshore as they do for domestic provisions. However, questions emerge about the feasibility of meeting such expectations, including by what degree such provisions can be adapted to effectively serve the markets and still meet Australian regulatory requirements. Whilst these 
institutional considerations are gaining attention, they do little to assist the understanding of the kind of actions that need to be taken by teachers engaged in transnational education. It is they who are the key curriculum-makers as they negotiate and enact transnational educational arrangements through their work.

This inquiry seeks to understand the implications of enacting Australian VET curricula in nine countries. It explores them from the perspectives of 13 Australian and expatriate teachers who had responsibility for enacting such provisions overseas. It is their proximity to the core issues of relevance and quality of Australian transnational VET provisions that renders their views significant in seeking to consider its sustainability.

\subsection{Background to the research problem}

Vocational education and training in its multiple forms of provision and regulation has become a critical investment for governments in an era of globalisation and economic competitiveness (Keating, 2008). As nation states seek to advance their human capital (i.e., workforce skills) through VET, many of them are looking towards nations with well-established VET systems, such as Australia, to secure such provisions. However, many and perhaps most of these countries which now host these provisions have industries, standards, work practices, values, and career paths that are different from those that Australian VET curricula have been specifically designed to address. Therefore, it is possible that the formal curricula might be dissociated from the needs and aspirations of these countries because they are premised on Australian domestic concerns, traditions, institutions, and interests, with certification based on and regulated by national standards. Such circumstances raise questions about the relevance, quality, and sustainability of Australian transnational VET provisions.

As is proposed in Chapter 2, it is often claimed that Australian VET courses are attractive to countries that choose to purchase such provisions because they are based on an integrated model of skills standards and accompanied by a framework for awarding qualifications (Keating, 2008; Ziguras, 2003). These compelling features have contributed to the export of accredited courses overseas (AEI, 2006). While the provision of these courses produces a range of educational, financial, economic, social, and cultural benefits for Australia and host countries, it also carries potential financial and reputational risks (ASQA, 2016). Indeed, the scale and reach of these provisions and the diversity of countries in which they are hosted, as well as the distinct stage of economic and institutional development they are experiencing, 
means that Australia's reputation can be harmed at any time by the actions of educational institutions. In 2017, it was estimated that 36,765 students were enrolled in VET transnational programs provided by 68 Australian public and private institutions in 40 countries (DET, 2018). This equates to 1 per cent of recorded Australian VET enrolments (Brown, Buttress \& Matthews, 2018). The main countries for the export of these programs were China, Fiji, Mauritius, Kuwait, and Hong Kong (DET, 2018). Therefore, the imperative to appraise the worth and quality of Australian VET transnational provisions is vital to protect the integrity and reputation of the export and to realise the expectations of all stakeholders, including those who invest their time and resources to secure productive outcomes for overseas students.

Australia's reputation for relevance and quality in transnational VET provisions is linked to how teachers enact the curriculum (Tran \& Le, 2017). Yet, the nature and scope of what overseas hosts expect Australian and expatriate teachers to do, in meeting local needs and requirements, is complex and can create substantial conflicts. This is because the underlying and incontestable principle of Australia's approach to quality is that the curriculum must be implemented with fidelity (Baird, 2010). However, the circumstances for enactment and a teachers' agency to make decisions in other countries is most likely to be very different compared to Australia. Thus, as explored through this dissertation, many teachers find themselves in the precarious situation of trying to negotiate for changes which are not always well understood by stakeholders offshore. Consequently, these teachers have a demanding and complex role that goes beyond merely being faithful implementers of what an Australian federal government has proposed through national curriculum documentation. However, more needs to be known about the factors that influence their decisions and subsequently transform the curriculum beyond what was intended. This is one goal of this dissertation.

While there is considerable research on the provision of Australian transnational education in the higher education field, it is not particularly relevant to the VET sector. This is because universities are not always required to adhere to a prescribed and standardised national curriculum, except where the course leads to a regulated occupation (e.g., nursing) or professional standards (e.g., Masters of Business Administration). In comparison, there are only a few studies on Australian transnational VET and these tend to comprise single-site case studies conducted by staff involved in these provisions (e.g., AEI, 2011; Bailey, 2011; Karthigesu, 2007; Shi \& Woodley, 2008; Woodley, 2007, 2008). The findings from these studies have revealed that teachers face many challenges in trying to enact the curriculum in the same way as they would in Australia due to a multitude of overlapping pedagogical, 
cultural, and political factors. Some studies have also highlighted the Australiancentric nature of the curriculum and its lack of relevance for transnational students. However, given the limited number of studies, it is not possible to draw any overall conclusions from the findings about the phenomena of Australian transnational VET.

It seems unlikely that there is uniformity amongst Australian VET provisions internationally given that many studies have shown that even nationally there is significant variability due to the diversity of educational contexts and student cohorts (Agbola \& Lambert, 2010; Guthrie, Perkins, \& Nguyen, 2006; Guthrie, 2009; Hoeckal, Field, Jutesen, \& Kim, 2008;). Moreover, many studies reveal that teachers find it difficult to maintain fidelity to the curriculum even in domestic circumstances because teaching and learning is negotiated and modified due to a range of contextual factors (Chappell, Solomon, Tennant, \& Yates, 2002; Down, 2003; Guthrie, 2009; Harris, Simons, \& Clayton, 2005; Simons, Meyers, Harris, \& Blom, 2003). Some of these factors have been found to be external to the situation, such as cultural and societal expectations, educational policy, funding, and the applicability of the subject matter. Other factors have been found to be internal to the situation such as students' abilities, interests, and needs, the availability of materials, facilities, and equipment, and the teachers' values, skills, and knowledge. All these factors influence the transformation of curriculum in implementation and demonstrate that there is variability in domestic VET provisions. It follows, then, that if inconsistencies exist within national VET systems, then it is far more likely that there is a greater degree of variability in VET provisions between Australia and other countries.

More broadly, and as discussed in Chapter 3, many studies in the field of curriculum development and implementation have also concluded that there is nearly always widespread variation in the implementation of any curriculum across a range of contexts (Fullan \& Pomfret, 1977). Further, that curriculum is rarely implemented with fidelity, and even when faithful implementation is initiated, it is rarely sustained (Fullan, 2008). These early studies proposed that the factors found in the local situation were the determinants of curriculum implementation. Other researchers found that educational policies did not have a strong influence over the success or otherwise of the implementation because most developers fail to address these critical local factors (Corbett \& Rossman, 1989; Fullan, 1982; Fullan \& Stiegelbauer, 1991; House,1996). This is hardly surprising in transnational VET given that those preparing national syllabi would be unaware of these circumstances and not expected to address them. Contemporary research has shown that the extent to which teachers can exercise agency to address these factors varies from context to context because their level of autonomy to make decisions and act is not just a 
matter of personal choice, but shaped by the constraints, opportunities, and actors' interpretations and expectations present in their situation (S. J. Ball, Maguire, \& Braun, 2012; Biesta \& Tedder, 2007; Priestley, Edwards, Priestley, \& Miller, 2012). Given these findings, it is questionable as to how realistic is the Australian federal government's policy objective of standardised outcomes for vocational education internationally.

As elaborated in Chapter 2, there is also the question as to whether such a uniform approach to curriculum implementation in transnational VET is even desirable. Many scholars claim that any approach that involves one country directly transferring a national model of education and training onto another effectively diminishes local values and practices and, in the process, reinforces and creates new forms of regional and global inequalities (Little, 2000; Marginson, 1999; McGrath, 2002). Further, some studies have shown that such an approach tends to fail because local factors are usually ignored or overlooked even in curriculum implementation (Epstein, 1987; Hulme, 2005; Perry \& Tor, 2009). However, other recent studies (Dempsey \& Tao, 2017; Reich \& Ho, 2017) have sought to examine how imported programs can be adapted to suit the needs and interests of other countries. This research suggests that if adaptations are made to national models of provision to suit local circumstances they have a better chance of success.

As proposed in Chapter 3 , the curriculum adaption approach is supported in the broader curriculum literature (D. L. Ball \& Cohen, 1999; Doyle, 1992; Priestley, 2010 ) in contrast to the curriculum fidelity approach where teachers are viewed as mere implementers of a top-down curriculum. The curriculum adaption approach enfranchises teachers to shape the curriculum according to their situation. It is proposed that curriculum adaption better meets the needs of students as it takes into account their differing learning needs, styles, and preferences. There is also the possibility of teachers extending their role further as curriculum developers, researchers, or makers where they get to decide what is meaningful and significant. All of these roles will inform their pedagogical interactions with students, beyond what is mandated. As a result, the curriculum is shaped by the decisions teachers make in enactment.

A conundrum of the Australian VET system is that while it requires fidelity to the curriculum content and outcomes, it also expects teachers to develop and use curriculum materials to assist students achieve those outcomes. Therefore, it is of central interest to this inquiry how Australian and expatriate teachers negotiate and deliberate with stakeholders to meet the needs of the students. This includes how teachers "develop" or even "remake" relevant and quality curriculum materials to 
facilitate students' learning when they have little knowledge about the social, political, economic, and cultural context in which they teach.

As is advanced in Chapters 2 and 3, Australia's reputation for relevance and quality in the global education market is linked to how teachers enact the curricula overseas. However, we need to know more about the experiences of teachers in trying to negotiate between the imperatives of national curriculum standardisation and the needs and interests of overseas students and sponsoring educational institutions in different cultural and institutional contexts. Only through this exploration can we understand how transnational vocational education can best progress. Thus, this inquiry seeks to understand the contextual factors influencing the decisions that a sample of 13 teachers made and the role these teachers played in the transformation of Australian VET curricula in nine countries.

\subsection{Research problem}

As proposed in Chapter 2, the lack of evidence about the worth and value of Australian transnational VET provisions is problematic given the investment and expectations of sponsors, students, and teachers. The ability of Australia to remain competitive and educationally viable in this expanding education and training market is dependent on ensuring both the quality and relevance of such provisions. If Australia is to continue exporting VET provisions to other countries it needs to consider how curriculum can be developed and enacted in ways that are relevant and sensitive to the various needs of those countries and students wanting to learn. In particular, it is proposed in Chapter 2 that there is a need for research which focuses on the contested realities of teachers within situated contexts, as the findings from these types of inquiries could identify whether current models of curriculum are suitable for international implementation. Thus, the inquiries need to progress beyond the handful of case studies in specific countries to more comprehensive and encompassing studies that are progressively more explanatory and insightful in considering the relevance, quality, and sustainability of Australian transnational VET.

\subsection{Research purpose}

This inquiry attempts to contribute to addressing these kinds of issues by examining how 13 Australian and expatriate teachers enacted Australian VET curricula in nine countries (see Chapters 5, 6, 7, \& 8). As detailed in Chapter 4, the practical inquiry identifies and explores the factors which emerge when teachers are 
expected to implement highly prescriptive, standardised, and regulated Australian national curricula in different cultural contexts. In particular, it focuses on how these factors influence the decisions made by teachers and how their actions transform the curriculum from what was intended. This inquiry considers that the teachers' role in the provision of Australian transnational VET positions their views and experiences as essential in seeking to understand the relevance, quality, and sustainability of Australian transnational VET as an export in the global market.

\subsection{Research questions}

Research projects need to be guided by clear intents and carefully considered questions. The principal questions guiding this inquiry are:

1. What is the relevance and quality of Australian VET provisions as an exported product (curriculum) in the global VET market?

2. How sustainable is the provision of Australian VET products in the current curriculum form as an export?

As detailed in Chapter 4, a phenomenological method of inquiry, comprising in-depth interviews with 13 Australian and expatriate teachers who worked abroad and taught Australian VET curricula in nine different countries, is adopted in this study. The interviews sought to answer the following research questions:

1. What are the contributing and impeding factors which affect teachers' implementation of the intended curriculum in transnational settings?

2. How do the contextual factors of transnational settings influence teachers' decision-making and problem-solving processes in enacting the curriculum in transnational settings?

3. In what ways are teachers the real curriculum-makers in such circumstances?

4. How is the intended curriculum of Australian VET transformed through the process of implementation in transnational settings?

The gathering of interview data and their analysis through the research design aimed to address these questions. 


\subsection{Conceptual foundation}

This dissertation is informed by a conceptual framework of curriculum that provides a broader perspective of curriculum beyond the intentions of the syllabus of Training Packages. Guided by the research questions and the literature, curriculum is defined as comprising both the planned and unplanned learning that occurs in implementation. Consequently, there is a need to consider the concept of curriculum as more than just the planned intentions of the developers, as it is also something that teachers enact and students experience (Billett, 2011). Curriculum theorists have advanced a number of conceptions and nine of those found in the literature are drawn together in a framework based upon Billett's (2011) three dimensions of the intended, implemented, and experienced curriculum. In Chapter 3 , it is explicated as the theoretical frame for the study. The framework is applied as a conceptual lens to elaborate on how the implementation of Training Packages might best be understood and realised in transnational education.

\subsection{Research design}

In Chapter 4, the phenomenological research design used as the methodology for this inquiry is explained and justified. This methodology seeks to capture the meanings for Australian and overseas expatriate teachers in enacting an Australian VET curriculum internationally. That is, their process of curriculum-making is explicated in the research method. The aim of phenomenological research is for teachers to reconnect with their original experience and illuminate and account for the meanings they hold about it (Moustakas, 1994). This inquiry focuses on the phenomenon of teaching in another country as teachers experience it rather than how it might be seen or speculated upon by others.

The use of qualitative interviews in the research design provides rich descriptions and in-depth accounts of the phenomenon (i.e., enacting VET curriculum) from the perspective of those involved (i.e., teachers) within the social context of teaching in a range of countries. Thus, the interviews provide a means to elicit, analyse, and consider data about the contextual experience, actions, and relationships of multiple teachers and about the different educational contexts in which they teach (Tierney \& Dilley, 2002). In this way, there is a clear alignment between what the intentions of this research are and the mode of enquiry. 


\subsection{Significance of the inquiry}

Considering the inevitable links between the teachers' enactment of curriculum and the relevance and quality of Australian transnational VET, it is surprising that so little research has been conducted into this phenomenon, as outlined in Chapter 2. This inquiry is one of the few conducted which specifically focuses on how Australian VET curricula can be developed and enacted in ways that are relevant and sensitive to needs of offshore students and their sponsors. Chapter 9 sets out four significant areas where the findings from this inquiry can contribute knowledge to the field of Australian transnational vocational education: (a) identify the factors that influence the curriculum implementation, (b) conceptualise the transformation of the curriculum; (c) elaborate the role of teachers as curriculum makers, and (d) identify strategies for strengthening the relevance, quality and sustainability of the curriculum as an export. This inquiry, therefore, aims to advance an informed consideration of the constraints and opportunities shaping teachers' adaption of Training Packages transnationally.

The first contribution to the field is the highlighting of factors that can influence curriculum implementation in transnational vocational education. The identification of these factors is important because they shape what is taught by teachers and learnt by transnational students. Moreover, it is these factors that will serve to raise or reduce curricula standards, and account for variations in the achievement of VET curricula standards between Australia and other countries.

Secondly, this inquiry contributes a conceptualisation of curriculum implementation to explain why a VET curriculum developed for Australian purposes and interests will most likely transform in another country. An examination of the processes of curriculum implementation in Australian transnational VET can provide a broader perspective of the curriculum, beyond the documented intentions of Training Packages embedded in the Australian VET system. It is proposed that this conceptual examination can contribute to a more complete account of curriculum implementation in Australian transnational VET.

The third contribution is the elaboration of the role of teachers as curriculum makers in Australian transnational VET. This is a central issue that is often overlooked in the literature on adapting Training Packages for international students (Tran, 2013b). Thus, this inquiry contributes to understanding the different types of adaptions that teachers make to the mandated curriculum and the challenges associated with developing materials for another country. It can also provide the 
basis for developing a model of professional development and support for the role of transnational teachers.

A fourth significant contribution is that this inquiry has identified strategies for strengthening the relevance, quality and sustainability of the curriculum as a global export. Thus, in contemplating the global convergence of national VET curricula this disseration provides insights into whether or not Australia should remain differentiated in line with national policy or move towards greater internationalisation of the VET curriculum and, hence, qualifications. Central to this, however, are the discussions in these chapters about whose interests will dominate Australian VET curricula as it converges with global patterns for securing human capital.

Aside from these primary contributions, this inquiry is also significant through its exploration of the phenomenon from the perspective of teachers. This inquiry utilises an 'emic' perspective which sees the knowledge of teaching as generated from those within the teaching profession (Elbaz-Luwisch, 1997) rather than the imposition of outsiders' perspectives of teacher effectiveness (Doyle, 1997). The emic perspective is important in this inquiry because, traditionally, quantitative and qualitative Australian VET research is often conducted by those outside the teaching profession and conclude with a set of rectifications or rules for teachers or educational institutions to follow (Dymock \& Billett, 2009). The findings from such inquiries tend to assist administrators and policy-makers to dominate and direct the practice of teachers leading to a high level of cynicism amongst stakeholders about the political influences that shape VET research agendas in Australia. Consequently, many teachers disregard the findings of such inquiries and, thus, much of the research has little impact on their practice (Dymock \& Billett, 2009). This inquiry aims to provide an alternative approach by enabling teachers to give emphasis to their meanings and actions in complex teaching and learning environments for the purposes of constructing critical inquiry and presenting the realities of teaching (Goodson, 1995). Further, this inquiry provides teachers with an opportunity to critique top-down curriculum development processes and search for knowledge which empowers rather than controls their practice (Elbaz-Luwisch, 1997).

Finally, this inquiry contributes new insights and perspectives about educational problems in a globalised world and challenges the uncritical transfer of educational policy from the western world to other countries in a postmodern and postcolonial era (Hickling-Hudson, 2003). This approach is distinct because an important component of the methodology is the in-depth interviewing of teachers across multiple and diverse socio-cultural and economic contexts. Thus, the teachers' stories allow the reader to consider the social and cross-cultural world in 
which they are embedded. This is important because, as discussed throughout, it is these teachers who are ultimately the curriculum makers in Australian transnational VET.

\subsection{Limitations of the inquiry}

While this inquiry seeks the views of offshore Australian and expatriate teachers, it is limited in that it does not represent the views of the entire population of the Australian transnational teaching workforce, and it did not involve gathering the views of locally employed teachers. A homogenous sample of Australian and expatriate teachers was selected because they share similar characteristics in relation to their knowledge and experience of a vocational curriculum and their limited knowledge of the country in which they taught. Consequently, the sample was chosen to examine, in more detail, the experiences of transnational teachers enacting an Australian vocational curriculum in unfamiliar contexts.

One of the strengths of phenomenological inquiry is the exploration of common experiences. In this case it was the common experiences of offshore teachers situated within a transnational teaching context. However, this inquiry is limited in that it did not seek the views of other stakeholders, such as students, administrators, or managers, about the factors which influence the relevance and quality of Australian VET provisions overseas. As discussed in Chapter 4, teachers were a deliberate focus because they have direct experience of the phenomena and their voices have been marginalised in the research that informs VET policy and practice in Australia. While seeking to give voice to teachers, the inquiry does not claim to represent all teachers' experiences of enacting an Australian VET curriculum overseas. The sample of 13 Australian and expatriate teachers across nine countries is important, not because it represents the population, but because it represents one aspect of the phenomena. Exploring the lived experiences of transnational teachers was considered significant to gain insight into the meanings for them to enact an Australian VET curriculum in another country.

\subsection{Organisation of the dissertation}

This first chapter introduces the research problem, design, and questions. It is followed by Chapter 2, which analyses the phenomenon of transnational education to provide the background to the research topic. It locates Australian VET policies and provisions in a global context and considers the worth of Australia's uniform 
approach to the provision of transnational VET. The literature review reveals that Australian VET programs offer the opportunity for governments and individuals to access relevant and quality vocational education in their own country. However, questions emerged about the sustainability of pursuing an approach to transnational education that expects and requires teachers, from Australia, to implement a national curriculum with fidelity in a country for which the curriculum was not designed. This analysis of the literature and research, at the macro level, provides a rationale for the inquiry and explains how the principal questions guiding it have emerged.

In Chapter 3, a review of the literature on curriculum development and implementation provides an understanding of the factors that influence teachers' decision-making, problem-solving, and curriculum-making in the transformation of Training Packages in Australian transnational VET. A framework of curriculum conceptions was used as a theoretical frame to understand the problem of implementing in another country a VET curriculum designed for Australia. It revealed that curriculum implementation in Australian transnational VET is a complex process that poses many unfamiliar problems and dilemmas for teachers trying to find the right balance between maintaining fidelity to the intentions of a mandated curriculum and adapting it to meet the needs of their students. However, this review also reveals that there are very few studies that have explored how teachers make curriculum decisions or the quality of the adaptions they make. Therefore, this chapter justifies the need for an inquiry that explores how teachers experienced the phenomenon and what their perspectives might mean for the relevance, quality, and sustainability of Australian transnational VET.

Chapter 4 describes and justifies the research methodology utilised in the inquiry. Between 2013 and 2015 a phenomenological inquiry was conducted to examine the experiences of offshore teachers involved in Australian VET provisions overseas. In-depth interviews were used to elicit data about the contextual experience, actions, and relationships of 13 teachers across nine countries. The chapter advances that a phenomenological research design was optimal as it enabled a detailed consideration of the lived experiences of the teachers.

Chapters 5, 6, and 7 report on the findings of this inquiry. Chapter 5 presents and discusses five key local factors that were shown to enable or constrain the teachers' enactment of the curriculum with fidelity, or as they would in Australia. Chapter 6 then discusses how these local factors also impacted on teachers' decision-making and problem-solving. It shows that their ability to influence those factors depended on whether or not there was support for an extended scope of role. Chapter 7 follows with a discussion of how the teachers, as a consequence of those 
factors and within their scope of influence, remade the curriculum to increase its relevance, learnability, and attainability for students. It also highlights how the teachers' interpretative and adaptive activities transformed the intended curriculum.

Chapter 8 provides a synthesis of the findings discussed in Chapters 5, 6 , and 7 . It identifies and explicates a conceptualisation of curriculum implementation to advance an understanding of how Training Packages are transformed when implemented in countries for which they were not designed. The chapter shows the local factors, which influence implementation and the cause and effect of different relationships on it as well. It also depicts the key processes of teacher decisionmaking and curriculum-making. The chapter also suggests five key strategies for improving the relevance, quality and sustainability of Australian VET provisions.

Chapter 9, the final chapter, reviews the contributions from the preceding chapters and summarises the findings and contributions from an interrogation of the literature and a practical inquiry. The contention that it is problematic for teachers to enact a vocational curriculum designed for Australia in another country, without an extended scope of role to understand and influence the local factors associated with curriculum implementation and make curriculum decisions is supported. It concludes with a discussion on the implications of the findings for future policy, practice and research. 


\section{Chapter 2}

\section{The quality, relevance, and sustainability of Australian transnational VET}

This chapter discusses whether Australia's uniform approach to transnational VET provision is achievable or even desirable, given that studies in the international education field conclude that the direct transfer of any educational policy, model, or provision from one country to another is rarely successful (e.g., Maurer \& Gonon, 2014; McGrath \& Lugg, 2012). Indeed, many of these studies suggest that foreign educational institutions need to pay attention not only to the means for realising quality education, but also to the cultural norms and values that make them relevant in the host country context (Anderson, 2006b; Middlehurst \& Woodfield, 2004; Tikly \& Barrett, 2011). Yet, the capacity of Australian educational institutions to work collaboratively with overseas sponsors to create locally relevant VET programs is constrained by federal government regulations that are used domestically to realise the kinds of qualities other countries desire. This situation creates a conundrum for educational institutions and the teachers that work for them. On the one hand, the curriculum must be implemented with fidelity and meet Australian standards, but on the other hand, it must be adapted to meet the needs and interests of sponsors and their students. Consequently, the sustainability of Australian transnational VET provisions relies on those providing it to simultaneously abide by national regulations and meet the expectations of an international market.

However, there is a very little research that informs how this conundrum can be resolved or that appraises the worth and relevance of Australia offering such highly prescriptive, standardised and regulated VET programs in the global education market. Indeed, all that is known about Australian transnational VET provision is based on the findings of a small number of case studies conducted in a few Middle Eastern, South Pacific, and Asian countries. Although few in number, these studies have pointed to Australian Training Packages losing meaning and relevance when implemented overseas because they are so nationally specific to the country for which they were developed. Further, trying to replicate Australian standards, as a way of ensuring quality in provision, is fraught with difficulties due to contextual differences between Australia and other countries (Hua, Harris, \& Ollin, 2011; Karthegisu, 2007; Woodley, 2007). However, the sustainability of Australian transnational VET provision depends on meeting the assorted expectations of foreign sponsors and students. Thus, understanding these diverse expectations is important 
because, despite the similarities in the purposes of VET provisions in Australia and host countries which have arisen from a common set of global conditions, there are also unique differences. So, in considering the sustainability of Australian transnational VET provision, it is important to understand the tensions and challenges arising from educational institutions, and the teachers who work for them, attempting to serve both the diverse purposes of an international market and the demands of the national regulator.

It is proposed in this chapter that Australia's approach to ensuring quality in transnational education through the impost of both national curricula and their associated quality systems onto other countries: (a) is most likely unachievable, and (b) potentially undermines the relevance of those provisions for sponsors and their students. Subsequently, the sustainability of this approach is questioned. In making its case, this chapter analyses the phenomenon of Australian transnational VET. Firstly, it considers the broader field of transnational education and the processes of globalisation which have shaped its demand and the interests it serves. Secondly, it focuses specifically on Australia's provision of transnational VET. It sets out a definition of VET and considers its purposes, then locates Australian VET policies and provisions in the global context. The chapter concludes with an analysis of the relevance, quality, and sustainability of Australian transnational VET. The intention of the chapter is to provide a sophisticated understanding of the broader economic, political, and cultural factors which shape a teacher's adaption of national curricula, such as Australian Training Packages, in an international context. This analysis of the literature and research, at the macro-level, explains how the principal questions guiding this inquiry have emerged:

1. What is the relevance and quality of Australian VET provisions as an exported product (curriculum) in the global VET market?

2. How sustainable is the provision of Australian VET products in the current curriculum form as an export?

\subsection{Transnational education}

This inquiry seeks to explore teachers' lived experiences of enacting a national curriculum that was designed for one country and expected to be enacted in a number of other countries. In order to understand these experiences, it is necessary to consider the broader phenomenon of transnational education. Thus, the first section of the chapter provides a background to the research topic and 
justification for further research. To establish the context for this inquiry, it gives a brief account of what constitutes the field of transnational education and the global market for it. This account is followed by an analysis of transnational education within the context of globalisation. This discussion helps to locate the teachers' experience in the wider context of transnational education.

\subsubsection{Transnational education and the global market}

Many vocational educational institutions, predominantly those based in Western countries, have extended their provision overseas, usually as a means to bolster their financial viability and profitability. This phenomenon is referred to as transnational education. There are also a multitude of other terms used to define and describe this educational provision, such as offshore education or borderless education (Knight \& McNamara, 2017). However, to provide clarity for this inquiry, transnational education refers to educational programs and providers moving across national borders to provide academic programs and credentials to students in their home or neighbouring country (Knight \& McNamara, 2017). This definition underpins the discussions here as it considers the mobility of Australian VET programs provided by Australian educational institutions.

In the field of transnational education, programs and providers move across international borders in diverse and multiple ways. Providers include national public and private educational institutions, as well as international ones (Little, 2000). Programs can be provided as an independent activity by one educational institution or as a collaborative effort involving a number of educational institutions and sponsors (Knight \& McNamara, 2017). Independent activities usually include franchise programs, international branch campuses, and/or self-study distance education. Collaborative efforts might include partnership programs and distance education or even joint universities or colleges. With independent provisions, the sending country or institution usually retains responsibility for awarding qualifications, developing the curriculum, and quality assurance. Within collaborative educational provisions these responsibilities are usually shared. These relationships and responsibilities are important because they determine how provision is arranged, regulated, and evaluated in the field of transnational education. Different models of transnational education reflect different relationships between providers and receivers and help to explain the diversity of provision characteristics internationally.

The market for transnational education has grown due to the burgeoning global middle class demand for educational qualifications (McBurnie \& Ziguras, 
2007). In 2012, the OECD reported that tertiary attainment levels increased significantly, with nearly 210 million people having completed either a vocational or higher education qualification. Initially, much of this demand was met through students studying at either local institutions or abroad. Yet, increasingly, it is also being met through the foreign provision of education programs closer to students' homes (McBurnie \& Ziguras, 2007). It is anticipated that the vast majority of the future demand for education will occur domestically (i.e., students staying in their own country or a nearby country to pursue education through a domestic or transnational provider) (EduWorld, 2013; McBurnie \& Ziguras, 2007). Thus, it is notable that the future growth of international education will primarily cater for students wishing to acquire an internationally recognised qualification close to their country of residence.

The literature points to two main reasons for the proliferation of transnational education. Firstly, the governments of many countries have been interested in attracting foreign provision to supplement, diversify, and/or replace existing educational provisions (McBurnie \& Zigarus, 2007). The major hosts of foreign programs are located in the Middle East and Asia, although they are also present throughout Africa, the Caribbean, and the Pacific islands (Jisc, 2018). Secondly, many educational institutions, especially from the West, have been motivated to provide transnational education to generate income (Chapman \& Pyvis, 2013; Ziguras \& McBurnie, 2015; P. Porter \& Vidovich, 2000). The main providers of transnational education are from Australia, UK, US, Canada, China, India, Germany, Netherlands, Russia and France (Jisc, 2018). Hence, developing countries tend to host transnational provision, whereas developed countries tend to export it. This trend has also led to some scholars (McBurnie \& Ziguras, 2009; Rizvi \& Walsh, 1998) criticising transnational education as the dominance of Western education models over the developing world. However, there are signs that this is changing, at least in the provision of higher education, as universities in the developing world are increasingly assuming a regional or global role in transnational education (Wilkins \& Juusola, 2018).

There is a significant lack of research, however, regarding the provision of transnational vocational education from which to develop a picture of the phenomenon or to make comparisons and generalisations about it (Adams, 2001; Brown, Buttress \& Matthews, 2018; Knight \& McNamara, 2017). For example, there is extremely limited data available in relation to enrolments, participation, completion rates, or even trade revenue, as very few countries which either supply or host transnational VET programs publish data. Thus, despite the prevalence and 
importance of transnational education, there is limited information to sufficiently describe or characterise it.

The literature reviewed in this chapter reveals that the provision of transnational education is located within different national education systems whose features and characteristics dictate different sets of arrangements. These differences are important because they will produce: (a) different stakeholder and management relationships, (b) different responsibilities for provision, and (c) variation in quality assurance arrangements. Thus, the phenomenon has far-reaching implications for the nature and structure of educational provision internationally. Moreover, these differences also make any comparisons across countries or generalisations about the phenomenon difficult.

\subsubsection{Transnational education in the context of globalisation}

Transnational education is discussed in this section of the chapter in relation to globalisation processes. Globalisation provides the context for analysing transnational education, beyond the simple concept of program and provider mobility. It refers to the growing interdependence of countries as a result of the international flow of finance, people, images, values, and ideas (Hurrell \& Woods, 1995). Many scholars in the field of education (Marginson, 2010; P. Porter \& Vidovich, 2000; Taylor, Rizvi, Lingard, \& Henry, 1997) have claimed that the economic, cultural, and political processes of globalisation have influence on the international politics of education, training policy, and provision. Indeed, these three processes are considered significant to this investigation as they frame the growth of transnational education (including VET), the interests it serves, and the forms of provision it takes.

Firstly, the economic processes of globalisation have significantly influenced the demand for and interest in transnational education. Economic development and competition have created a focus on skill development as a key driver for success in national and international markets (Ashton \& Sung, 2002; Bloom, 2004). As a result, most governments around the world now see the creation of human capital as essential for their nation's prosperity in a globalised economy. In broad terms, human capital can be defined as the knowledge and/or skills possessed by a nation state's workforce that maintains and enhances its competitive advantage (Quiggin, 1999; Van Der Linde, 2006; Wallenborn, 2010). To promote skill development, many governments have reshaped their education training policies and provisions (Bloom, 2004), leading some to use transnational education as one mode for building capacity (McBurnie \& Ziguras, 2007). Many educational institutions, in turn, have 
responded to this demand by extending their provision internationally as a means to increase revenue and generate profit (Avis, 2012; McGrath \& Lugg, 2012; P. Porter \& Vidovich, 2000). Thus, the market for transnational education has grown due to the demand for skills development, on the one hand, and institutional interest in revenue and profit, on the other.

Secondly, the political forces of globalisation have also influenced the demand for transnational education provision. The growth of international organisations and transnational networks (i.e., Organisation for Economic Cooperation and Development [OECD], the World Trade Organisation [WTO], and the European Union [EU]) has helped to spread and reinforce the links amongst education, skill development, and economic wealth (Dale, 2000; Moutsios, 2010). This political discourse is referred to as neo-liberalism. Wells, Carnochan, Slayton, Allen, and Vasuveda (1998) state that neo-liberal ideology is underpinned by three main beliefs: (a) that public institutions fail to perform satisfactorily in the marketplace, (b) that the role of government in the provision of services should be reduced, and (c) that the market is the preferable form of regulating institutions. These researchers claim that neo-liberal ideology is the reinforcing feature of human capital, which connects skills development to a nation state's economic success in a free market. Subsequently, transnational networks have facilitated the exchange of these ideas amongst nation states, while also promoting co-operation for economic outcomes for their members. It follows that the discourse of neo-liberalism has assisted the growth of transnational education because it promotes education as a tradable service in the global market.

At the same time, the spread of neo-liberal ideology through the political processes of globalisation has intensified the economic interests in educational provision (Marginson, 2010). Many scholars, such as Tikly and Barrett (2011), propose that these interests have served to undermine the values that support the contributions of citizens, students, and teachers concerned with the broader public purposes of education. There are many examples of transnational authorities and governments successfully reinforcing their interests in education, including transnational provisions, through bureaucracies that use the "new public management" techniques of "objective-based and outcome driven surveillance" over educational institutions (Moutsios, 2010; Murphy, 2001). These techniques include: (a) tying funding to outcomes; (b) setting performance indicators, benchmarks, and targets; (c) promoting best practice reports; and (d) comparing educational attainment across countries. Many of these techniques are also utilised to control educational provisions and justify claims of comparative success. Notwithstanding 
the problematic nature of using these techniques and surveillance, their application enables both national governments and international authorities to exercise power over citizens, teachers, students, and educational institutions.

Indeed, Billett (2011) suggests that many governments now achieve control over the provision of education by making decisions about what should be taught and assessed and then regulating that provision. One effect of this control over education in many Western countries has been a reduction in public funding to educational institutions. Reduced income has then forced many educational institutions to seek commercial revenue by competing in national and global education markets (Kendell, 2004). Consequently, the political processes of globalisation have also shaped both the demand and supply of transnational education for economic purposes.

Thirdly, the processes of cultural globalisation, through the movement of people amongst countries combined with mobile technology and the Internet, have also influenced the interest and growth in transnational education, as well as its forms and models of provision. Cultural globalisation has increased both homogeneous and heterogeneous cultural connections. P. Porter and Vidovich (2000) refer to homogeneity as the "McDonaldization" of the world through the dominance of either American or Western cultural imperialism. This homogeneity in education has arguably led to Western and English-language-based education models, such as those of Australia, the UK, and the USA, dominating international provision (Altbach, 2013; Little, 2000; McGrath, 2002). Interestingly, homogeneity has conversely created a heterogeneous cultural response for more localised cultural identities (P. Porter \& Vidovich, 2000). Rizvi (2009) claims that these responses have contributed to new hybrid cultural formations in education that are highly context specific, localised, and constantly changing. Thus, the cultural processes of globalisation have created a demand for both uniformity and variation in transnational educational provisions. Uniformity is evident through the intentional replication of education models internationally. Variation is evident in the development of contextspecific models. Thus, the cultural influences of globalisation have contributed to both the spread of Western-based transnational provision and opportunities for new and contextualised models of transnational education.

In summary, the combination of global economic, cultural, and political processes has influenced the growth of transnational education. Firstly, they have provided a greater focus on the principle of education and training as an investment for governments to increase their economic competitiveness through participating in the global market (Ashton \& Sung, 2002; Bloom, 2004). Secondly, they have created a convergence in the policies and structures of education and training provisions 
across the world, primarily through the spread of neo-liberal discourse by transnational authorities and networks (Marginson, 2010; Moutsios, 2010; Taylor \& Henry, 2000). Thirdly, they have created a demand for models of provision that can be replicated and others that can be developed specifically for local contexts. An explanation of these processes is necessary to understand the global forces that shape the demand, interests, and provision of Australian transnational VET. This explanation centres on what counts as quality and relevance.

\subsubsection{Quality and relevance of transnational education}

The growing interests in transnational education have raised questions in the literature as to its quality and relevance (Coleman, 2003). However, the differences in understandings and practices amongst exporting and host countries and institutions has meant that the quality of transnational education remains elusive in terms of what constitutes it and how it can be assessed (Bannier, 2016; Pyvis, 2011; Tikley \& Barrett, 2013). For example, the literature shows that the primary quality concerns of host countries are usually to protect their investment, students, and local reputation (Coles, 2006; Comyn, 2009; Middlehurst \& Woodfield, 2004). Examples for achieving this include: (a) residency restrictions on foreign providers; (b) quality assurance mechanisms such as local course accreditation; (c) imposing institutional rules such as course entry criteria, staff and student ratios, governance frameworks, and financial management; and (d) insistence on certain resources, curriculum materials, and assessment practices. However, McGrath and Lugg (2012) contend that many of these mechanisms and arrangements tend to perform poorly, especially in developing countries, due to practical constraints and/or differences in cultural understandings between hosts and foreign providers.

In comparison, the OECD (2004) has shown that exporting countries are usually more concerned with protecting the international reputation of their education systems and qualifications. McBurnie and Ziguras (2007) suggest that while a successful venture can enhance the local, national, and international reputation of an exporting country and its providers, an unsuccessful one can have the opposite effect. With so much at stake, the governments of many exporting countries regulate: (a) the educational institutions that can provide offshore education and training services, (b) the curricula that can be offered, and (c) the recognition of the qualification (CIE, 2008). Consequently, it is these domestic regulations that drive the priorities for providers of transnational education. 
Often these regulations dictate that educational institutions are to use equivalence as the primary quality concept, principle, and indicator (Qi, 2015). In most instances, equivalence is promoted and used as a principle for ensuring quality through standardisation (McBurnie \& Ziguras, 2007), whereby the home program functions as the sole point of reference (Pyvis, 2011). Research shows that standardisation is rarely achieved in international education (Chakroun, 2010; Mayer, 2001; Phillips, 2000; Phillips \& Ochs, 2003). This has led to many scholars (Boteju \& Burnapp, 2011; Woodfield \& Middlehurst, 2009) criticising the pursuit of standardisation because it does not consider the cultural context and socio-economic needs of host countries.

The literature also indicates that equivalence has proved elusive due to different interpretations and applications of it across different countries. For example, there is variation in the way that equivalence is defined in different national regulations (K. Smith, 2014) and interpreted in different contexts (Bannier, 2016; Pyvis, 2011; Tikly \& Barrett, 2013). At one end of the spectrum, it is interpreted as a straight replica of infrastructure, equipment, resources, curriculum, teachers, services, teaching and assessment practices, and/or student outcomes (Pyvis, 2011). At the other end of the spectrum, it is interpreted as an equivalent experience, which allows some flexibility for programs to be adapted for local conditions (K. Smith, 2014).

The three main criticisms of equivalence are that it is impractical, unenforceable, and irrelevant. Firstly, from a practical perspective, applying equivalence has not proved to be as straightforward as simply transferring an educational policy, model, or program from one country to another. Indeed, differences between goals (Steiner-Khamsi, 2013), contexts (Chakroun, 2010; Mayer, 2001; McGrath, 2002; Phillips, 2000; Phillips \& Ochs, 2003), and capability (Tikly \& Barrett, 2013) have all been found to make it impractical to replicate educational provision between two countries, especially between developed and developing countries (McGrath, 2002). Often, many of the preconditions for success are absent in developing countries (Tikly \& Barrett, 2013). Moreover, contextual factors also influence the adoption and development of any transnational education policy or program (Phillips \& Ochs, 2003; Perry \& Tor, 2009; Middlehurst \& Woodfield, 2004). As a result, hybrid models of education unintentionally evolve, which only partly resemble what was intended (Maurer \& Gonon, 2014; Middlehurst \& Woodfield, 2004). Thus, seeking comparability amongst sites of educational provision has not only been criticised as impractical, but can also be construed as a privileged indicator of quality when enforced on developing countries. 
Secondly, equivalence has proven difficult to enforce (Shams \& Huisman, 2012). While exporting governments might insist on certain regulations, there are doubts as to whether educational institutions are able to administer the institutional rules which are meant to control the quality of provision. Shams and Huisman (2012) have found that the application of these rules varies because they are subject to the ways that overseas sponsors understand, implement, and prioritise them within the local context and available conditions. Equivalence also implies a one-way rulemaking and rule-enforcing process (Abbott, 2017). Yet, as aforementioned, host countries will also be concerned with their own quality assurance goals and mechanisms. Consequently, these countries focus on enforcing their own rules, which may at times conflict with those of the exporting country. Thus, it appears that many transnational education programs are subject to different, and at times contradictory, sets of regulations. It is these differences in priorities that make equivalence an unenforceable indicator of quality in transnational education.

Thirdly, imposing equivalence constrains a country's capacity to offer educational programs that are relevant to the local situation (Qi, 2015). The imposition of one model of education onto another can sometimes mean that the relevance of the model is not always given precedence, contributing to a high failure rate (Epstein, 1987; Hulme, 2005; Perry \& Tor, 2009). Scholars (Chapman \& Pyvis, 2013; McBurnie \& Ziguras, 2009; Pyvis, 2011) point to these failures as examples of the uncritical transfer of educational policies and practices from the West to the rest of the world. In these situations, equivalence is criticised on the grounds that it is an imperialist indicator of quality as it is imposed on receiving countries without considering the relevance of replicating a foreign model of education (McBurnie \& Ziguras, 2009; Pyvis, 2011). Consequently, it is incumbent on those institutions that regulate and provide transnational education to consider the need for curriculum adaption (McBurnie \& Ziguras, 2007) and context-sensitive and collaborative measures of quality beyond the indicator of equivalence (Marginson \& McBurnie, 2004; Pyvis, 2011).

Teachers have also reported many difficulties in trying to achieve equivalence through their pedagogical practices (AEl, 2006; Keevers et al., 2014; Mahmud \& Sanderson, 2011). Equivalence has been found to both: (a) limit opportunities for teachers to negotiate how teaching and learning might be practised in particular situations, and (b) reduce opportunities for innovation (Qi, 2015). For example, Lim et al., (2016) found that equivalence was a contentious and difficult principle for teachers to apply in Malaysia for an Australian undergraduate degree program. The teachers reported that because equivalence was prioritised, resources were then 
dedicated to meeting minimum standards rather than meeting the students' actual learning needs. As a result, the curriculum was not adequately developed and for that reason it was not relevant and engaging for Malaysian students. Other studies indicate that transnational teachers find it difficult to teach how they would at home because: (a) they lack knowledge about the local context, the learning needs and styles of their students; and (b) overseas students do not respond to their teaching practice as do domestic students (Dunn \& Wallace, 2006; Szkornik, 2017). Moreover, professional development programs have been shown to be important to help teachers gain an understanding of the cultural, social, economic, and political contexts and to equip them with the skills they need to teach within their situated context (Dunn \& Wallace, 2006; Gribble \& Ziguras, 2003; Keevers et al., 2014). Such findings suggest that the relevance and quality of transnational education is more likely to be enhanced through professional support programs that help teachers adapt to teaching in another country as opposed to being expected to teach as they would at home.

In summary, it is difficult to reliably evaluate the quality and relevance of transnational education because of differences in educational goals and interpretations of quality. There is a tension between requirements for equivalence and the need to adapt curricula to suit the local context in transnational education. Moreover, the use of equivalence as a measure of quality is contentious because it can negate opportunities for negotiating and adapting educational provisions so they are relevant in different countries. Thus, the sustainability of transnational education is likely to rely on the capacity of providers to negotiate the curriculum for relevance and the way in which quality will be defined and measured in context.

\subsubsection{Sustainability of transnational education}

While transnational education promises an expansion of opportunities for governments and individuals to access education, concerns about the relevance and quality of it have led many to criticise and question its sustainability. The literature indicates three main concerns with it as: (a) a form of Western academic imperialism (Abbott, 2017; Tikly, 2013), (b) a form of "academic capitalism" (McBurnie \& Ziguras, 2009; Tikly, 2013), and (c) a contributor to global inequality (Altbach, 2013; Little, 2000; McGrath, 2002; Mok, Han, Jiang \& Zhang, 2018). Underlining these concerns is the conviction that transnational education involves the uncritical transfer of educational policy from the Western world to the developing world for economic and political reasons (Abbott, 2017; Tikly \& Barrett, 2011; McGrath, 2002). 
The first criticism of transnational education is that it is an act of Western academic imperialism. Many scholars (Abbott, 2017; Tikly, 2013) claim that the growth of transnational education has led to the global dominance and spread of Western educational models and associated privileged forms of knowledge, learning, and language. Others, such as Rizvi and Walsh (1998), suggest that other cultural and indigenous knowledge, learning, positions, interests, languages, and values have been eroded through the proliferation of Western models of education. Others still, such as the critical theorists who view education as a social and cultural process, see the dominance of Western models of education as a risk to both cultural identities (Altbach, 2004; Rizvi \& Walsh, 1998) and educational sovereignty (Abbott, 2017; McGrath, 2002; Tikly \& Barrett, 2011).

Those viewing transnational education as an act of imperialism propose that its provision is not sustainable as it replicates the neo-colonial model of education (Abbott, 2017; Tikly, 2013). Indeed, the comparative literature (Marginson, 1999; McGrath, 2002; Tikly \& Barrett, 2011) has shown that the direct transfer of education and training models from one country to another limits the ability of developing countries to develop their own educational policies and systems. For instance, many countries have ended up with the products of piecemeal foreign projects designed for different national systems with little co-ordination across and amongst them. This fragmentation has acted as a barrier to the development of a relevant and more robust national educational system for these countries. Subsequently, it is contended that transnational education in its current form is not sustainable as it undermines the capacity of countries to design and develop relevant and robust national education systems and programs.

Another criticism made of transnational education is that it constitutes a form of "academic capitalism" which serves the financial interests of educational institutions (McBurnie \& Ziguras, 2009) and Western governments and industries (Tikly \& Barrett, 2011). In the process, it is stated that: (a) the needs and rights of students are often overlooked (Stella, 2006), (b) the public nature of education is eroded (Robertson, 2006), and (c) indigenous curricula are replaced with Westernbased ones (Qi, 2015). The argument follows that transnational education is not sustainable because over time it will prove unaffordable, unattainable, and irrelevant for many people in developing countries.

Some claim that both the global dominance of Western education models and the financial interests in transnational education have created and reinforced new forms of regional and global social and economic inequality (Altbatch, 2013; Little, 2000; McGrath, 2002). For example, some countries have been unable to attract 
foreign educational providers, leading to many of their citizens moving abroad in the pursuit of an international qualification. In particular, McGrath (2002) asserts that the regions of Latin America, sub-Saharan Africa, and South Asia have little market appeal to foreign educational institutions due to their poverty and lower economic development. He reports that individuals in these regions, who could afford education, were seeking out foreign qualifications in neighbouring countries, resulting in a flow of educated workers leaving and moving to developed countries. This movement, he proposes, effectively creates a regional "skill and knowledge drain" contributing to systemic forms of regional inequality.

It is also claimed that the extension of the private sector in transnational education and training has contributed to global inequality (Altbach, 2013; Little, 2000). Little (2000) explains that private investors offer premium products in the market, which produce an elite pool of graduates holding internationally recognised qualifications with currency in the international job market. She contrasts these graduates with those from poorly funded public institutions, who gain nationally recognised qualifications but prove less competitive in a range of job markets. Little uses this example to show how private forms of transnational education can override the value of national educational provision and qualifications, which further contributes to regional inequality.

It is evident from the literature that despite the promises of transnational education, it has entrenched problems associated with it. On the one hand, it offers opportunities for governments to develop a skilled workforce and for individuals to gain internationally recognised qualifications. On the other hand, it can perpetuate the Western model of education and in the process create new forms of global inequality. So, when it comes to considering the sustainability of transnational education, it is important to consider not only economic and pedagogical perspectives, but also social and ethical ones. Hickling-Hudson (2003) states that these perspectives are important because they challenge the uncritical transfer of educational policy from the Western world to other countries in a postmodern and postcolonial era.

\subsubsection{Summary}

The literature demonstrates that transnational education is a complex phenomenon comprising benefits and risks. Yet, due to a dearth of research, little is known about its enactment, including its relevance or quality across a range of countries. Consequently, the benefits must be weighed against the risks. Indeed, 
many scholars are concerned about the implications of educational institutions simply transferring Western-based academic, linguistic, and cultural models without considering the means for realising a quality education and the cultural norms and values that make it relevant in context. This issue is central to this investigation as it has implications for Australia's approach to the provision of transnational VET that demands fidelity to Western-based domestic curricula and equivalence in provision as the hallmarks of quality. The next section of this chapter explores this issue in more depth.

\subsection{Australian transnational VET}

While transnational education comprises all forms of education, this inquiry is specifically concerned with VET. It seeks to understand teachers' experiences of enacting Australian vocational educational curricula across a number of other countries. Hence, this section of the chapter focuses on Australia's approach to the provision of transnational VET. It commences by discussing what is meant by VET and the purposes and interests it serves in a global context and market. This discussion is followed by an analysis of the nature and characteristics of Australian transnational VET. Finally, the quality, relevance, and sustainability of Australian transnational VET are discussed. This analysis is intended to consider the worth of Australia's uniform approach to the provisions of transnational VET and to understand the implications for those who teach it.

\subsubsection{VET in a global context}

There is no simple description of VET, as it differs from country to country in regards to its title, curriculum, and provision. Firstly, there is not an internationally agreed term for it (Arends, 2005; Billett, 2011; Keating, 2008; Moodie, 2002). While the term vocational education and training (VET) is used in Australia, other terms are used elsewhere, such as (a) technical and vocational education and training (TVET), (b) vocational and technical education and training (VTET), (c) technical and vocational education (TVE), (d) vocational and technical education (VTE), (e) further education and training (FET), and (f) career and technical education (CTE) (NCVER, 2017). Therefore, it is important to bear in mind that many of the countries that import Australian VET provisions are likely to use different terms.

The content of VET curricula also differs amongst countries. While the primary focus of the curricula is on the development of skills that individuals need for 
their job and careers throughout life (Billett, 2011), the occupational classifications they are based upon are not universal (Moodie, 2002). For example, in Australia, VET curricula are competency based and linked to specific occupations and national qualification levels (Misko, 2006). Thus, when it comes to applying VET curricula from one country to another, success will largely depend on the compatibility between the occupational type and levels in the respective countries.

It is also important to recognise that there are significant variations in the way that VET is provided internationally (Arends, 2005; Billett, 2011; Keating, 2008; Moodie, 2002). Indeed, the VET sector comprises a considerable variety of locations, institutions, clients and stakeholders, and models of provision. These variations reflect different historical and cultural traditions, as well as the extent to which the state, industry, private sector, and other non-government agencies have responsibility for deciding on VET purposes, mechanisms, and funding. This diversity in VET provision is recognised as an important aspect of this inquiry because it helps to explain why a uniform approach to the implementation of a VET curriculum may not always prove feasible or relevant internationally.

As can be seen from the preceding discussion, trying to define VET reveals the difficulties in reaching a common description that characterises it internationally. Indeed, it is probably not even ideal to reduce VET to a single characteristic or identity, given this diversity. However, for the purposes of this inquiry, the term used in Australia - vocational education and training (VET) - is the one referred to in this dissertation. VET is also understood as the provision of educational products and services, which are primarily concerned with the acquisition of knowledge and technical skills for employment in a particular occupation at a specific level (Billett, 2011; Moodie, 2002).

\subsubsection{VET in a global market}

VET, in its multiple forms of provision and regulation, including transnational VET, has become a significant investment for governments in an era of globalisation (Keating, 2008). Like most forms of education, VET is construed as pivotal to the pursuit of a nation state's economic competitiveness through the development of human capital (Avis, 2012; Marginson, 2010). The literature refers to human capital as the knowledge and/or skills possessed by a nation state's workforce that maintains and enhances its competitive advantage (Quiggin, 1999; Van Der Linde, 2006; Wallenborn, 2010). The development of human capital has gained momentum as justification for the investment in VET as a means to achieving social purposes as 
well. For example, many developing countries use VET to help close educational gaps, reduce poverty, and promote social inclusion (Chappell \& Johnston, 2001; Little, 2000; McGrath, 2002; Wallenborn, 2010). As nation states seek to advance their human capital through VET, many look towards other countries, such as Australia, with well-established educational systems, to import VET programs. Australia's VET system has proved attractive to many countries looking to import foreign VET provision as it offers a national regulatory framework for awarding qualifications (Keating, 2008) and portability across jurisdictions (Dempsey \& Tao, 2017). Yet, it is this very framework that inhibits its easy adaption to other countries' needs.

The literature shows that VET is also a tool that is used to achieve specific objectives and these often differ from country to country (McGrath \& Lugg, 2012). For that reason, when it comes to transnational VET, different nation states will select which educational systems, models, and programs they choose to import and how they will be controlled (Ziguras \& McBurnie, 2015). For example, in some countries VET supports broad economic and/or social purposes, while in others it serves specific occupations and industries (Nilsson, 2010). Consequently, success is measured differently depending on the achievement of those objectives. This is an important point, because if nation states are using transnational VET provision to reach specific objectives, then successful accomplishment relies on foreign educational programs meeting them. Thus, transnational VET provisions have to respond to the broader global goal of skill development, while also meeting local purposes and interests.

Understanding the similarities and differences in VET purposes is essential in evaluating the relevance, quality, and sustainability of Australian transnational VET provisions, for three reasons. Firstly, it explains that relevance in provision depends on Australian educational institutions having both a global understanding of the broader purposes of VET and the capacity to meet the specific needs and expectations of host countries. Secondly, it suggests that hosts will, to a large extent, judge the relevance and quality of specific vocational educational programs based on their perceptions of how they meet specific local objectives. Thirdly, it makes plain that the sustainability of transnational VET relies on serving the common and diverse needs of the global market. So, when considering the worth of transnational VET, it is necessary to account for its potential contribution to the specific needs of individuals, communities, countries, and regions as well as the broader, and often financial, needs and interests of transnational authorities, governments, employers, industries, and business. 


\subsubsection{Australia's approach to the provision of transnational VET}

To consider the worth of Australian transnational VET provisions in a global context, it is necessary to explain what constitutes vocational education in Australia, the interests that it serves, and the ways these shape provisions offshore. The reason it is important to explain all these conditions is that the Australian federal government dictates that all VET programs offered overseas must use nationally endorsed curricula and ensure they are implemented so they are equivalent to the same programs offered in Australia. Failure to do so can result in educational institutions losing their accreditation to offer certain courses and at worst being fined, deregistered, and/or taken to court. Thus, the following section of this chapter elaborates on the Australian VET system to understand what is exported overseas and the sorts of constraints and restrictions that are placed on educational institutions and the teachers they employ.

The Australian VET system reflects both global and national trends and interests. On the one hand, the system is like that of many other countries, in that it has evolved since the late 1980s in response to the processes of globalisation. The influence of neo-liberal ideology is evident in the federal government's use of three main mechanisms: (a) VET policies linked to human capital theory and thus focussed on skill development, (b) a national approach to the regulation of educational institutions and curricula, and (c) the establishment of a national VET market to reduce public funding (Agbola \& Lambert, 2010; Anderson, 2006a; Chappell et al., 2002; Chappell \& Johnston, 2001, 2003; Connell \& Yates, 2001; Cooney \& Long, 2010; Darwin, 2007). On the other hand, the system is also manifestly national in character, as it is based on serving domestic industry needs. Indeed, a salient feature of the Australian VET system is that the federal government prioritises the interests and concerns of industry and business and the need to curtail public spending over the needs of students, including those enrolled in transnational programs (Billett, 2004). Teachers' interests and input into the system, regulations, and curricula are also overlooked. As a result, the Australian VET system is predominantly based on the national interests of industry and government, rather than the interests of students and teachers.

To protect its interests and concerns, the Australian federal government plays a central role in the development and regulation of the VET system and its curriculum provisions, both nationally and internationally. It uses its legislative power and bureaucratic authorities to: (a) control the curriculum, (b) mandate educational outcomes and qualifications, (c) regulate educational institutions, and (d) direct the 
activities of teachers (ASQA, 2018). To comply with these rules, educational institutions seek permission from the regulatory body, the Australian Skills Quality Authority (ASQA) to: (a) firstly register as a provider, and (b) secondly apply to offer specific units and qualifications. Once a public or private educational institution is approved to offer these accredited units and qualifications, they can compete in national and international VET markets (ASQA, 2018). However, in the pursuit of quality assurance, the regulations demand that any provision, be it local, national, or international, must maintain fidelity to the curriculum and achieve equivalence in standards amongst all sites of provision (ASQA, 2018). Thus, there is no option for registered educational institutions to either change the national syllabi or create and accredit alternative curricula for national or overseas provision. Some authors have questioned whether such an approach to international education is "remaking the world in our (Australian) own image" (McBurnie \& Ziguras, 2003).

As can be seen from the preceding discussion, Australian educational institutions are constrained by government regulations to provide VET programs premised on national concerns, traditions, and interests, with certification domestically based on and regulated by national standards. Thus, implementing any component of Australia's VET system offshore is problematic as each component carries a regulatory relationship (Rahimi \& Smith, 2017). Considering these points, it is quite possible that Australian VET programs might be dissociated from the human capital needs and aspirations of other countries. Consequently, it is necessary to appraise the worth of Australia's approach to the provision of transnational VET in the remaining sections of this chapter.

\subsubsection{Australian transnational VET: An overview}

Many Australian educational institutions, both public and private, are active participants in the global VET market. For instance, in 2017, offshore provision comprised 68 Australian educational institutions, enrolling 36,765 students in 40 locations (DET, 2018). The Australian federal government has played a major role in facilitating this provision through aggressive marketing, General Agreement on Trade in Services (GATS) negotiations, and bilateral agreements with major trading partners such as Singapore, China, and New Zealand (Ziguras, 2003). As a result, Australian VET providers have increasingly responded to the global opportunities for the provision of transnational education.

Even though Australian regulation demands that all sites of VET provision meet Australian standards, the data reveal why there might be difficulties for 
institutions in achieving them. The data used in the following section to explain and analyse the nature of Australian offshore VET provision are taken from two surveys. The first, conducted annually by the National Centre for Vocational Education Research (NCVER) since 2003, captures quantitative data specific to public offshore providers, locations, students, and courses. However, the NCVER does not survey private providers. Consequently, the data on private provision are taken from a oneoff survey conducted by the Australian Council for Private Education and Training (ACPET) with its members in 2012. Therefore, the data for the year 2011 are used to define, quantify, characterise, and analyse Australian transnational VET as they provide the most comprehensive set available to date. However, these data do not provide a complete description of the phenomenon because of two limitations. Firstly, it is likely that the data for the private sector underestimate the total number of enrolments and activity, because not all private educational institutions are members of ACPET and not all members responded to the survey. Secondly, the NCVER collects data on a greater number of survey items than ACPET. So although it is the best year of data capture depicting the Australian transnational VET landscape, it is still not a comprehensive data set.

Notwithstanding these limitations, an analysis of the data shows that Australian transnational VET is a complex and far-reaching phenomenon, given that in 2011 there were 51 educational providers from all states and territories, offering 568 VET courses in all occupational fields except health, predominantly in partnership with a foreign entity (94.7\%), enrolling 65,287 students in 27 countries, with the majority of enrolments in China (67.2\%) (AEI, 2012). The data also reveal five notable characteristics of offshore provision, which make it different from domestic provision: (a) institutional arrangements, (b) country capacity, (c) student characteristics, (d) teaching context, and (e) teaching workforce. So, while onshore and offshore provision is founded on the same curricula and subject to the same regulations, these differences in arrangements, contexts, and stakeholders indicate that fidelity in curriculum implementation and equivalence in provision amongst countries and Australia, for all intents and purposes, is difficult to achieve for five distinct reasons.

Firstly, Australian offshore provisions are arranged quite differently across countries. The great majority of them involve foreign partners on a fee for service basis, and as a result are subject to different types of institutional arrangements (Brown, Buttress \& Matthews, 2018). For example, in 2011, 94.7\% of programs offered overseas by public institutions (no data available for the private sector) were developed through partnership arrangements where the responsibility for institutional 
provision was shared with foreign public or private institutions (AEI, 2012). How these arrangements manifest in different countries means that offshore provision is subject to a greater range of influences than domestic provision. These differences are of considerable importance as they are likely to come into play in the operational environment of offshore provision. Consequently, they will impact on the way the curriculum is supported, enacted, and experienced offshore. Thus, given the diversity in institutional arrangements amongst Australian providers and foreign partners in multiple countries, it is inconceivable that there is equivalence in provision amongst 27 different nation states and Australia.

Secondly, the economic status of countries which host these provisions is often lower than Australia's, which means that overseas partners might have less capacity to provide many of the standard facilities, equipment, and resources required for a vocational curriculum. For example, in 2011, the top five countries for public provision were all developing countries: China (74\%), Kuwait (3.8\%), Vietnam (3.5\%), Papua New Guinea (PNG) (3.2\%), and Fiji (2.9\%); two out of the top five countries for private provision were also developing countries: Sri Lanka (12.9\%) and China (10.3\%) (AEI, 2012). Based on these figures, it appears that almost half (41\%) of the Australian VET courses being enacted in these countries required intensive resourcing, as they were in fields such as architectural drafting, information technology, engineering, creative arts, and hospitality. It is likely, many of these overseas courses are not supported with a similar standard or availability of facilities, equipment, and resources compared to Australia. Yet, the capacity of host institutions to afford and implement the preconditions for success is important if there is to be consistency in implementation, equivalence in standards, and comparable student achievement amongst countries.

Thirdly, the student characteristics of Australian transnational VET are different, in that: (a) most students are located in their own or nearby country and have probably not been to Australia, (b) English is not the first language of most students or of the countries which host Australian VET, and (c) the majority of students are aged 24 years or less (87.8\%). It is also notable that two-thirds of students enrolled in Australian VET programs offshore in 2017 were from China (Brown, Buttress \& Matthews, 2018). When compared to domestic provision, only $43 \%$ of students were aged less than 24 years and $15.3 \%$ of Australian VET students came from homes where English was not spoken at home in 2011 (DET, 2012). Considering that English is the language of instruction for most transnational VET programs in countries where English is not widely spoken ( $81 \%$ for public provision and $95 \%$ for private provision), it is likely that students' English language and literacy 
issues are of much greater concern in offshore contexts compared to Australia. Indeed, Chinese students have reported that one of the main reasons for completing an Australian course at home is that it helps them to develop English language skills that make them more employable (Brown, Buttress \& Matthews, 2018). While the majority of educational institutions, in 2011, reported setting a minimum requirement for competency in English, the actual level that was set by institutions is not captured.

So it is likely that there is considerable variation in the entry-level English language skills amongst students across different contexts. Thus, it stands to reason that the support of English language skills needs to be an integral and important addition to the vocational curriculum, especially given the fact that diplomas are the most popular level for courses for approximately half the student population (public $49 \%$ and private $48 \%$ in 2011 ). Yet, only $28.7 \%$ of all public institutions, in 2011 , provided this additional language support (AEI, 2012). Based on the 2011 data, it is likely that students in transnational settings are far less prepared for studying an Australian VET course in English than their Australian peers. With no data available on transnational students' completions or comparisons of student achievement amongst countries, it is impossible to draw any conclusions.

Fourthly, the teaching environments of Australian transnational provision are different, in that most of it is in college classrooms ( $86 \%$ of all public provision and $66 \%$ of private provision), for long periods of duration (59\% enrolled in courses over a year's duration) (AEI, 2012). Compared with teaching domestically where teaching occurs flexibly in a range of settings (e.g., workplaces, schools, colleges, universities, trade training centres, and online), overseas teachers are faced with large classrooms of school leavers with varying levels of English language capability over long periods of time.

A final notable key difference between Australia's national and transnational VET provision is the composition of the teaching workforce and the nature of their employment. For example, in 2011, the transnational workforce comprised $36 \%$ Australian teachers and $60 \%$ local teachers employed by either an Australian institution or a foreign partner (AEI, 2012). It is possible that more than half the teachers involved in these programs are unlikely to have worked as a teacher or in industry in Australia. For this reason, they might interpret the curriculum, and its underpinning forms of knowledge, differently from Australian or expatriate teachers. On the other hand, local teachers may be more familiar than Australian or expatriate teachers with the students' needs and characteristics and the cultural context for teaching. Yet, unfortunately, there is very little information collected about the 
workforce employed to teach Australian VET programs overseas to properly analyse what these differences might mean in practice. Indeed, there are no data compiled or published on teachers' ages, gender, cultural backgrounds, language, qualifications, experience, length of service, time spent teaching overseas or in Australia, contractual or employment arrangements, and conditions. Further, little is known about the institutional support provided to them in relation to their orientation, induction, and ongoing professional development (Dempsey \& Tao, 2017). Therefore, it is impossible to infer what these differences in the workforce might mean for teaching in onshore and offshore contexts.

To sum up, the complex and diverse nature of Australian transnational VET, as well the data limitations, highlight the difficulties involved with researching the phenomenon. Yet, despite the deficiencies in data, the analysis of what is available shows that offshore VET provisions: (a) do not reflect the characteristics and boundaries that Training Packages were designed for; (b) are subject to an entirely different set of environmental, economic, social, and cultural factors; (c) may not be supported with a similar level of resources; and (d) involve different student demographics and characteristics. All these factors are likely to affect the supported, enacted, and experienced curriculum. Moreover, the lack of data also indicates that there is little importance placed on understanding the workforce charged with the responsibility for ensuring fidelity to the curriculum and consistency in provision. This is regrettable given the links between teacher quality and student achievement, especially in developing countries.

The next section of this chapter explores these issues further by analysing the qualitative research in relation to the relevance, quality, and sustainability of Australian transnational VET. However, as noted in Chapter 1, this research is also extremely limited, as it comprises only a small number of case studies conducted by either staff members involved in them or researchers contracted by government departments, with an interest in quality arrangements. Given the confines of this research, most of the following discussion about the phenomenon is exploratory.

\subsubsection{Relevance and quality of Australian transnational VET}

As aforementioned, when it comes to quality in transnational VET, Australia, like most exporting countries, is predominantly concerned with protecting the international reputation of its system and qualifications. It was shown that the Australian federal government achieves this by: (a) regulating the curriculum and the institutions that can implement it, and (b) promoting the principles of equivalence and 
standardisation (Productivity Commission, 2015). These domestic regulations and principles take precedence over the needs and goals of sponsors and their students. However, very little monitoring occurs offshore to determine the level of compliance (Dempsey \& Tao, 2017).

Yet, it is apparent from a number of case studies that it has been difficult for educational institutions and teachers to comply with the regulations due to differences between Australia and other countries concerning: (a) quality assurance arrangements and processes; (b) institutional practices and capacity; (c) stakeholder expectations, interpretations, and understanding of the curriculum and its implementation; (d) communication and negotiation styles; (e) planning capacities; (f) language; $(\mathrm{g})$ teacher recruitment practices; and $(\mathrm{h})$ technology (AEI, 2006; Bateman, 2007; Dempsey \& Tao, 2017; Rahimi \& Smith, 2017). These differences have presented Australian educational institutions with a different set of challenges compared to their operations in Australia where they have direct control (Foster \& Schulze, 2009). As a result, local actors and conditions have considerable influence over the capacity of Australian educational institutions and teachers to achieve standardisation with Australian VET provision.

Yet, Dempsey and Tao (2017) propose that there has been little effort on the part of the Australian federal government to address the difficulties that VET providers and teachers face in trying to maintain Australian educational standards in other countries. Moreover, they claim that even less effort has been placed on considering the impact of its regulations on not only the transnational implementation of the curriculum, but also the experience and outcomes of it for offshore hosts and students. Thus, part of the problem with examining the quality of Australian transnational VET provision is that because the views of the Australian federal government and industry take precedence, there are little data gathered in relation to other measures such as student satisfaction and/or outcomes. Indeed, E. Smith (2010) states that the acceptance of these stakeholders' views on the legitimacy of the Australian VET system has led to a continued focus on compliance to solve any perceived problems with the quality of the VET system and its components. As a result, the Australian federal government has remained focussed on pursuing a uniform approach to transnational VET. Any opportunities for teachers and others to negotiate quality so the implementation of the curriculum is relevant in context are minimised.

The prevailing view of the Australian federal government is that the quality of transnational VET is dependent on whether it "is delivered to the same standard as in Australia" (Baird, 2010, p. 6). However, the literature shows that there is confusion, 
especially amongst teachers, about what equivalence means in practice (AEI, 2007; Woodley, 2007\& Woodley, 2008; Woodley, 2008). For example, should learning, teaching, and assessment be exactly the same across student cohorts and contexts? Or must the conditions be the same, such as facilities, equipment, learning materials, technology, work placements, and/or contextual information like legislation and policy? Or does it relate to student outcomes? Such questions remain unanswered because there are no specific guidelines provided within the curriculum or the regulations on how teachers can achieve equivalence across jurisdictions. So, if there is no consistency in interpretations of equivalence or information about its application, then it is unlikely there is uniformity in Australian VET provisions internationally.

Adhering to Australian regulations has also hampered the relevance of the curriculum in some countries. Research has shown that in many cases teachers have tried to teach and assess offshore as they would in Australia, but have been hampered in their efforts because: (a) many taken-for-granted aspects of the curriculum do not apply (Dempsey, 2012; Dempsey \& Tao, 2017; Shi \& Woodley, 2008), and (b) the curriculum is so overly focussed on Australian content that it is often unsuitable (AEI, 2007; Anderson, 2006b; Dempsey \& Tao, 2017; Moran \& Ryan, 2003; Shi \& Woodley, 2008; Woodley, 2007). Additionally, and of equal concern to teachers, have been the consequences of ignoring local contextual influences and not making appropriate adjustments to the curriculum to meet the diverse needs of students and workplace demands (Bilboe, 2011; Heffernan, Morrison, Basu, \& Sweeney, 2010; Hua et al., 2011; Tran \& Dempsey, 2017). Dempsey and Tao (2017) report that many teachers have tried to adapt the curriculum by including local case studies and scenarios, but it has often proved unsatisfactory. Teachers have also received little training and materials to adapt the curriculum so it is relevant for different cohorts of students in different countries (Dempsey \& Tao, 2017; Leask, 2004). Yet, such support is crucial if teachers are to effectively respond to students from a diversity of cultures.

A number of case studies have shown that the relevance of Australian transnational VET has also been undermined because some educational institutions have used the curriculum for purposes for which it was not intended. As an example, many diploma programs have been marketed as a pathway program for entry into specific undergraduate programs at Australian universities (Anderson, 2006b). This practice is widespread because formalised pathways are a key selling point for transnational VET courses, with $63.8 \%$ of public providers having arrangements in place (NCVER, 2015). A recent study commissioned by the Australian Government, 
that involved a series of focus groups with Chinese students, revealed that many of them were enrolled in an Australian VET program because it offered a pathway into further education. In 2011 alone, 277 offshore graduates gained entry to higher-level courses in Australia (AEI, 2012). Yet, Training Packages are not designed as entrylevel programs for higher education. Rather, they are intended to prepare students for work in specific occupations. Consequently, when teachers are faced with students who expect to develop language and academic skills, they have reported difficulties engaging them because what they want to learn is not covered in the curriculum and what is covered is of little interest to them (Anderson, 2006b; Woodley, 2007). In these situations, the exported curriculum has proved to have little relevance or value for these students. It is only the qualification that has utility for them.

It is difficult, however, to assess the quality and relevance of Australian transnational VET because there is little research available on the phenomenon and little in the way of monitoring and reporting by the regulator. Further, the capacity of a recent project to comprehensively profile Australian transnational VET was hindered by a lack of participation by educational providers (Brown, Buttress \& Matthews, 2018). Yet, it appears from the accounts of those involved in Australian transnational VET provision that they experience difficulties trying to meet the regulations. There also remains little guidance, training, or materials provided to teachers to assist them to both maintain the curriculum standards and adapt it across culturally diverse contexts. Subsequently, the pursuit of equivalence appears to have constrained the capacity for making the curriculum relevant. For these reasons, the sustainability of Australia applying such a prescriptive approach to assuring quality in transnational VET is questionable.

\subsubsection{Sustainability of Australian transnational VET}

To date, there are few studies which have specifically focused on the sustainability of Australia's approach to transnational VET. Indeed, even in the field of Australian transnational higher education where there is considerably more research, there is little available in the way of longer term follow-up studies of student outcomes (Cuthbert, Smith, \& Boey, 2008; Harman, 2005). Yet, it is likely that the uncritical export of Australia's VET curricula with a national knowledge basis, and their associated pedagogy and regulation, are contributing to the global spread and dominance of Western-based education models of education. As long as the provision of offshore VET remains exclusively focussed on Australian interests and 
standards, it will continue to ignore divergent study purposes, differing student characteristics, increasingly diverse educational contexts, and indigenous approaches to teaching and learning.

It is also possible that Australia's approach to the provision of transnational VET through the imposition of Australian national industry standards onto other countries may not continue to prove attractive to the needs and aspirations of other countries or students in the longer term. For example, Dempsey and Tao (2017) claim that some governments, such as in China, are showing less interest in exporting national models of education. Conversely, they are reaching out for partners that can assist them to align curricula with local industries. It is also questionable whether Australian VET programs will continue to hold appeal to foreign students who do not intend to work in Australia (Tran, 2013a, b, d) or want to gain a broader set of skills to prepare for tertiary education (Rahimi \& Smith, 2017). In light of these changing circumstances, it is hard to envisage how Australian VET providers will continue to meet the diverse goals and expectations of the international market while at the same time adhering to prescriptive national curricula and standards. Accordingly, it is likely that Australia's approach to exporting national curricula will continue to prove problematic in transnational VET provision.

\subsubsection{Summary}

This section of the chapter has shown that contemporary VET provision is set within a turbulent global environment in which its definition, purposes, goals, and interests are diverse and difficult to capture. Yet, VET in its multiple forms of provision and regulation has become a significant investment for governments in an era of globalisation and economic competiveness. As nation states seek to advance their human capital through VET, they look towards other countries such as Australia to import VET programs. Indeed, Australia's VET system has proved attractive to many countries looking to import foreign VET provision because it offers portability across jurisdictions. The promise of curriculum portability, however, has proven difficult in practice.

While the research reported and discussed here makes it apparent that transnational VET provisions have the potential to assist governments and individuals to build workforce skills, it also shows that achieving this through the implementation of nationally derived curricula, such as Australian Training Packages, is not always achievable or desirable. Further, the requirements to maintain fidelity to the curriculum and apply Australian standards offshore are difficult for teachers due 
to the influence of local factors such as institutional arrangements, local conditions, and students' characteristics. Moreover, the sustainability of the Australian approach to the provision of transnational VET is questionable given that contemporary research highlights the importance of negotiating the curriculum and its measures of quality in implementation.

Yet, despite the strict regulations that pertain to the provision of Australian VET offshore, the federal government has placed little effort on determining the level of compliance or the impact of the regulations. Even less interest has been placed on determining levels of stakeholder satisfaction or student outcomes. Therefore, it is of considerable concern that Australia is contributing to the uncritical transfer of Western-based education models by exporting VET national curricula while contemporaneously ignoring the divergent purposes, student characteristics, occupational and industry standards, educational contexts, and approaches to teaching and learning internationally.

\subsection{Conclusion}

This inquiry seeks to explore the lived experiences of teachers enacting a national curriculum designed for one country in a number of other (mostly developing) countries. To understand these experiences, this chapter analysed the phenomenon of transnational education. Firstly, it considered the processes of globalisation and how these have shaped its demand and the interests it serves. Secondly, it discussed Australia's provision of transnational VET in a global context and concluded with an analysis of its relevance, quality, and sustainability. The intention of the review was to provide a sophisticated understanding of the broader economic, political, and cultural factors, which shape a teacher's adaption of Australian Training Packages in an international context.

This review of the literature reveals that transnational education is a complex phenomenon with far-reaching implications for the nature and structure of education provisions internationally. On the one hand, it offers opportunities for governments to develop human capital and for individuals to gain skills and qualifications. On the other hand, it perpetuates the Western model of education and in the process overrides other forms of knowledge and may even contribute to global inequality. Accordingly, the promises of transnational education must be weighed up against the risks.

On reviewing the literature associated with the phenomenon of transnational education, it is proposed that Australia's approach to its provision through the impost 
of national curricula and their associated quality systems onto other countries is most likely unachievable and undesirable. Further, the sustainability of this approach is questionable given that contemporary research indicates that local interests, goals, and circumstances must also be taken into account in the implementation of any curriculum, educational program, or model.

While the literature that has been examined in this chapter about Australian transnational VET provides some interesting insights relevant to the phenomenon, the research to date is not substantial enough to infer any broad patterns or conclusions about it. Consequently, there is a need for further studies, such as this one, that move beyond the current form of case studies in single sites to multi-site studies. The intention of such research is not to draw inappropriate generalisations but instead to contemplate how Australian transnational provisions are distinct and related across settings and to ascertain how the interaction of cultures creates different teaching and learning contexts.

This literature review also highlights an urgent need to consider the perspectives of a broader range of stakeholders that are progressively more explanatory and insightful in considering the relevance and quality of such provisions beyond compliance with national curricula and standards. In particular, there is a need for more research to determine the level of adaptations that are being made by teachers offshore, in order to make transparent the worth of the qualifications obtained in different contexts. Yet, sufficient analytical attention has not been given to examining the curriculum development and implementation processes of Australian transnational VET. Consequently, the next chapter of this inquiry focuses on the literature in relation to curriculum development and implementation. It seeks to understand how teachers might negotiate between the imperatives of national curriculum standardisation and the needs and interests of overseas students and their sponsors. 


\section{Chapter 3}

\section{Training Packages: Implementing the curriculum in Australian transnational VET}

This chapter seeks to elaborate on how the implementation of Training Packages might best be understood and realised in transnational education. As discussed in the previous chapter, transnational education needs to respond to the interests and demands of host countries. This necessitates a curriculum that is developed and implemented to meet these requirements. In view of the mandated requirements for fidelity to an Australian VET curriculum, a key concern is that the content that teachers must enact offshore may not meet these interests and demands. Therefore, teachers engaged in Australian transnational VET have to find the right balance between maintaining fidelity to the intended curriculum and adapting it to reflect the circumstances for enactment. However, a central issue that is often overlooked in the literature on Australian transnational VET provision is consideration of the relevance and quality of the curriculum modifications teachers make (Tran, 2013b, c).

This concern is not unique to these teachers, as the tension between fidelity and adaption is a recurrent theme in the curriculum studies field - the theme being the extent to which teachers can exercise their professional judgement to cater for the needs of their students in specific situations. Numerous studies have identified the factors which influence these decisions (Corbett \& Rossman, 1989; Fullan, 1982; Fullan \& Stiegelbauer, 1991; House, 1996). These factors are situational and influence what teachers enact at different locations (S. J. Ball et al., 2012; Hlebowitsh, 2005; Spillane, Halverson, \& Diamond, 2004). Teachers are required to adapt the curriculum because most developers fail to account for these factors at inception (Fullan, 2007; Fullan \& Pomfret, 1977). However, the concern here goes beyond the implementation of curricula across one jurisdiction. Rather, it is about understanding how teachers can enact a national curriculum, such as a Training Package product, in countries for which it was not designed.

Indeed, one of the main criticisms of Training Packages is that they do not consider the broader learning needs of students or the range of locations for implementation (Billett, 2004; Cornford, 2000). Certainly, they are not designed for an international market and so it is not surprising that there are reports of widespread confusion amongst teachers about how curricula developed for Australian industries can meet the needs of international students (Tran \& Dempsey, 2017). Many of the 
factors that most frustrate teachers offshore emerge from having to enact a curriculum that was not developed for a global market (Moran \& Ryan, 2003; Shi \& Woodley, 2008; Woodley, 2007, 2008).

Accordingly, this chapter proposes that teachers engaged in Australian transnational VET need an extended scope of role beyond that of mere implementers of the curriculum. This role is important if they are to make decisions and act purposefully to resolve the many problems and dilemmas which can emerge when implementing a highly prescriptive, standardised, and regulated curriculum in circumstances where the goals for learning are distinct from those that the developers intended. Yet, the extent to which teachers can exercise agency to address these problems and dilemmas will differ from context to context. This is because their capacity to make decisions and act is not just a matter of personal choice but is shaped by the constraints, opportunities, and actors' interpretations extant in their situation (S. J. Ball et al., 2012; Biesta \& Tedder, 2007; Priestley et al., 2012). Consequently, understanding the range of factors that influence teacher decision-making, problem-solving, and curriculum-making in the provision of Australian transnational VET is an important consideration.

It follows, then, that the objective of this chapter is to understand how teachers deliberate and negotiate between the imperatives of national curriculum standardisation, on the one hand, and the needs and interests of overseas students and their sponsors in different cultural and institutional contexts, on the other. In working towards this understanding, different conceptions of curriculum are proposed as a means of highlighting the factors that influence teacher decision-making, problem-solving, and curriculum-making. This involves examining the many influences where the curriculum is likely to transform in Australian transnational VET. Examination of these processes explains how and why teachers cannot enact a national curriculum product, such as Training Packages, with fidelity, or equivalent to Australian provision, in another country, without an extended scope of role to influence local factors. Rather than expecting teachers to adhere to a domestic curriculum, it is proposed that the quality of transnational VET provision is more likely to be strengthened if teachers can negotiate and adapt it so it is relevant in context. As established in Chapter 2, the sustainability of transnational education relies on the capacity of providers to negotiate both the curriculum and the way in which quality is defined and measured in context.

This chapter comprises four sections that present and discuss a number of curriculum conceptions, models, and approaches to understand the challenges associated with implementing a curriculum designed for Australia in another country. 
The first section of the chapter establishes a conceptual framework of curriculum as the theoretical basis for the chapter. It comprises nine conceptions of curriculum, organised into three dimensions, and discusses the relationships between the different types of curricula that are at work in educational institutions. It is proposed that this framework serve as an explanation for why there will be differences between the intentions of Training Packages and what is implemented offshore. The framework is then applied in the second section of the chapter as a means for analysing the intended and implemented curriculum in Australian transnational VET. The third section draws particular attention to the role of teachers in decision-making, problem-solving (A. C. Porter \& Smithson, 2001), and curriculum-making (Clandinin \& Connelly, 1992). This is an important perspective given that it is they, ultimately, who are the curriculum-makers in the different countries that import Training Packages and they are the ones responding to local requirements. The final section summarises the curriculum concepts discussed in the chapter and how they underlie the key issues highlighted in Chapter 2. It justifies the need for a qualitative orientation and phenomenological approach to investigating the lived experiences of the 13 teachers who were involved in the processes of Training Package implementation spread across nine countries. It is contended that their perspectives are significant in addressing the primary research questions, which seek to understand the relevance, quality, and sustainability of Australian VET provisions as an exported product (curriculum) in the global VET market.

\subsection{Conceptualising curriculum for Australian transnational VET}

The previous chapter illustrated the difficulties that arise with the direct transfer of the Australian VET curriculum model onto other countries due to different interpretations and applications in different countries. It is proposed that a discussion about how and why the curriculum transforms in offshore implementation commences with an understanding of what constitutes curriculum. This first section of the chapter establishes the various conceptions of curriculum as the theoretical basis for explaining why there will be differences between the intentions of Training Packages and what students in the different countries that sponsor Australian VET programs learn. Through this discussion, the processes that transform Training Packages in transnational VET are advanced. 


\subsubsection{Curriculum: Some definitions}

It is important to clarify the term "curriculum" for the purposes of this inquiry as it represents the knowledge, skills, and values that students are expected to learn in the provision of Australian transnational VET programs. These expectations also shape the teaching and learning opportunities that must be arranged offshore. Various actors use the term curriculum in diverse ways because it is embedded within particular sets of values and beliefs (D. L. Smith \& Lovat, 2003). The substance of these various definitions depends upon whether the emphasis is on the goals of the curriculum, the context in which it is found, the strategies that are used throughout the curriculum, or a combination of these factors (Oliva, 1997).

The actual word curriculum derives from the Latin word curro meaning a running track. D. L. Smith and Lovat (2003) suggest that by thinking about how different running tracks suit different runners, it can help to conceptualise the idea that different curricula are needed for different cohorts of students. Early definitions of curriculum conceived it as the entirety of the student learning that is planned and directed by a school to achieve its educational goals (Tyler, 1949). However, this definition assumes that only what is planned is learnt and does not acknowledge the interactions that occur amongst the curriculum document, students, and teachers. Long-standing definitions of curriculum recognise that it is planned and unplanned, such as this one put forward by Print (1993, p.9):

... all the planned learning opportunities offered to learners by the educational institution and the experiences learners encounter when the curriculum is implemented. This includes those activities that educators have desired for learners which are invariably represented in the form of a written document and the process whereby teachers make decisions to implement those activities given interaction with context variables such as learners, resources, teachers and the learning environment.

This definition acknowledges that curriculum is both emergent and dynamic, and accounts for what happens when the teacher enacts the curriculum. This definition underpins this inquiry as it: (a) explores curriculum implementation from the perspectives of teachers, and (b) accounts for both the planned and unplanned learning that occurs in Training Package implementation across a range of countries. 


\subsubsection{Curriculum conceptions}

The definition of curriculum provided above implies that there will always be a difference between what is planned in the syllabus of a Training Package product and what actually occurs in implementation offshore. Therefore, the "curro to be run" is not the same for all students, despite the curriculum intentions. Thus, there is a need to consider the concept of curriculum as more than just a documented set of intentions as it is also something that students experience (Billett, 2011). These considerations also extend to how these experiences are enacted by teachers and supported by educational institutions. Consequently, the application of Training Packages in transnational VET can be seen as having qualities associated not only with its intentions, but with implementation and experiences as well.

Curriculum theorists have advanced these conceptions in different ways. For instance, Glatthorn (2000) describes seven types of curriculum that represent the different interests and concerns of stakeholders involved in curriculum development and implementation and what students experience as a result. They include the recommended, written, taught, supported, assessed, learned, and hidden curricula. Other theorists have identified additional conceptions such as the teacher-intended curriculum (Remillard \& Heck, 2014; Ross \& Mannion, 2012) and the null curriculum (Eisner, 1985; Flinders, Noddings, \& Thornton, 1986). All of these conceptions provide a broader perspective of curriculum, beyond the intentions of the syllabus of Training Packages.

These different conceptions of curriculum are discussed in the remaining sections of this chapter as a basis for understanding what constitutes a comprehensive account of curriculum in Australian transnational VET. In Table 3.1 nine conceptions, found in the literature, are drawn together in a framework based upon Billett's (2011) three dimensions of the intended, implemented, and experienced curriculum. Each type of curriculum is briefly summarised in the table and then explicated as the theoretical frame for the study. In the second section of the chapter the framework is used as a conceptual lens to understand the different sets of concerns of stakeholders and dimensions of their decision-making in transnational VET. Moreover, the framework provides a means to understand why the intentions of Training Packages may not be realised in countries that import them and engage teachers to enact them. 
Table 3.1.

Framework of Curriculum Conceptions

\begin{tabular}{|c|c|c|c|}
\hline Dimension & Conception & Description & Theorists \\
\hline \multirow[t]{4}{*}{$\begin{array}{l}\text { Intended } \\
\text { curriculum }\end{array}$} & $\begin{array}{l}\text { Recommended } \\
\text { curriculum }\end{array}$ & $\begin{array}{l}\text { The curriculum } \\
\text { recommended by } \\
\text { professional organisations }\end{array}$ & Glatthorn, 2000 \\
\hline & $\begin{array}{l}\text { Written, explicit, } \\
\text { formal, or } \\
\text { intended } \\
\text { curriculum }\end{array}$ & $\begin{array}{l}\text { The curriculum that is } \\
\text { approved in documents }\end{array}$ & $\begin{array}{l}\text { Eisner, 2002; Glatthorn, } \\
\text { 2000; Schmidt et al., } \\
1996\end{array}$ \\
\hline & $\begin{array}{l}\text { Teacher-intended } \\
\text { curriculum }\end{array}$ & $\begin{array}{l}\text { The curriculum comprising } \\
\text { the plans and materials } \\
\text { teachers develop for } \\
\text { instruction }\end{array}$ & $\begin{array}{l}\text { Remillard \& Heck, 2014; } \\
\text { Ross \& Mannion, } 2012\end{array}$ \\
\hline & Null curriculum & $\begin{array}{l}\text { The curriculum that is left } \\
\text { out }\end{array}$ & $\begin{array}{l}\text { Eisner, 2002; Flinders et } \\
\text { al., } 1986\end{array}$ \\
\hline \multirow[t]{3}{*}{$\begin{array}{l}\text { Implemented } \\
\text { curriculum }\end{array}$} & $\begin{array}{l}\text { Supported or } \\
\text { available } \\
\text { curriculum }\end{array}$ & $\begin{array}{l}\text { The supported curriculum } \\
\text { includes the resources that } \\
\text { support implementation }\end{array}$ & $\begin{array}{l}\text { Glatthorn, 2000, } \\
\text { Hlebowitsh, 2005; } \\
\text { Spillane et al., } 2004\end{array}$ \\
\hline & $\begin{array}{l}\text { Taught or enacted } \\
\text { curriculum }\end{array}$ & $\begin{array}{l}\text { The curriculum teachers } \\
\text { enact }\end{array}$ & $\begin{array}{l}\text { Doyle, 1992; A.C. Porter } \\
\text { \& Smithson, 2001; } \\
\text { Remillard \& Heck, 2014; } \\
\text { Snyder et al., } 1992\end{array}$ \\
\hline & $\begin{array}{l}\text { Assessed } \\
\text { curriculum }\end{array}$ & $\begin{array}{l}\text { The curriculum which } \\
\text { appears in assessments }\end{array}$ & $\begin{array}{l}\text { Glatthorn, 2000; A.C. } \\
\text { Porter \& Smithson, } 2001\end{array}$ \\
\hline \multirow[t]{2}{*}{$\begin{array}{l}\text { Experienced } \\
\text { curriculum }\end{array}$} & $\begin{array}{l}\text { Learned } \\
\text { curriculum }\end{array}$ & $\begin{array}{l}\text { The curriculum students } \\
\text { learn }\end{array}$ & $\begin{array}{l}\text { Glatthorn, 2000; } \\
\text { Goodlad, Klein \& Tye, } \\
\text { 1979; A.C. Porter \& } \\
\text { Smithson, } 2001\end{array}$ \\
\hline & Hidden curriculum & The unintended curriculum & $\begin{array}{l}\text { Eisner, 2002; Glatthorn, } \\
\text { 2000; Jackson, 1968: } \\
\text { Seddon, } 1983\end{array}$ \\
\hline
\end{tabular}

\subsubsection{Intended curriculum}

The dimension of the intended curriculum, as presented in the framework of curriculum conceptions in Table 3.1, comprises the recommended, written, teacherintended, and null curricula. It involves ideals, entitlements, and intentions that are set out in the recommended and written curricula (Glatthorn, 2000). The written curriculum (also referred to in the literature as the intended, explicit, or formal curriculum), usually presented in official documents, is frequently constructed as a syllabus comprising overall goals and specific objectives that guide instruction and assessment (Billett, 2011).

Often, governments mandate the intended curriculum to try to achieve uniformity in implementation across different sites. Curriculum fidelity is defined as "the extent to which teachers implement an intervention, curriculum, innovation or 
program as intended by the developers" (Pence, Justice, \& Wiggins, 2008). The fidelity approach assumes that: (a) curriculum knowledge is derived from experts outside the educational institution, (b) implementation is a straightforward process, and (c) teachers will follow the curriculum according to its instructions (Print 1993). Thus, fidelity in implementation is the measure of success. Proponents of curriculum fidelity claim that the specification of standards, content, and pedagogy provides teachers with greater certainty about what and how to teach, thereby ensuring the quality of teaching and student achievement across educational settings (Slavin, 2002; M. S. Smith \& O'Day, 1991). However, the fidelity approach is also criticised on the grounds that it ignores the professional discretion of teachers to make decisions and resolve problems throughout the teaching and learning process in their situated context (C. A. Tomlinson \& Jarvis, 2006; Tyack \& Cuban, 1995). In comparison to the fidelity approach is the "mutual adaption" approach that assumes that different actors within educational institutions will implement the curriculum according to what they determine as most appropriate in the situation (Berman, McLaughlin, Bass, Pavly, \& Zellman, 1977; Fullan, 1991). This includes the adaptions that teachers make to address the constraints within the learning environment and the needs of students (Marsh \& Willis, 2007; Pinar, Reynolds, Slattery, \& Taubman, 2004; Snyder, Bolin, \& Zumwalt, 1992). Understanding the mutual adaption approach helps to explain why there might be differences among the intended, enacted, and learned curricula in Australian transnational VET.

In recognition of the mediating role that teachers will play in their adaption of the curriculum offshore, the conception of the teacher-intended curriculum is included as part of the intended curriculum in the framework presented in Table 3.1. The teacher-intended curriculum includes the plans and materials teachers develop for instruction for specific cohorts of students in different locations at particular times (Ross \& Mannion, 2012; Mannion, Fenwick, Nugent \& l'anson, 2011; Remillard \& Heck, 2014). Remillard and Heck (2014) contend that the conceptual distinctions among the intended curriculum, the teacher-intended curriculum, and the enacted curriculum are important because they highlight the role of teachers in interpreting and adapting the curriculum through the design of their instruction. Indeed, the relationship between the intended curriculum and the teacher-intended curriculum in Australian transnational VET is an important consideration because, as discussed in Chapter 2, teachers have found it difficult to develop materials for teaching the intended curriculum in a country for which it was not designed (Dempsey \& Tao, 2017). 
The null curriculum is the one that is not taught (Eisner, 1985). It is an important consideration as it highlights what content is valued or not valued, leading to questions about which knowledge is of most worth to individuals (Eisner, 1985). The null curriculum can be categorised as part of the intended and implemented curriculum. It is included in the concept of the intended curriculum here to draw attention to the content that is left out in an Australian VET curriculum, but that may be significant to students located in other countries. However, it is acknowledged that it is not just the developers who omit content, as teachers may also leave out certain elements of the curriculum. For example, teachers may omit content that is likely to be contested to avoid conflict with students and others in an institution (Flinders et al., 1986).

The dimension of the intended curriculum discussed above acknowledges that it is more than what is set out in the official documents of Training Packages, as it also represents what the developers intentionally leave out and the adaptions teachers make in their plans and materials for instruction offshore. These plans, however, often exist in the most detailed form in the teachers' minds, and thus, they may not always be documented or understood by others (Remillard \& Heck, 2014). An awareness of these conceptions provides a useful framework for analysing, in the second section of this chapter, the intended curriculum of Training Packages which is used in Australian transnational VET.

\subsubsection{Implemented curriculum}

The dimension of the implemented curriculum, as presented in the framework of curriculum conceptions in Table 3.1, includes the supported, taught or enacted, and assessed curricula. The supported curriculum is the one supported by the available resources such as equipment, facilities, supplies, books, materials, technology, and timetables. Stake (1977) refers to these as examples of antecedents, which are the pre-existing conditions that affect curriculum outcomes. Therefore, the capacity of educational institutions to support the curriculum, through the provision of specific resources, is essential for student achievement (Hlebowitsh, 2005; Spillane et al., 2004). In vocational education these resources are necessary to teach the technical competencies of the curriculum. Tools for trade programs or computers for information technology programs are examples of specific resources that might be important for vocational education programs. Yet, the way in which educational institutions in diverse locations support the curriculum varies due to different capacities, potentials, and limits (Lauder, Jamieson \& Wikeley, 1998). For 
example, one noteworthy study conducted by S. J. Ball et al. (2012) explored the enactment of three policies in similar but different English secondary schools to consider the "reality" of these schools implementing curricula. They identified that one of the four main dimensions affecting the policy work of these schools was the material context that included resources such as buildings, equipment, and budgets. Ball et al. also found that there were differences in curriculum implementation amongst sites due to the role of actors and the specific actions that they took in response to their own situated institutional context. Ball et al. attributed these differences to the active role local actors play in a process of interpreting, recontextualising, and translating policies into institutional practices. These findings indicate that differences will always occur in the ways that actors within educational institutions interpret and support the intended curriculum across jurisdictions (including different countries); they will also differ from what the developers intended. These findings also suggest that the overseas sponsors of Australian VET programs will have different capacities when it comes to supporting the technical elements of a vocational curriculum with specific resources.

As presented in Table 3.1, the implemented curriculum also comprises the taught and assessed curricula. These curricula are closely related and are simply expressed as what teachers actually teach and assess. Many scholars refer to the taught curriculum as the enacted curriculum, to emphasise what teachers actually decide to teach, regardless of what was intended (Doyle, 1992; A. C. Porter \& Smithson, 2001; Remillard \& Heck, 2014). Given that teacher decision-making is a primary interest of this dissertation, the term "enacted curriculum" is used. The conception of curriculum enactment views the role of the teacher as a developer who constructs educational experiences with their students (D. L. Ball \& Cohen, 1996; Clandinin \& Connelly, 1992) to respond to their needs and interests at a particular point of time (Snyder et al., 1992). The assessed curriculum is the one embodied in the performance measures of the assessments that are used by teachers (Glatthorn, 2000). A. C. Porter and Smithson (2001) stress that it is important to distinguish the assessed curriculum from the intended curriculum because what is assessed is often different from what was intended. In terms of the dimension of the implemented curriculum, both the enacted and assessed curricula are closely related as the teacher plays an active role in determining what is taught and assessed. Thus, it is contended that teacher decision-making in transnational VET is not just restricted to the intended curriculum because teachers will respond to the diverse learning needs of students in particular situations. 
The capacity of teachers to enact and assess the intended curriculum relies on what Ariav (1988) refers to as "curriculum literacy", that is, their understanding of the curriculum intentions and how to enact these in specific contexts. Curriculum literacy is important because what teachers think and do with the intended curriculum is fundamental to the students' experience (Taba \& Spalding, 1962). Many studies reveal that if teachers have only superficial knowledge of the curriculum (D. L. Ball \& Cohen, 1999; Spillane et al., 2004), it leads to incoherence and inconsistencies in implementation (Fullan, 2008; Spillane et al., 2004). Therefore, it is critical that teachers receive support in the form of professional development, information, and materials so they can develop curriculum literacy (Fullan, 2001; Marsh, 2009; Print, 1993). However, the way that this support is provided to teachers is also important (Clarke \& Hollingsworth, 2002; Penuel, Fishman, Yamaguchi, \& Gallagher, 2007) because, as Chin and Benne (1970) explain, there are three different strategies that influence the effectiveness of teacher learning: (a) power-coercive strategies based on rewards and punishment, (b) normative strategies based on providing new messages about the benefits of innovation, and (c) rational strategies based on appealing to individuals on the basis of new information. Coburn (2004) claims that power-coercive and rationalist strategies tend to have less effect with teachers because they dictate teachers to act in certain ways, which they may resist. In contrast, she suggests that normative strategies will have greater influence because they are based on encouragement. These differences in success are dependent on the ways that teachers are supported and how they interact with the messages in their institutional environment (Coburn, 2004). Thus, the enacted curriculum in Australian transnational VET will rely not only on the availability of resources but also on the quality of professional support that teachers receive at the site of implementation and the capacity of host institutions to provide it.

While institutions and teachers play a central role in implementation, there is another range of factors that shape the implemented curriculum that a plethora of curriculum researchers (Corbett \& Rossman, 1989; Fullan, 1982; Fullan \& Stiegelbauer, 1991; House, 1996) have identified and categorised as either internal or external. Internal factors are those found within the educational setting and include student characteristics, local conditions, access to excursions and work placements. External factors involve cultural and societal expectations, educational policy, funding and systems, leadership, government, and the applicability of subject matter. All of these factors influence the implementation of the curriculum, for better or for worse. Fullan and Stiegelbauer (1991) contend that it is the external factors that often have 
the strongest influence on curriculum implementation because they are usually out of the teachers' control.

It is claimed that the fidelity approach to curriculum implementation rarely succeeds because some adaption usually occurs to account for local factors (Fullan, 2007). The most influential research conducted in this area was Fullan and Pomfret's (1977) landmark study, which examined 16 case studies of curriculum implementation in the USA. They discovered variations in the degree to which different teachers enacted the same curriculum, as well as in the degree to which some teachers enacted the same components more effectively. Fullan and Pomfret concluded that contextual factors, such as the organisational climate, environmental support, in-house training, demographic factors, and political complexity were the determinants of curriculum implementation. This important study showed that educational policies that mandate fidelity to the intended curriculum tend not to have a strong influence on the implemented curriculum because most developers fail to address the critical factors for implementation. This finding indicates that it is unrealistic to expect that a national curriculum, such as a Training Package product, can ever be implemented with fidelity in another country because there will always be factors that have not been accounted for due to cultural, societal, and institutional differences between countries.

The above discussion highlights how the dimension of the implemented curriculum is important because it determines the level of fidelity and adaption of the intended curriculum. The capacity of institutions to support the curriculum and teachers' decisions about the particular experiences and assessment they enact for students, along with a range of situational factors, will all shape the degree to which the intended curriculum is realised across diverse sites of provision. Therefore, what students experience is based on the implemented curriculum, regardless of what is written down, planned, or intended. This dimension of the implemented curriculum offers a basis for understanding the issues associated with the implementation of Training Packages in Australian transnational VET that are discussed in the second section of this chapter.

\subsubsection{Experienced curriculum}

The dimension of the experienced curriculum, as presented in the framework of curriculum conceptions in Table 3.1, includes the learned and hidden curricula. The learned curriculum is the one that the students actually learn, regardless of whether it was planned or intended (Glatthorn, 2000; Goodlad et al., 1979; A. C. 
Porter \& Smithson, 2001). While the enacted curriculum primarily shapes the students' experience of the curriculum, the way that they choose to engage with it is also important (Nuthall, 1997). For example, students will decide whether they will participate in a course of learning, how they will participate, and with what degree of effort (Billett, 2011). Moreover, a range of student factors will also influence the learned curriculum such as prior knowledge, attitudes, values, motivation, and language proficiency. As discussed in Chapter 2, many of these factors are likely to influence the learned curriculum in Australian transnational VET, given that most transnational students have probably not been to Australia and English is rarely their first language. Thus, the learned curriculum is an important concept because student learning and outcomes are a salient concern for Australian transnational VET provision.

The hidden curriculum involves all the learning that takes place that is not planned but still occurs (Glatthorn, 2000). Originally, Jackson (1968) coined the term to refer to the unwritten, unofficial, and unspoken academic, social, and cultural messages that are communicated to teachers and students within educational institutions. These messages are concerned with power, authority, access, and participation and are embedded in an institution's structure, rules, customs, relationships, and rituals. Seddon (1983) contends that teachers and students learn to accept these messages, rather than face any ramifications from challenging them. As such, the messages are often far more powerful and significant than those that comprise the intended curriculum and can either reinforce or contradict it. The concept of the hidden curriculum explains that the messages that teachers and students receive vary from site to site and affect them in different ways. When it comes to Australian transnational VET it is likely that many of these messages will not be foreseen or obvious to teachers working in another country for the first time. Hence, their capacity to interpret, understand, and act on these messages will be limited until they become visible and known to them. This last point is particularly important, as effective decision-making relies on teachers understanding the cultural norms of the countries and institutions in which they are located.

In sum, the experienced curriculum has considerable influence on the enacted curriculum due to the interactions between teachers and students and their responses to the institutional messages they receive and act on. Thus, the dimension of the experienced curriculum offers a basis for understanding that student and institutional factors are likely to be key influences on the implemented curriculum in Australian transnational VET. Further, the way teachers respond to these factors will also determine their level of fidelity and adaption to the intended curriculum. 


\subsubsection{Relationship amongst curricula conceptions}

In an attempt to understand why there will be differences between the intentions of Training Packages and what is implemented offshore, the above sections have elaborated on nine conceptions of curriculum. Many researchers (e.g., Glatthorn, 2000; A. C. Porter, 2002; Squires, 2009) assert that student achievement is improved when there is a close alignment amongst the different curriculum types at work in an educational institution. However, as explained in the previous discussion, there is often a gap between what curriculum developers intend and what students learn. This is because different curricula types interact within educational institutions and have various patterns of influence on what is planned, implemented, and experienced.

Some curriculum types have greater influence than others on student outcomes. For instance, based on his research with a mathematics curriculum, Glatthorn (2000) found that the intended curriculum had a moderate influence on what is enacted, because teachers were more concerned with the learned curriculum. The decisions they made in enactment were based on the students' needs and responses to the enacted curriculum. Remillard and Heck's (2014) view is that the teacher-intended curriculum plays a mediating role between the intended and enacted curricula. This view emphasises the dynamic relationship between teachers and materials and the influence this has on the enacted curriculum (Remillard, 2018). It follows, then, that there is a similar relationship between the teacher-intended curriculum and the assessed curriculum. Thus, teachers play a significant role in determining the level of alignment between the intended, enacted, assessed, and learned curricula.

However, the alignment of curricula, in any situation, is also influenced by the constraints of the supported and hidden curricula. The hidden curriculum is particularly difficult to align with other curriculum types because it is unplanned and not accounted for in the intended curriculum (Pinar, Reynolds, Slattery, \& Taubman, 1995; Solomon, 2009). Glatthorn (2000) suggests that, because it has such an impact on student learning, institutional leaders should identify the hidden messages that are in opposition to the intended curriculum and alter them.

The above discussion suggests that the dimensions of the implemented and experienced curricula are likely to have considerable influence on whether the intentions of Training Packages are realised in the countries that sponsor Australian VET programs. Furthermore, the way these types of curricula will interact will be different across national and cultural contexts. Thus, in some situations there will be 
a closer alignment amongst the curricula types than in others. These differences are important because the decisions teachers will make about adapting Training Packages will be influenced by the extent to which they perceive the curriculum to be congruent with the situation (Doyle \& Ponder, 1977).

\subsubsection{Summary}

This first section of the chapter has proposed a theoretical framework relevant to the exploration of the factors that influence the implementation and transformation of Training Packages in Australian transnational VET. A framework of curriculum conceptions was advanced as a means for understanding why the intentions of a mandated curriculum are not always realised in implementation. The concepts of the intended and implemented curriculum are used in the following section of this chapter to explore the problem of implementing a vocational curriculum designed for Australia in other national contexts.

\subsection{Curriculum conceptions in Australian transnational VET}

In this section of the chapter the framework of curriculum conceptions, as discussed in the preceding section, is used as a conceptual lens to understand the problem of implementing a VET curriculum designed for Australia in another country. Thus, it provides a means to understand why the intentions of Training Packages may not be realised in the countries that import them and engage teachers from Australia to enact them. Thus, the following section discusses the dimensions of the intended and implemented curricula in relation to the Training Package model to assist in understanding this problem.

\subsubsection{The intended curriculum in Australian transnational VET}

Understanding the intended curriculum of Training Packages is important because it forms the foundation of what must be implemented with fidelity in Australian transnational VET. Thus, the intended curriculum is elaborated through a discussion of its model and in comparison with other theoretical models of curriculum. The purposes of this discussion are twofold. The first purpose is to highlight the limitations of using the highly regulated domestic curriculum of Training Packages in countries for which it was not designed. The discussion also draws attention to the difficulties this creates for the development of the teacher-intended curriculum. The second purpose is to consider what might constitute a more 
sustainable approach that responds to the opportunities for new and contextualised models of transnational vocational education (Dempsey \& Tao, 2017) as discussed in Chapter 2.

The curriculum that is used in Australian transnational VET is intended for the purposes and interests of Australian industry and not those of other countries, as has been outlined in Chapter 2 . The recommended curriculum is developed by organisations that represent the different sets of industry needs (ASQA, 2018). It is documented in a syllabus that comprises a set of learning outcomes and guidance for assessing student performance, which is endorsed and mandated by the Australian federal government (E. Smith \& Keating, 2003). The Training Package model can be viewed as a rational model of curriculum, initially put forward by Tyler in 1949, because: (a) the learning outcomes are mandated, pre-specified, and used as the criteria for assessment; (b) it constitutes a fixed body of knowledge and skills based on Australian workplaces; (c) the needs of the student are not considered in the development process; (d) teachers are not an integral part of the design process; (e) it is structured according to mandated rules, which must be followed with fidelity; and (f) teachers are expected to design and organise the learning experiences. Many of these features are regarded as strengths of a rational model of curriculum because they promote consistency in implementation and standardisation in outcomes (Print, 1993). However, other scholars (Pinar et al., 1995; Schwab, 1983; Skilbeck, 1992; Walker, 1971) have criticised the rational model because it does not take into account the factors that influence curriculum implementation and the numerous actors involved with it.

Indeed, many of the problems teachers encounter in trying to teach and assess the learning outcomes of Training Packages offshore are due to the top-down approach to the organisation of the curriculum (Fullan, 1994), where the needs of Australian industry take precedence over other stakeholders (Billett, 2004). As discussed in Chapter 2, the Australian Government uses its legislative power and bureaucratic authorities to control the curriculum, mandate its outcomes, and direct the activities of teachers (ASQA, 2018). A salient feature of the model is the prioritisation of industry needs over those of students, including those enrolled in transnational programs and their teachers (Billett, 2004). The consequence of this top-down approach is that offshore teachers are mandated to enact, with fidelity, a curriculum that is not designed for the needs and interests of transnational students or sponsors.

This discrepancy has led to a number of problems for those offshore teachers who must implement the intended curriculum. A notable problem is the focus on 
specific industry-defined competencies within the curriculum that are not relevant to preparing students for workplaces outside Australia. Many of the technical elements of the curriculum have not been well understood by students or their sponsors (Woodley, 2006), for example, the setting up of simulated workshops for trade programs or kitchens for cookery programs. Additionally, many of the features of the competency-based training format, such as formative assessment and workplace learning, are also unfamiliar to overseas students and local managers (Bilboe, 2011; Heffernan et al., 2010; Shi \& Woodley, 2008). The culturally bound (Hua et al., 2011) and linguistically bound (Moran \& Ryan, 2003; Woodley 2008) nature of Training Packages has also proved challenging for teachers. One problem relates to the requirement for Australian content to be taught when it is not relevant to the context. For example, in China, Woodley (2008) found that teachers were frustrated by teaching topics, such as Australian law, as part of the business curriculum because they were irrelevant to students who had no intention of working in Australia. Linguistic problems have also emerged because English is the mandated language of instruction, even though it is not the official language of many of the countries that host Australian VET programs. Teachers have reported that because Training Packages do not prescribe English level requirements, many students enter the programs without the language capability to succeed (Shi \& Woodley, 2008; Woodley, 2007). These problems are more noticeable when students are expected to use the technical language and Australian jargon employed in Training Packages that are not used in their home country (Woodley, 2007). Considering all these problems reported by teachers, it is unlikely that the promises of consistency in implementation and standardisation in outcomes can be realised in Australian transnational VET provision.

The requirement for teachers to maintain fidelity to a curriculum intended for Australian purposes has also hindered the level and types of adaptions they can make to respond to local requirements (Dempsey \& Tao, 2017; Rahimi \& Smith, 2017). A central concern that is often overlooked in the literature on Australian transnational VET provision is understanding the issues that teachers face in adapting Training Package products to meet the needs of their students (Tran, 2013a, b). Training Packages appear to offer flexibility because they require teachers to develop instructional materials to meet the needs of specific cohorts of students in different locations (Cornford, 1999; Southren, 2015; Tran \& Nyland, 2013). In the Australian VET system, these materials form the teacher-intended curriculum; however, the process of development is referred to as the "contextualisation of the curriculum" (Schofield \& McDonald, 2004). Some scholars (Down, 2002, 2003; 
Schofield \& McDonald, 2004) claim that contextualisation empowers teachers with pedagogic freedom and professional discretion. Other scholars (Barrow, 2006; Cornford, 1999; Hager, 2004), however, assert that teachers cannot be expected to contextualise Training Packages when they do not provide advice on how to design or organise the learning process, strategies, or materials. Hager (2004) describes this gap between the intended curriculum and the enacted curriculum as the "black box" of Training Packages, which teachers are uncertain how to fill. Barrow (2006) asserts that many of the problems associated with the implemented curriculum in Australian VET are concealed in this black box. It follows, then, that the way the black box manifests for teachers offshore is significantly more challenging given that they are likely to be working in countries that are substantially different from Australia. Dempsey and Tao (2017) claim that it is particularly difficult for teachers to contextualise materials for offshore provision if they are unfamiliar with the local industry (Dempsey \& Tao, 2017). Karthigesu (2007) suggests that the inclusion of guidelines for offshore implementation in Training Packages would help teachers bridge the gap between the intended and implemented curricula.

Teachers have reported that, because the intended curriculum is so tightly tied to Australian industry standards, it is difficult to develop and adapt materials for use in another country (Rahimi \& Smith, 2017). Subsequently, teachers have been placed in a difficult situation where they have to choose between being faithful to a prescriptive, standardised, and regulated curriculum or trying to adapt it to meet transnational students' goals for learning, which may, at times, differ or be irrelevant to the demands of the curriculum. Many authors (Anderson, 2006b; Billett, Henderson, Choy, Dymock, Beven, Kelly \& Smith, 2012; Dempsey \& Tao, 2017; Woodley, 2007) contend that a more interactive model of curriculum would allow for institutions and teachers to consider a broader range of student interests and aspirations.

There are other more dynamic and interactive models of curriculum that could be used in Australian transnational VET to cater for a broader set of needs and interests internationally. These models are different from the rational model of curriculum because they are less structured and encourage teachers to use their professional judgment in further developing the intended curriculum to meet local needs. The models offer two advantages for transnational VET provision because they: (a) emphasise the importance of the situation or context in the curriculum development phase, and (b) include a diversity of stakeholder input into the development of the curriculum. For example, Skilbeck's model (1976) includes a situational analysis while Walker's model (1971) provides for curriculum deliberation 
amongst stakeholders. It is these kinds of processes that are likely to be necessary to understand the situated requirements for effective transnational education. These models are elaborated on here to consider how a vocational curriculum could be developed to account for a diverse range of interests and contexts.

A situational model of curriculum, as proposed by Skilbeck (1976), is one that allows developers to design a curriculum relevant for different contexts. It involves conducting an analysis of the situation to identify all the internal and external factors present in the situation and then applying this to curriculum development (Print, 1993). Throughout the process developers look for consistencies and discrepancies between the situation and the curriculum intentions and develop an action plan to resolve high discrepancy factors. In this way, the developers are able to react systematically to those areas of greatest need. Thus, a situational model of curriculum would provide Australian institutions, and the teachers that work for them, with the opportunities to develop locally aligned and coherent curricula relevant to other countries.

Walker's (1971) is another model of curriculum that would assist teachers, through deliberation, to address the problems that emerge in implementation offshore. Schwab (1983) describes deliberation as a dynamic process that involves a range of stakeholders, including teachers, in an ongoing discussion about the curriculum and in generating alternative ideas and solutions to overcome problems in context. The model views the nature of the participants involved in curriculum development and the decisions they make as having a significant effect upon the final curriculum outcome. The intention is that the curriculum benefits from multiple perspectives of expertise and experience. Moreover, by involving teachers in the deliberations they are enabled to take practical possession of the curriculum because they have played a part in determining it (Ross, 1993, Schwab, 1983). It is contended that a deliberative curriculum is a viable alternative in transnational VET provision because the process is contextually bound. Moreover, it would enable teachers to forecast problems and involve local stakeholders in responding to problems.

It is evident from the above discussion that the developers of Training Packages have not engaged in the kinds of development processes that would account for the needs and interests of transnational students and their sponsors. This is a principal cause of the problems that teachers face in maintaining fidelity to the intentions of the intended curriculum in another country. As a result, many of the problems they encounter offshore emerge from having to enact a curriculum that is not designed for international implementation. These findings question the feasibility of expecting teachers to meet the imperatives of national curriculum standardisation 
while at the same time developing the teacher-intended curriculum to meet the needs and interests of students in diverse socio-cultural contexts. The following section discusses the conceptions of the implemented curriculum to understand the range of problems associated with implementing Training Packages and how and why they are transformed in other countries.

\subsubsection{Implementation of the curriculum in Australian transnational VET}

It has been proposed above that it is not possible to implement Training Packages with fidelity in countries outside Australia because the intended curriculum is not designed to meet the needs of students and their sponsors. Indeed, implementing the intended curriculum in any situation, let alone in an educational institution in a foreign country for which it was not designed, is a complex process. Frequently, things do not turn out as intended or planned. Hence, this section of the chapter considers the supported, hidden, and enacted curricula in Australian transnational VET to shed light on the factors that shape and transform the intended curriculum in implementation. It is important to note, however, as mentioned in Chapters 1 and 2, that the research on the implementation of Training Packages offshore is limited and is mostly comprised of single or multi-site case studies. Often this research is conducted by staff involved in these provisions or responsible for reporting on them (e.g., AEI, 2011; Bailey, 2011; Bilboe, 2011; Karthigesu, 2007; Shi \& Woodley, 2008; Woodley 2007, 2008). Hence, much of the following discussion about the implementation of Training Packages is explicative.

The supported and hidden curricula influence the implementation of Training Packages offshore because they define the structure and shape of what can be enacted (curriculum content) and achieved (curriculum standards). However, it was advanced in Chapter 2 that due to the economic status of countries that host Australian VET programs, some institutions may not have the capacity to support the intended curriculum. Indeed, it appears from the accounts of teachers that this is often the case as they have reported a number of limitations including: (a) a lack of resources especially for programs requiring specialised equipment such as cookery (Bailey, 2011), (b) the absence of customised teaching materials and texts (Bailey, 2011; Woodley, 2007, 2008), (c) difficulties accessing work-based placements or simulated work environments (Woodley, 2007), and (d) unsatisfactory institutional arrangements such as class sizes and timetimbles (Woodley, 2007). Some elements of the hidden curriculum have also emerged in relation to the cultural practices of countries. For example, in Kuwait, women are not allowed to attend classes at night, 
or to enter some workplaces (Bilboe, 2011). These limitations have made it difficult for teachers to teach and assess technical competencies of the curriculum when they have limited access to work-based resources and specialised equipment. These findings indicate that in some countries the limitations of the supported and hidden curricula narrow the range of experiences that teachers can provide for students, compared to those that might be organised for students in Australia. Thus, it is likely that the pursuit of equivalence, as well as fidelity to the intended curriculum, in Australian transnational VET is constrained by the supported and hidden curricula.

The enacted curriculum in Australian transnational VET also has considerable influence on what elements of the intended curriculum are taught and how they are taught. While it has proved difficult for teachers to enact the intended curriculum offshore because it was not designed for the needs and interests of transnational students, the learned curriculum has been shown to have considerable influence on the enacted curriculum (AEI, 2011; Bailey, 2011; Dempsey \& Tao, 2017; Karthigesu, 2007; Shi \& Woodley, 2008; Tran \& Le, 2017; Woodley, 2007, 2008). For example, teachers have reported that the way students engage with the intended curriculum offshore is unlike the engagement of students in Australia because they come from different linguistic, cultural, and educational backgrounds (Bailey, 2011; Tran \& Le, 2017; Woodley, 2007, 2008). Consequently, teachers have had to adapt their usual practices and materials, which has required them to develop new knowledge and skills. As demonstrated in Woodley's (2007) case study, teachers changed their communication style and developed new learning materials and assessments to assist students develop their English language skills. Bailey (2011) also reported that the teachers he interviewed had all changed their practices and materials to meet the educational needs of students from remote villages in the South Pacific. Their changes, however, were highly individualistic because the educational experiences they constructed were in direct response to their students' needs and interests in particular situations. These findings suggest that the enacted curriculum in Australian transnational VET is a transactional process where teachers and students make meaning of the curriculum in context (Snyder et al., 1992). Furthermore, transnational teachers need to learn new knowledge and skills to construct these experiences in situations that are culturally different from what they are used to in Australia.

A recent study has pointed to the importance of professional learning for teachers of international VET students. Based on in-depth interviews with 30 teachers, Tran and Le (2017) identified three primary learning needs. Firstly, teachers were interested to learn about their students' backgrounds and motives for 
enrolling in an Australian VET program so they could respond to their needs and interests. Secondly, they wanted to develop a new set of pedagogical practices in response to their students' language and cultural issues. Thirdly, they aspired to diversify their teaching methods to accommodate diverse cohorts of learners. These findings suggest that the way teachers best make sense of the circumstances for enactment in another country is through learning about their students' needs and how to respond to them.

It is also apparent from the preceding discussion that teachers need specific forms of professional support to develop new practices for enacting Training Packages in different cultural contexts. Yet, the literature indicates that there is a distinct lack of professional preparation and development available for teachers to learn the optimal ways to teach international students (Tran \& Le, 2017; Tran \& Nyland, 2013). There are two main deficiencies. Firstly, the mandatory course for teacher preparation has not proved to be an effective foundation for developing teaching practice because it is overly focussed on compliance with the intended curriculum (Clayton, 2009; Simons, Harris, \& Smith, 2006; E. Smith \& Grace, 2011; Wheelahan \& Moodie, 2011). Secondly, there is no cohesive approach to the ongoing professional development of teachers for international teaching in VET (Tran \& Le, 2017). Therefore, it is likely that the inadequacies in professional support for transnational teachers are a critical issue impacting on the quality of the enacted and learned curricula in Australian transnational VET.

It can be seen from the above discussion that the supported, hidden, and learned curricula all have considerable influence on the enacted curriculum in Australian transnational VET. As has been shown, there is a range of factors that makes the circumstances for enactment in another country very different from enactment in Australia. Consequently, teachers have a demanding and complex role that goes beyond being the faithful implementers of what an Australian federal government has mandated through the documented curriculum. However, due to the limited research available, little is known about the decisions that transnational teachers make in their enactment of the curriculum or the relevance and quality of their curriculum-making. Therefore, the next section of the chapter considers the broader field of educational scholarship as a means to understand the processes of teacher decision-making, problem-solving, and curriculum-making and how they might transform the curriculum in Australian transnational VET. 


\subsubsection{Summary}

It has been proposed in this section of the chapter that the provision of Australian transnational VET can be understood through the dimensions of the intended, implemented, and experienced curricula. Firstly, there is what the developers have set as the goals and content of the intended curriculum. It has also been proposed that these intentions overlook the needs of transnational students as the interests of Australian industry inform the curriculum. Therefore, the intentions of the curriculum may be dissociated from the goals of these students and their sponsors. Yet, Training Packages are the only curricula that can be implemented by Australian educational institutions offshore and the teachers who work for them.

Consequently, teachers have to make decisions about how to enact a curriculum that is culturally bound to Australia, in another country. The dimensions of the implemented and experienced curricula assume that these decisions will be influenced by access to resources and the influence of local factors. Hence, teachers' capacity to enact the intended curriculum with fidelity will largely depend on the alignment of the different types of curricula operating within the institutional environment. It is important to emphasise these influences on the intended curriculum because they will ultimately affect what students will learn and achieve. This might differ from the experiences and outcomes of Australian students. Thus, it is contended that teachers need an extended scope of role to influence the range of factors associated with the problem of enacting a curriculum designed for one country in another. This consideration is discussed in the following section of this chapter through a review of the literature on the role of the teacher in decisionmaking, problem-solving, and curriculum-making in enactment. This discussion advances the means by which the research problem can be understood and the justification for further investigation.

\subsection{Role of the teacher in Training Package implementation in Australian transnational VET}

The previous section established that curriculum implementation in Australian transnational VET is a complex process influenced by many factors and involving many actors. As a result, it is rarely straightforward, and teachers have to make adaptions to account for local conditions. Therefore, curriculum fidelity is difficult to achieve and variation between sites of implementation appears inevitable. The next section of this chapter considers these issues in relation to the role of teachers in the 
implementation of the intended curriculum. It is proposed that it is not possible for teachers to simply enact a curriculum designed for one country in another, without an extended scope of role to: (a) influence the range of contextual factors associated with implementation, and (b) develop the curriculum to meet the needs of their students. In making its case, this section analyses the literature in relation to teacher decision-making and curriculum-making. Firstly, it considers the different kinds of problems and dilemmas teachers face in curriculum enactment and the ways that teachers make decisions to resolve them, depending on their capacity to exercise professional discretion. Secondly, consideration is given to understanding decisionmaking in teachers' curriculum-making. The intention of this section is to conceive curriculum enactment in Australian transnational VET as a series of problems and dilemmas that teachers try to resolve through a diverse range of approaches and curriculum-making strategies, subject to the constraints placed on their agency.

It is important to acknowledge that there are many stakeholders who make decisions about the implementation of the curriculum. However, given that the primary concern of this dissertation is to understand the role teachers play in curriculum transformation in Australian transnational VET provision, the focus of this section of the chapter is on the role of teacher decision-making, problem-solving, and curriculum-making. Thus, it emphasises the perspectives of teachers, which are frequently overlooked in the implementation of a mandated curriculum model (ElbazLuwisch, 1997; McDonald, 1992) such as Training Packages (Dymock \& Billett, 2009).

\subsubsection{Teacher decision-making and problem-solving in Training Package implementation in Australian transnational VET}

It was established in the previous section of this chapter that teachers experience many problems in the enactment of Training Packages offshore for a range of reasons. This is not surprising given that many scholars conceive curriculum enactment as a series of problems and dilemmas that teachers have to resolve (Lampert, 1985; Katz \& Raths, 1992; Windschitl, 2002). Some problems require simple solutions, while others exist as multiple layers of concerns that are complex, ill defined, and multi-dimensional (Stevens, 2000; Windschitl, 2002). When these problems overlap they often create dilemmas, which are challenging for teachers in that they are not easily resolved and often involve choosing from a competing set of priorities. Windschitl (2002) categorises the dilemmas that teachers experience into four types: conceptual, pedagogical, cultural, and political. Conceptual dilemmas 
emerge from the teachers' attempts to understand the curriculum; pedagogical dilemmas arise when teachers apply this understanding, or lack of it, to their practice. In Chapter 2, for example, it was shown that many aspects of Training Packages that teachers would generally take for granted in Australia do not apply in some countries (Dempsey, 2012; Dempsey \& Tao, 2017; Shi \& Woodley, 2008). In practice, cultural dilemmas emerge between teachers and students in the role that the curriculum presupposes. For example, Bilboe (2011) found that cultural dilemmas became an issue for transnational teachers in Kuwait. She reported that the requirement for teachers to assess competencies was culturally specific and not well understood by students. Situations like this can lead to political dilemmas, as conflict develops amongst stakeholders, norms are questioned, and authority is redistributed.

Therefore, teachers may find themselves in a precarious situation trying to negotiate for changes that local stakeholders in another country may not understand. All these dilemmas can also interact with each other at different times and in different ways. It is these intersections which present the greatest challenges for teachers (Windschitl, 2002). This is more likely to be true for transnational teachers because many of these dilemmas will be unfamiliar to teachers working in another culture for the first time.

Dilemmas force teachers into deciding amongst alternatives and taking action in response (Lampert, 1985; Taba \& Spalding, 1962). The way that teachers make these decisions has been described in the literature as intuitive, analytic, deliberative, practical, reflective, and emotional. Given that one of the goals of this dissertation is to reach a better understanding of the decisions teachers make in their enactment of Training Packages offshore, these six approaches are discussed and evaluated below.

Teacher decision-making involves intuitive, analytic, and deliberative decisions (Eraut, 1997, 2000). Intuitive decisions are usually based on prior experience and are made quickly as they come to mind (Eraut, 1997, 2000). Thus, when transnational teachers make decisions offshore, they will relate to their teaching experience in Australia. These reflections will set the conditions for the way teachers think about the intentions of Training Packages in new situations. However, it is likely that many of these prior conceptions will be challenged in a new country. Therefore, the intuitive approach may well prove ineffective for transnational teachers compared to other types of decision-making. In contrast, the analytic and deliberative modes of decision-making are likely to be better choices for transnational teachers. Analytic decision-making is useful in new situations because it involves teachers finding and using information to guide and justify decisions, rather than relying on their assumptions (Eraut, 1997, 2000). For example, transnational teachers might 
survey the students' interests and use the results to inform the development of materials. The deliberative mode of decision-making is effective for resolving complex problems and dilemmas (Eraut, 1997, 2000). While it involves teachers using their intuition, they also subject their ideas to critical analysis. However, both the analytic and deliberative modes of decision-making are usually constrained by time. These findings suggest that the quality of teacher decision-making offshore can be enhanced through the provision of information and through allowing time for teachers to learn about the circumstances for enactment.

The literature also positions teacher decision-making as reflective practice (Duncan-Andrade \& Morrell, 2008; Stenhouse, 1975). A reflective perspective sees decision-making as involving research and theory (Moore, 2000; Stenhouse, 1975). When theory and practice are connected it is referred to as praxis (Friere, 1970). Duncan-Andrade and Morrell (2008) describe reflective decision-making as a continuous, self-reflective cycle between theory and action that involves: (a) identifying a problem and researching it, (b) developing a collective plan of action to address that problem and implementing it, and (c) evaluating the action and assessing its efficacy. Consequently, teachers are involved in a constant cycle of evaluating thought with action, theory, with practice. Therefore, the primary benefit of reflective decision-making for transnational teachers is that it connects them with their colleagues to focus on overcoming specific problems in their situated context.

Teacher decision-making is considered practical when curriculum problems and dilemmas emerge in situations and something needs to be done (Coburn, 2004; Doyle \& Ponder, 1977). Schwab (1978) provides a useful contrast of theoretical and practical decision-making. He states that theoretical decision-making is driven by principles whereas practical decision-making is based on the factors found in specific situations. Doyle and Ponder's (1977) concept of the "practicality ethic" is particularly useful to explain how teachers will most likely judge the merit of enacting an Australian VET curriculum in a new country, based on the extent to which they perceive that they can practically enact it. Doyle and Ponder propose that teachers use three criteria to determine whether or not a curriculum proposal is practical: instrumentality, congruence, and cost. Firstly, teachers will look for instrumental content, such as a set of procedures, to support implementation in another country. If they find there are few guidelines or materials for enacting the curriculum, then they may decide that the curriculum is not of much practical use. Subsequently, they are likely to make their own decisions about what and how to teach an Australian VET curriculum offshore. Secondly, teachers make decisions in terms of the extent to which the curriculum is congruent with the situation; that is, the match between what 
is intended and the prevailing conditions. This implies that if teachers perceive dissonance between an Australian VET curriculum and the circumstances for enactment, then they will be less likely to follow the curriculum with fidelity. Instead, they will be more concerned with meeting the needs of the students within the existing constraints. Thirdly, teachers apply the criteria of cost. Here, cost is defined as the ratio between investment and return. For example, teachers are more likely to put considerably more effort into resolving problems if students and local stakeholders appreciate their actions. Hence, the practicality ethic explains that transnational teachers will have to exercise their professional judgment because Training Packages do not provide the specific guidelines that they need for enactment in countries outside of Australia. Further, the amount of effort that they will put in to overcoming any dissonance between the intended and supported curriculum will depend on the responses of students and local stakeholders.

Some authors (e.g., Hargreaves, 2004; Zembylas, 2005) contend that theoretical and practical explanations of teacher decision-making ignore the involvement of emotions. Research on the various demands that are placed on teachers suggests that emotions will play a major part in the decisions that they make (Helsby, 1998; Troman \& Woods, 2000). For instance, research shows that negative emotions, such as shame, blame, or dissatisfaction, reduce the quality of teacher decision-making because it affects their: (a) capacity to cope in difficult situations (Hargreaves, 2000), (b) ability to connect with students (Hargreaves, 2000), (c) sense of vulnerability (Lasky, 2005), and (d) sense of powerlessness (Smylie, 1999). In contrast, positive emotions have been shown to increase a teacher's capacity for effective decision-making. For example, Gallo and Tassinari (2017), in their exploratory study in Germany, found that positive emotions such as enthusiasm and joy provided foreign language teachers with a sense of harmony with their students, which led to the teachers feeling appreciated and valued for their contributions. They also found that these feelings were affected by individual factors, like a teacher's sense of well-being. In contrast, other studies show that emotions are often associated with the conditions of teachers' work (Akın, Aydın, Erdoğan, \& Demirkasımoğlu, 2013; Hargreaves, 1994). In particular, collegiality, trust, and social support can all foster teachers' positive emotions in periods of change (Hargreaves, 1994). This suggests that even though transnational teachers' decisions will be affected by their own personal attitudes, institutions can still play a role in enhancing their capacity for decision-making by creating a supportive environment.

The preceding discussion indicates that there are a number of ways that transnational teachers will try to resolve the problems and dilemmas that beset them 
in attempting to provide programs and secure outcomes to the same standard, in an unfamiliar country, as they would in Australia. Therefore, their capacity to use professional discretion to make decisions and solve problems and dilemmas within their situation is an important consideration. However, it is likely that conflict will arise when teachers act on their decisions offshore and in the process, norms are questioned and authority redistributed (Campbell, 2012). Consequently, how teachers make choices, exert influence, and take stances in curriculum enactment will be subject to institutional structures, culture, and associated power relationships (Allen, 2002). Indeed, a recent study has shown that the quality and scope of teachers' relationships within institutions has a critical influence on problem-solving. Priestley, Biesta and Robinson (2015) analysed the social-cultural interaction and practices of two secondary schools in Scotland to determine institutional influences on teachers' agency. Agency can be defined as the capacity of teachers to act on their decisions and resolve problems in their immediate situation. In one school, where relationships were reciprocal, symmetrical, and collaborative, teacher agency was enhanced. One of the main reasons that teachers in this school were able to achieve agency was because they were able to draw upon the relational resources afforded by their networks. Conversely, in the other school, where relationships were reported as asymmetrical and less reciprocal, a comparative lack of resources hindered teachers' achievement of agency. Without access to resources, teachers in these environments were less able to solve many of the problems they encountered in curriculum implementation. Thus, this study indicates that the relational conditions through which teachers will achieve agency in different institutions overseas is important.

However, other studies have shown that even in highly controlling environments where teacher agency is not supported teachers will still exercise their agency by intentionally disguising, resisting, subverting, and/or opposing the curriculum intentions in enactment (Apple \& Jungck, 1990; Sonu, 2012). For example, Sonu's (2012) study of New York high schools found that teachers would increase their performative stealth to subvert some aspects of the intended curriculum and institutional control, in order to pursue their own goals. Scott (1990) refers to these acts as "illusions of compliance" whereby teachers perform according to the "public transcript" (what is expected of them by the institution), but in their own private space, away from scrutiny, they act according to their values, emotions, and intentions. Therefore, it is likely that despite the level of control that local institutions might place on teacher agency offshore, some teachers will still make decisions based on their own moral purposes. 
Yet, teacher agency in transnational VET is not only subject to the controls placed on them by local institutions. They are also expected to meet Australian regulations even though they are located in another country. Many scholars assert that placing these types of external controls on teachers lowers their capacity for teacher discretion (Fullan, Rolheiser, Mascall, \& Edge, 2004). This issue of control is particularly the case in those systems that use rational and mandated models of curriculum (Priestley et al., 2012; Sachs, 2001), such as Training Packages, where teachers are forbidden to change the curriculum content, assessment criteria, or standards (Black \& Reich, 2010; Darwin, 2007; Davids, 2008). Apple and Jungck (1990) and Hargreaves (2000) explain that the reason these rational curriculum models exert control over teachers' practice is because they enforce the fidelity aspect of the curriculum. However, as aforementioned, there will be times when transnational teachers will have to adapt Australian curricula to meet the needs of students in another country. Thus, as Billett (2011) contends, these attempts to "teacher-proof" the curriculum are misdirected.

It seems that the geographical distance of transnational VET provision might affect teacher agency in different ways than it does domestically. For example, Rahimi and Smith (2017) found in their case studies in China, Kuwait, and Laos that teachers are often the key actors in ensuring the effective implementation of Training Packages. They suggest that there is an implicit expectation that teachers will enact Training Packages as a "technology of trust" in different settings and under different teaching and assessment practices. In other words, teachers are responsible for ensuring that Australian industry standards are upheld for non-Australian students. While it could be expected that the expectation to uphold standards might reduce teacher agency and autonomy, these researchers found that it actually increased autonomy because of the implicit trust in this arrangement for teachers to act professionally in their judgements.

The preceding discussion explains that curriculum enactment in Australian transnational VET can be conceived as a series of problems and dilemmas that teachers have to solve in unfamiliar situations. Thus, it is unlikely that they will be able to rely on their past experience to make decisions when they first arrive in a new country. Instead, they will need to spend time appraising the situation, finding and considering new information, deliberating with stakeholders, taking practical action, and reflecting on their practice. At times, their decision-making will also be influenced by their emotions. However, their capacity to exercise professional judgement is more likely to be influenced by their own moral purpose and the level of controls placed on them by local institutions, than via the remote surveillance by Australian 
regulators and institutions. Thus, the decisions teachers make offshore will challenge or subvert the intended curriculum at different times and under different conditions.

This extends to the decisions they make about the level and types of adaptions they make to the curriculum.

\subsubsection{Curriculum-making for Australian transnational VET}

It has been acknowledged above that attempts to teacher proof the curriculum tend to fail because teachers are decision-makers who interpret and modify the intended curriculum to meet the needs of their students in context. In this regard, teachers play a crucial role as curriculum-makers, because it is they who translate the intended curriculum into teachable forms (Wallace \& Priestly, 2016). It follows, then, that transnational teachers, in their role as curriculum-makers, have considerable influence over what students learn, and how. To understand teachers' approaches to curriculum-making in Australian transnational VET, this part of the chapter considers five roles they might adopt in implementation: (a) curriculum implementer, (b) curriculum adaptor, (c) curriculum developer, (d) curriculum researcher, and (e) curriculum maker. It is contended that all of these roles would enable teachers to overcome many of the problems associated with enacting a curriculum designed for Australia in another country, as they would be able to use their professional discretion to further develop the intended curriculum so it is relevant in context.

The rules that govern the model of Training Packages prescribe teachers to take on the dual roles of curriculum implementer and curriculum adaptor. In these roles they are expected to implement the curriculum with fidelity but make changes to meet specific local needs and work within constraints (Snyder et al., 1992). In Australian transnational VET, teachers are expected to make these adaptions through the development of the teacher-intended curriculum (or what is referred to in Australia as the "non-endorsed" curriculum); that is, the plans and materials teachers develop for instruction (Ross \& Mannion, 2012; Remillard \& Heck, 2014), as discussed in the first section of this chapter. However, as outlined in Chapter 2, teachers have found it difficult to develop materials because they have not been provided with training to make the curriculum relevant in different countries (Dempsey \& Tai, 2017).

So, while the role of curriculum adaptor enfranchises transnational teachers to contextualise Training Packages in another country, their capacity to do so is limited by their lack of local knowledge. However, if teachers were afforded an 
extended scope of role as developers, researchers, or makers, they might be better placed to acquire the knowledge they need to make the curriculum relevant in context. Firstly, as developers, transnational teachers could learn about the factors present in the situation and apply that analysis to curriculum development (Print, 1993; Skilbeck, 1976). They could also deliberate with local stakeholders (Schwab, 1983; Walker, 1971) to further develop the curriculum to meet the needs of students and future workplaces. Secondly, in the role of researchers, they could collect information and trial course materials to develop materials and improve teaching practices (Marland, 1987; Stenhouse, 1983). Thirdly, as curriculum makers, transnational teachers could negotiate the curriculum with their students to create their own meaning of it (Clanindin \& Connelly, 1992; Mannion et al., 2011). Thus, teachers would continue to develop the curriculum throughout the teaching process (Remillard, 2000) as they interact with students. By adopting one or more of these roles, transnational teachers could gain a better understanding of the situation to negotiate and develop a curriculum that is locally aligned, coherent, and relevant to the situation. Indeed, all these roles would allow transnational teachers to use their professional discretion to make decisions in the best interests of their students, rather than simply implementing or adapting a curriculum that was not developed with their students' needs in mind. This proposition is supported by Bailey's (2011) finding that the scale and complexity of transnational teaching in the South Pacific requires teachers who can maintain multiple identities and roles that extend beyond the classroom.

If transnational teachers were able to adopt the roles of adapters, developers, researchers, and/or curriculum makers, they would be able to negotiate the curriculum to account for the specifics of their teaching situation prior to implementation. Thus, teachers might remove, reduce, change, emphasise, substitute, and/or expand the curriculum content (D. L. Ball \& Cohen, 1996; Remillard, 1999; B. Tomlinson, 1998). They may also negotiate with stakeholders to change the levels and standards of the curriculum, the way it is assessed and graded, the language of instruction (Hawthorne, 1992; Jackson, 1968), and/or the duration, sequence, and pace (Beauchamp, 1972; Johnson, 1967). In these roles, they would also spend more time and effort on developing lesson plans, learning activities, and assessments (Archbald \& Porter, 1994; Brown, 2009; Remillard, 1999). D. L. Ball and Cohen (1996) propose that the way teachers develop and use these materials is influenced by five domains: (a) thinking about their students, (b) their understanding of the material, (c) the ways they prefer to design teaching, (d) the intellectual and social environment of the class, and (e) the views of the broader 
community. Thus, using their professional discretion, transnational teachers could respond to the different linguistic, cultural, and educational backgrounds of their students in ways that are place and time sensitive.

The above discussion shows that the roles of implementer and adaptor that teachers are permitted to adopt in Australian transnational VET constrain their capacity as teachers to respond to the needs of their students. It posits that an expanded scope of role for teachers, as developers, researchers, and/or makers in curriculum implementation offshore, would enable them to improve the relevance of Australian VET programs for students and their sponsors in another country. It is these kinds of roles that are likely to be necessary for teachers to understand the situated requirements for effective curriculum-making in another country. Therefore, there is a case to be made for teachers to take on a different role than they do at home when enacting the curriculum overseas so they can negotiate and develop a curriculum that is fit for purpose.

\subsubsection{Summary}

The review of the literature in this section of the chapter raises questions about the feasibility of expecting teachers to meet the imperatives of national curriculum standardisation in diverse socio-cultural contexts. It has shown that curriculum enactment in Australian transnational VET is a complex process that poses many unfamiliar problems and dilemmas for teachers trying to find the right balance between maintaining fidelity to the intentions of a mandated curriculum and adapting it to meet the needs of their students. While the research reported here makes it apparent that teachers need to play a role in curriculum-making, it also shows that the decisions that transnational teachers make may not be supported by local institutions or the Australian regulator. However, other research has shown that despite the controls that are placed on them, teachers will at times subvert the intentions of the intended curriculum if they believe it is in the best interests of their students. Therefore, it is of considerable concern to understand the influences on the curriculum-making practices of transnational teachers and the implications for the relevance, quality, and sustainability of Australian transnational VET provisions.

\subsection{The need for further investigation}

It has been acknowledged in this chapter that transnational teachers are decision-makers who interpret and modify the intended curriculum to make it relevant 
to the needs of their students. Thus, they play an important role in Australian transnational VET as curriculum-makers. However, teachers' interpretations of what is relevant may not align with the intentions of an Australian VET curriculum in another country. Thus, the curriculum they make through the teacher-intended, enacted, and assessed curricula may not be congruent with the intended curriculum. However, their capacity to achieve their aims will be constrained not only by their lack of local knowledge but also by the quality of the supported curriculum, the messages they receive from the hidden curriculum, and the level of control placed on their agency by the local institution. It has also been shown, in this chapter, that there are other models of curriculum that might provide an extended scope of role for teachers to further grasp the knowledge they need to understand and influence the situational factors that influence curriculum implementation in another country and respond by developing and enacting a vocational curriculum that meets the needs of students and their sponsors. However, the regulations that govern the implementation of Training Packages in Australian transnational VET prevent teachers from adopting the kind of roles that would facilitate these outcomes. Instead teachers are expected only to enact a vocational curriculum in another country designed for Australia. How teachers respond to these challenges and the quality of the curriculum they make are important considerations if the promises of transnational education are to be realised.

While previous research has identified some of the problems associated with enacting Training Packages in other countries, there are few studies that have focussed on the contextual factors which influence the implementation of Training Packages in different countries. Very few studies have explored how teachers make curriculum decisions in Australian transnational VET. Therefore, the primary goal of this dissertation is to investigate the factors that influence teacher decision-making, problem-solving, and curriculum-making in the enactment of a vocational curriculum designed for one country, in another. The focus here is on Australian and expatriate teachers who have enacted Training Packages offshore. The inquiry draws on phenomenology as the methodological approach to understand the perspectives of these teachers as decisionmakers and curriculum-makers in Australian transnational VET.

A theoretical framework of curriculum conceptions has also been advanced as a key construct for this inquiry. It involves the three dimensions of the intended, implemented, and experienced curricula. In reference to this inquiry, the focus is primarily on the intended and implemented curriculum. Including the theoretical framework allows the phenomenon of Australian transnational VET to be understood as a process of curriculum transformation. This inquiry contributes to the knowledge 
base of the relevance, quality, and sustainability of Australian transnational VET through an analysis of the accounts of 13 teachers about their role as curriculummakers across nine countries. 


\section{Chapter 4}

\section{Investigating the experiences of teachers' enactment of the curriculum in Australian transnational VET}

This inquiry seeks to understand the implications of teachers enacting VET curricula designed for Australia across a range of overseas countries. Through a review and analysis of the literature in the previous two chapters, it is proposed that Australia's approach to the provision of transnational VET, via the impost of national curricula and their associated quality systems onto other countries, is more than likely unachievable and undesirable, in terms of both what is intended by the Australian VET system and in effectively meeting the needs of the hosting countries. Indeed, research shows that local factors must be considered in the development and implementation of any curriculum (Fullan, 2007; Fullan \& Stiegelbauer, 1991). It is of central concern to this inquiry, therefore, to understand the lived experiences of these factors on teachers' decisions to maintain fidelity or adapt the curriculum in practice in Australian transnational VET provision.

This chapter outlines and justifies the use of a phenomenological approach to investigate the lived experiences of some teachers involved in the provision of Australian transnational VET provisions. It comprises three sections. Firstly the qualitative orientation and the decision to adopt a phenomenological approach are described. On the basis of this justification, the second section outlines the research design, including the interpretive framework, research questions, selection of informants, collection and analysis of the data, validity, and ethical considerations. The final section introduces the informants and the settings for the inquiry.

\subsection{Research orientation and approach}

The use of phenomenological research to understand the factors that affect teachers' decision-making and role in the enactment of Australian VET curricula is most appropriate for qualitative analysis. This is because phenomenological research is primarily focussed on understanding the experiences of individuals to gain insight into a particular phenomenon. The aim of using a phenomenological approach here is to foster an understanding of curriculum implementation in Australian transnational VET, through the experiences and perspectives of teachers involved in the process. It is their proximity to the core issues of relevance, quality, and sustainability of 
Australian transnational VET provisions that renders their views as significant in addressing the primary research questions.

\subsubsection{Qualitative orientation}

The orientation of this inquiry is more qualitative than quantitative.

Quantitative research is a means for testing objective theories whereas qualitative research is a means for exploring, illuminating, and understanding the meaning individuals ascribe to a problem (Creswell, 2009). Thus, a qualitative approach was fitting because this inquiry does not attempt to prove an objective theory or hypothesis; rather it is concerned with understanding the experiences of teachers enacting in one country a curriculum that was designed for another. A qualitative approach to research was also selected as it provides opportunities to gain insights into how teaching and learning are conceptualised. Moreover, it allows the researcher to take an interpretative approach by attempting to capture the informants' perspectives on the meaning of reality (Denzin \& Lincoln, 2005).

There are many important elements of qualitative orientation that help to justify its use in this inquiry. Firstly, it allows for direct experimental contact with the phenomenon under inquiry to understand events and activities in a specific situation within an overall context (Hathaway, 1995). In this case, it allowed the phenomenon of Australian transnational VET to be explored in nine countries within a global context. Secondly, a qualitative orientation seeks to understand and analyse a phenomenon through an individual or collective definition of a situation (Guba \& Lincoln, 1994). This emic perspective is deemed important for this inquiry because, as shown in Chapter 3, little is known about the experiences of teachers who have responsibility for enacting Training Packages overseas. Therefore, it seeks to provide teachers with a voice to share their experiences and perspectives. Thirdly, qualitative research is useful in exploring less understood or researched phenomena (Creswell, 2013). Subsequently, the orientation of this inquiry is helpful given that the review of the literature in Chapters 2 and 3 revealed that the phenomenon is an underresearched area. Fourthly, a qualitative orientation helps to explore complex processes, such as curriculum implementation, and to highlight the multifaceted nature of teachers' experiences (Creswell, 2013). For all these reasons, a qualitative approach was deemed the most suitable for understanding the processes of curriculum implementation for teachers in Australian transnational VET. 


\subsubsection{Phenomenological approach}

Qualitative research methodology is a way of thinking about and studying social reality (Strauss \& Corbin, 1998). It comprises a number of specific approaches and strategies that are suited to particular types of research problems. The phenomenological approach to inquiry is situated within this matrix of qualitative research and is best suited to a research problem where it is important to understand several individuals' shared experiences of a phenomenon (Creswell, 2018).

In broad terms, the goal of phenomenological inquiry is to explore the lived experiences of the research informants (Creswell, 2009). It is as much a philosophy as it is an approach to research (Miles \& Huberman, 1994), comprising a number of different philosophical stances (J. A. Smith, Flower, \& Larkin, 2009), which share the common aim to explore experience. A phenomenological approach to research is based on the view that our knowledge of the world is grounded in our experiences of it, which requires the researcher to suspend their own presuppositions of the phenomenon and carefully describe the participants' experiences of it (Hammersley, 2013). One of the foundational concepts for understanding the use of the phenomenological approach for this inquiry is the intentionality of consciousness, which holds that all thinking and conscious activity is always directed to or at something (Husserl, 1970). In other words, the description of experience shows that it will always be the experience of something. Thus, an individual cannot separate the experience of a phenomenon from what is experienced. Hence, knowledge and meaning are interdependent with the external world and an individual's lived experiences (van Manen, 1990). Thus, it is the task of the researcher to put aside their own previous life experiences and presuppositions and attentively describe, explain and communicate the experience of a particular phenomenon as understood by the research participants (Hammersley, 2013).

Two broad categories of philosophy can be identified: transcendental (sometimes referred to as descriptive) and hermeneutic. Husserl's transcendental phenomenological approach draws on a number of procedures illustrated by Moustakas (1994). These procedures commence with researchers bracketing out their experiences to put aside their preconceptions and collecting data from several informants who have experienced the phenomenon. In the data analysis, the researcher reduces the information to significant statements or quotes and categorises them into themes. In the next step, a textual description of what the informants experienced and a structural description of how they experienced it are developed. These analyses are combined to convey an overall essence of the 
experience. In comparison, the hermeneutic approach involves the researcher interpreting text (van Manen, 1990). There are no fixed set of rules or methods; however, it usually involves the researcher: (a) choosing a phenomenon of interest, (b) reflecting on its essential themes, (c) writing a description of the phenomenon, and (d) interpreting the meaning of the lived experiences. While the transcendental phenomenological approach attempts to convey the overall essence of the experience, the hermeneutic approach may only attempt to capture a particular experience as experienced by specific people (Smith et al, 2009). Hopkins, Regehr, and Pratt (2017) assert that while there are differences between the approaches, it is not necessary for researchers to adhere to a single approach. Hopkins et al. contend that one of the advantages of doing phenomenological research is that it encourages creativity through the use of a variety of methods. Similarly, Polkinghorne (1983) states that a creative approach in qualitative research is necessary to understand the research problem.

A phenomenological approach was chosen for this inquiry to provide insight into the challenges that teachers face in enacting a curriculum designed for one country in another country. The advantage of the approach was that it provided an opportunity to understand curriculum implementation issues by exploring the experiences and perspectives of teachers who have been involved in the process. The approach is aligned with my research interests because this strategy of inquiry helps to identify the essence of human experiences about this phenomenon as described by teachers. However, it is important to note that the descriptions and interpretations are drawn from the participants' experience and not my own experience as a transnational teacher. Thus, it is through the participants' experiences that the phenomenon becomes known.

The phenomenological approach is also reflected in how the research problem is elucidated. That is, it does not simply question how the curriculum is enacted and what supports or constrains it, but also questions what the experience means for the teachers in their enactment of the curriculum. Moreover, the approach does not try to solve the problem of curriculum implementation, instead seeking to better understand it by asking the teachers who lived through it what it was like. In this way, the focus is on the phenomenon as teachers experience it rather than how it might be theorised by others (Moustakas, 1994) and, thus, can be used to challenge normative assumptions. 


\subsection{Research design}

The previous section of this chapter provides a rationale for the choice of a phenomenological approach to this inquiry. As noted earlier, one of the advantages of phenomenology is that researchers can draw on different philosophies based on their own stance as researchers and the research questions they compose. In this inquiry, strategies were chosen primarily from the transcendental approach, but the methodology was adapted to include some strategies from the hermeneutical approach. This section of the chapter describes the research design, including a detailed account of when and how these strategies from both philosophies were selected and used. It comprises an account of the research design including the interpretive framework, research questions, selection of informants, collection and analysis of the data, validity, and ethical considerations.

\subsubsection{Interpretative framework}

This inquiry applies a social constructivist framework to understand the world in which teachers live and work. Constructivist frameworks commonly guide phenomenological inquiries (Constantino, 2008). A constructivist epistemology asserts that knowledge is a product of the social context where meaning is constructed through interaction with others (Lincoln \& Guba, 2000).

Constructivism is evident in the purpose of this inquiry as it aims to explore how teachers create and understand meaning of their realities through their own social constructions. As a former transnational VET teacher and now researcher, I am motivated to understand the complexity, rather than narrow meanings, of teachers' views. The intention of the inquiry is to understand the perspectives of teachers and what these might mean for the relevance, quality, and sustainability of Australian transnational VET provisions. Thus, my abiding interest is in curriculum enactment in Australian transnational VET.

Constructivism is also evident in the data collection, analysis, and presentation of this inquiry. Typically, constructive studies emphasise interviews as a primary research method, and these are used in this inquiry. Teachers were invited to answer open questions to enable them to construct their meaning of the situation. In each case, the focus was on understanding the teacher's specific cultural contexts. The rich descriptions given by the teachers guided the analysis. Finally, the presentation of the findings uses teachers' quotes to highlight their voice and their lived experiences; this use of quotes is also demonstrative of the phenomenological approach (Moustakas, 1994). 


\subsubsection{Research questions}

This qualitative inquiry is broadly framed by two central research questions that seek to understand the relevance, quality, and sustainability of Australian transnational VET provisions. These questions are:

1. What is the relevance and quality of Australian VET provisions as an exported product (curriculum) in the global VET market?

2. How sustainable is the provision of Australian VET products in the current curriculum form as an export?

For the purposes of understanding and analysing these concerns, the inquiry explores these issues from the perspective of 13 Australian and expatriate teachers who had responsibility for enacting such provisions overseas. Their experiences provide much-needed knowledge about how teachers deliberate and negotiate between the imperatives of national curriculum standardisation and the needs and interests of overseas students and their sponsors in different cultural and institutional contexts. The two central questions for this inquiry emerged from my own experience teaching Training Packages overseas. From here, I became interested in exploring how other teachers experienced the phenomenon and what their perspectives might mean for the relevance, quality, and sustainability of Australian transnational VET.

Four sub-questions follow the central questions to narrow the focus onto the phenomenon as experienced by other teachers. The four sub-questions questions are:

1. What are the contributing and impeding factors that affect teachers' enactment of the intended curriculum in transnational settings?

2. How do the contextual factors of transnational settings influence teachers' decision-making and problem-solving in enacting the curriculum in transnational settings?

3. In what ways are teachers the real curriculum-makers in such circumstances?

4. How is the intended curriculum of Australian VET transformed through the process of implementation in transnational settings?

All four questions focus on the "what" and "how" questions of the research topic (Gubrium \& Holstein, 1997). The "what" questions address the content of meaning and focus on the people and settings. In this case, the focus is on VET 
teachers' construction of meaning in their experience of enacting an Australian VET curriculum in specific countries. The "how" questions are meant to emphasise the production of meaning, which in this inquiry involves the examination of how the contextual factors influence curriculum enactment.

The four sub-questions further focus the central questions into specific areas of inquiry. The intent of the first three sub-questions is to explore a complex set of factors surrounding curriculum implementation in Australian transnational VET from the perspective of teachers. The first question focuses on the factors as experienced by teachers in their specific contexts; the second focuses on how these factors influenced their decision-making and problem-solving; while the third focuses on the curriculum-making role the teachers adopted as a consequence of those experiences. The fourth question is designed to illuminate the ways in which the curriculum is transformed as a result of the interplay amongst the contextual factors, teachers' decisions, and the role and approach they adopted in the implementation of the curriculum. All four questions guided the specific questions asked during the interviews, as elaborated in Table 4.1 in Section 4.2.4 describing the data collection.

\subsubsection{Selection of informants}

Importantly, the sample for this inquiry involves individuals who had experienced the phenomenon (van Manen, 2014). The 13 informants selected for this phenomenological inquiry had all enacted an Australian VET curriculum in one of nine countries in the Pacific, Asian, and Arabic regions of the world (i.e., where the majority of Australian transnational VET is provided). This sample is in the upper range of acceptability, as sample size for phenomenological research can vary between three and 15 (Creswell, 2018).

Snowball sampling was used to select these informants. Typically, snowball sampling uses a small number of initial informants to nominate other informants (Saumure \& Given, 2008). It proved to be a useful way to pursue the goals of purposive sampling for three reasons. Firstly, it helped locate a hidden population. It is not possible to determine the size of the overall population in this inquiry because, as shown in Chapters 2 and 3 , little is known about the transnational teacher workforce. Secondly, there are no obvious sources for locating members of this population. Although the National Centre for Vocational Education Research (NCVER) publishes data on Australian transnational VET, the names of educational institutions that employ the population are withheld. Thirdly, the population is also difficult to reach given that it is dispersed across the world. Thus, snowball sampling 
was a way to identify cases of interest from people who knew individuals, across the globe, with information-rich stories to share (Creswell, 2018).

The sampling commenced in two ways. Firstly, in 2014, one advertisement was placed in the newsletter, A-news, published by the Australasian Vocational Education and Training Research Association (AVETRA) (see Appendix A). This newsletter informs members about the latest developments in VET in Australia and overseas as well as promoting matters of interest to VET researchers. The advertisement was approved as part of the ethical clearance for the inquiry and five teachers expressed interest in participating in the study after seeing it. Secondly, professional networks were used to make contact with two individuals who had experience of the phenomenon. It was then possible to recruit another six cases through these initial seven informants. Thus, an iterative process was followed by gradually selecting teachers building on insights and connections over time from the data collected and by following up on new and unexpected leads (Marshall \& Rossman, 2006).

The method used for snowball recruitment was to politely ask the first seven informants, after the first interview, if they would be willing to pass on information about the inquiry to other teachers they knew who had taught overseas. Where the informants agreed to help, they were provided with information about the inquiry (see Appendix B) to pass on to other teachers. The purpose of this method was twofold. Firstly, it was important not to invade an individual's privacy by requesting personal details; secondly, it avoided placing undue pressure on individuals by cold-calling them. The six informants recruited through this method all expressed interest in participating in the study, either by email or phone, and the nature of the inquiry was discussed with them before they agreed to participate.

The method used to request the informants' participation was the same. I introduced myself to the teachers using either phone or Skype and explained my interest in the research topic. This was followed with an outline of the research purpose and why the experiences and perspectives of teachers were important. They were also advised about the process of data gathering and potential demands upon them. Finally, the ethical carriage of the research was outlined. When a teacher agreed to consent to and participate in the inquiry, they were provided with a description of the nature of the interviews and the process for collecting the interview data. From there, practical details were negotiated such as time and place and obtaining informed consent. An Information Sheet (Appendix B) and Informed Consent Form (Appendix C) were sent to teachers by email. The selected teachers are introduced in the final section of this chapter. 
It is also incumbent on me as the researcher to mention the two limitations involved with the sampling design and the steps that were taken to minimise these. Firstly, the sample is unlikely to be representative of the population (Creswell, 2007); however, as previously explained, it is difficult to determine the overall population anyway. Further, it is not the intention of this inquiry to claim representativeness through this sample. The sample is important not because it represents the population, but because it represents instances of relevance of the phenomenon (Flick, 2007). Consistent with the phenomenological approach, the intention of the sampling process was to ensure a variety of experiences were considered through the informants' gradual selection. The cases chosen were varied enough to make meaningful comparisons possible but not so different that it was difficult to identify common features amongst them. Ultimately, what was of most importance was that the teachers had experienced the phenomenon and were willing to reflect on it.

The second potential limitation with the sampling method is that it may be considered biased because my professional networks were used to help locate individuals (Morgan, 2008). The concern with this method is that the sample may not be representative. However, as aforementioned it is hard to ensure representativeness when there is no sampling frame. Despite this shortcoming, three steps were taken to address the issue of representativeness within the selected sample. Firstly, both male and female teachers were included in the sample. This proved slightly difficult as, in the initial phase, most of the individuals who expressed interest in participating in the study were male. These informants were asked specifically if they knew of any female teachers who might participate in the inquiry. This strategy was successful as the final sample included eight men and five women. Secondly, the selected cases reflected the countries where most Australian transnational VET provisions occur. Finally, the curriculum areas taught by the teachers included some of the popular courses offered offshore by Australian educational institutions (i.e., Business courses). Further details on the representativeness of the teachers, settings, and curricula are presented in the final section of this chapter. The intention in taking these three steps was to reduce bias by purposefully selecting cases over time, built on knowledge (Miles \& Huberman, 1994). The aim was to enhance the quality of the data by searching for informationrich cases of individuals who had experience of the phenomenon (Englander, 2012). 


\subsubsection{Data collection}

A defining feature of phenomenological studies is the use of interviews with individuals who have experienced the phenomenon (Creswell, 2018). In this inquiry, 13 Australian and expatriate teachers who worked abroad and taught Australian VET curriculum, in nine different countries, were interviewed three times each. Further characteristics of the teachers are discussed in Section 4.3.1.

The objective of the interviews was to elicit each teacher's story. The use of interviews in the research design provided rich descriptions and in-depth accounts of the phenomenon (enacting VET curricula) from the perspective of those involved (teachers) within the social context of teaching in a range of countries (setting). The transcripts from these interviews formed the basis of the data.

Each teacher was interviewed three times over a 3-month period between September 2013 and August 2014. This time frame was necessary to reach all the teachers and fully address the complexity of the phenomenon being examined (Seidman, 2013). Each interview was conducted between two and four weeks apart and took one to two hours. The justification for conducting the interviews with each participant within a 3-month period was based on the pilot, which showed that long intervals between interviews hindered the participant's memory of what had been shared and re-engagement in the process.

This time frame did not include the pilot inquiry, which was conducted between April and June 2013. The intervals in time allowed me to listen to and reflect on the interviews and then follow up on ideas or points of clarification with the teachers at the next interview. It also gave time for teachers to reflect between encounters on what they had shared. In this way, the second interview helped to clarify the first interview and the third interview elaborated on the second interview. This process ensured that the data analysis was subject to verification and validation.

Wherever possible the interviews, especially the first one, were conducted face to face with the aim of building rapport with teachers. However, this was not always feasible or affordable as teachers were located across four Australian states and territories and six were often abroad in diverse locations, which may be considered a limitation of the inquiry. In eight instances, the first interview was conducted face to face with the teachers. In three instances, all interviews were conducted face to face. In the other 10 cases the interviews were either all conducted online through Skype or combined with face-to-face interviews.

Each interview was recorded with a digital recorder for practical reasons (Warren, 2002). Firstly, it was comfortable using simple and portable technology. 
Secondly, it enabled me to interact with interviewees by looking at them and following their narrative, occasionally interjecting and, if necessary, guiding the flow of the interview. Finally, the recording provided a detailed account of the interview for transcription. A central concern of using recorders relates to the level of power and control interviewers exert over the interviewee, the issue of trust, and how these might affect authenticity and bias (Poland, 2002; Scott \& Usher, 2011). Recorders can also act as a structuring device, signalling that the conversation is "public", which may inhibit interviewees from self-disclosure (Scott \& Usher, 2011). To limit these potential threats, teachers were asked for permission to be recorded before the interview began and were informed of their right to stop recording at any time. Teachers were provided with a copy of each transcript along with a request to discuss, clarify, and/or make any final changes with the researcher before the data were used in the analysis. Finally, teachers were assured that the audio file would be erased once the interview was transcribed. The recordings were duly deleted.

The interviews undertaken for this inquiry were individual, in depth, and semistructured (see Appendix D). The largest part of the interviews comprised a list of questions designed to explore the phenomenon. Often in phenomenological research, interview questions tend to be open so that the research informants can construct their meaning of the situation (Creswell, 2018). With this in mind, the interview schedule included open questions. The schedule was flexible so probing questions could be used to clarify answers or request further information and follow up questions were employed to pursue the implications of answers to the main questions (Rubin \& Rubin, 2005). For example, a probing question was: "and when you say you modified the language, give me an example?"

This approach helped attend to a variety of meanings as they emerged throughout the interview process (Creswell, 2009). In addition to the questions, some quantitative instruments such as tick boxes and scales were used. Requests for demographic information were also used in the first interview. It is not unusual for constructivist researchers to use quantitative information within a qualitative inquiry to obtain richer interpretations or as a basis for internal comparison (Onwuegbuzie, Johnson, \& Collins, 2009). In this inquiry, the aim of collecting quantitative data alongside the teachers' qualitative responses was to discuss and compare the teachers' characteristics and perspectives.

The pilot study, mentioned earlier, was conducted to test the quality of the interview schedule; it involved one teacher. While, one pilot may be considered a limitation, the interview questions were drawn from the literature. Thus, the purpose of the pilot study was to eliminate confusing or redundant questions, create new 
questions, and refine the interview process (Merriam, 2009). This teacher was interviewed three times over a period of 3 months. Once all the pilot study interviews were completed, the approach to collecting the data was evaluated and discussed with the teacher. Subsequently, a number of improvements were made to the interview schedule based on lessons learnt from the pilot. These improvements included: (a) reducing the interview time, (b) restructuring the interview schedule, and (c) setting limits on the intervals between interviews.

Firstly, the interviews had to be reduced in time because during the pilot study they took over two hours. Indeed, the only way to get through the second interview schedule during the pilot study was to meet with the teacher on a subsequent occasion. The questions were reviewed, and some were deleted where there was some overlap and duplication. As a result, the total number of open questions decreased from 33 to 29 . This helped to limit the duration to less than two hours for each interview.

Secondly, the interview schedule had to be restructured because it did not adequately guide the teacher on a journey to understand what Dilley (2000) refers to as the "big" questions. The problem emerged from combining the quantitative and qualitative questions together under specific focus areas. The teacher's feedback was that it was distracting and disruptive to be following a line of inquiry with open questions only to be suddenly asked to tick some boxes on a piece of paper and then resume to an open line of questioning again. To overcome this problem, all the questions that involved demographic information, tick boxes, or scales were moved to the front of the interview schedule. These questions were provided online to teachers in the form of data collection sheets with the interview schedule to fill out ahead of each interview. Providing these questions to teachers in one format ahead of time certainly helped with the flow of the interviews. It also provided teachers with an opportunity to prepare for and engage with the topics before each interview.

Another reason that the interview schedule was restructured after the pilot was to provide a better focus for each interview. For example, the first interview was designed to build a rapport with teachers by collecting demographic information and gathering a background history. However, I had also included eight questions under the topic of "understanding curriculum". Afterwards, the pilot informant provided the feedback that asking questions about his understanding of the curriculum in an initial interview "felt like a test". Consequently, this section was moved to the end of the schedule for the second interview as it was better aligned to its purpose. This restructuring of the interview schedules established the teachers' ability to answer the questions and also put them at ease. 
The final improvement was to ensure that the interval between interviews did not exceed 4 weeks. In the pilot, there was a 5-week interval between the first and second interviews, during which the teacher had forgotten some of the content he had shared and initially lost focus at the second interview. As a result, it was time consuming to re-engage him with the inquiry.

The above discussion shows that the use of a pilot was crucial for a number of reasons. It helped to trial the questions, test the duration, and reformat the schedules. All these improvements helped to improve the interview format and process in this inquiry. Once all these changes were made the interview schedule was submitted for ethical clearance. Both the collection instrument and process were approved by Griffith University on 22 February 2013 (see Appendix E).

The teachers were interviewed three times, as mentioned above. Before each interview, teachers were provided with copies of the interview schedule which included both the quantitative and qualitative questions. The different means for gathering data and examples of items are presented in Table 4.1. Teachers were asked to fill in the data collection sheets comprising closed questions, tick boxes, and scales before the interview. The data collected in this sheet were reviewed at the commencement of the interview. Interviews 2 and 3 were followed with a recap on the previous interview. The first interview was used to establish a rapport with the teachers and focused on collecting the teachers' teaching history and experience. A range of closed and open questions were used to obtain each teacher's (a) demographic information, (b) teaching experience, (c) qualifications, and (d) background. The second and third interviews focused on the details of the teachers' lived experience of the phenomenon. For example, the second interview opened with the following question: "Can you start by describing the cultural context of the classroom and the students in your classes at place $x$ ?" This question helped the teachers to focus on their own specific context where they taught the curriculum. Their answers also assisted me to understand the cultural settings they were teaching in.

Consistent with a semi-structured approach, the second and third interviews had an underlying structure based on the four research sub-questions. Table 4.1 presents the distribution and comprehensiveness of the interview items in relation to the focus of each of these sub-questions. As presented in this table, the second interview emphasised the cultural, pedagogical, conceptual, and political factors that supported or constrained the teachers' enactment of the curriculum in their specific context. These categories were based on Windschitl's (2002) framework of dilemmas as discussed in Chapter 3. It was important to start the second interview by eliciting 
the teachers' responses to these factors so as to explore how they shaped their decisions and role in curriculum implementation. The third interview built on the previous exploration, including how they perceived their agency was exercised or constrained. As presented in Table 4.1, teachers were also asked questions in both these interviews about how the curriculum was transformed by the influence of the factors, their decisions, and the role they adopted. The second and third interviews also provided the opportunity for any clarification of what had arisen in previous interviews and the testing of any initial findings or deductions. During the third interview, the teachers were asked to consider their answers and rate the relevance, quality, and sustainability of Australian transnational VET from their perspective.

Table 4.1

Means for Gathering the Data and Examples of Items

\begin{tabular}{|c|c|c|c|}
\hline Focus area & $\begin{array}{l}\text { Interview } \\
\text { question } \\
\text { number }\end{array}$ & $\begin{array}{l}\text { Means for } \\
\text { gathering } \\
\text { data }\end{array}$ & $\begin{array}{l}\text { Example of items used to secure the } \\
\text { data }\end{array}$ \\
\hline $\begin{array}{l}\text { Research sub- } \\
\text { question 1: } \\
\text { Cultural } \\
\text { factors }\end{array}$ & $\begin{array}{l}\text { Interview 2: } \\
3.1,3.2,3.3 \text {, } \\
3.4,3.5 \\
\text { Interview } 3 \text { : } \\
2.1\end{array}$ & $\begin{array}{l}\text { Open } \\
\text { question }\end{array}$ & $\begin{array}{l}\text { What cultural factors or practices did } \\
\text { you find the most difficult to adjust to? }\end{array}$ \\
\hline $\begin{array}{l}\text { Research sub- } \\
\text { question 1: } \\
\text { Pedagogical } \\
\text { factors }\end{array}$ & $\begin{array}{l}\text { Interview 2: } \\
2.1,2.2,2.3 \text {, } \\
2.4,3.6,4.1 \text {, } \\
4.3,4.4 \\
\text { Interview } 3 \text { : } \\
2.1\end{array}$ & $\begin{array}{l}\text { Scale, tick } \\
\text { box, open } \\
\text { question }\end{array}$ & $\begin{array}{l}\text { What percentage of your teaching was } \\
\text { teacher and student centred in place } x \text { ? } \\
\text { How did this compare to teaching in } \\
\text { Australia? } \\
\text { Which of the following were features of } \\
\text { your provision of course/unit } x \text { in place } \\
x \text { ? Recognition of prior learning/Work- } \\
\text { based learning and assessment/Face- } \\
\text { to-face teaching/Student choice/Other- } \\
\text { please describe. } \\
\text { What were the main factors that affected } \\
\text { your teaching in place } x ?\end{array}$ \\
\hline $\begin{array}{l}\text { Research } \\
\text { question 1: } \\
\text { Conceptual/ } \\
\text { curriculum } \\
\text { factors }\end{array}$ & $\begin{array}{l}\text { Interview 2: } \\
1.1,1.2,1.3 \\
1.4,1.7,1.9 \\
5.1,5.2,5.3 \\
5.4,5.5,5.6 \\
\text { Interview } 3 \text { : } \\
2.1\end{array}$ & $\begin{array}{l}\text { Scale, tick } \\
\text { box, open } \\
\text { question }\end{array}$ & $\begin{array}{l}\text { Below is a set of definitions of what } \\
\text { might constitute curriculum. Using these } \\
\text { definitions, could you indicate the } \\
\text { degree by which (1-5: } 1 \text { = no } \\
\text { resemblance } 5 \text { = strong resemblance) } \\
\text { they describe curriculum, as you } \\
\text { understand it? } \\
\text { What is the relative value you place } \\
\text { upon the requirements of government, } \\
\text { local industry, and student needs in } \\
\text { regard to curriculum development? That } \\
\text { is, what emphasis of these interests } \\
\text { needs to be expressed in the curriculum } \\
\text { development process? Please quantify } \\
\text { these values out of } 100 \text { in the table } \\
\text { below. }\end{array}$ \\
\hline
\end{tabular}




\begin{tabular}{|c|c|c|c|}
\hline & & & $\begin{array}{l}\text { How helpful were the curriculum } \\
\text { materials provided to you in place } x ?\end{array}$ \\
\hline \multirow[t]{2}{*}{$\begin{array}{l}\text { Research sub- } \\
\text { question 1: } \\
\text { Political } \\
\text { factors }\end{array}$} & $\begin{array}{l}\text { Interview } 2: \\
1.8,4.6,6.1 \\
6.2,6.3,6.4 \\
6.5,6.6,6.7 \\
6.8,6.9,6.10 \\
\text { Interview } 3: \\
1.4,1.5,1.8 \\
2.1,4.3,4.4\end{array}$ & $\begin{array}{l}\text { Tick box, } \\
\text { open } \\
\text { question }\end{array}$ & $\begin{array}{l}\text { What did you perceive as the outcomes } \\
\text { of the competency-based training model } \\
\text { in the place you worked overseas? } \\
\text { Improving the national economy/ } \\
\text { Enhancing student employment } \\
\text { outcomes/Reducing the cost of training/ } \\
\text { Preparing student for into onshore } \\
\text { higher education courses/Other - please } \\
\text { describe. }\end{array}$ \\
\hline & & & $\begin{array}{l}\text { How was the quality of your teaching } \\
\text { and the courses judged at place } x ?\end{array}$ \\
\hline $\begin{array}{l}\text { Research sub- } \\
\text { question 2: } \\
\text { Decision- } \\
\text { making and } \\
\text { problem- } \\
\text { solving }\end{array}$ & $\begin{array}{l}\text { Interview } 2 \text { : } \\
3.5,4.5,6.6 \\
\text { Interview } 3: \\
1.1,1.2,1.3 \\
1.4,1.5,1.6 \\
1.7,1.8,2.2 \\
2.4,2.5,2.6, \\
2.7,2.8,2.9 \\
2.10,2.13 \\
3.1,3.2,3.3, \\
3.4,3.5,3.6 \\
3.7\end{array}$ & $\begin{array}{l}\text { Tick box, } \\
\text { open } \\
\text { question }\end{array}$ & $\begin{array}{l}\text { How important is teacher discretion (i.e., } \\
\text { ability make decisions) to being an } \\
\text { effective vocational educator/teacher? } \\
\text { Not at all, important, very important, } \\
\text { essential for effective teaching. } \\
\text { In what ways did these factors influence } \\
\text { your decision-making in place } x \text { ? }\end{array}$ \\
\hline \multirow[t]{2}{*}{$\begin{array}{l}\text { Research sub- } \\
\text { question 3: } \\
\text { Role }\end{array}$} & $\begin{array}{l}\text { Interview } 2: \\
1.5,1.6,2.1 \\
2.2,2.5,3.5 \\
3.7,4.4,6.2 \\
\text { Interview } 3: \\
2.11,2.12 \\
2.13,2.14 \\
4.1\end{array}$ & $\begin{array}{l}\text { Tick box, } \\
\text { open } \\
\text { question }\end{array}$ & $\begin{array}{l}\text { What do you see as the most important } \\
\text { roles VET teachers should uphold? } \\
\text { Please tick the statement you most } \\
\text { agree with: Implementers of curriculum } \\
\text { designed elsewhere/Adapters modifying } \\
\text { curriculum to meet local needs/ } \\
\text { Developers of the curriculum and } \\
\text { learning and teaching materials/ } \\
\text { Researchers trialling new approaches to } \\
\text { teaching and evaluating the curriculum }\end{array}$ \\
\hline & & & $\begin{array}{l}\text { In our second interview you indicated } \\
\text { that the most important role for VET } \\
\text { teachers was as implementer/adapter/ } \\
\text { developer/researcher. Were you able to } \\
\text { fulfil this role in place } x \text { ? Please } \\
\text { elaborate. }\end{array}$ \\
\hline \multirow[t]{2}{*}{$\begin{array}{l}\text { Research sub- } \\
\text { question } 4: \\
\text { Curriculum } \\
\text { transformation }\end{array}$} & $\begin{array}{l}\text { Interview } 2: \\
4.2,4.5,5.5 \\
6.6,6.9,6.10 \\
\text { Interview } 3: \\
1.9,1.10 \\
2.2,4.1,4.3 \\
4.5,4.6\end{array}$ & $\begin{array}{l}\text { Tick box, } \\
\text { open } \\
\text { question }\end{array}$ & $\begin{array}{l}\text { What type of changes did you make and } \\
\text { to what extent in the place you worked } \\
\text { overseas? Please select: Pace/ } \\
\text { Emphasis/Sequence/Experience/ } \\
\text { Activities/Teaching and learning } \\
\text { materials/Assessment judgements/ } \\
\text { Standards }\end{array}$ \\
\hline & & & $\begin{array}{l}\text { What were the scope of changes you } \\
\text { had to make to account for these factors } \\
\text { and provide effective training } \\
\text { experiences in place } x \text { ? }\end{array}$ \\
\hline
\end{tabular}




\subsubsection{Data analysis}

A qualitative phenomenological approach was used for the data analysis. The organising and analysing of the data were initially informed by methods used in the transcendental approach. However, as the analysis proceeded, the method was adapted to include an element of interpretation.

Commencing with Moustaka's (1994) approach, I bracketed my experiences with the phenomenon in an attempt to set these aside to focus on the teachers. Once the interviews commenced, I listened to the audios of the transcripts to immerse myself in the experiences as recalled by the teachers. Each interview was transcribed, including slang, response tokens (i.e., OK, yeah), incorrect grammar, and involuntary vocalisations (i.e., laughing) as they are part of the everyday speech of teachers in their context (Rapley, 2004). A potential disadvantage of presenting data to teachers in this way is that it can appear naïve outside the social context of the speech and can lead to prejudiced assumptions in the final account (Oliver, Serovich, \& Mason, 2005). To counter these assumptions, teachers were provided with a copy of their transcript to afford them the opportunity to amend the transcripts. To minimise any embarrassment teachers can sometimes feel when they read their transcription, they were also informed that grammar and speech irregularities are part of everyday conversation, which offer important insights about their meaning. However, teachers in this inquiry were given the opportunity to amend the final transcript, the presentation of their transcript, and any quotes used. In most cases, the teachers made minor changes or none to their transcripts and returned them to me by email. A meeting was held with one teacher, Shiraz, at her request to change some of the language in the transcripts, as she wanted to change her expression in some places. Her original transcripts were deleted and replaced with the amended ones.

The data analysis was conducted simultaneously with data collection from each interview. Each interview was analysed separately to progressively focus the interviews. This approach presented an understanding of individual cases of specific contexts and meanings before they were aggregated. Using Moustaka's (1994) method, each of the teachers' transcripts was examined, and significant statements, sentences, or quotes highlighted to provide an understanding of how the teachers experienced the phenomenon. These units of meaning were scrutinised, and redundant units were eliminated.

Typically, at this stage in transcendental approach, the statements from each interview would be clustered into themes. However, before organising the highlighted statements into themes the statements were categorised under the four focus areas 
of the inquiry: (a) contextual factors, (b) teacher decision-making, (c) curriculummaking role, and (d) curriculum transformation. If a statement appeared to have a relationship with more than one category it was repeated across the categories. This additional step was taken because of the inter-relationship between the questions. For example, it was important to identify the contextual factors, in the first instance, because they laid the foundation for the remaining areas of focus. However, the factors were not categorised under the four areas of conceptual, pedagogical, cultural, and political factors as the teachers' responses did not fit neatly into these categories. Once the factors were identified, the other three focus areas were analysed.

Themes were formed, within each category, by grouping units of meaning together. In developing these themes Moustaka's (1994) steps of elimination and reduction were followed by merging related statements or anecdotes and separating paragraphs into smaller pieces to identify possible meaning units. Table 4.2 presents a partial and illustrative example of how some themes were summarised for one informant.

Table 4.2

Partial Example of Themes and Supporting Statements for One Informant

\begin{tabular}{|c|c|c|}
\hline Focus area & $\begin{array}{l}\text { Example } \\
\text { of themes }\end{array}$ & Examples of informant's statements and phrases \\
\hline \multirow[t]{8}{*}{ Factors } & $\begin{array}{l}\text { College } \\
\text { conditions }\end{array}$ & $\begin{array}{l}\text { Large class sizes with lack of options for doing anything } \\
\text { innovative. }\end{array}$ \\
\hline & Resources & $\begin{array}{l}\text { So say if you had } 10 \text { teachers in the staff room they had one lousy } \\
\text { printer, just one and it wasn't very good. }\end{array}$ \\
\hline & Materials & $\begin{array}{l}\text { I didn't have much in the way of supporting materials ... keep in } \\
\text { mind l'd never taught anywhere outside of Australia before I went } \\
\text { to China so it was a big ask. }\end{array}$ \\
\hline & Information & $\begin{array}{l}\text { Well, as I said to you, it would have been nice to have understood } \\
\text { the students better, so it would have been nice if somebody had } \\
\text { done a focus group study or demographic profiling or something } \\
\text { like that just so I could get my head around who l'm talking to. }\end{array}$ \\
\hline & Students & $\begin{array}{l}\text { Well obviously language was a big issue. I really was unclear as } \\
\text { to how much of my language they understood. }\end{array}$ \\
\hline & & $\begin{array}{l}\text { Well, when I got there I just found the students most of the } \\
\text { students were not up to a level I could teach, that I would expect } \\
\text { in Australia. I think most of them couldn't keep up. }\end{array}$ \\
\hline & & $\begin{array}{l}\text { I would describe their learning style as rote, behaviourist, teacher } \\
\text { comes in, teacher's obeyed. }\end{array}$ \\
\hline & & Some of the students were there without much academic interest. \\
\hline \multirow{2}{*}{$\begin{array}{l}\text { Decision- } \\
\text { making and } \\
\text { problem- } \\
\text { solving }\end{array}$} & Reactive & I guess a lot of the time urgent got my attention. \\
\hline & Appraise & $\begin{array}{l}\text { So therefore I really had to figure out so first thing I had to analyse } \\
\text { the situation and figure out what's going on here. }\end{array}$ \\
\hline
\end{tabular}




\begin{tabular}{lll}
\hline Role & Interactive & $\begin{array}{l}\text { So yeah, I was trying to work on that relationship with the Chinese } \\
\text { because I felt like we could get a lot further if we could talk to them. }\end{array}$ \\
\hline $\begin{array}{l}\text { Subjective } \\
\text { Curriculum } \\
\text { developer }\end{array}$ & $\begin{array}{l}\text { The students won out in my decision-making. } \\
\text { I developed simulations. } \\
\text { teachers as }\end{array}$ & $\begin{array}{l}\text { So I had good relationships with some of the students, particularly } \\
\text { some of the top students, and they would tend to help me teach } \\
\text { sometimes. }\end{array}$ \\
\hline $\begin{array}{l}\text { Curriculum } \\
\text { transformation }\end{array}$ & $\begin{array}{l}\text { Lowering } \\
\text { standards/ } / \\
\text { level }\end{array}$ & $\begin{array}{l}\text { I worked out what the bottom line was in terms of standards. I tried } \\
\text { to teach in accord with what was in my bottom line, in terms of what } \\
\text { I was prepared to pass or not pass, so it became a bit like that. } \\
\text { I was constantly trying to simplify and bring it down to a level at } \\
\text { which the students could actually do an assignment on. }\end{array}$ \\
\hline
\end{tabular}

Once this process was completed, connections between the factors were identified with the decisions teachers made, the role and approach they adopted in curriculum-making, and how the curriculum was transformed as a consequence. After rereading the transcripts all three interviews were summarised as a narrative account for each teacher to try to understand the core essence of the experience, and how they made sense of it (van Manen, 1990). This included capturing phrases to describe the meaning from their perspective; these phrases were checked against the themes that had been established. Finally, a check was conducted to ensure the essence of the phenomenon for each individual had been captured through the themes and the narrative accounts (Hycner, 1999).

The next stage involved a wider cross-analysis of all the informants' cases. The first step involved collating the quantitative data from all the interviews into a series of tables. An example of this collation is shown in Table 4.3.

Table 4.3

Example of Collation of Quantitative Data

How important is teacher discretion (i.e., ability to make decisions) to being an effective vocational educator/teacher?

\begin{tabular}{|c|c|c|c|}
\hline Not at all & Important & Very important & Essential for effective teaching \\
\hline & Sean & Alex, Rachael & $\begin{array}{l}\text { Annabel, Mary, Shiraz, Peter, } \\
\text { Steven, Mick, Damien, Jo, Sam, } \\
\text { Rowena }\end{array}$ \\
\hline
\end{tabular}

The second step involved a cross-analysis of the themes. All of the themes were taken from each category across all cases to discern similar and different patterns. In moving back and forth between cases some themes were grouped and 
labelled with similar expressions, while others were eliminated. Specific individual responses were also captured and considered within the data analysis. In the final summation, terms for the main themes were used that were in keeping with those used in the curriculum field (Giorgi, 2010). For example, the factors were described as information, resource, material, institutional, and student readiness. Using broad headings for themes was also useful for describing variation between cases (J. A. Smith et al., 2009). For example, the descriptors for factors could be referred to as "constraining" for some teachers and "enabling" for others. In another example, headings such as "institutional arrangements" enabled the capture of differences such as timetabling issues for some teachers and segregated classrooms for others. Presentation of the themes in this way showed how the factors are salient to the meaning of the experience for teachers in specific cultural contexts.

The third step, in line with the goals of phenomenological research, was to determine the essence of the phenomenon. Some researchers, inspired by Husserl (1859-1938), look for what is common across every instance of a phenomenon; others concern themselves with the individual's experience (J. A. Smith et al., 2009). In this inquiry, both approaches were adopted. I found I had to move back and forth between each of the teachers' narrative accounts on multiple occasions to understand the whole experience. I also found that due to the diversity of contexts there were some details of individuals' experiences that helped to understand certain aspects of the general essence. Therefore, there are times in the presentation of the findings where the general essence is at the foreground, but the particular experiences of some teachers are emphasised. Consequently, the presentation of the findings is organised thematically and explicatively (van Manen, 1984). For example, Chapter 5 presents five contextual factors which influenced the teachers' enactment of the curriculum. Once these factors are established, the experience is then illuminated by systematically varying the examples. Each example highlights some essential nature of the experience. Varying the examples was also a way of addressing the themes so that the invariant aspects of the phenomenon came into view (van Manen, 1984).

Finally, in the process of writing up the descriptions that illuminated the teachers' experience of the phenomenon, I asked myself: why are these stories important? To answer this question, I worked towards interpreting these experiences to understand their relationship with the central research questions. Part of this process involved reflecting on the literature again. This final part of the analysis was important because the contribution of this inquiry to the field is to use the teachers' experience and perspectives to provide much needed knowledge about the 
relevance, quality, and sustainability of Australian transnational VET. Thus, the methodology of phenomenology enabled me to go back and forth among these various levels of questioning to allow a rigorous interpretation of the data (van Manen, 1990).

\subsubsection{Validity}

Validity was achieved through four main methods in this inquiry: (a) use of phenomenological research questions and procedures, (b) member checking, (c) thick descriptions, and (d) reflexivity. Firstly, the research design met two important standards for assessing the quality of phenomenological research put forward by Creswell (2018). In the first instance it used phenomenological sub-questions to guide the inquiry (Creswell, 2018; Gubrium \& Holstein, 1997). For example, the "what" questions focus on the teachers' construction of meaning in their experience of enacting the curriculum in specific countries while the "how" questions examine how the contextual factors influence curriculum enactment. In the second instance it used phenomenological procedures recommended by Moustakas (1994) and van Manen (1990) to provide both descriptive richness and interpretative depth.

The second method, member checking, was used to ensure that the transcriptions were accurate and conveyed the meaning of the teacher (Giorgi, 2010). Teachers were provided with all three transcripts for checking and most teachers made either no changes or minor ones. However, as noted previously, one teacher did arrange for some changes to be made to her transcripts as she did not like the way some of her answers were expressed when she saw them in writing. The transcripts were followed up with each teacher until final agreement was received. For example, Sam replied:

These interviews made for some interesting reading. I have no changes and feel that they adequately reflect the ideas and meaning of our conversation.

Thirdly, rich, thick descriptions were used to provide details about each theme (Lincoln \& Guba, 2000). For example, the narrative in Chapters 5 and 6 presents the context, feelings, perspectives, and social relationships of the lived experiences so that the meanings of the teachers are heard (Denzin, 2001). The presentation and descriptions of the themes comprise shared characteristics between teachers, as well as variations. Each example includes an indication of the number of teachers who shared similar experiences. These descriptions are also supported with 
teachers' direct quotes and extracts to make the evidentiary base of the inquiry transparent (J. A. Smith et al., 2009).

Even though bracketing and reflexivity are sometimes viewed as two opposing tensions in phenomenological research, I considered both to be important. My aim was to achieve what Finlay (2008) describes as striving for "reductive openness" and "reflexive self-awareness". With the aim of reductive openness, I followed Husserl's approach of bracketing to put aside my pre-understandings of the phenomenon. However, I also felt an ethical obligation to practise reflexivity because it is not possible to be entirely objective (Luttrell, 2000).

Reflexivity was achieved in three ways. Firstly, the decisions made in the process of analysing and representing data were documented. Secondly, I focused on the meaning that the teachers held about their experiences in their circumstances even though their views were not always consistent with my own views and values (Gubrium \& Holstein, 1997). Finally, I practised reflexivity through my writing. Initially, I wrote down notes and ideas while reading the transcripts to try to make sense of the teachers' experiences. I used these writings not only to reflect on what the teachers had shared but also to clarify meanings with them after the interviews. I also wrote narratives, as part of the data analysis, for each teacher so I could understand their particular experiences. These narratives also helped me to draw out common themes. Most of the chapters were also rewritten multiple times as the process of writing enabled me to observe what was said through different lenses (Emerson, Fretz, \& Shaw, 1995). At times this reworking of the chapters led to a restructuring of themes as I gained greater insight into the phenomenon. For example, in the first draft of the findings I had included the theme "political factor" in the first section of Chapter 5. However, later in the writing of the section on decision-making, it became apparent that the political dimension of the teachers' experience had more to do with their experience of taking action to resolve the problems caused by the contextual factors. Consequently, I moved the discussion about the political aspects of the teachers' experience from the first to the second section of Chapter 5.

\subsubsection{Ethical issues}

The ethical principles underpinning this inquiry are: (a) respect for people, (b) concern for welfare, and (c) justice (Creswell, 2018). These principles were addressed throughout several phases of this inquiry, commencing with a submission for ethical clearance that was approved by Griffith University on 22 February 2013 (Appendix E). 
Respect for people was shown through my treatment of the teachers and their data (Creswell, 2018). Teachers were treated as active subjects with considerable control over the frame of the interview and the way in which their data were treated (Gubrium \& Holstein, 2002). A number of methods were employed to provide teachers with this control and limit any potential discomforts that they felt. For example, teachers chose the location and time of the interview. They also received a copy of the interview schedule by email. At the first interview, the interview process, the expected time frame, and their right to break or terminate the interview was explained to teachers. The ethical issues of anonymity and confidentiality were also discussed. It was explained to teachers that when they received copies of their transcript they would have the opportunity to check and amend these documents. Finally, informed consent was re-established with teachers before proceeding with the topics and questions. These steps were intended to enable teachers to feel comfortable enough in the interview to offer valuable insights into the topics under discussion and to address the ethical issues pertaining to their rights.

The principle of concern for the teachers' welfare was addressed by protecting the teachers' identity to avoid exposing them to risk. Confidentiality was addressed in this inquiry in four ways. Firstly, each teacher chose a pseudonym and these names are the ones used throughout the chapters. Secondly, the organisations they worked for in Australia and/or overseas are not reported. Thirdly, the name of one country was withheld at the teacher's request, as it would have identified them. Finally, the data recordings were deleted after interviews were transcribed. The main risk for the teachers in this inquiry was jeopardising their employment through the inclusion of any details that might reveal their identities or the identities of the students and sponsors of the programs. Therefore, at various times the reporting of the data does not always identify the country and/or curriculum and/or pseudonym of the teacher if it is likely to risk the identification of teachers. For example, a profile of each teacher is not presented in the findings as the combined details of the teachers' history, industry experience, gender, teaching area, and country constitutes a risk in the revelation of their identity.

Finally, the principle of justice was demonstrated in three ways. First, the selection of informants was on the basis of potential teachers matching the sampling criteria. Secondly, the presentation of the findings reports the multiple perspectives of all the teachers, including contradictory findings. Lastly, there was no unfair burden placed on teachers when I requested their help in recruiting other teachers for the sample. 


\subsection{Introduction of the teachers and settings}

As foreshadowed, the teachers in this inquiry comprised 13 Australian and expatriate teachers, eight men and five women, all aged in the 40 -- 69 age bracket. The teachers came from a diverse range of industry backgrounds and teaching experience. For example, prior to teaching the informants had worked in a range of fields including business, management, finance, design, cookery, hospitality, architecture, electro-technology, and aged care. Subsequently, teachers enacted an Australian vocational curriculum related to their specialist field. All the teachers, except one, had taught the curriculum domestically before teaching it overseas. The one exception, however, had extensive experience in vocational and further education internationally. The teachers, each based in one of nine countries in the South Pacific, Asia, and the Middle East, were interviewed about their specific instance of enacting the curriculum in one country.

The remaining section of this chapter provides a summary of the teachers and settings to supplement the reading of the findings in Chapters 5, 6, 7 and 8 . It is important to reiterate that these summaries do not involve a detailed description of each teacher or their setting in order to protect the confidentiality of the individuals and organisations involved in the experience.

\subsubsection{Teachers}

The 13 teachers in this inquiry are captured in Table 4.4 that presents their pseudonyms, gender, age grouping, highest qualifications in occupational area and teaching, area of teaching expertise, and years of teaching experience. As indicated in this table, eight informants were male and five were female. This combination of gender broadly reflects the composition of the Australian vocational education workforce. For instance, the Productivity Commission (2011) estimated that 50\% of VET teachers in Australia are female.

Table 4.4

Teacher Demographics, Qualifications, Expertise, and Experience

\begin{tabular}{lllllll}
\hline Pseudonym & Gender & $\begin{array}{l}\text { Age } \\
\text { group }\end{array}$ & $\begin{array}{l}\text { Highest } \\
\text { occupational } \\
\text { qualification }\end{array}$ & $\begin{array}{l}\text { Highest } \\
\text { teaching } \\
\text { qualificatio } \\
\mathbf{n}\end{array}$ & Specialist field & $\begin{array}{l}\text { Years } \\
\text { teaching } \\
\text { VET }\end{array}$ \\
\hline Alex & M & $40-49$ & $\begin{array}{l}\text { Masters } \\
\text { Degree }\end{array}$ & Diploma & Design & 11 \\
Annabel & F & $40-49$ & $\begin{array}{l}\text { Masters } \\
\text { Degree }\end{array}$ & CIV & $\begin{array}{l}\text { Project } \\
\text { Management }\end{array}$ & 4
\end{tabular}




\begin{tabular}{|c|c|c|c|c|c|c|}
\hline Damien & $M$ & $40-49$ & Diploma & $\begin{array}{l}\text { Graduate } \\
\text { Certificate }\end{array}$ & $\begin{array}{l}\text { Cookery/ } \\
\text { Hospitality }\end{array}$ & 8 \\
\hline Jo & $M$ & $50-59$ & Diploma & CIV & $\begin{array}{l}\text { Electro- } \\
\text { technology }\end{array}$ & 30 \\
\hline Mary & $F$ & $50-59$ & Diploma & $\begin{array}{l}\text { Masters } \\
\text { Degree }\end{array}$ & Business & 20 \\
\hline Mick & $M$ & $50-59$ & $\begin{array}{l}\text { Bachelors } \\
\text { Degree }\end{array}$ & $\begin{array}{l}\text { Masters } \\
\text { Degree }\end{array}$ & Business & 26 \\
\hline Peter & $M$ & $60-69$ & $\begin{array}{l}\text { Bachelors } \\
\text { Degree }\end{array}$ & $\begin{array}{l}\text { Masters } \\
\text { Degree }\end{array}$ & $\begin{array}{l}\text { Business/ } \\
\text { Language }\end{array}$ & 8 \\
\hline Rachael & $F$ & $50-59$ & $\begin{array}{l}\text { Graduate } \\
\text { Diploma }\end{array}$ & $\begin{array}{l}\text { Masters } \\
\text { Degree }\end{array}$ & $\begin{array}{l}\text { Events } \\
\text { Management }\end{array}$ & 11 \\
\hline Rowena & $\mathrm{F}$ & $60-69$ & $\begin{array}{l}\text { Graduate } \\
\text { Diploma }\end{array}$ & $\begin{array}{l}\text { Graduate } \\
\text { Diploma }\end{array}$ & Education & 24 \\
\hline Sam & $\mathrm{M}$ & $50-59$ & $\begin{array}{l}\text { Masters } \\
\text { Degree }\end{array}$ & CIV & $\begin{array}{l}\text { Hospitality/ } \\
\text { Business }\end{array}$ & 7 \\
\hline Sean & $\mathrm{M}$ & $50-59$ & $\begin{array}{l}\text { Bachelor } \\
\text { Degree }\end{array}$ & $\begin{array}{l}\text { Graduate } \\
\text { Diploma }\end{array}$ & Architecture & 10 \\
\hline Shiraz & $\mathrm{F}$ & $60-69$ & CIV & CIV & Aged Care & 11 \\
\hline Steven & M & $60-69$ & $\begin{array}{l}\text { Masters } \\
\text { Degree }\end{array}$ & $\begin{array}{l}\text { Graduate } \\
\text { Diploma }\end{array}$ & Management & 24 \\
\hline
\end{tabular}

The age grouping of the teachers shows they were all mature adults. This is not surprising as typically, those working in the VET sector are of mature age and have had significant periods of work experience prior to teaching. Indeed, all were over the age of 40 with 10 of them aged over 50 years. Three were aged $40-49$, six were aged $50-59$, and four were aged between 60 and 69 . So, the median age was in the 50 - 59-year age group. As such, they were slightly older than the average age of 49 years for VET teachers in Australia (Productivity Commission, 2011). Nine of the 13 teachers $(69.2 \%)$ had 10 or more years of teaching experience, which is higher than the average of $31.8 \%$ of teachers with more than 10 years' service in Australian VET (Guthrie, 2010).

The occupational qualifications of the male teachers comprise Design, Tourism and Hospitality, Electronics and Electrical Engineering, Business and Management, and Architecture. The occupational qualifications of the female teachers comprised Business and Management, Tourism and Hospitality, Education, and Aged Care. In total, five teachers taught in Business and Management, which corresponds with the largest teaching area for the VET workforce in Australia (17.7\%) and the top broad field of education (59\%) offered offshore by Australian educational institutions. 
All these teachers held the mandatory qualification, the Certificate IV in Training Assessment and Education (CIV TAE), which is a requirement to teach Australian VET courses. Eight of the teachers (61.7\%) also had a higher level qualification in education beyond the mandatory qualification. Of these, seven - four males and three females - held one or more postgraduate educational qualifications. In this way, on average, the teachers held higher qualifications than most VET teachers. For instance, the Productivity Commission estimated that in 2011 only $60 \%$ of VET teachers held an educational qualification. Of those teachers with qualifications the breakdown was $40 \%$ with a CIV TAE, $25 \%$ with a diploma, and $35 \%$ with a higher level qualification.

In summary, the informants by and large reflected the profile of the Australian VET teaching workforce, albeit slightly older and with longer periods of service and higher level qualifications in teaching. While little is known about the Australian and expatriate transnational VET workforce data, it is not surprising that highly experienced and qualified teachers are recruited for working offshore and that mature individuals are at a point in their lives where they can relocate overseas or be away from home for extended periods of time.

\subsubsection{Settings}

Table 4.5 presents details about the settings where teachers were located, including (a) the countries, (b) the type of teaching environment, (c) the student cohort, and type of arrangement (d). As indicated in this table, six teachers were located in the Asian region with four in China, one in Vietnam, and one in the Philippines. Four were located in the Middle East, with two in the United Arab Emirates (UAE), and one in Kuwait. Three were located in the South Pacific region. This combination of countries broadly reflects the countries where most Australian transnational VET provisions occur. For instance, the top countries for export in 2017 included China, Fiji, Kuwait, Vietnam, and the Philippines (DET, 2018). It is also not surprising that four teachers were located in China, given that it comprises $56.75 \%$ of Australian transnational VET enrolments (DET, 2018). Two teachers taught students, who were employees, directly on site in their workplace. The remaining 11 teachers taught in classrooms, with four of these teachers also having access to simulated or real workplaces for teaching the technical components of the courses. While the teaching environments for Australian VET teachers are more varied, classroombased teaching reflects the general trend of Australian transnational VET provision at 86\% (DET, 2011). 
Table 4.5

Country, Teaching Environment, Student Cohort, Type of Arrangement, for Teachers

\begin{tabular}{|c|c|c|c|}
\hline Country & $\begin{array}{l}\text { Teaching } \\
\text { environment }\end{array}$ & Student cohort & Type of arrangement \\
\hline China & Classroom & Chinese school leavers & $\begin{array}{l}\text { Collaborative } \\
\text { (public/public) }\end{array}$ \\
\hline China & Classroom & Chinese school leavers & $\begin{array}{l}\text { Collaborative } \\
\text { (public/public) }\end{array}$ \\
\hline China & Classroom & Chinese school leavers & $\begin{array}{l}\text { Collaborative } \\
\text { (public/public) }\end{array}$ \\
\hline China & Classroom & Chinese school leavers & $\begin{array}{l}\text { Collaborative } \\
\text { (public/public) }\end{array}$ \\
\hline Fiji & $\begin{array}{l}\text { Classroom and } \\
\text { simulated } \\
\text { workplace }\end{array}$ & $\begin{array}{l}\text { Individuals from many } \\
\text { South Pacific countries }\end{array}$ & Aid sponsored \\
\hline Iran & $\begin{array}{l}\text { Classroom and } \\
\text { studio }\end{array}$ & Young wealthy Iranians & $\begin{array}{l}\text { Collaborative } \\
\text { (public/private) }\end{array}$ \\
\hline Kuwait & $\begin{array}{l}\text { Classroom } \\
\text { segregated male } \\
\text { and female }\end{array}$ & $\begin{array}{l}\text { Individuals from many } \\
\text { countries living in Kuwait }\end{array}$ & $\begin{array}{l}\text { Collaborative } \\
\text { (public/private) }\end{array}$ \\
\hline $\begin{array}{l}\text { Papua } \\
\text { New } \\
\text { Guinea }\end{array}$ & $\begin{array}{l}\text { Predominately } \\
\text { workplace with } \\
\text { workshops in } \\
\text { classroom }\end{array}$ & $\begin{array}{l}\text { Individuals employed by } \\
\text { government }\end{array}$ & Aid sponsored \\
\hline Philippines & $\begin{array}{l}\text { Classroom and } \\
\text { work placements }\end{array}$ & $\begin{array}{l}\text { Filipino young people with } \\
\text { a local nursing qualification }\end{array}$ & $\begin{array}{l}\text { Collaborative } \\
\text { (private/private) }\end{array}$ \\
\hline $\begin{array}{l}\text { South } \\
\text { Pacific } \\
\text { country* }\end{array}$ & $\begin{array}{l}\text { Workshops in } \\
\text { workplace }\end{array}$ & $\begin{array}{l}\text { Individuals employed by } \\
\text { sponsor }\end{array}$ & $\begin{array}{l}\text { Collaborative } \\
\text { (public/public) }\end{array}$ \\
\hline UAE & $\begin{array}{l}\text { Classroom } \\
\text { segregated male } \\
\text { and female }\end{array}$ & $\begin{array}{l}\text { Emirati nationals of all } \\
\text { ages }\end{array}$ & $\begin{array}{l}\text { Collaborative } \\
\text { (public/public) }\end{array}$ \\
\hline UAE & Classroom & Emirati females of all ages & $\begin{array}{l}\text { Collaborative } \\
\text { (public/public) }\end{array}$ \\
\hline Vietnam & $\begin{array}{l}\text { Workshops in } \\
\text { workplace }\end{array}$ & $\begin{array}{l}\text { Individuals employed by } \\
\text { sponsor }\end{array}$ & $\begin{array}{l}\text { Collaborative } \\
\text { (public/private) }\end{array}$ \\
\hline
\end{tabular}

As can be seen from Table 4.5, teachers were involved in different types of transnational arrangements including: (a) a collaborative partnership between an Australian and a foreign public or government institution (7), (b) an aid program administered by an Australian public institution (2), (c) a collaborative partnership between an Australian and a foreign private college (1), (d) a collaborative partnership between an Australian public institution and a foreign private college or business (3). Given that there is no data kept on the types of Australian transnational arrangements between sponsors, it is difficult to assess whether these arrangements 
are typical or not. However, they are important to note as the type of arrangements has some bearing on the findings presented in the following chapters.

\subsection{Summary}

This chapter has advanced a case for the use of a qualitative methodology with a phenomenological approach to explore the challenges teachers face in enacting in one country a curriculum designed for another country. The particular kinds of teaching and learning situations in transnational VET merit a qualitative research design to enable a detailed consideration of the contextual elements from the teachers' perspective. A phenomenological research design was justified as the methodology for this inquiry as it sought to capture the meanings for teachers in enacting an Australian VET curriculum internationally. On the basis of this justification, the chapter has reviewed and discussed the research design including the interpretive framework, research questions, selection of informants, the collection and analysis of the data, validity, and ethical considerations. The final section has introduced the teachers and the settings for the inquiry.

In conclusion, a phenomenological approach to this inquiry helps to illuminate the teachers' experience of curriculum enactment in transnational VET provision. In this way, the findings from this inquiry will contribute to the field by considering the relationship between the processes of curriculum implementation and the relevance, quality, and sustainability of Australian transnational VET provisions. 


\section{Chapter 5}

\section{The influence of situational factors on curriculum implementation in Australian transnational VET}

The previous chapter advanced the case for the use of a qualitative phenomenological approach to explore the challenges teachers face in enacting in another country a vocational curriculum designed for Australia. The findings from this inquiry are presented and analysed across Chapters 5, 6, and 7 and a synthesis of the findings is presented in Chapter 8 . This chapter presents the first part of the inquiry's findings about the situational factors that influenced the implementation of Australian Training Packages in nine countries, from the perspective of 13 teachers who are the informants for this enquiry. It elaborates what was outlined in Chapter 3 : that situational factors are important determinants of curriculum implementation. Five key factors emerged through the analysis of the interview transcripts that enabled or constrained the teachers' enactment of the intended curriculum in these overseas locations: (a) information, (b) resource, (c) material, (d) institutional, and (e) student readiness. Rather than being a uniform set of factors, they were manifested quite differently in each setting. In combination, they determined the readiness of the: (a) sponsors to support the intended curriculum, (b) teachers to enact it, and (c) students to learn what was intended in the curriculum. All these local factors are important because they determine the level of alignment amongst the intended, implemented, and experienced curricula in each situation. It is advanced here that teachers cannot simply enact Training Packages in another country with fidelity unless they have support for an extended scope of role to learn about the factors in the situation and the capacity to influence them.

In making its case, this chapter is divided into eight sections. It commences with an overview of the aforementioned five factors. In the next five sections, each factor is explained and discussed in relation to the concepts elaborated in Chapters 2 and 3. The seventh section discusses the teachers' experience of the factors and the concept of dissonance is advanced as the basis for understanding the teachers' approaches to decision-making, problem-solving, and curriculum-making that is subsequently elaborated on in Chapters 6,7 and 8.

These situational factors, as frequently reported by the informants, are illustrated by a sample of quotes of the terms, phrases, and statements used by the teachers about each factor and its influence on curriculum implementation. It is important to acknowledge that the findings discussed in this chapter represent the 
concerns of these 13 teachers and may not be shared by other actors. However, given that this inquiry seeks to interrogate curriculum implementation from a phenomenological perspective, the focus of this analysis is to understand these teachers' experiences of these factors across a number of countries. Their perspectives help to identify the key indicators of teacher success in the enactment of the intended curriculum in transnational vocational education.

\subsection{Overview of situational factors}

As foreshadowed, there are a range of situational factors that shape how the intended curriculum is enacted by teachers in transnational settings. Table 5.1 presents five factors identified from the analysis of the interview transcripts as having either an enabling or constraining influence on curriculum implementation in Australian transnational VET. The factors, listed across the row at the top of the table, are (a) information, (b) resource, (c) material, (d) institutional, and (e) student readiness. The student readiness factor comprises four sub-factors: (a) goals and interest, (b) language proficiency, (c) prior knowledge and abilities, and (d) learning styles. In the left-hand column, the participants' pseudonyms are listed. The factors are marked with a positive symbol $(+)$ if the teachers perceive it as an enabling influence on curriculum implementation and a negative symbol (-) where the factor is perceived as having a constraining influence. Where there is no symbol recorded, this means that the teachers either did not mention it or considered it as neither enabling nor constraining. 
Table 5.1

Factors Rated by Teachers as an Enabling or Constraining Influence on Curriculum Implementation

\begin{tabular}{|c|c|c|c|c|c|c|c|c|}
\hline \multirow[t]{2}{*}{ Teacher } & \multicolumn{8}{|c|}{ Factors and sub-factors } \\
\hline & Information & Resource & Material & Institutional & $\begin{array}{l}\text { Student } \\
\text { goals } \\
\text { and } \\
\text { interest }\end{array}$ & $\begin{array}{l}\text { Student } \\
\text { language } \\
\text { proficiency }\end{array}$ & $\begin{array}{l}\text { Student } \\
\text { prior } \\
\text { knowledge } \\
\text { and } \\
\text { abilities }\end{array}$ & $\begin{array}{l}\text { Student } \\
\text { learning } \\
\text { styles }\end{array}$ \\
\hline Alex & - & - & - & - & - & - & - & - \\
\hline Annabel & - & - & - & - & - & - & - & - \\
\hline Damien & - & - & - & & + & - & - & - \\
\hline Jo & - & - & - & - & - & - & - & - \\
\hline Mary & - & - & - & - & & - & - & - \\
\hline Mick & - & - & - & - & - & - & - & - \\
\hline Peter & - & - & - & - & - & - & - & - \\
\hline Rachael & - & & - & - & - & - & - & - \\
\hline Rowena & + & - & + & + & + & + & - & \\
\hline Sam & - & + & - & + & + & - & - & - \\
\hline Sean & - & - & - & - & + & + & - & - \\
\hline Shiraz & + & + & + & + & + & + & - & \\
\hline Steven & + & & + & + & + & + & - & - \\
\hline
\end{tabular}

All the factors brought together in Table 5.1 highlight their complexity in contributing to curriculum implementation. It is important to note that regardless of whether they were positive or negative influences, this array of factors influenced the implementation of the curriculum according to the experiences of these 13 teachers. It appears that what mattered most to these teachers were those factors relating to the supported curriculum (i.e., the availability of information, resources, materials, and institutional support) and the learned curriculum (i.e., students' needs and responses). It is held that the teachers' perception of these factors determined their experience of dissonance arising from the misalignment of the intended, implemented, and experienced curricula. The next five sections elaborate on each of the factors as reported by teachers and summarised in Table 5.1, followed by a discussion of their experience of dissonance.

\subsection{Information factors}

Having adequate information to make decisions about curriculum enactment is very important. It is, therefore, critical that teachers receive professional support and information to develop their curriculum literacy (Ariav, 1988). Otherwise, as 
outlined in Chapter 3, without adequate knowledge about the curriculum and how to enact it within their situated context, teachers cannot be effective curriculum-makers (Fullan, 2008; Spillane et al., 2004). Thus, as presented in Table 5.1, it is not surprising that all the teachers reported information as an important factor influencing curriculum implementation. Teachers wanted information about: (a) the educational institution or workplace (i.e., resources, timetables, policies), (b) the students (i.e., demographics, characteristics, goals), (c) their role, (d) local industry, and (e) the society (i.e., cultural norms). All of this information was considered important for these teachers' preparation for enacting the curriculum.

Information about the local situation played an important role in teachers' learning and understanding about their situation and how they went about enacting the curriculum. The quality of information available to teachers influenced the way they planned through the teacher-intended curriculum (i.e., material development) and consequently how they taught. Even though the majority of teachers were equipped with the curriculum knowledge and pedagogical expertise for Australian teaching, they wanted to understand how to apply this knowledge and experience in a new country. However, as Table 5.1 shows, 10 teachers reported that a lack of information was a constraining influence as they were not adequately informed through documents, inductions, and/or professional development opportunities before or after they arrived overseas. In these instances, a lack of knowledge meant that teachers were often unsure about how to plan and enact the curriculum in another country, as Mick explains:

I think a better induction, a more serious induction would have been helpful ... an induction in the country is important ... to have your feet on the ground in the country and talking to the people who are there ... I wanted to know and what I needed to know as a teacher is more about where the students are at, where they are going, so I could pitch my teaching. I didn't really quite understand where I was pitching my teaching ... I started to get to know that as time went by but as the semester was almost over ... (Mick, business teacher in China)

Mick's comments suggest that if he had received the information he needed when he arrived in China, then he might have been better prepared for interacting with the local people and teaching the students. Mick went on to explain why this information was so critical for him despite having taught the curriculum in Australia for 24 years: 
It was a foreign situation. I'd never really been out of the country of Australia ... so you have a curriculum and there was no explanation as to how we the teachers had to implement this. (Mick, business teacher in China)

Thus, it can be seen that despite Mick's significant experience in Australia, he still needed specific information about how to enact the intended curriculum in another country. Mary's experience was similar. She had also taught the curriculum for 20 years in Australia, but without adequate information she was surprised by how unprepared she was for enacting the exact same curriculum (i.e., Training Package) in another country. She describes what it was like for her not having the knowledge she needed:

I had really no great lead in, in terms of what the hell do I do now? Every day there would be many things that I learnt along the way and just go "how naïve or how can you not be aware of that stuff'? Well, because you don't live in that environment. You don't know that culture ... l'd been overseas but not to Asia. (Mary, business teacher in China)

Teachers such as Mick and Mary attributed a lack of information about the circumstances for enactment as a barrier to their ability to successfully adapt to teaching in a new country. Indeed, in some instances, teachers claimed that a lack of information led to them developing materials and teaching in ways that were not suitable for the local context. For example, Sam found that his plans for enactment were ill conceived given that no one had gathered or imparted information about the teaching and learning situation in Vietnam before he and his colleague commenced teaching. He described how it caused problems for him, as follows:

... to me that was our main deficit and what led to preparing things that were inappropriate ... because no one from Australia had actually been to the hotel in Vietnam to check it out so no one knew what we were getting into ... we had never delivered training over in an Asian country let alone another country ... so it was pretty silly. (Sam, hospitality teacher in Vietnam)

Sam's comment shows how a lack of information can lead to ineffective teaching, which also affects students' learning. Thus, it appears that for 10 teachers, their interpretive skills were constrained by their lack of local experience and information. It meant they had no pre-existing approach for enacting Training 
Packages in any country other than Australia. As a result, the only learning available to the teachers was through the experience itself. Without the opportunity to learn new knowledge in the situation (Clarke \& Hollingsworth, 2002; Penuel et al., 2007; Spillane et al., 2004) many of them felt deprived of the knowledge they needed to be successful in their offshore enactment of the curriculum.

In comparison, three teachers reported that the information provided to them was an enabling factor because it did help them to understand the situation and plan accordingly. Steven's comment explains why the information he received from the local sponsors was helpful in his preparation for enacting the intended curriculum in PNG:

... it was always quite beneficial for me because of the insight it would give you into the likely people you were going to have and some of the issues ... and then what these skills these people needed ... so you're on top of those all the way through... (Steven, management teacher in PNG)

In Steven's case, information was a positive influence because it prepared him for teaching and also helped him to understand and plan for some of the problems he could expect. Therefore, the diffusion and dissemination of information helped those teachers to develop a localised understanding and prepared them for curriculum enactment (Clarke \& Hollingsworth, 2002; Fullan, 2001; Penuel et al., 2007).

From the accounts of the teachers it can be seen that having information about the local situation helped three participants to prepare suitable curriculum plans and materials. In contrast, 10 of them considered a lack of information about the local situation as a constraint to planning and enacting the intended curriculum in a new country. Chapter 4 showed that many of these teachers had considerable experience teaching the same curriculum in Australia. For example, Mick and Mary had 26 years and 20 years teaching experience, respectively. This finding suggests that while teachers might be experienced and qualified for enacting a vocational curriculum in Australia, this does not mean that such expertise simply transfers to enacting the same curriculum in another country. Indeed, similarly to the reports of other transnational teachers (Bailey, 2011; Woodley, 2007), this group of teachers reported that they needed information to assist them to learn how to construct educational experiences in situations that were culturally different from what they were used to in Australia. From these findings, it is suggested that there is a dissonance between a teacher's curriculum understanding and expertise in an Australian context and what is required in another country. It is contended that the 
provision of information about the local situation would have helped these teachers overcome this dissonance and make better sense of their circumstances for enactment in another country.

\subsection{Resource factors}

As proposed in Chapter 3, the capacity of educational institutions to support the curriculum through the provision of resources is essential for the quality of the enacted and learned curricula (Hlebowitsh, 2005; Spillane et al., 2004). However, as presented in Table 5.1, out of the 11 teachers who reported resources as a key factor influencing curriculum implementation, only two (Sam and Shiraz) reported resources as an enabling factor. Both these teachers highlighted the importance of having access to good quality resources because it meant that there was alignment in standards between the intended and supported curriculum, as Shiraz's comment illustrates:

$\ldots$ the equipment was great, the training rooms were phenomenal ... you know everything was really great with all those things ... it was on par. (Shiraz, aged care teacher in the Philippines)

In contrast, the other nine teachers reported resources as a constraining factor. In these instances, it was found that the allocation of certain educational and technical resources would have provided teachers with the means to enact the intended curriculum at the required standard.

The availability and standard of resources played an important role in the provision of practical support for teaching and learning the intended curriculum. Teachers needed certain resources to support the students' learning of both the theoretical and technical elements of the curriculum. Firstly, the 13 teachers all expected that basic educational resources, such as books, computers, whiteboards, projector screens, and stationery, would be accessible to support the teaching of theoretical elements of the curriculum. Annabel explains why these basic resources were so important for the students' learning of the curriculum:

The students needed to read. They needed books. They needed access to the Internet and good Wi-Fi. They needed equipment. You know computer access or computers. They needed books in the library to look up things. (Annabel, project management teacher in UAE) 
Yet, teachers reported that many of these resources were unavailable or of such poor quality they could not be properly utilised. Mary's statement below illustrates the extent of resource constraints in some situations, especially in China:

... the fact that the books, resources, paper, pens, all those sorts of things, were not things that were available, or easy to get, was a bit of a challenge ... I think for me in the initial stages it was the lack of resources. So what did I have? How could I just meld that into some sort of consolidated program? So that was a bit of a challenge. (Mary, business teacher in China)

From this comment, it can be seen that Mary did not have access to many of the basic educational resources that she expected would be made available to support the theoretical elements of curriculum. Therefore, she had to work out how she was going to overcome this unexpected constraint and teach the curriculum without books, papers, or pens. Sean's situation in Iran was also particularly challenging because the Iranian government bans the use of textbooks and Internet material from Australia or any other Western country. Yet, the explicit outcome of the curriculum was for students to learn about the design of buildings covered by the Building Code of Australia. Sean claimed that he could not use the local textbooks as a substitute as building design and regulation in Iran is very different from Australia. Sean explains the difficulties he faced without these resources:

Well, there were logistical problems because it [the curriculum] relied on the provision of very good resources, i.e., being able to have direct access to libraries. It relied on a whole world of cultural history, because we were doing architecture, Western cultural philosophy and history. It just didn't exist in Iran.... The syllabus we had and all the learning outcomes and the projects that you were given was for Western Sydney [Australia], with a brick veneer house and the suburban dream. And you think, okay, this may not work. (Sean, architecture teacher in Iran)

Sean's account illustrates the impracticality of trying to teach the theoretical content of an Australian vocational curriculum in another country without the necessary resources.

Secondly, the teachers shared an expectation that they would be provided with the resources they needed to teach the technical elements of the curriculum. For example, based on their understanding of the curriculum, teachers knew that 
Training Packages mandate the teaching and learning environment (i.e., studios, laboratories, and work places) and the tools, equipment, supplies, and documents to be used. The teachers assumed that the local sponsors would make these resources available. They placed great value on using these resources in their teaching because they were seen as critical for developing skills for the students' future employment, as Damien reports:

... my passion is to make sure that the learning outcome is not just, not just a piece of paper, but a skill that they can actually carry on with them for the rest of their life. (Damien, hospitality teacher in Fiji)

Yet, the teachers reported that many of the technical resources that were mandated for use in the curriculum were either unavailable or below standard. For example, Damien did not always have all the equipment and supplies he needed to teach the students how to prepare certain food and drinks as part of the hospitality curriculum in Fiji, as he explains:

The most important thing would be more resource allocation and the reason why I say that was the Espresso machine that was there wasn't maintained for the last two or three years.... The spices were the problem and the cheeses were a problem ... and vegetables, they didn't have any vegetables in the hotel either ... the different types of gelatine that you can use in making, you know, mousses and thickeners and so on. (Damien, hospitality teacher in Fiji)

This statement indicates that Damien believed that the resources that were made available to support the technical components of the curriculum were not to the standard he expected. Jo also reported dissatisfaction with the resources that were made available to support the curriculum. He claimed that he did not have access to a laboratory, fitted out with the necessary equipment and supplies, to teach the technical skills for the electro-technology curriculum in China. Jo explains how this lack of resources negatively impacted on the students' experience of the technical elements of the curriculum:

There was absolutely no allowance made for these students to do any practical work whatsoever. I mean classroom-based skills development like we normally do in an electronics laboratory with tools and test equipment ... 
the course can't be delivered that way. There has to be practical work. (Jo, electro-technology teacher in China)

The above examples about resource constraints illustrate the gap between the intended curriculum and the ability of teachers to enact it in some countries. In these situations, it can be seen that teachers found it impractical to enact the technical elements of an Australian curriculum in another country without specialist supplies, equipment, and facilities.

The findings presented above suggest that the provision of resources was an important determinant of curriculum implementation for teachers in this investigation, as they viewed them as essential for meeting the requirements for curriculum fidelity and equivalence with Australian standards. In particular, the provision of antecedent conditions was viewed as critical for student achievement (Hlebowitsh, 2005;

Spillane et al., 2004; Stakes, 1977). However, in nine instances, it was reported that, similarly to other studies (Bailey, 2011; S. J. Ball et al., 2012), many of the necessary antecedents were not put in place. Thus, it was shown that there was dissonance between the intended curriculum and what teachers appraised as practically possible within the resource constraints. It is held from the participants' responses that the resource factors in some countries produced practical barriers to their enactment of the intended curriculum. Thus, it was shown that the supported curriculum had considerable influence on what the teachers could enact.

\subsection{Material factors}

In different ways, all 13 teachers reported materials as a factor influencing curriculum implementation. However, this was reported as not always to the detriment of what was enacted. Table 5.1 presents data showing 10 teachers reported materials as a constraining factor and three as an enabling factor. The difference between these two groups was that one had materials and the other group did not. Participants asserted that material support was critical for curriculum adaption (Fullan, 1991) so the curriculum could be "contextualised" to suit the learning environment and the needs of students (Schofield \& McDonald, 2004).

The three teachers who reported curriculum materials as an enabling factor were the ones who had the time, information, and expertise to prepare the plans and materials that comprised the teacher-intended curriculum (Remillard \& Heck, 2014) before they left Australia. These teachers cited their past experience in teaching offshore as helpful, as Rowena states, "I think probably my teaching in China helped 
me". They also expressed confidence in their ability to adapt their materials as they learnt more about their students. Steven's statement illustrates the confidence these teachers had in the materials they had developed and their capacity to adapt and use them:

They [materials] were fantastic because I developed them all ... I'd developed the materials before I went up there [PNG]. So, I mean we had a pretty schmick product and it didn't take too much to contextualise it. (Steven, management teacher in PNG)

The combination of experience, time, and information meant that these teachers were convinced of their ability to interpret and adapt the intended curriculum so it was relevant in context.

However, similarly to previous studies, 10 teachers reported material factors as a barrier to the relevance and quality of their teaching in a foreign country (Dempsey \& Tao, 2017; Leask, 2004). It appears from their accounts that the provision of customised and relevant site-specific curricular materials would have provided these teachers with the means to: (a) adapt the curriculum content so it was relevant to the local context, and (b) teach it to students with different characteristics than those they had taught in Australia. The provision of materials was important for these teachers because they needed to develop "curriculum literacy" (i.e., what the curriculum should be and how to teach it) (Ariav, 1988) as they had not previously taught the curriculum in another country.

These 10 teachers reported that, because they were unfamiliar with the local society and culture, they expected to be provided with materials suitable for the site of provision (Fullan, 2001). However, these expectations were not realised, as Rachael explains: "There was very little teaching resources.... It should have already been localised". This absence of site-specific materials compounded the problems of these teachers because they were the same 10 teachers who reported having a lack of information. Thus, it was these teachers who reported the greatest difficulty in developing materials for adapting and teaching the curriculum because they had such a limited understanding of the situation and the students' characteristics.

The main concern about materials for these 10 teachers was the teacherintended curriculum, or what is referred to in the Australian VET system as the "nonendorsed" component (i.e., learning strategies, assessment resources, and professional development materials) of the Training Package curriculum they were engaged to enact. All teachers reported that they had access to the endorsed 
component of the curriculum (the intended curriculum), which comprised: (a) learning outcomes and performance criteria to be achieved, (b) required skills and knowledge to be learnt, (c) assessment guidelines, and (d) advice on gathering assessment evidence. Yet, apart from this syllabus, these 10 teachers reported that they were not provided with a full set of unit outlines, lesson plans, assessment tools, marking guides, student learning materials, or work placement guides.

Teachers described many problems in relation to accessing and using the materials that were available. For example, there were problems with the storage and access to materials, as Alex states:

There was virtually nothing, no physical examples and the digital repository we had was just a mess, it was just, there was no order to it, it was just all over the place. (Alex, design teacher in UAE)

They also complained about the poor quality of the materials they did receive. For example, they claimed that some materials were designed for an Australian context and were not transferable:

Whatever curriculum was put together in the past, prior to my arrival to the hotel, they were very much useless because they were very much contextualized to the Australian way of life. There was very little contextualization of how it really is in Fiji. (Damien, hospitality teacher in Fiji)

The resources were unhelpful because they were inappropriate for Chinese students as everything was contextualized for Australia ... and not contextualized for China. They weren't helpful because nobody thought about the students ... (Mick, business teacher in China)

In other instances, the materials were tailored to the local context, but the teachers said they did not find them helpful, as Mary explains:

... a teacher that had been there three or four years before sent me some resources she had developed and used as part of her delivery ... I didn't actually use them though. (Mary, business teacher in China) Participants claimed that part of the problem with the materials was that they were usually developed by other teachers who, like themselves, did not have 
local knowledge, and had not been subjected to any quality assurance process, as Alex explains:

We got a couple of folders of their work but one of the previous teachers wasn't even a design teacher. Helen was a design teacher and I got, certainly got more from her ... but even that was just sort of disarray and, you know, not that useful. (Alex, design teacher in UAE)

As a result, teachers reported that they were uncertain whether the materials they were provided with by other teachers were: (a) suitably adapted, and/or (b) consistent with the curriculum intentions. Thus, it was shown that without quality materials, teachers were deprived of the means for proper enactment, as reported by other scholars in the field (Barrow, 2006; Cornford, 1999; Hager, 2004). With only inadequate material support, these 10 teachers who lacked local information and offshore experience found themselves further disadvantaged because they did not have a plan or quality materials for enacting the intended curriculum in a foreign situation.

The teachers' accounts about material factors suggest that it was difficult for teachers with no transnational experience to develop and use site-specific materials in another country without the opportunity to learn about the local situation or the time to develop the materials. This finding is consistent with Dempsey and Tao's (2017) claim that transnational teachers need to receive training if they are to successfully adapt the curriculum to make it relevant for different cohorts of students in different countries. These findings also reveal the difficulties associated with the black box of Training Packages (a curriculum without explicit implementation strategies) where teachers were uncertain how to "fill in the gap" between the learning outcomes and assessment guidelines (Barrow, 2006; Hager, 2004) in an unfamiliar culture. It is contended that the provision of materials and training for teachers, especially for those who were new to transnational teaching, would have assisted their readiness to plan and enact a quality and relevant vocational curriculum in another country.

\subsection{Institutional factors}

The capacity of educational institutions to provide the necessary arrangements to support the intentions of the curriculum is important (Hlebowitsh, 2005; Spillane et al., 2004). However, similarly to findings reported by Woodley 
(2007), 12 teachers claimed that the host organisation did not put the appropriate arrangements in place to support the intended curriculum. Consequently, institutional factors (i.e., timetables, class-room allocations, work-based arrangements) were another key influence on the implementation of the curriculum. These teachers reported that how the curriculum was planned, organised, and managed, served to structure and shape both the curriculum content (i.e., what could be taught) and standards (i.e., what could be achieved). Table 5.1 shows that eight teachers reported the institutional arrangements as a constraint for curriculum implementation. Conversely, it shows that four teachers identified that the institutional arrangements supported curriculum implementation. It is important to note that all the teachers who reported negative arrangements taught full-time, in an ongoing capacity, in large educational institutions, in China or the Middle East region. Three of the teachers who reported positive arrangements were teaching within the students' workplace in other Asian countries or in the South Pacific region. These differences, in the main, were reported to be of considerable influence as they shaped the operational environment in which the teachers had to enact the curricula.

All the teachers expected that the local hosts would ensure that the proper arrangements were put in place to support the curriculum intentions. For example, they expected that arrangements such as time schedules, timetables, classroom allocation, and work placements would all be arranged as per the curriculum requirements. However, eight teachers working in these large institutions claimed these expectations were not met, as Jo's reflection illustrates:

Yeah, when I look back at it, I was very naïve and accepting of what I was told - 'Yeah, it'll all be right, everything's organised.... We've arranged it all with the Chinese people. It'll be fine." And none of it was true ... I think it was just very, very poorly organised with a very poor understanding. (Jo, electrotechnology teacher in China)

This statement highlights how he, like others, attributed the inadequacy of the arrangements to poor communication (Lauder et al., 1998), a lack of planning (House, 1996), and stakeholder understanding (Spillane et al., 2004).

Local institutional factors posed challenges to how teaching could be practised and significantly influenced the educational experiences that teachers could construct for their students. For example, how institutions selected and enrolled students, allocated resources, set the timetables, employed and managed staff, and determined academic procedures were all important for the quality of the 
enacted curriculum. Often, seemingly mundane decisions about program timetables and class schedules were revealed to have had a subtle and pervasive influence on the implementation of the curriculum. For example, teachers stated that they expected that local administrators would structure and sequence the learning program according to the Training Package mandated rules. These rules detailed: (a) the nominal hours for each unit of competency, (b) the vertical (subject matter pursued simultaneously) and horizontal (subject matter exposed sequentially over time) offering of units, and (c) the amount and type of work-based learning that should occur. However, in these eight instances the teachers claimed that the curriculum rules were not followed in the programming of the timetable. As a result, the teachers reported that the time allocated to class was insufficient for them to adequately engage with all of the curriculum content, as Peter explains:

The reality was that a 1-hour class was actually 45 minutes long because there was a need for every 45 minutes there was a need for a 15-minute break. So this reduced your curriculum by $25 \%$. (Peter, business teacher in China)

The scheduling of units in the incorrect order was another issue reported by teachers. This sequencing was problematic as the teachers claimed they were unable to build the students' knowledge and skills from one unit to the next. For example, Jo described the schedule for the electro-technology program in China as "incoherent" and "illogical" because it was not based on the horizontal offering and clustering of units as prescribed in the curriculum. As a result, Jo claimed that it was "virtually impossible" for him to progress the students through a specific sequence of integrated theory and practice units, as he elaborated:

The timetable didn't make any sense at all, and contained what seemed to be a random mix of semester one, semester two and semester three subjects with no consideration for the prerequisite chain ... and to make things worse, all of the subjects were to be delivered as theory only and not integrated theory and practical as we have been trained to do ... the course can't be delivered that way ... the timetable must have all of the prerequisite units completed first. (Jo, electro-technology teacher in China)

As can be seen from these illustrative quotes, local program arrangements and timetables influenced what elements of the curriculum could be taught, when 
they could be taught, and for how long. In many cases these arrangements did not support curriculum intentions.

Teachers also perceived that social and cultural mores took precedence over the curriculum. One notable area of concern for three teachers located in the Middle East region was that the curriculum was organised differently for female students compared to male students within the same institution. These teachers reported many examples where work-based or other external learning opportunities were either restricted or not made available to female students because local practices prohibited their involvement. For example, in Kuwait, Rachael claimed that she was only allowed to organise the female students' attendance at a restricted number of events, such as fashion shows or wedding displays, as part of the Events Management curriculum. In comparison, she claimed that the male students had unlimited access to numerous events across a greater range of fields such as sport, business, and trade. In another example, Alex asserted that he found it difficult to arrange female students' attendance at art exhibitions as part of the Graphic Design curriculum. Alex claimed he was not allowed to accompany these students to these events because he was "a man and teaching women and when you're taking women out you've actually got to have a female companion with you". However, he said that the female teachers were not always available to assist him because they were busy teaching. So, in these situations, teachers were unable to afford their female students the same learning opportunities as their male counterparts or experiences similar to those provided to students in Australia.

In comparison to these reports of inadequate institutional arrangements, four of the teachers asserted that the institutional arrangements did support curriculum implementation. As mentioned previously, three of these teachers taught in the students' workplace and they reported that curriculum implementation was well supported by the sponsor, as Sam notes:

So this was planned weeks in advance for them [sponsor] to make sure that people were available and the schedule was set appropriately ... and it was good. (Sam, hospitality teacher in Vietnam)

All these teachers linked successful implementation with well-supported institutional arrangements.

The teachers' accounts reveal that institutional factors had a pervading influence on curriculum implementation because they determined the structure and shape of the curriculum content and activities that could be enacted by teachers and 
the experiences they could provide for their students. From the findings reported above it can be seen that in some situations the teachers agreed that the institutional arrangements were aligned with the curriculum intentions; in other situations, they did not agree this was the case. These findings are aligned with those in other studies that show there are differences between sites of curriculum implementation due to the role of local actors in interpreting and translating the intended curriculum into institutional practices (S. J. Ball et al., 2012; Lauder et al., 1998; Woodley, 2007). In view of these findings it appears that the institutional and cultural practices of host institutions had considerable influence over the quality of the vocational learning experiences that teachers could provide for transnational students.

\subsection{Student readiness factors}

Regardless of what experiences are planned and provided for students, their readiness to engage with them is salient and central to the learned curriculum (Billett, 2011). Transnational vocational education is no exception here. It was found that while the implemented curriculum shaped how the students experienced the curriculum, the way that students decided to engage with it was a key influence on the teachers' enactment of it. Teachers claimed that varying levels of student readiness influenced their capacity to engage students in learning the curriculum content and facilitating their achievement of the curriculum outcomes. The student readiness factor, as presented in Table 5.1, comprised four sub-factors: (a) goals and interest, (b) language proficiency, (c) prior knowledge and abilities, and (d) learning styles and preferences. Teachers considered these sub-factors as having considerable influence on student achievement (the amount of curriculum content learnt in the set amount of time).

Many of the pedagogical problems teachers experienced were the result of students not responding to the curriculum as they expected. This finding is similar to those reported concerning other Australian VET teachers' experiences offshore (Bailey, 2011; Bilboe, 2011; Hua et al., 2011; Woodley, 2007). Based on their prior professional experience, teachers held their own beliefs and values about how the curriculum should be taught and how students should engage with it. In this inquiry teachers expected that students would be: (a) interested in the curriculum content, (b) ready to communicate and learn in English, (c) ready to learn the content at the prescribed course level, and (d) ready to take an active role in their learning. When some or all of these expectations were not met, many teachers reported that the 
students were not ready to engage, communicate, and learn at the prescribed level of the curriculum, as Alex states:

I don't honestly believe that they (students) were ever going to be at a level what I would teach in Australia, for a whole gamut of reasons, language skills, understanding, motivation, family needs, all those sorts of things ... that you'll get in an Australian student compared to these students. (Alex, design teacher in UAE)

Consequently, all teachers claimed that they were concerned that the needs and interests of their students might not be met through an Australian vocational curriculum. In particular, their reports about the students revealed their main concern was that the curriculum may not prove relevant, learnable, or achievable in some instances. These issues are elaborated on for each student readiness factor in the following four sub-sections of this chapter.

\subsubsection{Student goals and interest}

Students' goals and interest in the curriculum are an important student readiness factor for teachers. As presented in Table 5.1, six teachers reported students' goals and interest as a constraining sub-factor and six reported it as an enabling sub-factor. At the heart of teachers' perspectives was their belief that students who were specifically interested in the vocational outcomes of the curriculum (i.e., electricians, aged care nurses, architects, managers, designers, or educators) were more motivated to learn and achieve them. Shiraz expressed her view thus: "They worked really, really hard because they knew they had a goal and they were going to get there".

Teachers also reported the reverse to be true (i.e., that students who were uninterested in the vocational outcomes of the curriculum were less likely to learn and achieve them). Consistent with findings from other case studies in China and Kuwait (Bilboe, 2011; Shi \& Woodley, 2008; Woodley, 2007), six teachers reported that in these countries and in the UAE, many students were enrolled in programs for reasons unrelated to the vocational intentions of the curriculum. For example, teachers in China explained that many students enrolled in the program as a pathway into a higher degree program to please their parents, as Jo reports: 
The students in my classes had all got to [college] because their family had bought a place in the course. Very few of them had much interest in the subjects, and even fewer actually applied themselves to trying to study.... A lot of them [students] just weren't interested ... these people were just switched off, you know. Many of them didn't want to be there. (Jo, electrotechnology teacher in China)

In another example, teachers in the UAE and Kuwait reported that many female students were looking to enhance their social status by achieving a higher level of education, as Annabel explains:

The women [students] were usually non-working and never had worked, never will work and the class of society, wealthy. Not really motivated to study or to learn the content they're being taught. They just wanted some sort of diploma or paper. (Annabel, project management teacher in UAE)

The above examples demonstrate the way the teachers perceived that the primary purpose of the curriculum was irrelevant to some of their students and when the students did not show interest, they considered them as unmotivated. In these instances, teachers reported that a lack of motivation affected the students' achievement of the curriculum outcomes, as Annabel reports:

They [students] struggled, they knew they had to find a project and treat things as a project, but they struggled with that and they may have gotten through that experience, but they didn't seem to have the interest to pursue the roles similar to that nature. (Annabel, project management teacher in UAE)

While the teachers perceived there to be a lack of intrinsic motivation from many students, they also suggested the curriculum content contributed. Teachers perceived that in many cases the content was just not relevant to students' personal lives or the broader social and cultural context in which they lived. Indeed, even teachers with highly motivated students conceded that some parts of the curriculum were irrelevant for offshore students who did not intend to work or live in Australia, as Rowena explains: 
I mean what's the point of telling them this is what's happening in [a state of Australia] when what you're talking about ... means absolutely nothing to them when they are so many thousands of miles away from Australia. (Rowena, education teacher in South Pacific)

Thus, similarly to other findings (AEI, 2007; Anderson, 2006b; Dempsey \& Tao, 2017; Moran \& Ryan, 2003; Shi \& Woodley, 2008; Woodley, 2007) many teachers concluded, that, by degree, certain elements of the curriculum content lacked relevance for many students because they were overly focused on Australian values, standards, and practices, as Mick explains:

You know, the curriculum in Australia was designed for Australian conditions, not designed for Arabian or Chinese or whatever conditions and that disturbs me.... If the standards were negotiable that would be much more preferable because they're [curriculum developers] trying to create students based on Australian conditions and I don't think that's very easy to do and perhaps impossible. (Mick, business teacher in China)

Mick's statement indicates the importance he placed on being able to negotiate an Australian curriculum so it was relevant and achievable for students in another country. Indeed, Steven asserted that because he had the opportunity to "negotiate the program upfront" with the local sponsors he was able to adapt the curriculum to meet the goals of the sponsors and develop materials based on documentation from the students' workplace.

It can be seen from the teachers' comments above that they perceived that the students' readiness to meaningfully engage with the curriculum was influenced by whether or not their goals and interests were aligned with its intentions. As reported in Chapter 2, many other studies have also reported that the content of Training Packages is so overly focused on Australian circumstances that it ignores the needs and interests of international students (AEI, 2007; Anderson, 2006b; Dempsey \& Tai, 2017; Shi \& Woodley, 2008; Woodley, 2007). The teachers' stories reveal the value they placed on enacting a curriculum that was relevant to students. In light of these findings it is contended that if teachers had been afforded the opportunity to negotiate and develop the intended curriculum in their situation, as suggested by many scholars (Anderson, 2006b; Dempsey \& Tao, 2017; Woodley, 2007), it would have helped them to enact a curriculum that was relevant to the aspirations of their students. 


\subsubsection{Student English language proficiency}

Language proficiency was another student readiness sub-factor reported by all teachers. Table 5.1 shows that this sub-factor was a constraining influence for nine teachers and an enabling influence for four. All the teachers were teaching in countries where English was not the official language. However, the language of instruction was English. In four instances, teachers reported that most students were fluent in English and the only adjustment they needed to make to their teaching was to occasionally slow down their speaking and help the students with the technical vocabulary. They reported that teaching the curriculum in English was relatively straightforward. However, the other nine teachers asserted that many students did not have the required level of English language proficiency to learn and achieve the curriculum outcomes at the prescribed qualification level (i.e., at a certificate or diploma level).

Teachers reported two types of language difficulties for students: (a) learning in English, and (b) learning the technical vocabulary of the curriculum. The first language barrier was student proficiency in English. Teachers stated that they expected that their students would be able to study in English because it was the language of instruction for the curriculum. However, nine of the teachers reported being surprised to find that many students had difficulties communicating and learning in English. For example, Mary comments:

Well, I was told that they all had reasonably good English. I would say that wasn't actually correct. (Mary, business teacher in China)

Consistent with other studies (Shi \& Woodley, 2008; Woodley, 2007), these teachers reported that English language difficulties affected the way they taught the curriculum and the way students experienced it. Some teachers, like Jo, found it difficult to communicate with students in English at the most basic level. He recalls his first day in China:

My first, conversation did not work at all. Went into my first class and started my normal, "gidday, how are you going", type of thing, not in those words, but I mean, "okay this is the topic and this is what we're going to talk about and this, and let's start with some words", and I wrote some words up, "and let's discuss these". Blank looks, not a single word, not a single facial expression. "What does this mean, what do you reckon?", you know the way you 
introduce a class and get that interaction going, the icebreakers and things, not a word. They either didn't know the words or didn't understand a word I was saying. So halfway through of the 2-hour lesson and I'm wondering what the hell do I do now? So, I struggled ... this isn't going well ... I'm just about reduced to tears, just frustration. (Jo, electro-technology teacher in China)

Jo's account reveals the sense of exasperation he experienced at being unable to communicate and build rapport with students. When communication was this difficult, teachers reported that language barriers affected the students' abilities to learn the curriculum content and achieve its outcomes. The teachers reported an array of problems with: (a) reading and translating materials, (b) asking questions, (c) participating in group discussions, (d) listening and giving presentations, (e) watching videos, and (f) writing reports. Peter sums it up this way:

They were pretty poor English language skills, much lower than is required. They lacked a lot of confidence in their use of English. So as a result, they didn't ask many questions because they didn't want to appear to be inaccurate in their utterances. They had very poor listening and comprehension skills. So, I think those are probably the most significant contributing issues. (Peter, business teacher in China)

As Alex explains, these difficulties with English had a major impact on his teaching:

It was the language ability of the students I was teaching to and their understanding and for me as a teacher to actually find a way to understand that I had been understood, for me to assess that I had been successful in communicating what needed to be done. (Alex, design teacher in UAE)

As can be seen from these examples, it was difficult for teachers to enact the intended curriculum when students had difficulty communicating and learning in the language of instruction.

A second language problem for teachers, similarly to other findings (AEI, 2007, 2011; Shi \& Woodley, 2008; Woodley, 2007), was teaching the technical vocabulary of a vocational curriculum. Jo reports the problems he experienced in trying to teach the technical vocabulary of the electro-technology program in China: 
I very soon learnt that they (students) didn't have, they had very poor English technology language ... when they're talking just basic technology things, they had no idea of the words ... O H and S principles ... risk, hazard, simple words like that which don't come up in normal conversation ... So they had no idea. (Jo, electro-technology teacher in China)

Even in situations where teachers perceived their students as having a good level of English language proficiency, they reported teaching the technical vocabulary as difficult because many of the terms referred to in the curriculum were not used in the local industries. Steven provides the following example:

Well I think a fair bit of it was technical language. Some of it was the processes that organisations in Australia would do ... so in terms of "risk management" and things like that that was something that they weren't very familiar with because they never got exposed to it ... "key performance indicators" and those types of, that language. (Steven, management teacher in PNG)

As can be seen from these examples, all the teachers discovered that students were not familiar with many of the technical terms used in the curriculum. However, teachers reported greater difficulties teaching the technical vocabulary when students had lower levels of English language proficiency.

Many of the preceding accounts reveal that teachers concluded that the students' lack of English proficiency had a major bearing on their ability to communicate with the students and teach the curriculum content. Further, low levels of technical vocabulary added another dimension of difficulty because their overseas students were not familiar with many of the technical terms used in the curriculum, or their meanings. Consequently, teachers reported numerous problems teaching the students they assessed as having a lower level of language proficiency than they expected. These findings are similar to those reported in other studies in Australian transnational VET (AEI, 2007, 2011; Shi \& Woodley, 2008; Woodley, 2007).

\subsubsection{Student prior knowledge and abilities}

A third student readiness factor reported by teachers was the students' prior knowledge and abilities. All the teachers claimed that, because students had neither been educated in nor lived in Australia, they did not always have the necessary prior 
knowledge to initially understand and meaningfully engage with an Australian vocational curriculum. Teachers reported that the students' acquisition of new knowledge and skills was influenced by their existing knowledge rather than by the conceptions the curriculum was based upon.

Students' understanding of the Australian values and practices of the curriculum was important to teachers, given that the purpose of Training Packages is to prepare people for working in Australian occupations. However, it took greater precedence for two teachers, Shiraz and Sean, who were preparing students to migrate for work in Australia. Shiraz was teaching aged care to students in the Philippines and Sean was teaching architecture to students in Iran. All their students intended to migrate to Australia to work in their chosen fields. Therefore, both teachers wanted to ensure that their students would succeed in Australian workplaces, as they explain:

I would ask - am I bringing back (to Australia) students who are really capable of working in our aged care industry? Whilst they had the knowledge and skills ... did they have an understanding the Australian way of doing things so different from over there (the Philippines)? (Shiraz, aged care teacher in the Philippines)

The syllabus we had and all the learning outcomes and the projects that you were given was for Western Sydney (Australia), with a brick veneer house and the suburban dream ... so we actually had to make sure that we were going to prepare them (students) for possibly working in Australia. (Sean, architecture teacher in Iran)

However, both of these teachers reported that the students' prior knowledge was not always helpful in their understanding of the intended curriculum because the way that older people are cared for in the Philippines, or the way houses are designed in Iran, is different compared to Australia. Shiraz and Sean realised that they needed to teach the students about certain Australian values and practices before they could learn the curriculum content. The following examples illustrate why they perceived it was important to help their students learn about the Australian way of life:

There was a cultural difference in how they [students] viewed aged care. It was a huge thing because older people are part of the family and the younger 
people become their mum and dad [in the Philippines] ... saying what's good for them and what's not good for them and what they will do and won't do.... So that was one of the biggest things because in Australia we have the 'Charter of Rights' for our residents in aged care homes.... They have the right to choose and the right to make decisions, and things like that.... So that was probably the most difficult concept for them [students]. (Shiraz, aged care teacher in the Philippines)

... there was the issue, the cultural issues ... especially the artistic background and the history of architecture within the country [Iran] because they've been isolated for so long and you had some students whose knowledge of the world was very sort of restricted.... So all of a sudden their required knowledge to do this particular course, just went, it doubled for the technical knowledge. (Sean, architecture teacher in Iran)

These accounts reveal that teachers understood that the implicit cultural values imposed by the intended curriculum were not always meaningful for students who do not live in Australia. This finding is supported by other studies that claim that many taken for granted aspects of the Training Packages do not apply offshore (Dempsey, 2012; Dempsey \& Tao, 2017; Shi \& Woodley, 2008). The teachers' stories reveal how important it was for the teachers to assist students to successfully accommodate new learning in relation to the cultural values and related practices embedded in the intended curriculum.

\subsubsection{Student learning styles and preferences}

Similarly to previous research findings in the field (Bailey, 2011; Heffernan et al., 2010; Hua et al., 2011; Shi \& Woodley, 2008; Woodley, 2007) learning styles and preferences were reported as another concern for 11 teachers (as seen in Table 5.1). These teachers reported that many of the pedagogical practices they used, such as student presentations, project work, group discussions, and competencybased assessment, were unfamiliar to many students and their sponsors. As a result, these teachers reported being initially unsure how to adjust their teaching practice given that the students' basis for engagement was so different compared to teaching students in Australia.

Eleven of the teachers were primarily concerned with the disparities in role beliefs and pedagogical expectations between themselves and students. They perceived that many of their students were overly reliant on instruction and rote 
learning, neither of which the teachers favoured. The following statements convey their concerns with students' learning styles and preferences:

I would describe their learning style as rote, behaviourist, teacher comes in, teacher's obeyed. (Mick, business teacher in China)

... the passivity of the students was the most significant factor and their dependence on the teacher, so lack of independence is learnt. (Peter, business teacher in China)

You'd say, "so what do you think, which is your favourite design?" and they would go "I don't know you tell me, you choose" and it's like "no l'm asking you because it's important to have an opinion" and they would just stand there and they wouldn't actually say anything. (Alex, design teacher in UAE)

These statements show that the teachers had expected their students to actively participate in the classroom. Often, these expectations were not met. In some situations, the teachers reported trying to accommodate the students' preferences. However, their prevailing view was to introduce new ways of learning, as Peter explains:

I guess the difference in learning cultures is probably the most significant thing and adjusting, having to adjust my teaching style to acknowledge those differences and gently leading the students through ... to an acceptance that they needed to change ... they needed to change the way they learnt. (Peter, business teacher in China)

All 11 teachers asserted that they actively tried to introduce new methods of learning to encourage their students to take a more active role in their learning and overcome their reliance on rote learning. They stated that they were concerned that rote learning hampered the students' ability to process information, solve problems, complete tasks, and think creatively, laterally, and critically. However, some teachers reported concluding that, despite their best efforts, many students were simply unable to learn certain elements of the curriculum content or achieve outcomes at the prescribed level due to their learning preferences.

As can be seen from the preceding discussion, most of the 13 teachers found it challenging to enact the intended curriculum as they intended because their 
students did not learn in the ways they expected. This finding supports those reported in other studies, as discussed in Chapter 2, where academics and teachers have found it difficult to respond to the learning needs and styles of their students in transnational education (Dunn \& Wallace, 2006; Szkornik, 2017). In situations where students did not respond to their teaching style, teachers appraised them as less likely to achieve certain elements of the curriculum. Their stories reveal the implicit assumptions that teachers made about the pedagogical practices that underpin the Training Package model as a cultural construction and the ways in which their beliefs and values influenced the students' experience of the curriculum.

\subsubsection{Combination of student readiness factors}

The teachers' accounts about student readiness reveal that their expectations of their students as learners were derived from their own experience and beliefs about the ways in which they ought to teach the intended curriculum and how students should experience it (D. L. Ball \& Cohen, 1996). Yet, the preceding analysis demonstrates that teachers experienced key differences in the students' understandings, backgrounds, and bases for engagement compared to those for whom the courses were designed in Australia. Consequently, four significant dissonances were revealed based on the teachers' accounts of enacting a vocational curriculum where the needs and interests of their students had not been considered in development. These were the dissonances between the students' (a) goals and the curriculum intentions, (b) ways of being literate and the dominant literacies required by the curriculum, (c) previous knowledge and the assumed values and beliefs embedded in the curriculum, and (d) learning styles and preferences and the assumed pedagogical practices which underpin the curriculum model. Thus, student readiness factors were found to be a salient concern for teachers because they influenced their capacity to engage students in learning the curriculum content and facilitating their achievement of the learning outcomes.

\subsection{Teachers' experience of situational factors}

The essence of the experience of enacting an Australian VET curriculum in another country for these teachers was found to be one of dissonance between their expectations for curriculum implementation and the reality of their situations. This dissonance was illustrated by five prominent factors that were discussed in the preceding sections of the chapter. These local factors included student readiness, 
institutional arrangements, and the availability of material, information, and resources. In some situations, these factors had a constraining influence and in others an enabling influence. Overall, it was the student readiness sub-factors that accounted for most of the teachers' reported concerns.

While many of the teachers' stories were found to converge around distinct elements of dissonance, the stories about the experience of dissonance diverged. In some contexts, teachers described the situation in positive terms, experiencing many enabling factors. In contrast, other teachers described the experience in negative terms, experiencing many constraining influences. The consequences of these divergent experiences for teachers' decision-making, problem-solving, and curriculum-making are presented and discussed in Chapters 6 and 7.

A summary of the localised factors and their overall role and influence in curriculum implementation are presented in Table 5.2. The first column of the table identifies the five factors. The second column states the role of each factor on the teachers' enactment of curriculum. The third column details the influence of each factor on the teachers' enactment of curriculum.

Table 5.2

Factors, Role, and Influence on Teachers' Enactment of Curriculum

\begin{tabular}{lll}
\hline Factor & Role & Influence \\
\hline Information & $\begin{array}{l}\text { Teachers' understanding and } \\
\text { learning about the situation for } \\
\text { curriculum implementation }\end{array}$ & $\begin{array}{l}\text { Teacher preparedness for enacting the } \\
\text { intended curriculum in another country }\end{array}$ \\
\hline Resource & $\begin{array}{l}\text { Practical support for enacting the } \\
\text { intended curriculum }\end{array}$ & $\begin{array}{l}\text { Means by which teachers could } \\
\text { achieve the curriculum standards }\end{array}$ \\
\hline Material & $\begin{array}{l}\text { Pedagogical support for adapting } \\
\text { the curriculum to meet students' } \\
\text { interests and needs }\end{array}$ & $\begin{array}{l}\text { Means by which teachers could adapt } \\
\text { the curriculum for relevance }\end{array}$ \\
\hline Institutional & $\begin{array}{l}\text { Institutional arrangements in place } \\
\text { to support the implementation of }\end{array}$ & $\begin{array}{l}\text { Defined the structure and shape of } \\
\text { what could be taught (curriculum } \\
\text { content) and achieved (curriculum } \\
\text { standards) }\end{array}$ \\
& the intended curriculum & $\begin{array}{l}\text { Teacher capacity to engage students in } \\
\text { learning the curriculum content and } \\
\text { facilitate their achievement of the } \\
\text { curriculum outcomes }\end{array}$ \\
\hline $\begin{array}{l}\text { Student } \\
\text { readiness }\end{array}$ & $\begin{array}{l}\text { Student readiness for learning the } \\
\text { curriculum content and achieving } \\
\text { the curriculum outcomes }\end{array}$ & \\
\hline
\end{tabular}

As presented in Table 5.2, the five localised factors played a role in the teachers' understanding of the curriculum context, the practical and pedagogical support available to them, and the students' readiness for engaging with the curriculum. All of these localised factors were important because they set the potential and the limits within which the intended curriculum could be enacted by teachers and learnt by students (S. J. Ball et al., 2012; Lauder et al., 1998). 
These local factors, however, were manifested quite differently in each of the settings in which transnational teaching was occurring. For instance, as was shown in the previous discussion on institutional factors, the social and cultural mores in some countries in the Middle East determined one set of institutional arrangements for female students and another for male students. It was also shown in the discussion on resource factors that the broader environment in Fiji determined the types of food that were available for the hospitality curriculum. Thus, rather than being a uniform set of factors, these were experienced differently by teachers across national and cultural contexts. This finding is not surprising given that many other studies have shown that there are significant differences between Australia and the socio-cultural contexts for Training Package implementation in other countries (Bailey, 2011; Bilboe, 2011; Hua et al., 2011; Woodley, 2007).

The influence of these five factors on both the teachers' and the situational readiness for curriculum implementation is also presented in Table 5.2. It shows that the combination of local factors influenced the teachers' readiness for: (a) enacting the curriculum as it was intended, (b) adapting it for relevance, (c) engaging the students in its content, and (d) facilitating their achievement of its outcomes. The findings presented in Table 5.2 also show that the availability and quality of the local antecedent conditions influenced the degree to which the local circumstances comprised a situational readiness for implementation of the curriculum (Corbett \& Rossman, 1989; Stakes, 1977).

It is noteworthy that all five sets of factors were particular to the situation (i.e., those found within the educational setting). While internal factors have been identified as influential in other curriculum implementation studies (Corbett \& Rossman, 1989; Dickie et al., 2004; Fullan, 1982; House, 1996; Mitchell et al., 2006), what differs, in this inquiry, is that the internal factors were found to have far greater influence than external factors. Most other curriculum studies have identified external factors as having the stronger influence because they are usually the ones most out of teachers' control (Fullan \& Stiegelbauer, 1991; Harris et al., 2005). Yet, in this inquiry, it was the internal factors that were found to be the most influential. However, the reasons these internal factors were the most important for teachers in this inquiry were precisely for which other studies have found external factors to be the most important. That is, these factors were often out of the teachers' control. Therefore, what was of central concern to the teachers in this investigation was their capacity to influence the internal factors associated with curriculum implementation. 


\subsection{Summary and conclusion}

This chapter presents the first part of the inquiry's findings. It has discussed the constraining and enabling factors that influenced the implementation of the intended curriculum as experienced by the 13 informant teachers. Five sets of localised factors were identified through the convergence of emergent themes: (a) information, (b) resources, (c) material, (d) institutional, and (e) student readiness. In some cases, these factors were enabling and, in other cases, constraining. The conception of dissonance associated with enacting transnational education often arose for these teachers as a result. This was a product of the combination of factors that provided a structuring of what they experienced and had to address. It shaped their sense making about the situation for curriculum implementation.

Dissonance emerged when teachers tried to apply their existing schema of curriculum implementation in Australia to their new situation, only to find incongruity. Consequently, their prior conceptions, knowledge, and practices were challenged. Indeed, it was shown in many instances that the challenges associated with fidelity to the intended curriculum and achieving equivalency in their practice were fraught with incommensurability. Therefore, what was of central concern to the teachers in this investigation was their capacity to influence the local factors associated with curriculum implementation.

The findings advanced and discussed in this chapter about the localised factors that influence curriculum implementation serve as a useful reminder that Training Packages, with their implicit epistemological and pedagogical orientations which differ from those found in other countries, are culturally bound to Australia. Such reminders are important for understanding that the cultural values imposed by the curriculum model in other countries are not always mutually understood or meaningful between teachers bound to the model and their students. Indeed, as reported in other studies (Bilboe, 2011; Heffernan et al., 2010; Moran \& Ryan, 2003; Shi \& Woodley, 2008; Woodley, 2006, 2008), many of the factors that frustrated the teachers the most, emerged from having to enact a curriculum that was not developed with the students' needs, abilities, goals, and interests in mind. The teachers' accounts also support Dempsey and Tao's (2017) claim that there needs to be a greater focus on negotiating, developing, and adapting Training Packages for international provision, as well as providing teachers with the professional and material support to interpret and apply them. Indeed, highlighting these teachers' experiences supports Tran and Le's (2017) finding in regard to the importance of professionally preparing and supporting teachers for situations that are substantially 
different from what they are used to in Australia. In particular, it shows that teachers would have benefited from the provision of detailed information, customised inductions, and ongoing professional development to assist them to develop new knowledge and skills for developing and using materials in enactment.

The findings also question the capacity of some sponsors to adequately support the implementation of Training Packages. In many instances, these teachers were, to varying degrees, critical of the curriculum implementation processes. Based on the teachers' accounts there were key differences in the teaching and learning experiences offered to students offshore compared to Australia. Hence, it is critical that Australian educational institutions negotiate with sponsors to ensure that antecedent conditions are in place for teachers to enact the curriculum as intended and that gaps between the curriculum requirements and institutional arrangements are monitored. Otherwise, it is not possible for teachers to achieve equivalence with Australian standards through their practice.

In conclusion, the findings analysed in this chapter reveal the challenges associated with teachers enacting in one country a vocational curriculum designed for another. It was shown that even though situational factors were not accounted for in the development of the intended curriculum (Fullan, 2007; Fullan \& Pomfret, 1977), they still influenced enactment in different ways in different locations (S. J. Ball et al., 2012; Hlebowitsh, 2005; Spillane et al., 2004). The identification of five factors and their influence on curriculum enactment as shown in Table 5.2 provides the basis for understanding the importance of providing teachers with the knowledge, skills, and means to enact a relevant and quality educational experience for students. These findings indicate that it is simply not possible for teachers to meet the standards set out in Australian Training Packages in another country without the opportunity to learn about the situation, adapt the curriculum so it is relevant, learnable, and achievable for transnational students, and influence the range of situational factors associated with implementation. 


\section{Chapter 6 \\ The influence of situational factors on teacher decision- making and problem-solving in Australian transnational VET}

This chapter proposes that it is not possible for teachers to enact a curriculum designed for one country, in another, without the capacity to mediate and influence the range of situational factors associated with its implementation. Moreover, without adequate preparation and support for an extended educational role to make decisions and solve problems, there are factors that cannot be addressed by teachers and for which they cannot be held accountable.

This chapter presents the second set of the inquiry's findings. It discusses how the situational factors, reported in Chapter 5, influenced the teachers' decisionmaking and problem-solving during their transnational enactment of the curriculum. The chapter commences with an overview of the four main approaches to decisionmaking and problem-solving as reported by teachers: (a) reactive, (b) practical, (c) interactive, and (d) subjective. In subsequent sections, each approach is discussed in relation to the concepts elaborated on in Chapters 2 and 3. Finally, the teachers' experience of decision-making and problem-solving is analysed as a response to the apparent dissonance between the curriculum intentions and circumstances for enactment.

The influence of situational factors on teachers' decision-making and problem-solving approaches, as frequently reported by informants, is supported by a sample of quotes of the terms, phrases, and statements they used. It is important to acknowledge that the findings that are discussed represent the concerns of teachers and may not be shared by other actors. However, given that this inquiry seeks to interrogate curriculum implementation from a phenomenological perspective, the focus of the analysis here is to understand the teachers' experiences of decisionmaking and problem-solving across a number of countries. Their perspective helps identify the key indicators of teacher success in the enactment of the intended curriculum in transnational vocational education.

\subsection{Teacher decision-making and problem-solving}

Chapter 3 established that curriculum enactment can be conceived as a series of problems and dilemmas that teachers have to resolve (Katz \& Raths, 1992; Lampert, 1985; Windschitl, 2002). Dilemmas and problems force teachers to decide 
amongst alternatives and to take action in response to the factors present in their situation (Lampert, 1985; Taba \& Spalding, 1962). The ways in which teachers make these decisions have been described in the literature as intuitive, analytic, deliberative, practical, reflective, and emotional. Given that one of the goals of this dissertation is to reach a better understanding of teachers' decisions in the enactment of Training Packages in another country, this chapter reports on the influence of the five local factors, as reported in Chapter 5, on the informants' decision-making and problem-solving.

The analysis of the interview data reveals that teacher decision-making and problem-solving was driven by the teachers' desire to overcome the mismatch between the curriculum intentions and the circumstances for enactment.

Furthermore, it reveals that in situations of dissonance, teachers utilised four main approaches to decision-making and problem-solving. Table 6.1 provides a summary and explanation of these approaches. In the first column the four approaches are listed: (a) reactive, (b) practical, (c) interactive, and (d) subjective. In the second column each approach is explained.

Table 6.1

Summary of Teachers' Decision-Making and Problem-Solving Approaches

\begin{tabular}{ll}
\hline Approach & Explanation \\
\hline Reactive & $\begin{array}{l}\text { Teachers' decision-making was reactive because they were initially } \\
\text { unprepared due to a lack of local knowledge and experience, influence, and } \\
\text { time to solve the multiple and overlapping problems they faced under } \\
\text { pressure. }\end{array}$ \\
Practical & $\begin{array}{l}\text { Teachers' decision-making and problem-solving was often practical because } \\
\text { their appraisal of the factors in the situation led them to try to resolve } \\
\text { discrepancies amongst the intended, implemented, and experienced } \\
\text { curricula through resourcefulness and trial and error. }\end{array}$ \\
Interactive & $\begin{array}{l}\text { Teachers' decision-making and problem-solving was, at times, interactive } \\
\text { because they needed to gain the support of Australian stakeholders to } \\
\text { enforce standards, and of local stakeholders to address the situational } \\
\text { factors outside of their control. }\end{array}$ \\
& $\begin{array}{l}\text { Teachers' decision-making and problem-solving was often subjective } \\
\text { because it was framed by their own interpretations and judgements of the } \\
\text { situation and what they thought was in the best interests of their students. }\end{array}$ \\
\hline
\end{tabular}

The decision-making and problem-solving approaches brought together in Table 6.1 were used by teachers at different times and in different combinations to solve particular types of problems and dilemmas about enacting the curriculum in their transnational teaching situation. However, teachers reported using the reactive approach more frequently when they first arrived overseas because of their unfamiliarity with the situation. Over time, they were able adapt their decision-making 
and problem-solving approach and use a practical or interactive approach depending on the types of challenges that they confronted. However, most of the time these approaches were also found to be subjective because they were framed by the teachers' own interpretations and judgements about the situation. Sometimes, teachers reported these decision-making and problem-solving approaches as successful. At other times, they were not successful, as how the teachers made choices, exerted influence, and took stances in curriculum enactment was subject to the institutional structures, rules, culture, and relationships (Allen, 2002). The next four sections elaborate on each of the decision-making and problem-solving approaches reportedly used by teachers, as summarised in Table 6.1, followed by a discussion of their experience of these approaches.

\subsection{A reactive approach to decision-making and problem-solving}

Teachers reported that their decision-making offshore was often reactive, especially in the initial phase of their experience in teaching overseas, because there were so many competing and constraining factors present in the situation over which they had little control. Furthermore, their capacity to use other, more effective modes of decision-making at this time was shown to be constrained by: (a) their inexperience (D. L. Ball \& Cohen, 1999; Spillane et al., 2004), (b) a lack of local knowledge (Clarke \& Hollingsworth, 2002; Penuel et al., 2007; Spillane et al., 2004), and (c) time (Eraut, 1997, 2000). Indeed, it was reported that in many instances, the teachers' readiness to make informed decisions and to solve problems was limited, as they believed they were inadequately prepared for enacting the curriculum when they first arrived overseas.

Reactive decision-making was shown to be the most pronounced for the 10 teachers who were novices (i.e., who had not taught offshore before and had not received adequate information about the local situation). These teachers expressed that decision-making in another country was "totally different to Australia" and was significantly more challenging because they were so "unfamiliar" with the situation. Peter explains that he was "much more reactive" in his decision-making in China compared to Australia because there were so many more demands placed on him. Many teachers described their initial experience of teaching in a new country as being "thrown in the deep end" and having to either "sink or swim". For example, Mary reports that she was more "certain in decision-making in Australia" because she "got the cultural context" and, in comparison, felt "unprepared and naïve" making decisions in China without local knowledge and experience. These teachers also 
discovered that they could not rely on intuitive decision-making (Eraut, 1997, 2000) because their past experience in Australia was not always relevant or appropriate in another country. Sam states that if he had known about some of the cultural norms, such as "saving face", "male-female relationships", and "dealing with hierarchy", then he may have made better decisions when he first arrived in Vietnam. These findings indicate that a lack of information also constrained the teachers' capacity to make analytic decisions in a new situation (Clarke \& Hollingsworth, 2002; Eraut, 1997, 2000; Penuel et al., 2007; Spillane et al., 2004). Thus, it can be seen that teachers perceived their decision-making as reactive because they could not rely on intuitive or analytic modes of decision-making to make informed decisions in unfamiliar situations.

Teachers reported that reactive decision-making was also a consequence of their inability to influence the competing and constraining factors that created many of the complex problems and dilemmas that confronted them. Most teachers claimed that curriculum implementation was rarely straightforward because of the dissonance between the intended curriculum and how it was supported by the host institution. Ten teachers spoke candidly about feeling "overwhelmed" by their inability to solve the problems they faced in relation to inadequate information, resources, materials, and arrangements. Mick describes how all these constraining factors added up to become a problematic situation:

I wouldn't say that a lot was working. I'd say it was pretty difficult.... Our textbook system was totally out ... there were no resources ... these students don't know enough English to be able to talk to them ... the size of this class. There were all these dilemmas. (Mick, business teacher in China)

In this quote, Mick conveys the challenges of trying to enact the intended curriculum in less than ideal conditions. His experience reflects Windschitl's (2002) contention that it is the intersection of dilemmas that presents the greatest challenges for teachers. Mick claims that it was difficult to overcome these problems and solve dilemmas because there was "no time to sit down and reflect on what to do" and make "strategic changes" to improve the situation. Alex likens the process of reactive decision-making in these situations to "basically, bushfire putting out". He claims that when "you've got demands it was just like deal with what was the most urgent on the day and there was always about three things all happening at the same time". In these situations, these teachers report that they were making reactive decisions because there were so many demands all competing for their attention. These 
findings show that many teachers often reacted to the demands placed on them because they did not have time to engage in reflective practice (Duncan-Andrade \& Morrell, 2008; Stenhouse, 1975) that would have enabled them to research the problems and develop a plan to overcome them in a systematic way. As Mick remarks, "it created an environment of urgency rather than reflectiveness".

The preceding discussion shows that the teachers' decision-making was often reactive in the initial phase of their experience due to the combination of constraining factors that caused a problematic situation that they did not fully comprehend (i.e., complexity of the problem). The pressure and dynamics of the situation also appeared to foster on-the-spot decision-making. Consequently, teachers reported that the quality of their decision-making to effectively solve problems was at times compromised by their lack of understanding about the situation (i.e., situational awareness). It was the teachers' frustration and dissatisfaction with this initial approach to decision-making and problem-solving that motivated them to learn more about the situational factors and how to overcome them practically as time progressed (i.e., become curriculum-makers).

\subsection{A practical approach to decision-making and problem-solving}

It was found in all instances that these teachers' decision-making and problem-solving was practical. They adopted a practical approach because their appraisal of the factors in their situation (Doyle \& Ponder, 1978; Schwab, 1978) led them to resolve problems through resourcefulness and the practice of trial and error in the classroom. Indeed, even in the most chaotic situations, teachers still reported making practical attempts to overcome the constraints, rather than ignore them. Mick explains that "given the difficult conditions" he "needed to be pragmatic and expedient in solving problems".

Practical action was shown through: (a) appraisal, (b) resourcefulness, and (c) trial and error. Firstly, these teachers demonstrated what Doyle and Ponder (1977) refer to as the "practicality ethic" by appraising the situation and making decisions about the extent to which the curriculum was congruent with it, as Mick explains: "I had to analyse the situation and figure out what's going on here". The teachers also compared the situation to their experience in Australia. They considered this comparison as a critical component of their appraisal, as they were cognisant of the regulatory requirements to enact the curriculum in accordance with "Australian standards"; as Jo explains, he "held the Australian standards as a benchmark" and was "trying to align it with my experiences back home". Throughout 
the comparison these teachers were searching for congruence (Doyle \& Ponder, 1977; Stakes, 1967) and looking for consistencies and discrepancies (Print, 1993). These teachers were shown to perceive discrepancies as the differences between their interpretation of the reality of the situation and their idealised state (Print, 1993). The highest discrepancy factors were judged to be the most significant and informed their priorities for action. These priorities were dependent on how the different factors came together and manifested in each situation, as discussed in Chapter 5. However, a common concern for the teachers related to overcoming the practical problems caused by the absence of many antecedent conditions; that is, the conditions, such as resources, materials, and institutional arrangements, that existed prior to the teaching and learning, and related to their ability to achieve the curriculum outcomes as intended (Stake, 1967). Consequently, many of them reported that their priorities required practical action, such as: (a) accessing and organising resources to support both the theoretical and practical elements of the curriculum, (b) arranging the work-based curriculum experiences, and (c) locating materials to teach the curriculum. Their expressed concern was to decide on the actions they needed to take to overcome the constraints that they believed prevented them from enacting the curriculum as it was intended.

Secondly, the teachers' practical approach to decision-making and problemsolving was demonstrated through their resourcefulness. The teachers' endeavours to address the priorities they identified in their appraisal led them to actively search for information, resources, materials, and other opportunities to overcome constraints. Teachers brought up a number of examples that demonstrated their resourcefulness in improving the conditions and standards of curriculum implementation. In China, the teachers claim they resolved resource problems by buying printers, stationery, and books for themselves and/or their students. In Fiji, Damien states that he improved the standards of the teaching environment for the enactment of the hospitality curriculum by repairing furniture and equipment. He also claims he travelled long distances every weekend to purchase the food and wine that he needed to teach the students the required cookery skills. Three teachers in the Middle East also provided accounts of how they organised student excursions and guest speakers to make up for the lack of work-based arrangements. Most teachers also gave descriptions of accessing materials from colleagues and the Internet in an effort to make their teaching relevant to the context and engaging for students. It can be seen from these examples that teacher resourcefulness played an important role in addressing the problems caused by inadequate information, resource, material, and institutional arrangements. 
Thirdly, teachers demonstrated a practical approach to overcoming the student readiness factors through the trial-and-error method of problem-solving in the classroom. In Chapter 5, it was proposed that teachers experienced key differences in the students' understandings, backgrounds, and bases for engagement compared to those they taught in Australia and other countries. Without adequate information and materials to teach these students, teachers reported that their efforts were not always as effective as they hoped, as Sam explains:

... the way we were delivering the first couple of days was not engaging, plain and simple ... we could see it in their faces. (Sam, hospitality teacher in Vietnam)

Therefore, they learnt how to teach these students through the practice of trial and error, as Mary states:

It just meant that when I made a decision about something in China it was about saying, "OK well that worked for the students. How's that working? It's not working. Okay, I'm going to change it and move onto the next thing". So if I didn't hit the mark, which happens, then you'd just go "Okay, I'm going to have to change that and make it a bit more interesting or a little bit different". (Mary, business teacher in China)

Mary's account shows that the trial-and-error approach was characterised by repeated attempts to find a baseline solution that could then be improved over time. However, many teachers reported frustration with the process because it was not always successful, as Alex notes:

Like if it's [teaching] not working you've got to try a different approach. Or if you didn't get results as high as you were hoping you'd think about well how could I do it differently next time ... it was pretty frustrating. (Alex, design teacher in UAE)

Some of the teachers experienced less success with the practice of trial and error than did others. For instance, Mary remarks, "I don't know that I hit the mark, necessarily all the time". Mick simply states, "I wouldn't say a lot was working" and Jo bluntly described the practice as "second rate". Some teachers also explained that local factors still placed limits on what they could try out, as Mick illustrates: 
So if you've got 60 students in a small classroom you revert back to behaviourism, talk and chalk, lecture because you don't have any options. (Mick, business teacher in China)

Other teachers noticed gradual improvements from the practice of trial and error, as Annabel states:

... over time it's much better now ... you've been through a trial period for a semester, you see what works, doesn't work, you get ideas... (Annabel, project management teacher in UAE)

It can be seen from these examples that teachers persevered with the practice of trial and error to learn the most successful ways of responding to the different needs, abilities, and interests of students.

The preceding discussion indicates that teachers appraised the merit of the curriculum proposal based on the extent to which they perceived that they could practically enact it (Doyle \& Ponder, 1977). Teachers used the discrepancies they identified from their appraisal as a basis for taking practical action. Practical problemsolving was characterised by resourcefulness and the practice of trial and error. In many instances, it was shown that the teachers' practical action helped to overcome the constraints in their specific situation (Schwab, 1978). However, there were also many problems that the teachers claimed they could not resolve through their own practical actions alone because many local factors remained outside their control. For example, Jo needed access to an electronics laboratory to teach the technical elements of the electro-technology curriculum and Alex needed computers to teach graphic design skills. To overcome these types of problems the teachers' goal became to interact with and enlist the support of stakeholders. That is, they had to adopt an interactive approach to decision-making and problem-solving.

\subsection{An interactive approach to decision-making and problem-solving}

Teachers' decision-making and problem-solving was, at times, found to be interactive because they wanted to enlist the support of: (a) Australian stakeholders, to help enforce curriculum standards in implementation; and (b) local stakeholders, to influence those factors that were outside their control. All the teachers stated that they expected that stakeholders would be willing to engage in a discussion about the intended curriculum and develop solutions for problems in its implementation 
(Walker, 1971). Some of the teachers reported that these expectations were met. However, other teachers claimed that some stakeholders would not even engage with them, which adversely impacted on their capacity to address the priorities they had set for themselves on the basis of their appraisal of the situation. Thus, similarly to the findings of Priestley et al. (2015), the quality of these teachers' relationships within the institution had considerable influence on their capacity to solve problems and provide experiences that were faithful to what was intended.

Three of the teachers reported satisfaction with their interactions with Australian stakeholders, although they conceded that they did not need to interact with them very often because they were able to solve most of their problems at the local level. In contrast, 10 other teachers expressed frustration and dissatisfaction with their interactions with Australian stakeholders. These 10 teachers claimed that the responses from Australian stakeholders ranged from "uninterested" to "hostile" and that most of their requests to solve problems were ignored. Jo reports his experience trying to interact with the Australian stakeholders to help him secure the resources he needed to enact the electro-technology curriculum:

I didn't get any help at all from (Australian stakeholders).... Most often the emails I sent were ignored or came back weeks later with no real information ... I couldn't achieve the outcomes ... I couldn't achieve the Australian standards. There's no way in the world that I could achieve that. (Jo, electrotechnology teacher in China)

Jo's statement shows the importance he placed on engaging Australian stakeholders to assist him to achieve the curriculum outcomes and standards. Sean also considers that the involvement of Australian stakeholders was critical in assuring that Australian standards were achieved in Iran. He explains that he had requested his colleagues back in Australia to work with him to validate and moderate the students' completed assessments, but that they refused. Without their support, Sam eventually decided to resign because he was not prepared to make all the assessment decisions on his own, as he reports:

... in the end it got too much for me, It was the lack of support and the antagonism ... I just said, "I can't do it here (Iran) all by myself and take all the responsibility". (Sean, architecture teacher in Iran) 
The shared experiences of these two teachers indicate that their interactive decisionmaking was primarily aimed at involving Australian stakeholders to realise wider support for enforcing the curriculum standards offshore. Further, without this support they believed that they were unable to achieve those standards.

In most instances, the teachers' interactions with local stakeholders took precedence in problem-solving because they were seen as having the greatest influence over many of the factors that were out of the teachers' control. However, teachers reported key differences in the quality and scope of their interactions and relationships with local stakeholders. At one end of the spectrum, seven of the teachers recounted successful interactions that led to resolving curriculum problems, as these examples illustrate:

I think because the powers to be were very interested in making it work. I was able to make it work and there was support there. (Rowena, education teacher in South Pacific)

The really good thing about being in a situation like that, you would basically meet the program managers and talk about some of the issues ... who fortunately was on a similar wavelength to me in most cases, and so that made that process relatively easy for me to do. (Steven, management teacher in PNG)

As foreshadowed in Chapter 5, Steven also claimed that many problems were also avoided in curriculum implementation because he had the opportunity to "negotiate the program upfront" with the local sponsors so that it was relevant to the local context. These interactions helped Rowena and Steven to solve problems and also helped to increase their understanding of the context for implementation and the needs of their students.

At the other end of the spectrum, seven teachers reported that many issues could have been simply resolved if the local stakeholders had been willing to negotiate and deliberate with them (Schwab, 1983). These teachers claimed that their attempts to interact with local stakeholders were not appreciated because teachers were not expected to question local norms (Campbell, 2012). For example, Jo claimed that he was labelled as a "trouble-maker" after he met with local administrators to discuss reorganising the timetable so it aligned with the mandated curriculum requirements. Compared to the other teachers who were working overseas for brief intervals of time in small private colleges or workplaces, these 
seven teachers were permanently located in large-scale educational institutions. In these settings teachers reportedly learnt about the power-coercive messages and rules that served to constrain their interactions and their capacity to exercise agency beyond the classroom (Coburn, 2004). Annabel summarised these rules as: "Teach. Follow the rules. Don't rock the boat.... Keep it under control". Some teachers claimed that they were unaware of the rules or the consequences of breaking them at first because they were not informed about them. Consequently, it was only through their interactions with local stakeholders that they said they came to realise that some of these rules contradicted the curriculum intentions and they were not permitted to discuss them (Fullan, 2008; Spillane et al., 2004). For example, Rachael reports that the Events Management curriculum required students to manage real events in the workplace. However, these arrangements were not put in place for female students in Kuwait due to cultural norms. Rachael asserted that it was only through her interactions that she realised teachers had no influence over these arrangements and so could not teach the curriculum as it was intended. So, there were times that teachers claimed that they could only work within the limits of what was practically and politically possible. This was when they could not deliberate with local stakeholders to make the changes that were necessary to meet the mandated requirements of the curriculum.

It can be seen from these teachers' accounts that they expected to interact with stakeholders to help them influence those local factors that they considered were outside of their control and an impediment to achieving the curriculum standards in implementation. The findings suggest that, in most instances, there was little interaction with or responses from Australian stakeholders. Consequently, the most influential interactions were those with local stakeholders. However, the differences in the quality of those relationships appear to have been predicated on stakeholders' perceptions about the role of teachers in curriculum implementation, which differed from country to country. Thus, the differences between the teachers' experiences of these interactions were shown to be rooted in the cultural and social structures of the local institution and the power relationships within them (Priestley et al., 2012). These structures and relationships were found to shape the teachers' capacity to influence those local factors that were out of their control. Moreover, many of the rules they learnt from these interactions became another barrier to effective decision-making and problem-solving. It is contended that the effectiveness of teacher decision-making and problem-solving to enact the curriculum as it was intended was significantly influenced by the quality of their interactions with 
stakeholders. This then led to their decision-making becoming increasingly subjective.

\subsection{Subjective approach to decision-making and problem-solving}

Teacher decision-making and problem-solving was found to be subjective because it often involved the teachers' interpretations, judgements, and discretion. Decision-making was framed by teachers' interpretations and judgements of the situation and what needed to be done to overcome the dissonance between the intended curriculum and the circumstances for enactment. Even in the most controlling situations many problems were found to be solved through teacher discretion.

Decision-making was shown to be subjective because teachers interpreted the circumstances for enactment based on their own appraisal of the situation, often without information (as discussed previously in Section 6.3 about practical decisionmaking and problem-solving). These appraisals were reported as self-initiated and informal. In 10 instances, the teachers could only rely on their observations and interactions, as they were not provided with any other information or data about the situation. On the basis of their interpretations, the teachers were shown to form their own set of judgements to explain the differences between their perceived reality of the situation and their idealised version of how the intended curriculum should be enacted. Rowena's statement is reflective of the subjectivity of the teachers' judgement of the situation and the actions that she intended to take:

This is what I see. This is what needs to be done. This is what I have to cover. This is how l'm going to do it.

Notably, the teachers' interpretation of the intended curriculum was also subjective depending on their past experience, as Jo's statement indicates:

I've sort of got a basic framework or concept of how I think it should be, my understanding of the Training Package and the knowledge and skills in it, my understanding of how people learn ... so I guess that's the basis behind all of the decision-making...

While teachers perceived themselves to be making judgements based on the criteria of curriculum standards, their interpretation of these standards was also 
subjective as it was based on their own experience. For example, Jo states that in hindsight he realised that the cognitive benchmarks he set for determining fidelity and equivalence were "probably a hindrance" because it meant he formed "an artificial standard, which just wasn't applicable" in China. He reflected that it might have been easier for him if he had just focussed on what was practically possible rather than ideally possible. As other studies attest, his account reflects the difficulties that transnational teachers have reported when trying to understand what equivalence means and how to apply it without any guidelines (AEI, 2007; Shi \& Woodley, 2008; Woodley, 2008).

Teachers' subjective judgements about what constitutes equivalence were also found to influence their perceptions of the student readiness factors. For example, without taking in a range of information such as student records or feedback, some teachers judged that many transnational students were not at an equivalent level of ability to Australian students. Alex's opinion reflects the view of many teachers:

... the standard was just nowhere near what I would expect from a first-year student in Australia to a first-year student here. (Alex, design teacher in UAE)

Teachers reported making these decisions about the "standard" of their students based on their observations and interactions with them in the classroom. Often, these judgements were shown to be negatively biased in the domains of knowledge, learning, and language, as reported in Chapter 5. Thus, some teachers were applying the principle of equivalence not only in relation to resources, materials, and arrangements, but also to students' differential abilities. Teachers reported that as a consequence of their judgements they set out to "rectify" these perceived deficits by teaching the students Western styles of learning, because as Peter explains: "they needed to change the way they learnt". Thus, the teachers' appraisal of the student readiness factors influenced their approach to enactment, which subsequently meant that students were subject to unfamiliar learning and teaching methods.

The subjective quality of teachers' judgements was also apparent when they came to solving the dilemmas that emerged from the dissonance between the curriculum intentions and the circumstances for enactment. Across countries, different dilemmas emerged on a daily basis for teachers. They reflected a continuum of subjective concerns of teachers at one end, through to the political realities of the situation at the other end (Windschitl, 2002). Many of these dilemmas involved teachers having to choose between fidelity to the curriculum and responding 
to the students' needs or the local rules. For example, they had to decide whether to allow students to speak in their own language or English in the classroom. In another example, they had to decide whether to break an institutional rule or a curriculum rule. One dilemma, experienced by many teachers, lies at the heart of this inquiry: that is, the dilemma of passing or failing students when the constraints meant that certain elements of the curriculum could not be taught. Mick expresses the dilemma in the following way: "You as a teacher are put in a situation where how do you fail whole cohorts?" This dilemma was most pronounced for the seven teachers who reported the greatest number of negative influences on curriculum implementation. They judged that a lack of situational readiness meant that students were set up for failure, as Jo said: "the way it was set up, there's no way they [students] could achieve the same standard as in Australia". These teachers claimed they were in a no-win situation because, in their opinion, so many of their students were not at the "level they could teach them". Seven of the teachers admitted that the main way they resolved the dilemma of failing or passing students was by making a subjective decision to set their own minimum standards of acceptability, as Mick explains:

I had to dumb it [curriculum] down. I had to ... I was constantly trying to simplify it and bring it down to some level at which the students could actually do an assignment on. (Mick, business teacher in China)

Such decisions have far-reaching implications and are discussed further in Chapter 7 , which looks at the way in which the teachers' decisions in curriculum-making transformed the curriculum. However, this quote from Mick reflects the extent to which discretion was exercised by teachers in resolving dilemmas.

All the teachers rated discretion as important because they considered themselves as the key experts in the curriculum implementation process (Rahimi \& Smith, 2017). Steven sums up the prevailing view as: "You're the expert you run it the way you want to." Peter explains that it was also necessary because he believed he had a better picture of what needed to be done to overcome the constraints because:

It's just that the Australians aren't there, so they've got no idea really, and then the Chinese don't really have any idea because they've never been exposed to an Australian way of doing things. (Peter, business teacher in China) 
However, there were discernible differences in how teachers were able to exercise their discretion. The seven teachers who reported positive interactions with local stakeholders were the same ones who reported that they could exercise discretion with ease because they had local support for an extended scope of role. These teachers claimed that the "support was there from the local people" who "trusted teachers' judgements" and treated them with "respect" because these sponsors held the role of the teacher in curriculum implementation in "high esteem". In contrast, the six teachers who reported disappointment with their interactions with the local stakeholders also claimed that "not a lot of autonomy was given for freedom" and that as "foreign teachers" they were treated with "suspicion". It appears from the accounts of these teachers that they learnt about the constraints on their agency through the unspoken academic, social, and cultural messages that they received from local stakeholders (Glatthorn, 2000; Jackson, 1968). Mick sums it up this way:

There's always the overhanging threat, you know they'll give you as much rope as you want to hang yourself with. (Mick, business teacher in China)

These teachers claimed they learnt about the "threat" through the stories that circulated amongst the teaching staff about foreign teachers "being sent home" for contesting or breaking the local rules. They interpreted these stories as cautionary tales, as Rachael reports:

He (teacher) got the sack funnily enough.... It was a lot of back door stuff. That's why you're just better not saying anything. Keep your mouth shut. (Rachael, Events Management teacher in Kuwait)

As can be seen in Rachael's statement, teachers subjected to these power-coercive messages learnt that it was better not to interact with local stakeholders to resolve problems. However, it did not prevent them from exercising discretion in private, as Rachael explains:

... you're making your own decisions all the time ... you could take it further if you wanted but you could actually deal with it in the classroom ... you actually manage it better than that ... so you just do it within your classroom.

(Rachael, Events Management teacher in Kuwait) 
Rachael's explanation reveals that in situations of low trust and high control, teachers still chose to exercise discretion and subvert these controls by maintaining an outward illusion of compliance, while making the changes they deemed necessary to pursue their own priorities within the classroom (Apple \& Jungck, 1990; Scott, 1990). This approach also helped them to avoid adverse consequences from their actions (Scott,1990).

The findings presented above highlight the subjective nature of the teachers' approach to decision-making and problem-solving as they relied on their own interpretations then used their discretion to act on their judgements. It was found that these teachers learnt to trust their judgements over those of stakeholders.

Consequently, the decisions they made in curriculum enactment appear to have been influenced not only by the situational factors and the support afforded to them through their interactions but also by their own experience, beliefs, goals, and priorities (Scott, 1990). These findings suggest that these teachers used their discretion to support or subvert the curriculum intentions and/or the institutional rules at different times to achieve their own priorities based on their assessment of the situation and the students' needs (Apple \& Jungck, 1990; Sonu, 2012). That is, they exercised discretion in problem-solving and decisions about the enactment of the curriculum.

\subsection{Experience of teacher decision-making and problem-solving}

The five situational factors advanced in Chapter 5 influenced these teachers' experiences of decision-making and problem-solving. While each factor had specific influences, taken together they determined the experience of decision-making and problem-solving for each teacher. The impact of these factors was reported by teachers as giving rise to a diverse range of problems in their enactment of the curriculum. The teachers' accounts show that they were aware of the dynamic and complex nature of decision-making and problem-solving in these situations.

The findings reported in this chapter reveal that curriculum enactment was experienced by teachers as a series of new and unfamiliar problems and dilemmas that arose from the dissonance between the curriculum intentions and the circumstances for enactment. Indeed, it was shown that many of the dilemmas that teachers faced emerged from the experiences that prevented them from enacting the curriculum as they idealised. Thus, they were forced to examine their prior conceptions and knowledge about the curriculum and how it should be implemented.

All the teachers were shown to take action to overcome dissonance. They tried to resolve problems through understanding the situational factors and 
addressing the gaps between the intended and available curriculum. Dissonance was an opportunity for them to demonstrate their resourcefulness and apply their professional expertise. However, the teachers' interpretive skills were reported to be constrained by their lack of experience and knowledge and they, therefore, would have benefited from professional guidance and support. Such opportunities would have helped teachers to better understand their situation and exercise their professional judgement.

Dissonance afforded an opportunity for the development of resourcefulness and innovation; however, it also led to conflict. Teachers experienced conflict between having to abide by the rules of one country - by meeting Australian regulatory requirements - as well as the rules of the institution. The teachers' stories reveal that, in many instances, they tried to resist the limitations and expectations placed on them by local stakeholders. The boundaries set on teachers' agency (Allen, 2002), in some instances, affected the type, extent, and quality of the changes that teachers wanted to make to improve the situation. Therefore, the level of control placed on teachers was found to have a significant bearing on their experiences of decision-making and problem-solving.

The capacity of these teachers to influence the situational factors was shown to be relational to the quality of stakeholder relationships. The teachers came to believe that the way that stakeholders responded to their requests was dependant on their own interpretation of the situation, the curriculum, and the role of the teacher in implementation. Teachers' reports of their experience interacting with stakeholders diverged. In instances where stakeholder relationships were reciprocal, teachers were able to draw upon the relational resources afforded by their networks (Priestley et al., 2015). In contrast, where stakeholder relationships were reported as discorded, teachers were less able to influence the range of factors. Highlighting these divergent experiences reveals the importance of stakeholders supporting an extended scope of role for teacher decision-making and problem-solving in curriculum implementation offshore. It suggests that if teachers can interact collaboratively with stakeholders then many of the factors constraining implementing the curriculum as intended can be overcome. On the other hand, if such interactions are not supported then there are many factors that teachers cannot address and, thus, cannot be held accountable for when the curriculum is not implemented with fidelity or with equivalence to Australian standards.

Overall, the findings reveal that there were two dimensions to the teachers' experience of decision-making and problem-solving in this investigation. Firstly, the local factors together with the teachers' prior teaching experiences largely 
determined their initial experience. As a result, all the teachers experienced dissonance between the knowledge and skills they brought to the situation and their expectations for curriculum implementation. However, their success in resolving this dissonance was dependant on the relational conditions and this is where the teachers' experiences were shown to diverge. In some situations, the teachers described the process in positive terms, experiencing success in influencing the factors associated with implementation. In contrast, other teachers described the experience in negative terms because they were unable to overcome many of the constraints. The consequences of these divergent experiences in relation to curriculum-making are discussed in Chapter 7.

\subsection{Summary and conclusion}

This chapter has presented the second part of the inquiry's findings. It has discussed the teachers' experience of decision-making as a response to the dissonance between the curriculum intentions and the circumstances for enactment. The process of decision-making was frequently expressed as reactive, practical, interactive, and subjective. The experiences of the teachers reveal the challenges associated with teachers making decisions and resolving problems in situations that are substantially different from what they are used to in Australia. Teachers recounted facing many new and unfamiliar problems and dilemmas. The central concern of teachers was to learn how to effectively overcome the problems associated with their experience of dissonance. Many of the teachers' stories were found to converge around distinct elements of decision-making. For example, many described the dynamics of the situation and how they had to react under pressure with little preparation. In other instances, the teachers' stories of decision-making diverged. Some teachers described the decision-making and problem-solving in positive terms, experiencing a great sense of achievement from overcoming constraints through resourcefulness, the practice of trial and error in the classroom, and interacting with local stakeholders. In contrast, other teachers described decision-making and problem-solving in negative terms, experiencing a sense of disappointment and frustration that their efforts were hampered by rules and a lack of stakeholder support. It is proposed that in these situations, teachers were unable to enforce Australian standards because the application of the curriculum requirements conflicted with how local stakeholders understood and prioritised those (Shams \& Huisman, 2012). The consequences of these divergent experiences of dissonance 
provide a basis for understanding how the teachers forged their unique ways of overcoming the local factors through curriculum-making in the following chapter.

The findings discussed in this chapter about teacher decision-making and problem-solving also suggests that Australian providers did not always account for the realities of transnational provision. Indeed, it was shown that much of what occurred in curriculum implementation was unplanned and unexpected. Moreover, in many instances it was found that Australian stakeholders did not monitor curriculum implementation or assist teachers to enforce the curriculum standards. This finding supports Dempsey and Tao's (2017) claim that the Australian federal government has done little to address the difficulties that teachers face in trying to maintain Australian standards offshore. Consequently, it is held that the teachers' role was a mediating influence in curriculum implementation, subject to the level of control placed on them by local sponsors.

The experiences of the teachers reveal the challenges associated with teachers making decisions and resolving problems in situations that are substantially different from what they are used to in Australia. Teachers recounted facing many new and unfamiliar problems and dilemmas. The central concern of teachers was to learn how to effectively overcome the problems associated with their experience of dissonance. It is contended that a greater focus on supporting the role of teachers as the key experts in the curriculum implementation process might well enhance the quality of curriculum implementation in Australian transnational VET. Indeed, highlighting the experiences of teachers' decision-making and problem-solving demonstrates, as also concluded in Chapter 5 , the importance of onsite professional support to teachers, particularly in countries such as China, the UAE, and Kuwait where sponsors are more likely to use power-coercive strategies to control teacher agency and, thus, limit their ability to achieve Australian standards.

In conclusion, the findings analysed in this chapter instantiate and illuminate the problems associated with teachers enacting in one country a curriculum designed for another. They indicate that it is simply not possible for teachers to enact Australian Training Packages in another country without the capacity to understand and influence the range of local factors associated with implementation, which extends to support from Australian colleagues and local actors. Moreover, it reveals that without an extended scope of role to make decisions and solve problems in another country, there are factors that cannot be addressed by teachers. Consequently, the ability of teachers to maintain Australian standards and fidelity to the curriculum will at times be compromised by such factors. 


\section{Chapter 7}

\section{Curriculum remaking in Australian transnational VET}

It is proposed in this chapter that it is not possible for teachers to enact a curriculum designed for one country, in another one, without remaking it in ways that address the dissonance between the curriculum intentions and the circumstances of curriculum implementation. Furthermore, the chapter proposes that teachers need both local and external support for their role as adaptive curriculum-makers to assist with making the enacted curriculum relevant, learnable, and achievable for specific cohorts of students transnationally.

It was advanced in Chapters 4, 5, and 6 that 13 teachers arrived overseas with the subject matter, pedagogical practices, and curricular knowledge based on their experience in Australia and/or another country. Yet, they lacked much of the preparation for and/or information about their new situation upon which to make meaningful adaptation to what they taught and assessed. To increase their understanding of the circumstances in which the curriculum was to be enacted, teachers appraised the situation and considered how to overcome the problems associated with the resources, materials, institutional arrangements, and student readiness. It follows that this chapter proceeds to describe and critique how these teachers applied their analyses to curriculum development and, through the process of enactment, remade the curriculum beyond what was intended. That is, it elaborates how they became the curriculum-makers in these circumstances.

In doing so, this chapter presents the third part of the inquiry's findings, commencing with an account of the curriculum-making practices of 13 teachers in Australian transnational VET provision across nine countries. It discusses curriculum remaking as the teachers' predominant approach to curriculum-making. Most notably, six curriculum strategies emerged as commonly used by teachers, through analyses of their interview transcripts: (a) curriculum appraisal, (b) curriculum prioritisation, (c) curriculum change, (d) curriculum expansion, (e) curriculum design and experimentation, and (f) curriculum collaboration. Firstly, an overview of these strategies is presented. In subsequent sections each strategy is then explained and discussed in relation to the concepts elaborated in Chapters 2 and 3 . The following section discusses the teachers' experience and role as adaptive curriculum-makers. It reveals that the essence of the experience of curriculum-making was, for many teachers, a tension between the expectation to maintain fidelity to the intentions to an Australian curriculum and meeting the interests and needs of their overseas 
students. The final section of the chapter discusses how the curriculum was remade through the teachers' development of the curriculum to increase its relevance, learnability, and achievability for students.

The curriculum-making strategies, as frequently reported by the teachers, are illustrated by a sample of illustrative quotes of terms, phrases, and statements used by them about each strategy and how they remade the intended curriculum through their actions. The findings discussed in this chapter represent the concerns of these 13 informants, which may or may not be shared by other actors (e.g., other teachers, administrators, educational designers) involved in the provision of Australian transnational VET. However, the focus of this inquiry is to understand the phenomenon as experienced by teachers as it is contended that their perspectives help identify the key indicators of success in the enactment of the intended curriculum in transnational vocational education.

\subsection{Overview of curriculum remaking}

It was acknowledged in Chapter 3 that teachers are important curriculum decision-makers who interpret and modify the intended curriculum to meet the needs of their students and make it relevant in context (Marsh \& Willis, 2007; Pinar et al., 2004; Snyder et al., 1992). These practices were shown to include adapting, developing, researching, negotiating, and making curricula. It was identified from the analyses of the interviews with the teachers that curriculum remaking was the predominant approach to the teachers' adaptive curriculum-making. Table 7.1 presents the six distinct and common curriculum strategies used by teachers. These strategies are presented in the first column with corresponding examples of the actions that teachers took in the second column. A rationale based on the teachers' explanations for the use of each strategy is provided in the third column. 
Table 7.1

Common Curriculum Remaking Strategies Utilised by Teachers

\begin{tabular}{|c|c|c|}
\hline $\begin{array}{l}\text { Curriculum } \\
\text { strategy }\end{array}$ & Specific actions & Rationale \\
\hline $\begin{array}{l}\text { Curriculum } \\
\text { appraisal }\end{array}$ & $\begin{array}{l}\text { Decided what and how to } \\
\text { teach }\end{array}$ & $\begin{array}{l}\text { Appraised the intended curriculum to decide } \\
\text { what was relevant, learnable, and attainable } \\
\text { for students }\end{array}$ \\
\hline $\begin{array}{l}\text { Curriculum } \\
\text { prioritisation }\end{array}$ & $\begin{array}{l}\text { Removed content } \\
\text { Emphasised content } \\
\text { Changed pace } \\
\text { Changed sequence }\end{array}$ & $\begin{array}{l}\text { Prioritised those areas of the intended } \\
\text { curriculum to decide what was relevant, } \\
\text { learnable, and attainable for students within } \\
\text { the local constraints }\end{array}$ \\
\hline $\begin{array}{l}\text { Curriculum } \\
\text { change }\end{array}$ & $\begin{array}{l}\text { Substituted local content } \\
\text { for Australian content } \\
\text { Changed language } \\
\text { Changed assessments } \\
\text { Changed level and } \\
\text { standards }\end{array}$ & $\begin{array}{l}\text { Changed the intended curriculum to make it } \\
\text { relevant, learnable, and attainable for } \\
\text { students given their: (a) interests and goals, } \\
\text { (b) language proficiency, (c) prior knowledge } \\
\text { and abilities, and (d) learning styles }\end{array}$ \\
\hline $\begin{array}{l}\text { Curriculum } \\
\text { expansion }\end{array}$ & $\begin{array}{l}\text { Supplied missing } \\
\text { elements } \\
\text { Arranged alternative } \\
\text { curriculum experiences } \\
\text { Extended duration }\end{array}$ & $\begin{array}{l}\text { Expanded the intended curriculum to support } \\
\text { student achievement and enhance the quality } \\
\text { of their learning experience }\end{array}$ \\
\hline $\begin{array}{l}\text { Curriculum } \\
\text { design and } \\
\text { experimentation }\end{array}$ & $\begin{array}{l}\text { Created and trialled new } \\
\text { materials and activities }\end{array}$ & $\begin{array}{l}\text { Developed materials and activities to form } \\
\text { the teacher-intended curriculum for } \\
\text { instruction to facilitate student learning and } \\
\text { achievement }\end{array}$ \\
\hline $\begin{array}{l}\text { Curriculum } \\
\text { collaboration }\end{array}$ & $\begin{array}{l}\text { Facilitated storytelling } \\
\text { Enlisted students as } \\
\text { teachers }\end{array}$ & $\begin{array}{l}\text { Collaborated with students to create a } \\
\text { relevant, learnable, and attainable curriculum } \\
\text { with students }\end{array}$ \\
\hline
\end{tabular}

Table 7.1 shows that teachers used the five curriculum remaking strategies of appraisal, prioritisation, change, expansion, and collaboration to redevelop the intended curriculum (i.e., the endorsed component of Training Packages) to make it more relevant, learnable, and achievable for students. The table also shows that teachers used the strategy of design and experimentation to remake the teacherintended curriculum to support the curriculum they enacted. It is held that all the actions brought together in Table 7.1 represent the teachers' efforts to align the intended, implemented and experienced curricula to improve student achievement (Glatthorn, 2000; A. C. Porter, 2002; Squires, 2009). The next six sections of the chapter elaborate each of these strategies to understand how and why teachers made these changes to the curriculum. This is followed by a discussion of their experience and role as adaptive curriculum-makers. In all, these sections illuminate how the teachers' remade a curriculum, based on their interpretation of the intended curriculum that could be enacted and learnt by students within the constraints that existed in their situation. 


\subsection{Curriculum appraisal}

Curriculum appraisal, as shown in Table 7.1, was the initial strategy teachers used to develop the curriculum. Teachers appraised the intended curriculum to decide what was relevant, learnable, and attainable for students. As reported in Chapters 5 and 6 , all the teachers were initially concerned with securing curriculum outcomes to the same standard as they would in Australia, as Rowena's statement reflects:

I certainly am very conscious that you know they're [students] going to get an Australian qualification. They need to be able to demonstrate that they can do it to Australian standards. (Rowena, education teacher in South Pacific)

Thus, at this stage the teachers expected to enact Training Packages as a "technology of trust" (Rahimi \& Smith, 2017) by upholding standards. Yet, the feasibility of meeting such expectations, including the degree to which the curriculum could be remade to meet local needs, proved challenging. Indeed, in many instances, as Chapters 5 and 6 indicate, teachers reported that it was not possible to simply implement or adapt the intended curriculum due to the limitations of the supported curriculum (i.e., what they could teach using the available resources) (Glatthorn, 2000). These limitations were shown to confine the extent of teaching activities and learning experiences that were possible. Consequently, as shown in Chapter 5, these teachers appraised these constraints and the curriculum requirements and then used their discretion to make decisions about what could be taught and how. When making these decisions, the teachers were also concerned about the readiness of the students to engage with the intended curriculum. Therefore, they also appraised the intended curriculum to determine if it was relevant, learnable, and achievable for students. Peter explains his perspective thus: "there were educational goals, but you had to critically analyse those and, according to the needs of the students". His statement reveals that curriculum appraisal was a strategy for teachers to cognitively determine the extent to which they could enact the curriculum intentions and still meet the needs of the students.

How teachers made sense of their situation was the mediating link between what was possible and what occurred in curriculum remaking and enactment. As advanced in Chapter 5, the teachers' decisions were a result of their own subjective analyses of the situation, in terms of what they noticed, how they selected information, how they made meaning of it, and subsequently how they acted on 
those interpretations and judgements (Skilbeck, 1992). The teachers were shown to construct their understanding about curriculum development by placing this new information into their pre-existing practices and views. For instance, Steven explains that:

the frontline management program was an original product but then very much became my product because of what I thought needed to be done. (Steven, management teacher in PNG)

As teachers acted on their interpretations, they developed new materials and practices which they combined with those from the past to develop the teacherintended curriculum (Remillard \& Heck, 2014; Ross \& Mannion, 2012). Consequently, the curriculum that teachers developed and enacted (i.e., remade) reflected their own assessment of what they could teach based on their prior experience and what seemed relevant, learnable, and attainable for students within the local constraints (Doyle \& Ponder, 1977; Schwab, 1978). Thus, curriculum appraisal was shown to be the key strategy used by teachers to inform their priorities and strategies for curriculum remaking. These are the strategies elaborated in the following five sections of the chapter.

\subsection{Curriculum prioritisation}

Based on their appraisal of the situation and the intended curriculum, all the teachers were shown to initially prioritise those areas they deemed relevant and perceived that students could learn and attain within the local constraints. As shown in Table 7.1, prioritisation involved teachers removing and/or emphasising content (D. L. Ball \& Cohen, 1996; Remillard, 1999; B. Tomlinson, 1998) and changing the pace and/or sequence of the curriculum (Beauchamp, 1972; Johnson, 1967).

One priority that teachers reported was to omit content (D. L. Ball \& Cohen, 1996; Remillard, 1999; B. Tomlinson, 1998) that could not be taught due to local factors. Teachers based in China were more likely to leave out some elements of the curriculum due to resource factors, as teachers there reported the most diminished conditions. For example, Jo was unsuccessful in his negotiations to secure any of the facilities or equipment he needed to teach the technical skills as prescribed in the electro-technology curriculum. Consequently, he reported, "I had to get rid of all the practical stuff". In other examples, teachers omitted content when they decided that 
the students would not be able to learn all the content, given their "limited abilities" within the time constraints. As Peter explains:

... it's (curriculum) stripped back to the bare necessities ... you only cover what you can effectively cover ... really it ends up being at a lower standard... (Peter, business teacher in China)

It can be also seen from this statement that Peter understood that by omitting some of the curriculum content, he was also reducing the curriculum standards.

In other instances, teachers reported omitting content if they decided it was irrelevant to the students' interests and goals. For example, some teachers removed content that was specific to Australia. Teachers were more likely to do this when they inferred that students were not likely to work in Australia. For example, Rachael removed technical content that was specific to Australian human resource systems in the events management curriculum because it was not relevant to students who wanted to work in the field in Kuwait, as she explains:

A lot of the terminology that you'd use, you don't teach all of it. So, like the performance manager system for HR [Human Resources] is a halo system ... I would have taught that in Australia ... I wouldn't even attempt that in Kuwait. (Rachael, events management teacher in Kuwait)

However, it is noteworthy that the teachers' perceptions of the relevance of the curriculum content in relation to their students' future job aspirations were entirely subjective, as nine of them reported no contact or involvement with the local industry.

Twelve teachers reported prioritising the curriculum by emphasising certain elements of it (D. L. Ball \& Cohen, 1996; Remillard, 1999; B. Tomlinson, 1998). Nine rated this change as moderate to major. The main reason that teachers gave for emphasising some content was to assist students to understand the conceptions upon which the curriculum was based. For example, Shiraz states that she "put emphasis on different parts of the curriculum, such as privacy and confidentiality" because the students were not familiar with these foundational elements that underpinned the aged care curriculum. She explains that she felt this change was necessary because she had to "readjust them [Filipino students] to bring them over to work in Australia". From this explanation, it can be seen that Shiraz perceives that the curriculum needed to be enhanced to ensure that students had adequate background knowledge in preparation for working as an aged carer in Australia. In 
these instances, it was found that the main reason that teachers emphasised certain elements of the curriculum was to ensure that students could attain the standards of the intended curriculum.

All the teachers reported changing the pace and sequence of the curriculum (Beauchamp, 1972; Johnson, 1967). In most instances, these changes were rated as moderate to major. The main reason the teachers gave for slowing the pace was to account for the students' language proficiency, prior knowledge and abilities, and learning styles. For example, most of these teachers claimed that language barriers meant everything took longer to explain to students and longer for them to understand and complete activities, as Steven expresses, “... perhaps would need to go over things more frequently and move at a slower pace". Teachers also reported changing the sequence of the curriculum because of institutional factors and students' needs. Teachers like Jo claimed they had no choice but to teach the sequence of the curriculum differently than the specified order as the timetable had not been arranged by the local sponsors as it was intended. Other teachers claimed they changed the sequence of topics because they thought it was the best way to accommodate the students' learning needs, as Rowena explains:

There is a set pattern in which the delivery of this course is suggested, and I did change it around a little bit because it seemed to link in more logically with what they [students] were needing to do. (Rowena, education teacher in South Pacific)

In this instance, Rowena's initiative can be seen as an expression of her concern for the students' needs.

The teachers' accounts of curriculum prioritisation reveal that they used this strategy to make decisions in the remaking of the curriculum about: (a) what content to include, (b) what content not to include, (c) how much time and emphasis would be spent on some content areas compared to other areas, and (d) in what order the content would be learnt by students. Their actions show that at times they had to modify the curriculum because many of the preconditions for success were absent (Stake, 1977; Tikly \& Barrett, 2013); at other times it was necessary to cater for the students' interests and needs (Glatthorn, 2000). The priorities set by teachers were important as they accounted for the differences between the intended and learned curricula in each situation. It is also held from some of the participants' responses that they understood that, at times, their actions did not support the intended curriculum outcomes. This finding suggests that the teachers' strategy of curriculum 
prioritisation transformed both the content and standards of the intended curriculum in implementation.

\subsection{Curriculum change}

It was shown in the preceding section that teachers initially prioritised the curriculum to determine what they believed the students could achieve based on their interests and abilities and within the constraints that existed in their situation. The teachers' accounts reveal that, over time, they made further changes to the curriculum when they found it was impractical to enact a curriculum that was not designed or supported with the students' interests and needs in mind. Indeed, it was shown that in many instances these changes were significant and many of them impacted on the curriculum standards. However, it is notable that the responses from two teachers about curriculum change were contradictory. During interviews, when teachers were asked to answer in writing whether they made changes to the curriculum content, language, assessments, or standards, 11 teachers replied in the affirmative. Of these 11 teachers, most rated the changes as moderate to major. However, two teachers who answered in the negative to these questions in writing then went on in the interviews to provide many examples of changes they made to the intended curriculum. Therefore, their examples are also counted and included in this section of the chapter on curriculum change.

The types of curriculum changes teachers reported, and that are shown in Table 7.1, included: (a) substituting content (D. L. Ball \& Cohen, 1996; Remillard, 1999; B. Tomlinson, 1998), (b) changing the language of instruction, (c) changing assessments and judgements (Hawthorne, 1992; Jackson, 1968), and (d) reducing the pitch, levels, and/or standards (Hawthorne, 1992; Jackson, 1968). The main reasons teachers gave for changing the curriculum was to address the student readiness factors by making it relevant, learnable, and attainable.

Some teachers reported changing (i.e., remaking) the curriculum by substituting some of the content they omitted when they prioritised the curriculum (D. L. Ball \& Cohen, 1996; Remillard, 1999; B. Tomlinson, 1998). In many instances, these teachers claimed they removed some of the Australian content and replaced it with local content. For example, Damien replaced some of the content in relation to Australian food and drink in the hospitality curriculum with local content. The reason teachers gave for making the switch was to "contextualise" the curriculum so it was relevant to the situation. Another common curriculum change was to remove the 
technical vocabulary and replace it with terms that were used locally, as Steven explains:

... you just substitute the language and the documentation and processes to suit the local environment ... the terminology they use up there [PNG] is slightly different to down here [Australia].... So you would have to change the language that you may have used because of the technical nature that they may not have been exposed to. So terms like planning and risk management and key performance indicators. (Steven, management teacher in PNG)

As can be seen from Steven's statement, he viewed substitution as a legitimate form of curriculum change because he decided that students needed to use the technical terms used in their workplaces rather than those used in Australia.

Some teachers reported that they changed the curriculum by allowing students to learn in their own language even though the mandated language of the curriculum was English. In most instances, this type of change was minor, as most teachers claimed that the use of local language was restricted to classroom discussions. Sam explains his rationale for encouraging students to communicate with each other in Vietnamese:

Giving them a group activity where they can talk in their own language was extremely helpful to them ... instead of always struggling with a different language ... it's just too hard doing it in a second language. (Sam, hospitality teacher in Vietnam)

Sam's explanation reflects his willingness to accommodate his students' language preferences to support their learning. However, in one instance, this change to the language of instruction was major. In Iran, Sean made the decision to allow parts of the curriculum to be taught and assessed in Farsi with the help of local teachers, as he explains:

... we started to translate everything into Farsi as well ... this course is supposed to be delivered in English, but look in the end we decided no, the learning's much more effective. (Sean, architecture teacher in Iran)

Sean's account shows that he was aware that changing the language of instruction was not aligned with the curriculum intentions. Yet, he was prepared to change the 
prescribed language of instruction as he concluded that by taking this action he was promoting student learning.

Many teachers reported changing the assessment methods and criteria as prescribed in the intended curriculum (Hawthorne, 1992; Jackson, 1968) due to local constraints. The three business teachers in China all claimed they had little choice but to substitute assessment methods due to the institutional requirement for exambased assessments. So, rather than use the prescribed assessment methods such as collecting evidence of work samples or through observation, they had to develop and use exams. In another example, Jo claimed that he did not have the resources to assess the students as mandated in the intended curriculum. He explained that he had to change the assessment method from testing and repairing an electrical circuit in a laboratory or workplace to a scenario-based assessment in the classroom where students were required to write a report on how they would test and repair an electrical circuit. Thus, in these instances, teachers were found to change the assessment criteria and methods because they were unable to assess the students' competencies due to institutional practices and resource constraints.

Seven teachers also provided examples of curriculum change that involved reducing the level of the curriculum content and lowering the assessment standards to account for student readiness factors. As discussed in Chapter 6, these teachers admitted that because, in their opinion, so many of their students were not at the "level they could teach them", they changed the curriculum by setting their own minimum standards of acceptability in place of the curriculum standards, as the following statements convey:

I worked out what the bottom line was in terms of standards. I tried to teach in accord with what was my bottom line in terms of what I was prepared to pass or not pass ... I had to dumb it down ... I didn't teach as I would in Australia. (Mick, business teacher in China)

You just knew if they [students] couldn't get across the line, you just brought it [standard] all down... There is no comparison [between Australia and Kuwait] ... it doesn't equate at all ... so you're thinking, "I've got to make, teach for the lowest denominator". (Rachael, events management teacher in Kuwait)

It is notable that the seven teachers' decision to reduce the level and standard of the curriculum was not made lightly. They all recounted the tension and 
unease they experienced in having to decide between their fidelity to the curriculum standards or to student achievement, as Mick's statement sums up:

Well I took the standards fairly seriously. You know, my responsibilities were to teach and assess students to the standard and to provide evidence that they had reached the standard. The dilemmas we felt because the students were sincere people and trying to do their best and so on. We were constantly at war with ourselves about the dilemma of how to meet the standards given the capabilities. (Mick, business teacher in China)

Mick's statement reflects the tension experienced by these seven teachers when faced with a choice between complying with the mandated requirements of the intended curriculum or changing it so the curriculum was learnable and achievable for students. Yet, it was found that all seven teachers resolved this dilemma by reducing the standards of the intended curriculum to a level that students could attain. These findings suggest that when teachers are faced with the possibility of having to "fail whole cohorts of students", it forces them to reconsider the expectation that they can enact Training Packages as a "technology of trust" (Rahimi \& Smith, 2017) and uphold Australian standards. Indeed, the accounts of these seven teachers suggest that teachers will prioritise the learned curriculum over the intended curriculum if, over time, they deem that the standards are not achievable for specific cohorts of transnational students.

The teachers' accounts of curriculum change highlight the ways in which they remade the curriculum beyond its intentions to accommodate contradictory interests and goals in transnational education (Steiner-Khamsi, 2013). In some instances, it appears that the curriculum changes were made to overcome resource constraints or to comply with institutional practices. In other instances, it was shown that teachers made curriculum changes to accommodate student readiness factors. The changes that teachers reported remaking to the curriculum content, language, assessment criteria, and standards were all significant because the curriculum that was enacted and learnt in many situations was, by their own admissions, different from what they understood as the curriculum intentions. These changes were made by teachers to allow the student cohort to complete their course with an outcome acceptable to the local stakeholders and the students themselves. Further, these teachers were prepared to prioritise student achievement over the curriculum intentions to varying degrees. Curriculum change, however, made apparent the need for curriculum remaking to further support student achievement. 


\subsection{Curriculum expansion}

The teachers' appraisal of the curriculum also led them to expand it to support the students' achievement of the learning outcomes as prioritised by the teachers. As Table 7.1 shows, all the teachers reported expanding the curriculum by supplying missing elements, creating alternative learning experiences, and/or extending the duration of the curriculum (D. L. Ball \& Cohen, 1996: Remillard, 1999; B. Tomlinson, 1998). In all instances, teachers were shown to make these expansions to enhance the quality of their learning experience and to support student achievement.

Some teachers supplemented the curriculum to compensate for those elements that could not be enacted due to a lack of resources or inadequate institutional arrangements. For example, three teachers organised excursions to make amends for the work-based learning opportunities that they claimed were not organised by the local stakeholders. Annabel explains why she organised excursions for students:

It [excursions] gives value or another dimension to their [students'] learning ... so these were opportunities where they ... meet with people in industry. So, whether it be a conference or whether it be somebody guiding them around a company, the value to see ... what's really going on. (Annabel, project management teacher in UAE)

Annabel's account demonstrates her commitment to enriching the students' learning experience despite the limitations imposed on them by the lack of support received to enact the curriculum. Damien demonstrated a similar commitment to the enhancement of his students' learning experience by organising opportunities for students to gain vocational experience in a restaurant he created in Fiji, as he explains:

Well, I suppose one of the biggest changes that I made in Fiji was to the actual training restaurant that we were in ... we actually invited three wedding parties to happen in the restaurant ... in that way you actually get real, genuine learning experience.... It put the excitement into the learning ... for once in their life [they] can actually see that their learning is real; it's no longer in the classroom, it's no longer from a book, it's no longer from a teacher.... 
Yes, their learning accelerated immensely ... wow, it was exciting. (Damien, hospitality teacher in Fiji)

The reference Damien makes to "the real, genuine learning experience" relates to the importance he placed on ensuring that his students had the opportunity to learn in an authentic work environment, as a central tenet of a vocational curriculum.

Other teachers supplemented the curriculum to ensure that their students were properly prepared for working in their chosen industry. For example, Shiraz was concerned about the students' lack of prior knowledge of the values that underpin aged care practice in Australia. So she decided to extend the curriculum with additional assessments so she could be sure that they understood these values and could apply them in practice. She also created an additional work placement for the students in Australia, prior to their employment, because she "decided that the industry experience they were doing" in the Philippines "wasn't enough to move into our industry over here [Australia]". Shiraz's statements demonstrate that she gave prominence to those parts of the curriculum that she expanded.

All the teachers in this inquiry extended the curriculum by frequently repeating the content to reinforce it. Teachers provided numerous examples of the materials and practices they developed and used to facilitate these reviews. Rowena describes the way she facilitated these reviews:

l'd get them [students] to do a bit of a brainstorm at the end of every day. What have we learnt from this? What do we need more help with? Get it up on the board and then I'd take photos of it. Then the next day I would start from that point. "Remember we did this yesterday. This is what we've covered. Now you've had time to reflect, what, or anything else that's come up from it? How can we use it? What would you use it here for?" (Rowena, education teacher in South Pacific)

Rowena's account reveals the significant amount of time and effort that she put into reviewing the content with students at the beginning and end of every day. Her aim was to ensure that they understood the content and how it might be applied in practice. Damien, however, expanded the curriculum to allow his students to apply the knowledge and skills they were learning. He provided his students with repeated opportunities to develop their learning in real-world settings.

The biggest adjustment I made to the curriculum was basically to give them more time to practise what was being taught. I also knew as I was teaching 
the students that they needed to do things more than once. (Damien, hospitality teacher in Fiji)

Another way that most teachers supplemented the curriculum was by teaching the students "how to learn". These teachers were all critical of what they described as "rote learning", which they associated with "short-term memory of information", "surface learning", and "passive learning". Teachers were shown to put considerable time and effort into introducing students to new ways of learning to develop their intellectual processes (Eisner, 2002). The analyses of the teachers' stories showed that they all shared similar expectations for how students should learn the curriculum content. Most notably, teachers focussed on teaching active learning and conceptual understanding. Mary mentions how she helped the students develop their learning skills, so they could learn the curriculum content:

Look, very early days I just, I sort of realised that just giving them [students] the concepts of, let's say leadership and what that meant, wasn't really going to sink in. They had to be actively engaged and understanding how it all worked. So I did a lot of reading around that and just really did a lot of team little activities or project based stuff so that they would sort of get the concepts. (Mary, business teacher in China)

Annabel reflects on why she extended the curriculum to teach students how to learn in a different way:

I want them to walk away with a set of tools, so I always tell them that even the content that they're learning they may never remember the details of it but just the skills of how to look up something, how to ask something, how to write something, how to present something, whatever that something is. (Annabel, project management teacher in UAE)

Annabel's reflection reveals the value she placed on ensuring that her students developed new skills such as researching, questioning, writing, and presenting to the extent that she prioritised their achievement of these over the intents of the curriculum.

Four teachers extended the curriculum duration by offering additional tutorials or classes outside of the allocated time (Beauchamp, 1972; Johnson, 1967).

Teachers provided these opportunities at their discretion and in addition to their usual 
workload. They were willing to spend this extra time with the students to help their progression, as Steven explains:

I would always allow more time, much more time than I had in Australia, simply because some of the learning that was going to take place was going to come from a lower base than say their equivalent would have in Australia $\ldots$ and perhaps they weren't used to doing and working things out for themselves ... perhaps you would need to go over things more frequently and things move at a slower pace than here [Australia]. (Steven, management teacher in PNG)

Steven also extended the curriculum through the addition of a 2-day review workshop at the end of each program when the students had finished their workplace assessment. He explained that this 2-day "recap" was a critical aspect of the students' learning as they could "pull together all the learning that had taken place and look forward to how it could be implemented in the future". These findings indicate that teachers extended the duration of the curriculum to ensure that the students had sufficient time and opportunities to learn.

As can be seen from the teachers' accounts, they all expanded the curriculum to enhance the quality of the learning experience for students and to provide sufficient opportunities for them to achieve the curriculum outcomes. Sometimes, they expanded the curriculum to make up for the experiences that had not been arranged by the institution. At other times, they did so to include all the content that they believed their students needed because their needs and interests were not considered by the Australian curriculum developers. It is held that, in many instances, these expansions were put in place to account for the null curriculum (Eisner, 2002). It is notable, however, that teachers put other enhancements in place because of the value teachers placed on Western-based learning approaches, which is one of the primary concerns associated with the provision of transnational education (Abbott, 2017; Tikly, 2013). Thus, it is contended that the curriculum was in many instances extended to provide the underpinning knowledge and skills that teachers perceived that students needed to effectively engage with the intended curriculum. This then led teachers to design and experiment with materials and activities for students to develop the knowledge and skills they intended them to learn. That is, they remade the curriculum to meet these needs. 


\subsection{Curriculum design and experimentation}

As established in Chapters 5 and 6 , accessing and developing quality materials for teaching and learning was a priority for teachers, particularly for those who lacked transnational teaching experience, local information, and time. Therefore, teachers reported spending considerable time on designing and experimenting with different teaching methods. Table 7.1 shows that they developed materials and activities to form the teacher-intended curriculum for instruction. Nine teachers described the extent of this curriculum remaking as moderate or major. Material development involved adapting previous materials to create new ones or designing brand new material (D. L. Ball \& Cohen, 1996; Remillard, 1999; B. Tomlinson, 1998).

Teachers focussed on developing materials that were engaging so students could learn and attain the curriculum that they, the teachers, had prioritised. In many instances, it involved teachers developing an extensive range of materials to cater to students' needs, interests, language proficiency, goals, and abilities, as Peter explains:

I needed to look at activities which contextualised the background knowledge that the students needed. I needed to maximise engagement by having, using surveys ... provoking active learning where they'd physically get up from their seats ... or putting the information they need up on the walls in various forms ... that they could immediately relate to them, thus grasping the concept fairly quickly by that visual reinforcement ... to get around the listening, the lack of listening skills ... l'd take pictures of events that happen in China, and give them concrete examples. (Peter, business teacher in China)

Teachers used information they secured from their students to inform their development of teaching materials. For example, Rowena claimed she used the results from a learning style questionnaire to create activities that catered for a "hands on" approach to learning. In another example, Peter used surveys in the class to find out what his students were interested in, so he could tailor the content. All the teachers also learnt about what worked and did not work through their classroom observations and interactions. For example, Damien realised success with his presentations because his PowerPoints were "very minimal in terms of words and very maximum in terms of pictures, so they [students] loved that". He claimed that the visual aids he developed helped solve some of the English language barrier problems. 
Teachers provided numerous examples of the ways in which they developed material based on students' interests. For example, Steven created a simulation for managing an Australian rugby league competition as part of the management curriculum. He used it as the basis of classroom learning across the entire taught curriculum. He explains why it was successful with students:

Well most of them [students] were mad keen Bronco [rugby league team] supporters, so you would use case studies that l'd made up. Really I wouldn't have a clue how the Broncos ran their comp, but I would make up stories and case studies and say, "oh you know this has been signed off by Alan Langer and Wally Lewis". And they'd go berko - thinking this was fantastic. I had an interest in football so that enabled me to do that sort of stuff and they certainly responded. (Steven, management teacher in PNG)

Other teachers would assign the students projects to complete based on their interests. For example, as part of the project management course in the UAE, Annabel arranged for the students work on projects such as "planning a wedding, which was a classic one, or building a shack". In another example, to stress the importance of certain content, Alex would incorporate quotes from the country's rulers because the students had "a lot of respect for their leadership and their Sheikh". These teachers' accounts demonstrate their attempts to create relevant and meaningful materials and activities that engaged students' interest and connected with what they already knew. These accounts suggest that teachers equated relevant curriculum materials with effective learning.

However, as discussed in Chapter 6, teachers reported varying levels of success with their experimentation with teaching and learning materials. Ten teachers reported that they were not professionally prepared or supported for responding to the diverse needs, interests, and abilities of students in another country (Tran \& Le, 2017). Indeed, in many instances, teachers learnt what type of materials and methods were ineffective through the process of experimentation, as Peter recalls:

Well, I found lecture style delivery just didn't work ... so language laden PowerPoints couldn't be used in class ... use of video didn't work either...

He also explains that, given time, experimentation also led to success: 
So there's been an improvement as time's gone on. But the initial, my initial experience was I was fairly much thrown in the deep end ... it was seen as a huge task to try and get the Chinese, the offshore program into line. And it happened, but it's taken pretty much 8 or 9 years to get that. (Peter, business teacher in China)

However, it is questionable whether teacher experimentation provides the best quality learning experience for students or effectively facilitates student achievement. Therefore, it is held that inadequate professional and material support for these 10 teachers necessitated their experimentation with teaching and learning and that, at times, this adversely impacted on the quality of the enacted and learned curricula.

The preceding accounts show that teachers were compelled to spend considerable time and effort experimenting with the design and use of a variety of teaching and learning materials to cater for student readiness factors. The materials developed became critical and defining components of the enacted curriculum because they supported the teachers' priorities and intentions. The findings suggest that teachers developed materials to meet the needs of the diverse student body they encountered in their transnational settings. Thus, it is contended that the teachers played a mediating role in the adaption of the curriculum offshore through the teacher-intended curriculum (Remillard \& Heck, 2014). However, the relative inexperience of some teachers in teaching vocational education programs offshore, combined with a lack of information and material support, meant that their experimentation with materials and methods was not consistently effective. Thus, curriculum design and experimentation, whether effective or not, was an important determinant of curriculum remaking. However, the interactions undertaken by the teachers to understand the interests of the students, and their attempts to engage students with the subject matter, became the basis of the collaborations that would lead to new, creative learning and teaching advancements and a further iteration of the curriculum: remaking the curriculum.

\subsection{Curriculum collaboration}

Teachers collaborated with their students in the creation of new curriculum knowledge, learning, and teaching. Table 7.1 shows that collaboration occurred through storytelling and engaging students in the teaching process. By taking these actions teachers were able to continually develop the curriculum throughout the teaching process (Remillard, 2000) as they interacted with students. 
The way teachers shared stories about their own experiences and encouraged students to reciprocate is indicative of the curriculum collaboration process. Initially, many teachers relied on storytelling to overcome material constraints, as Rachael explains:

You couldn't do anything with them [students] and hand out pieces of paper and do activities... it was really difficult...so, there was lots of chats, conversations from work ... it became a conversation in the classroom really. (Rachael, events management teacher in Kuwait)

Five teachers, however, reported that the students who were predominantly motivated by storytelling were those who were particularly interested in the vocational outcomes of the curriculum (i.e., aged carers, hospitality workers, managers, and educators). As a consequence, these teachers told their own stories more frequently and explicitly encouraged their students to do so too. These teachers reported that students were interested in listening to them talk about their previous industry experiences because it provided them with real-life examples that they could relate to, as Shiraz claims:

My personal stories, where I worked, what I did, was hugely helpful. Made it totally real. (Shiraz, aged care teacher in Philippines)

These stories also helped these teachers establish their credibility as vocational teachers, as Steven explains:

... when you're asking them [students] to do things in their workplaces you could talk about what was done in other workplaces with some credibility. (Steven, management teacher in PNG)

These statements indicate that Shiraz and Steven were using their own stories to make a personal connection and to increase their students' understanding of the material.

At the same time, the five teachers recognised that their students were also "experts in their own field" and so encouraged students to share their stories. Sam explains, "All my examples were from personal stories and then trying to evoke, you know, some of their stories on things". He explains why storytelling was such an 
effective strategy for teaching students who were working in the hotel where they were located:

... [it] makes it interesting for people because they can talk about their stories, not just yours. And the stories that you do bring up don't have to be as many but they can be very meaningful because you pick and choose what the story is for the thing that maybe they're not quite understanding or getting the gist of ... or you know a variety of things that are a little bit more complex ... it gives you more to work with. (Sam, hospitality teacher in Vietnam)

As can be seen from Sam's statement, he used storytelling to construct a learning environment where students were able to create their own meaning of the curriculum (Clandinin \& Connelly, 1992; Mannion et al., 2011) and apply their learning with their colleagues in a real-life workplace.

Teachers were also shown to collaborate with students by including them in the teaching process. For example, Rowena involved some of her students as facilitators of other students' learning of the curriculum content, as she explains:

I also appointed team leaders so that I would brief the team leaders before the session started on what we were going to be doing and what I expected from that particular session, and then at the end of it we would do a debrief and that's when I was able to pick up on what worked, what didn't work, what we could then go back over that. (Rowena, education teacher in South Pacific)

This example is a clear indicator of curriculum collaboration. Rowena relied on student team leaders to assist her in instructing other students in the activities that she had set and then to provide her with important feedback for reviewing gaps in the class's learning of the curriculum content. In other examples, many teachers relied on students with good English language skills to help support the teaching and learning of the curriculum. Sam explains his rationale for collaborating with these students:

There were always one or two males who usually asserted their leadership with their ability to speak English. I worded them up at the beginning ... "if you notice some people aren't sure what I'm saying or they're getting behind or there's some terms I use that you don't think everybody would use or would 
be familiar with it would help me a whole lot for you to tell me that".... And then I would even say that to the whole group before I started ... then you would either have somebody that had permission to interrupt the teacher ... or whisper something to somebody on the side because they knew their English wasn't quite good.... So that worked well. (Sam, hospitality teacher in Vietnam)

Curriculum collaboration proved an effective strategy for teachers in this inquiry. It assisted them to overcome material and student readiness factors. Their accounts illustrate the ways in which teachers and students came together as active teachers and producers of their own knowledge, rather than just using the codified knowledge contained in the explicit curriculum (Clandinin \& Connelly, 1992). These findings suggest that curriculum collaboration had a key influence on how the remaking of the curriculum was enacted and what was learnt by students.

\subsection{Teachers' experience and role as adaptive curriculum-makers}

Overall, for teachers, transnational vocational education was experienced as an opportunity to play the role of adaptive curriculum-maker to positively influence student achievement. However, it was also an experience of tension between maintaining fidelity to the intentions of an Australian VET curriculum and meeting the learning needs of their students. The findings show that teachers expressed great concern to uphold the curriculum standards, while conversely enunciating prioritisation of the students' learning needs. Their stories reveal that, over time, the students' interests and needs prevailed in the actions they took as adaptive curriculum-makers. Indeed, many of the omissions, adaptions, and expansions teachers made to the intended curriculum were purported to be based on what they thought were of most value to students (Flinders et al., 1986).

For many teachers, the experience of curriculum-making was also one of uncertainty because many teachers were not sure how to fill the "black box" between the endorsed and non-endorsed components of Training Packages (Barrow, 2006; Hager, 2004). That is, they were uncertain how to create and use site-specific materials to form the teacher-intended curriculum. Although some teachers experienced success with the materials they developed, others were less than satisfied with them because they simply did not have an adequate knowledge about the society, culture, or industry upon which to base material development. These findings suggest that transnational teachers need to learn new knowledge and skills 
to develop materials and construct educational experiences for students in situations that are culturally different from what they are used to in Australia.

The findings presented in the preceding sections of this chapter illustrate how the teachers resituated themselves in transnational settings and worked through the challenges that confronted them to bridge the intended, implemented, and experienced curricula. Indeed, as shown in Chapters 5 and 6 , the dissonance between these and the issues associated with them had considerable influence on the teachers' capacity to enact the curriculum. Teachers were found to respond to these challenges through remaking the curriculum. Thus, the teachers' role in curriculum-making was shown to extend well beyond that of implementers and adaptors: They were shown to be active teachers in the redevelopment of the intended curriculum (Remillard, 2000), at times in collaboration with students (Clandinin \& Connelly, 1992, Mannion et al., 2011).

While a rational model of Training Packages assumes teachers to be faithful implementers and adaptors of the curriculum (Snyder et al., 1992), all the teachers were of the opinion that a teacher's role extends beyond these narrow expectations. Indeed, when asked if teachers should be involved in curriculum development, they all agreed. Three teachers reported this role as primarily making modifications to contextualise the curriculum. The other 10 informants reported that a teacher's role is to plan, organise, and/or develop parts or the entire curriculum. Therefore, it is not surprising that 11 teachers described the changes they made to curriculum to meet the needs of the students as significant or major. Indeed, many of the examples that are reported above support their opinions. So, the role teachers adopted in this inquiry was not the one presupposed by the curriculum model. Rather, it was adopted on the basis of the teachers' own beliefs about the role of a teacher in curriculum implementation and what they perceived was in the best interests of their students.

Notably, the teachers' reports also reveal a dissonance between their professed changes and their fidelity to the intended curriculum. Many of the teachers' accounts contained examples where they had made changes to the intended curriculum, that is, to the curriculum goals, content, language, and/or standards. Yet, when asked to indicate the degree to which they implemented the curriculum with fidelity, on a scale from none to all of the time, all the teachers except for one selected all of the time (2) or most of the time (10). These findings suggest a contradiction between 12 teachers' beliefs and actions. While it is difficult to know the exact reasons for the discrepancy, it is worth considering some explanations. One simple but plausible explanation is that teachers did not want to convey a negative 
impression as being "non-compliant" with Australian regulations by ticking a box without providing some elaboration or justification. A second explanation is that, as reported by other scholars, they were confused about the dual demands of fidelity and adaption, which is linked to a lack of professional expertise (D. L. Ball \& Cohen, 1999; Spillane et al., 2004) or resistance (Down, 2003). Yet, most of the teachers in this inquiry had experience with the curriculum and were not resistant to its primary intentions. However, it is possible that they were less certain about the types and extent of adaptions they could make to "contextualise" the curriculum in another country. An alternative explanation is that the teachers may have considered the adaptions they made as complementary, rather than contradictory. That is, they viewed curriculum remaking as a means for increasing the level of fidelity or achieving the curriculum standards. Although this was true in some instances (e.g., Shiraz added content to assist the students to achieve the curriculum standards), in other instances this was not the case, as seven teachers claimed they lowered the standards of the curriculum to a level that students could achieve. While it is not possible to say which explanation, if any, is applicable, they all have significant implications because they reveal the illusory nature of curriculum remaking in transnational vocational education. In essence, this contradiction represents the central dilemma teachers faced in their experience of transnational education: fidelity to Australian curriculum standards or to the learning needs of students?

In sum, the experience of teaching in countries so fundamentally different from Australia forced the teachers to consider the curriculum and its implementation in a different light. On the one hand, it opened up opportunities for them to make new curriculum materials and practices. On the other hand, they also had to accept local constraints and recognise their own limitations due to their lack of local knowledge and experience. Consequently, teachers filtered and developed the curriculum according to what they understood as relevant, learnable, and attainable for students within the local constraints. The teachers' experiences demonstrate how they reinterpreted the intended curriculum, dependant on their circumstances in specific situations, and subsequently re-developed it to fit (Ben-Perez, 1990; Mannion et al., 2011). These findings are important as they provide insight into the processes by which teachers engaged in curriculum-making in an effort to align the intended, implemented, and experienced curricula. It is through these processes that the curriculum is remade. 


\subsection{Curriculum remaking}

The experiences of the teachers reported in the preceding sections of the chapter show that the intended curriculum was remade through six curriculum strategies. The curriculum remaking that the teachers engaged in to adapt it to the situation involved both the endorsed and non-endorsed components of Training Packages. As was explained in Chapter 3, the endorsed components form the intended curriculum whereas the non-endorsed components form the teacherintended curriculum. To recap, under Australian regulations, teachers are expected to develop the teacher-intended curriculum to support the intended curriculum.

Much of the curriculum remaking the teachers recounted in the preceding sections of this chapter was shown to be in relation to the intended curriculum. Nine teachers reported that they either re-orientated or significantly changed the intended curriculum. Of these, seven reported that the extent of these changes was greater than those they usually made in Australia. The findings reported show that teachers employed five main processes of remaking the intended curriculum: (a) omitting, substituting, and/or adding content; (b) changing pace and sequence of learning; (c) increasing the duration through additional classes and work placements; (d) changing the language of instruction; and (e) lowering the standards for learning and assessment. These findings are noteworthy because, when teachers change what is taught and assessed, it creates variability between what is learnt and achieved by Australian students and transnational students.

It appears from the teachers' accounts that there both subtle and pervasive remaking of the intended curriculum occurred. At one end of the spectrum the extent of this remaking that teachers reported was minimal. For example, Shiraz reported the addition of some assessments on topics pertaining to Australian values and was circumspect with her judgements. At the opposite end of the spectrum, seven teachers lowered the standards, which is a significant act of remaking the curriculum. The extent of the adaptions made to the intended curriculum reveals the high level of discretion exercised by many teachers. Conversely, it is also important to note that the intended curriculum was remade because some teachers were not afforded the scope of role to influence many of the situational factors associated with implementation. For example, Jo could not teach the technical component of the curriculum without electrical equipment and facilities. Therefore, it was both the actions and inactions of teachers that remade the intended curriculum.

It is also notable that this remaking of the curriculum was unknown to other actors (e.g., administrators, heads of departments, auditors) for a variety of reasons. 
Sometimes, the curriculum changes were hidden, simply because teachers like Damien and Rowena worked by themselves in remote locations. At other times, teachers concealed the changes they made because, as Mick shared, "the truth of what is happening overseas is too difficult to admit to". However, it appears from many of the teachers' reports that the main reason that their curriculum remaking was hidden was the lack of monitoring undertaken by Australian educational institutions or the regulator. For example, as shown in Chapter 5, 10 teachers claimed that locally developed materials were rarely subjected to validation, review, or audits. In Chapter 6 it was also reported by 10 teachers that there was little engagement with Australian stakeholders. Therefore, it is not possible to discern whether the teacher-intended curriculum minimised, rather than maximised, the relevance and quality of the experienced curriculum.

In sum, the intended transnational curriculum was remade because teachers adapted it to make it relevant, learnable, and achievable for the students. In this regard, teachers were shown to play a significant role in determining the level of alignment between the intended, enacted, and learned curricula (Remillard \& Heck, 2014) in Australian transnational VET.

\subsection{Summary and conclusion}

The first part of this chapter analyses how these teachers, as a consequence of the situational factors and within the scope of their decision-making, remade the curriculum to increase its relevance, learnability, and attainability for students. Six curriculum remaking strategies were identified through the convergence of emergent themes: (a) curriculum appraisal, (b) curriculum prioritisation, (c) curriculum change, (d) curriculum expansion, (e) curriculum design and experimentation, and (f) curriculum collaboration. In some instances, these strategies supported the curriculum intentions and in other instances, did not. The teachers' experience of curriculum-making was identified as a response to the dissonance between the curriculum intentions and the circumstances for enactment. The identification of these six strategies laid the foundation for understanding the teachers' role as adaptive curriculum-makers during the data analysis. While each strategy was implemented for different reasons and at different times by these teachers, taken together, they highlight the role of teachers in remaking the intended curriculum in Australian transnational VET.

The process of curriculum remaking was frequently expressed as the means to address the tension between the expectation to maintain fidelity to the intentions to 
an Australian curriculum and meeting the needs of their overseas students. Many of the teachers' stories were found to converge around distinct elements of curriculummaking. For example, many described the extensive design and experimentation with materials. In other instances, the teachers' stories of curriculum-making diverged. In some contexts, teachers provided additional classes to help students attain the outcomes; in contrast, other teachers described reducing the standards of the curriculum so that it matched the academic level of students. Highlighting these divergent experiences provides a basis for understanding how the teachers forged their unique ways of overcoming the local factors through curriculum-making. Overall, the teachers made efforts well beyond the requirements of the curriculum to influence the students' learning. However, these practices were not always shown to be consistent with their proclaimed fidelity to the curriculum.

The teachers' experiences reported in this chapter highlight the problems associated with teachers enacting an Australian vocational curriculum in another country. Similar to the findings of other studies (AEI, 2007; Dempsey \& Tao, 2017; Moran \& Ryan, 2003; Shi \& Woodley, 2008; Woodley, 2007) all the teachers found that some of the elements of the curriculum were simply not relevant to the students, especially when they did not intend to work or live in Australia. Their experiences suggest, as contended by many scholars (Anderson, 2006b; Billett et al., 2012; Dempsey \& Tao, 2017; Woodley, 2007), that a more interactive model of curriculum would have enabled teachers to cater for a broader range of students' needs, interests, and aspirations. Further, it would have provided them with the authority and flexibility to negotiate and develop the curriculum in context. In this way, the quality of the curriculum and its enactment may have been enhanced and made transparent.

The findings provide key insights into how and why teachers remake the curriculum in enactment offshore. They also raise questions as to the relevancy and quality of the adaptions teachers make, given that they were often conducted in secrecy and rarely reviewed by others. Additionally, it appears from the teachers' stories that there was little attempt made to provide them with either the materials or professional support to adapt the curriculum to meet the varied needs, interests, and abilities of students in specific countries. Based on their stories, consideration needs to be given to how the curriculum can be meaningfully adapted for transnational vocational education and how materials can be developed and evaluated for specific situations well ahead of time.

The findings also show the failure of Training Packages to accommodate the pedagogical aspects of a quality curriculum enacted. A principal concern for all the teachers was to provide students with the necessary skills and processes to help 
them learn how to learn. Their concerns were based on their appraisal of the students' abilities. However, the curriculum did not provide them with any pedagogical guidance. Thus, it is important for Australian providers to ensure that teachers are provided with opportunities to develop the knowledge and skills for teaching students from other countries. These findings align with those from similar studies that acknowledge the challenges teachers face when students do not respond to their teaching practice as domestic students do (Dunn \& Wallace, 2006; Szkornik, 2017). Indeed, as previously contended in Chapters 2, 3, 5, and 6, the importance of preparing and supporting teachers for transnational teaching and curriculum development cannot be overstated.

In conclusion, the identification of six curriculum strategies for remaking the intended curriculum to meet the needs and interests of transnational students provides the basis for understanding the teachers' role as adaptive curriculummakers in Australian transnational VET. It was shown that teachers adapted the intended curriculum to make it relevant, learnable, and achievable for students. However, the findings also indicate that teachers need adequate preparation and time to develop the necessary knowledge and skills to ensure the quality of those adaptions. Thus, it is contended that teachers need professional support for an extended scope of role as active, informed curriculum-makers to realise the aspirations of students and their sponsors in transnational vocational education. 


\section{Chapter 8}

\section{Conceptualising curriculum implementation in Australian transnational VET: Implications for quality, relevance, and sustainability of provision}

This chapter consolidates the findings from the previous three chapters, makes deductions, and offers explanatory frameworks about how the implementation of transnational curriculum can be made relevant and sustainable. Based on analysis of the literature in Chapters 2 and 3, it was proposed that Australia's approach to the provision of transnational VET through the impost of a national curriculum and its associated regulations onto other countries is more than likely unachievable and undesirable. The conceptual goal of this chapter is to synthesise the findings from Chapters 5, 6, and 7 to identify and explicate a new perspective of curriculum implementation in Australian transnational VET. This view challenges the assumption that Training Packages can and should be implemented internationally with fidelity and in an equivalent way to how they are implemented in Australia. The intention is to contribute explanatory and insightful perspectives into the relevance, quality, and sustainability of Australian transnational VET provision.

The previous three chapters analysed the findings of this inquiry from detailed interviews with 13 teachers, each of whom had experience in VET transnational education. The findings presented and discussions advanced in those chapters provided a nuanced understanding of their particular experiences in enacting Training Packages in nine countries and how a range of interrelated factors and actors impacted their enactment transnationally. Chapter 5 presented and discussed five key factors that were shown to enable or constrain these teachers' enactment of the curriculum with fidelity or as they would in Australia. Chapter 6 then discussed how the range of interrelated factors also impacted on their decision-making and problem-solving, and showed that their ability to influence those factors depended on whether or not there was support for an extended scope of role. Chapter 7 followed with a discussion of how the teachers, as a consequence of those factors and within their scope of influence, remade the curriculum to increase its relevance, learnability, and attainability for students. It also highlighted how the teachers' interpretative and adaptive activities remade the intended curriculum.

This chapter synthesises and advances key inferences from the findings and explains the teachers' perspectives of the dissonance between the intended and transformed curricula and the factors, actors, and processes that influenced it. 
Dissonance is conceptualised as the misalignment between several different types of curriculum that were at work in each situation. Each of these curricula is shown to represent the different sets of interpretations, interests, and concerns of the various stakeholders involved in the provision of the programs. Engaging in curriculum development throughout the enactment process (i.e., remaking) was identified as the teachers' key strategy for aligning those curricula. It also provided them with a framework for making decisions about the relevance and quality of the curriculum in enactment. It is proposed that the teachers' engagement in curriculum development as a process for educational decision-making and problem-solving is critical in understanding how the curriculum was remade as they negotiated between the imperatives of standardisation and the needs and interests of their students in a specific situation at a particular moment of time.

To elaborate on these issues, the conceptualisation of a situational model of curriculum implementation is presented and discussed in the first section of the chapter. Drawing on this synthesis of findings, the second and final section of the chapter provides an overview of five key improvements that would assist teachers in gaining access to a relevant curriculum and support for the provision of quality teaching and learning in Australian transnational VET provision. If Training Packages are to be exported in a global market, then it is proposed that these five improvements would also assist the curriculum to be: (a) ready and fit for purpose before implementation, (b) locally aligned and coherent, (c) relevant to the students' needs and interests, and (d) adequately supported in implementation. This perspective offers an alternative to the policy objective of a standardised approach to the provision of Australian transnational VET. It also responds to the two central research questions that seek to understand the relevance, quality, and sustainability of Australian transnational VET provisions. These questions are:

1. What is the relevance and quality of Australian VET provisions as an exported product (curriculum) in the global VET market?

2. How sustainable is the provision of Australian VET products in the current curriculum form as an export?

It is important to acknowledge that the conceptualisation identified and explicated in this chapter is not the only one that could be identified through the data analysis. However, this conceptualisation was informed by the theoretical framework of curriculum conceptions elaborated on in Chapter 3 that was proposed as a means to understand why there will be differences between the intentions of Training Packages and what is implemented offshore. It is recognised that the conceptualisation may not reflect the concerns of other actors. However, the purpose 
of this inquiry is to interrogate curriculum implementation from a teacher's perspective. Thus, the focus of the analysis is to understand the teachers' experiences of the implementation of Training Packages offshore to offer a perspective that questions the relevance, quality, and sustainability of Australia's current approach to the provision of transnational VET.

\subsection{Conceptualising curriculum implementation in Australian transnational VET}

In synthesising the findings from this inquiry, a conceptualisation of curriculum implementation in Australian transnational VET is advanced in this section of the chapter based on 13 teachers' experiences of Training Package implementation in nine countries. A conceptual scheme of curriculum implementation, informed by the curriculum conceptions discussed in Chapter 3 , is presented to depict the key processes, factors, and relationships that influenced it. It outlines the process of teacher decision-making from the intended curriculum to the transformed curriculum showing the factors and actors that influenced each of the decision points. Thus, it provides a heuristic for investigating the relationship amongst the elements of curriculum implementation and the influences on it by mapping the terrain and revealing the tensions within it. Moreover, it points to the situational nature of curriculum transformation and, in doing so, offers a perspective that questions the objective of standardised curriculum implementation in Australian transnational VET.

The conceptualisation of curriculum implementation is represented through a series of figures and tables, accompanied by an explanation and discussion to gain an understanding of the overall conceptual scheme. This conceptualisation is shown in Figure 8.1 and depicts a dynamic and situational explanation of curriculum implementation, which sits in stark contrast to the regulatory expectations for a logical and systematic approach to Training Package implementation. It shows the relationships amongst the different types of curricula that interacted in the teaching and learning environment and how the teachers tried to align them through a threephased process of curriculum development. The conceptualisation presented here builds on the framework of curriculum conceptions established in Chapter 3 to capture the complexity for teachers in having to enact a vocational curriculum designed for one country in another one. So, an expanded concept of curriculum implementation is presented based on the teachers' experiences, but also influenced 
by the conceptions advanced by other theorists. These influences are mapped in Tables 3.1 (in Chapter 3) and 8.1 and also in the accompanying discussion.

The scheme, as shown in Figure 8.1, commences with the intended curriculum and ends with its transformation. The elements shaded in blue denote the types of curricula present in the teaching and learning environment, including the (a) intended curriculum, (b) teacher-idealised curriculum, (c) supported curriculum, (d) hidden curriculum, (e) null curriculum, (f) teacher-intended curriculum, (g) enacted curriculum (including what was taught and assessed), and (h) learned curriculum. The transformed curriculum appears at the bottom of the figure in grey. An explanation of these types of curricula and the ways they interact is presented in Section 8.1.1. Dissonance sits at the top of the diagram to characterise the teachers' perception of incongruence between the various curricula. The experience of dissonance was the motivation for teachers to engage in three phases of curriculum development to resolve it. The three boxes shaded in pink at the top and in the middle of the diagram encapsulate these phases as (a) assessment, (b) deliberation, and (c) curriculum remaking. This component of the model is elaborated in Section 8.1.2. The arrows within the diagram, as shown in Figure 8.1, are intended to show the relationship of the curricula types as they interacted and the ways they influenced curriculum development. In sum, the arrows indicate how all these elements came together to transform the curriculum. The conceptualisation of curriculum implementation is elaborated in the following three sections of the chapter through a discussion of the: (a) interaction of curricula types, (b) three phases of curriculum development, and (c) recontextualisation of quality. 


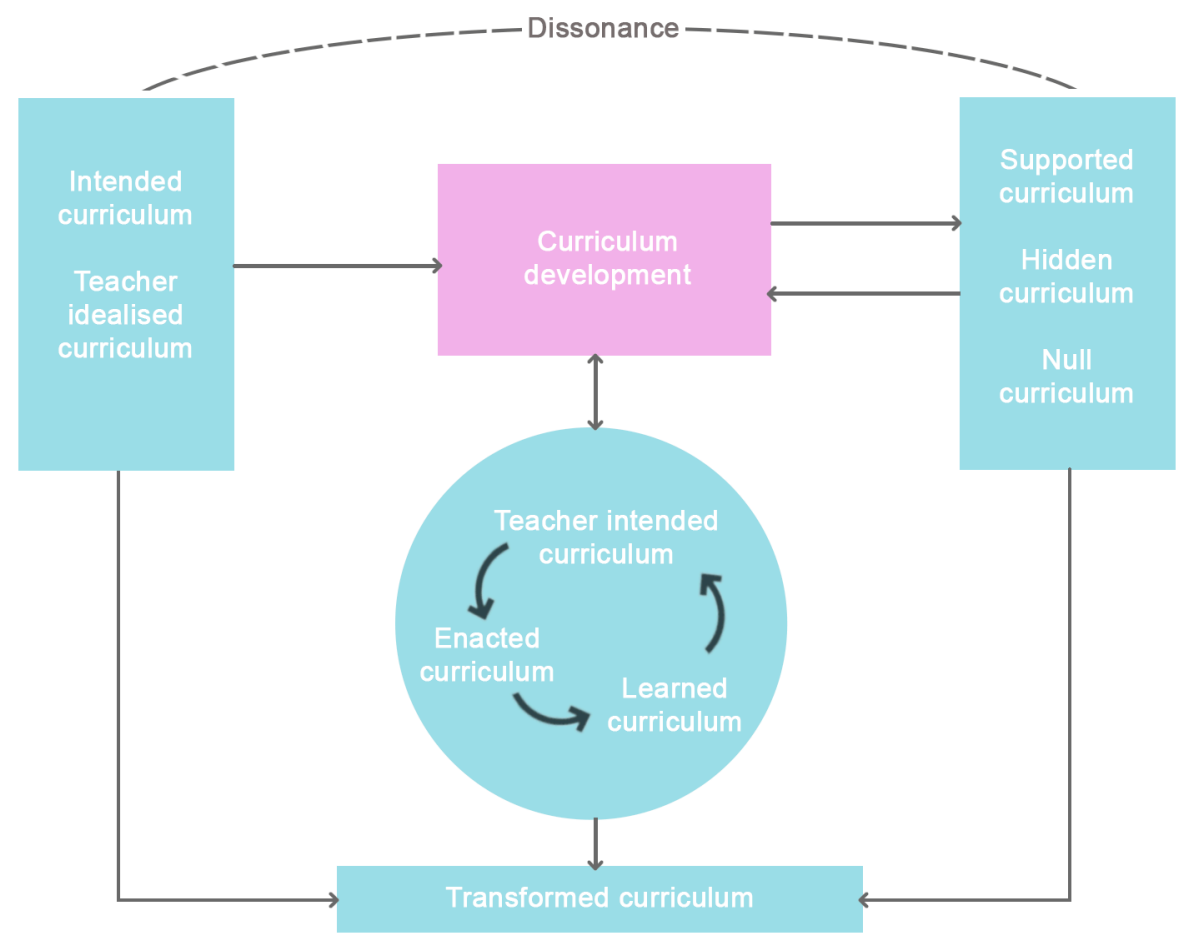

Figure 8.1. Situational model of curriculum implementation.

\subsubsection{Interaction of curricula types}

Several scholars (e.g., Doyle, 1992; Eisner, 2002; Glatthorn, 2000; Remillard \& Heck, 2014) have defined the various types of curricula that operate within an educational institution. As discussed in Chapter 3 , these types of curricula are important because they represent different sets of interpretations, interests, and concerns. The conceptualisation of curriculum implementation presented in this chapter identifies eight types of curricula that appeared to operate simultaneously in each of the 13 participants' situations and these represent the different priorities of stakeholders in transnational vocational education. The construct as presented in Figure 8.1 shows how these different curricular types interacted to influence the transformation of the curriculum, including the processes of remaking undertaken by teachers. The transformed curriculum (which sits at the bottom of the diagram in Figure 8.1) encompasses eight curricular types: (a) intended curriculum, (b) teacheridealised curriculum, (c) supported curriculum, (d) hidden curriculum, (e) null curriculum, (f) teacher-intended curriculum, (g) enacted curriculum, and (h) learned curriculum. Each curricular type is also linked to curriculum development with the arrows indicating the flow of influence.

All the concepts of curricula brought together in this diagram conceptualise the influences on curriculum transformation. The eight types of curricula shown in the 
construct and their description and influence are summarised in Table 8.1. It includes seven curricular conceptions discussed in Chapter 3, as indicated in the table, and an additional one termed "teacher-idealised curriculum". The teacher-idealised curriculum refers to the one that exists between the intended curriculum and the supported, hidden, and null curricula. It represents the intended curriculum as conceived in the minds of teachers based on their prior experiences, most notably in Australia. It is also important to note that the intended curriculum refers to the "endorsed" component of Training Packages. The non-endorsed component was developed to support the teacher-intended, enacted, and learned curricula. The concept of the "transformed curriculum" refers to the final one that was enacted in each specific situation due to the factors and actors that influenced it and the development process that it went through.

Table 8.1

Curriculum Conceptions, Description, and Influence

\begin{tabular}{|c|c|c|}
\hline Conception & Description & Influence \\
\hline \multirow[t]{2}{*}{$\begin{array}{l}\text { Intended } \\
\text { (Eisner, 2002; } \\
\text { Glatthorn, 2000; } \\
\text { Schmidt et al., } \\
\text { 1996) }\end{array}$} & $\begin{array}{l}\text { The syllabus of Training } \\
\text { Packages comprising the } \\
\text { "endorsed" components: goals, } \\
\text { content and standards. }\end{array}$ & $\begin{array}{l}\text { Weak influence, as it did not hold } \\
\text { due to different conditions, } \\
\text { practices, capacities, interests, } \\
\text { needs, priorities, languages, and } \\
\text { understandings. }\end{array}$ \\
\hline & $\begin{array}{l}\text { The syllabus that was regulated } \\
\text { and teachers were expected to } \\
\text { implement with fidelity and to } \\
\text { an equivalent standard as } \\
\text { Australia. }\end{array}$ & $\begin{array}{l}\text { Weak influence, as it did not } \\
\text { provide guidelines to prepare } \\
\text { teachers for enacting the } \\
\text { curriculum and developing } \\
\text { materials in a foreign country. }\end{array}$ \\
\hline Teacher-idealised & $\begin{array}{l}\text { Teachers' idealised version of } \\
\text { what should be enacted and } \\
\text { assessed and how, based on } \\
\text { their prior experience, } \\
\text { knowledge, beliefs, and } \\
\text { understanding of the intended } \\
\text { curriculum. }\end{array}$ & $\begin{array}{l}\text { Strong influence, as it formed a } \\
\text { cognitive benchmark that teachers } \\
\text { used to compare the readiness of } \\
\text { the situation and students to } \\
\text { Australia. }\end{array}$ \\
\hline $\begin{array}{l}\text { Null } \\
\text { (Eisner, 2002; } \\
\text { Flinders et al., } \\
1986 \text { ) }\end{array}$ & $\begin{array}{l}\text { The curriculum that was not } \\
\text { taught. }\end{array}$ & $\begin{array}{l}\text { Strong influence because students } \\
\text { did not have prerequisite } \\
\text { foundational knowledge about } \\
\text { Australia or about how to apply the } \\
\text { knowledge and skills they learnt for } \\
\text { occupations in their own country. }\end{array}$ \\
\hline $\begin{array}{l}\text { Hidden } \\
\text { (Eisner, 2002; } \\
\text { Glatthorn, 2000; } \\
\text { Jackson, 1986) }\end{array}$ & $\begin{array}{l}\text { The curriculum that was } \\
\text { unplanned and embedded in } \\
\text { the institutions' structure, } \\
\text { culture, rules, relationships, } \\
\text { and rituals. }\end{array}$ & $\begin{array}{l}\text { Strong influence on teachers' } \\
\text { scope of role to influence factors } \\
\text { and provide certain experiences for } \\
\text { students. }\end{array}$ \\
\hline $\begin{array}{l}\text { Supported } \\
\text { (Glatthorn, 2000; } \\
\text { Hlebowitsh, 2005; } \\
\text { Spillane et al., } \\
\text { 2004) }\end{array}$ & $\begin{array}{l}\text { The curriculum that includes } \\
\text { arrangements, resources, and } \\
\text { materials. }\end{array}$ & $\begin{array}{l}\text { Strong influence on the means by } \\
\text { which teachers could enact the } \\
\text { curriculum with fidelity and adapt it } \\
\text { for relevance. } \\
\text { Strong influence on the structure } \\
\text { and shape of what could be taught } \\
\text { (content) and achieved } \\
\text { (standards). }\end{array}$ \\
\hline
\end{tabular}


Teacher-intended (Remillard \& Heck, 2014; Ross \& Mannion, 2012)
The intended curriculum (endorsed) remade by teachers to accommodate factors and enact the curriculum. The non-endorsed curriculum (materials) developed by teachers to support the remade curriculum.

\begin{tabular}{lll}
\hline $\begin{array}{l}\text { Enacted } \\
\text { (Doyle, 1992; A. C. }\end{array}$ & $\begin{array}{l}\text { The curriculum that comprised } \\
\text { the teacher and students' } \\
\begin{array}{l}\text { Porter \& Smithson, } \\
\text { interaction with the materials, }\end{array}\end{array} \begin{array}{l}\text { Influence varied according to } \\
\text { quality and relevance of curriculum } \\
\text { remaking and scope of role to } \\
\text { influence factors. }\end{array}$ \\
$\begin{array}{l}\text { Heck, 2014; } \\
\text { activities, and assessment } \\
\text { developed as part of the } \\
\text { teacher-intended curriculum. }\end{array}$ & $\begin{array}{l}\text { The curriculum that teachers } \\
\text { co-constructed with students } \\
\text { through collaboration. }\end{array}$ & $\begin{array}{l}\text { Strong influence on relevance and } \\
\text { understanding of the curriculum } \\
\text { content. }\end{array}$ \\
\hline $\begin{array}{l}\text { Learned } \\
\text { (Glatthorn, 2000; } \\
\text { Smithson, 2001) }\end{array}$ & $\begin{array}{l}\text { The curriculum learnt by } \\
\text { students. }\end{array}$ & $\begin{array}{l}\text { Influence varied according to what } \\
\text { could be enacted and how and the } \\
\text { abilities and interests of students. }\end{array}$ \\
\hline
\end{tabular}

Strong influence as it was based on teachers' interpretations, judgments, decisions, and actions about what would be taught and how within their perceived scope of influence.

The diagram, shown in Figure 8.1, conceptualises the relationship between the curriculum intents and how it differed from what was enacted and learned. Implicit is the assumption that the curriculum existed in different forms, at different times, in different situations. It shows how the curriculum was remade from Australian intentions to local imperatives and reconfigured by the teachers' intentions. However, it also reveals that even before the intended curriculum is influenced by local intentions, teachers already have an idealised version of it based on their prior experience with it. The teacher-idealised curriculum was important because, as was shown in Chapters 5 and 6 , it informed their expectations of the supported curriculum.

It is also important to note that the teacher-intended curriculum was based on the teacher-idealised curriculum, not on the intended curriculum. That is not to say that the teacher-intended curriculum did not comprise elements of the intended curriculum; rather, the materials teachers developed were for the curriculum they interpreted based on past experience and decided to enact given the situational opportunities and constraints. Consequently, as shown in Chapter 6, material development proved an important component of the transformation of the curriculum, as teachers made it fit for the specifics of the situation. The identification of both the teacher-idealised and teacher-intended curricula recognises the mediating role teachers played between the mandated requirements for implementation and what occurred offshore. It is contended that these conditions were the bookends dividing their expectations and what they perceived was practically and politically possible and relevant in the situation. 
The conceptualisation, as illustrated in Figure 8.1, shows that the difference between the teacher-idealised and teacher-intended curricula was due to influence of the supported, hidden, and null curricula. Firstly, as reported in Chapter 7, the supported curriculum (Glatthorn, 2000; Hlebowtish, 2005; Spillane et al., 2004) had considerable influence over what the teachers could enact. At the most basic and practical level, how local institutions selected students, scheduled the program, allocated time for classes, arranged vocational experiences, allocated supplies, equipment and facilities, provided curricula support, and determined assessment practices all led to teachers remaking the curriculum to accommodate this range of factors. Secondly, it was shown in Chapter 6 that the hidden curriculum (Eisner, 2002; Glatthorn, 2000; Jackson, 1986) also had considerable influence on teachers' curriculum remaking decisions as there were many local rules that they were expected to follow. Additionally, the boundaries that institutions set on the teachers' agency also influenced the type, extent, and quality of curriculum development that teachers were able to undertake to achieve their desired improvements. For example, as reported in Chapter 6, the more limits and controls that were placed on teachers' agency, the less they were able to influence the key factors associated with curriculum implementation. Therefore, both the supported and hidden curricula forced teachers to consider alternative resources, experiences, and curriculum content. As a consequence, the teacher-intended curriculum was accommodated within the institution's values, understanding, and resources. Finally, as reported in Chapter 5, the null curriculum (Eisner, 2002; Flinders et al., 1986) was significant because teachers found that the foundational content that transnational students needed to meaningfully engage with an Australian vocational curriculum was absent. Often, the expansions that the teachers made to the curriculum, and reported in Chapter 7, were to compensate for the null curriculum. Thus, the teacher-intended curriculum also accounted for a curriculum that was not developed for the students' needs, interests, and abilities.

The final component of the conceptualisation focuses on the relationship between the teacher-intended curriculum, the enacted curriculum, and the learned curriculum. As aforementioned, the teacher-intended curriculum was the one that teachers developed through its remaking. The enacted curriculum in this scheme also includes the assessed curriculum given that they are closely related as the teachers played an active role in determining what was taught and assessed offshore (A. C. Porter \& Smithson, 2001). Although the enacted curriculum was influenced by the teacher-intended curriculum, it was also informed by the learned curriculum (Glatthorn, 2000). For example, in Chapter 7 it was shown that teachers collaborated 
with students through storytelling and engaging them in the teaching process. Figure 8.1 presents these three curricula in the circle at the bottom of the diagram. The circular arrows linking the three curriculum types emphasise the dynamic relationship amongst them. It draws attention to the role of teachers and students as coconstructors of knowledge and practice in the teachers' classrooms (Clandinin \& Connelly, 1992). The external arrows also show the link to the curriculum development phase to indicate that the teachers, as teachers, continued to perform in the developer role in enactment (Remillard \& Heck, 2014; Ross \& Mannion, 2012). This final component of the construct reveals both the teachers' reconstruction of the curriculum and the co-construction that they undertook with their students within the institutional constraints.

The identification and discussion of these eight curricula types explains the various types of curriculum that were at work in transnational settings. Each curriculum conception represents the differences in interpretations, interests, concerns, priorities, and capacities of stakeholders. This conceptualisation provides insight into the challenges faced by teachers in trying to create a coherent curriculum; that is, a curriculum that responded to both the demands of a mandated curriculum and the needs of sponsors and students within the institutional boundaries. It follows that the next section of the chapter focuses on curriculum development as the teachers' predominant approach to decision-making, problemsolving, and curriculum remaking to align the curricula.

\subsubsection{Phases of curriculum development}

Engaging in curriculum development throughout the enactment process is identified as the teachers' key strategy for aligning the different curricula types. In practice, this meant the teachers adopted the role of curriculum developers, whereby they took their conceptualisation of the curriculum and constructed one that could be implemented and learnt (Print, 1993). Teachers initiated the process of curriculum development because of their sense of dissonance. That sits at the top of the diagram in Figure 8.1. The convergence of experiences arising from the analysis of the interviews with teachers, and presented in Chapters 5, 6, and 7, contributed to an understanding of curriculum enactment as informed by three distinct curriculum development phases: (a) assessment, (b) deliberation, and (c) curriculum remaking. Figure 8.2 provides further detail on this component of the conceptualisation and sets it within the teachers' sphere of decision-making. Incorporating the terms reactive, practical, interactive, and subjective within the diagram is intended to highlight the 
various approaches to decision-making and problem-solving that teachers used throughout the phases of curriculum development. Thus, it takes into account the decisions made by them in response to the factors and the relational resources afforded by their networks. Moreover, the conceptualisation as elaborated in the following discussion illustrates how curriculum development provided a framework of decision-making that enabled teachers to move from a reactive mode of decisionmaking to one that was more analytical, deliberative, and practical over time: remaking the curriculum.

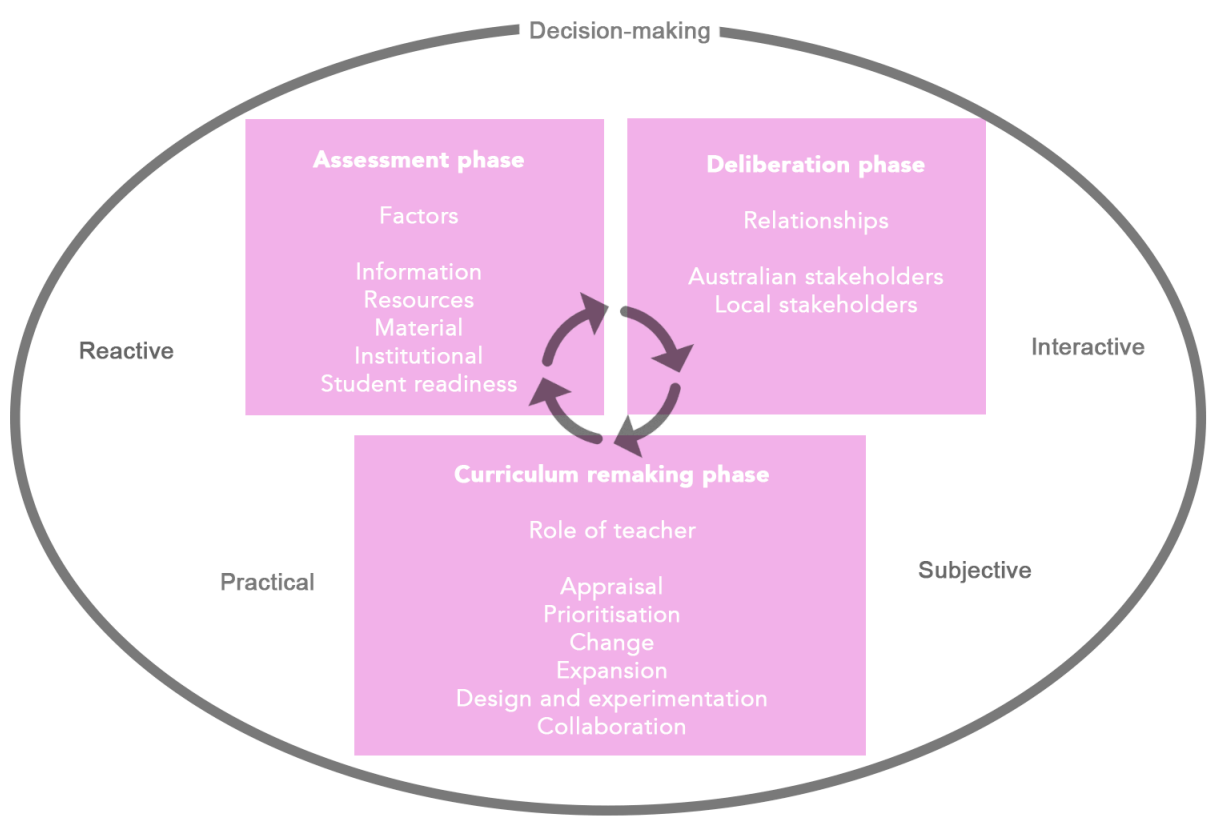

Figure 8.2. Curriculum development as a framework for teacher decision-making and problem-solving.

Distilling the teachers' experiences into three phases of curriculum development emphasises the process engaged in by teachers in remaking the educational provision to resolve the tension between the expectation to maintain fidelity to the intentions of an Australian VET curriculum and to meet the needs of their students. It shows how their perspective of the quality and relevance of enacting an Australian VET curriculum in a foreign country changed, as they had to accommodate various needs and interests as well as different conditions. Thus, the conceptualisation presented also represents the accompanying shifts in the teachers' conceptions of the relevance and quality of the curriculum in their specific situation.

As illustrated in Figure 8.2, the assessment phase comprises the five key factors that were discussed in Chapter 5: (a) information, (b) resource, (c) material, (d) institutional, and (e) student readiness. The deliberation phase characterises the interactions between the teachers and the Australian and local stakeholders as well as the practical action they undertook, as discussed in Chapter 6. The curriculum re- 
making phase is shown to constitute the six development processes discussed in Chapter 7: (a) curriculum appraisal, (b) curriculum prioritisation, (c) curriculum change, (d) curriculum expansion, (e) curriculum design and experimentation, and (f) curriculum collaboration. The circular arrows linking the phases emphasise the dynamic and interactive nature of the development process. They also help to explain the relationship between the factors, the interactions amongst actors, and the role the teachers played in the transformation of the curriculum.

A description of the process, purpose, and intended outcome of each phase is summarised in Table 8.2. The assessment phase as presented in the first row of Table 8.2 describes the teachers' initial experience. This is followed by an outline of deliberation in the second row of the same table. The last phase, remaking, is described in the third row. While distilling the experiences into three key phases, it is also important to note that the teachers' lived experiences did not necessarily occur in sequential phases, although they all started at the assessment phase. Rather, each phase was interconnected with other phases. For example, the teachers' remaking of the curriculum depended on how well they understood the situation and their scope of influence over the factors. Moreover, while challenges emerged in each phase they were also embedded in the interplay between them. The following three sub-sections elaborate on each phase as summarised in Table 8.2.

Table 8.2

Three Phases of Curriculum Development Undertaken by Teachers

\begin{tabular}{|c|c|c|c|}
\hline Phase & Process & Purpose & Intended outcome \\
\hline $\begin{array}{l}\text { Assessment } \\
\text { (Print, 1993; } \\
\text { Skilbeck, 1976) }\end{array}$ & $\begin{array}{l}\text { Situational analysis } \\
\text { Comparative analysis }\end{array}$ & $\begin{array}{l}\text { Sense making } \\
\text { Knowledge building } \\
\text { Situational } \\
\text { understanding } \\
\text { Understanding how } \\
\text { equivalence can be } \\
\text { achieved }\end{array}$ & $\begin{array}{l}\text { Identify contextual } \\
\text { factors, constraints, } \\
\text { and gaps between the } \\
\text { intended and } \\
\text { supported curriculum }\end{array}$ \\
\hline $\begin{array}{l}\text { Deliberation } \\
\text { (Schwab, 1983; } \\
\text { Walker, 1971) }\end{array}$ & $\begin{array}{l}\text { Stakeholder interaction } \\
\text { and negotiation } \\
\text { Practical action }\end{array}$ & $\begin{array}{l}\text { Present focussed and } \\
\text { practically oriented } \\
\text { Enlist support } \\
\text { Influence contextual } \\
\text { factors and overcome } \\
\text { constraints } \\
\text { Problem-solving }\end{array}$ & $\begin{array}{l}\text { Reduce the dissonance } \\
\text { between the intended } \\
\text { and supported } \\
\text { curriculum by } \\
\text { influencing local factors }\end{array}$ \\
\hline $\begin{array}{l}\text { Remaking } \\
\text { (Ben-Peretz, 1990; } \\
\text { Clandinin \& } \\
\text { Connelly, 1992; } \\
\text { Mannion et al., } \\
\text { 2011) }\end{array}$ & $\begin{array}{l}\text { Curriculum appraisal } \\
\text { Curriculum prioritisation } \\
\text { Curriculum change } \\
\text { Curriculum expansion } \\
\text { Curriculum design and } \\
\text { experimentation } \\
\text { Curriculum collaboration }\end{array}$ & $\begin{array}{l}\text { Goal directed and future } \\
\text { oriented } \\
\text { Redevelop the intended } \\
\text { curriculum to overcome } \\
\text { constraints and meet } \\
\text { students' needs } \\
\text { Develop materials for } \\
\text { the teacher-intended } \\
\text { curriculum to support } \\
\text { the remade curriculum }\end{array}$ & $\begin{array}{l}\text { Enact a relevant, } \\
\text { learnable, and } \\
\text { attainable curriculum } \\
\text { for students within } \\
\text { constraints and scope } \\
\text { of role }\end{array}$ \\
\hline
\end{tabular}




\subsubsection{Assessment phase}

The assessment phase, as shown in the first row of Table 8.2, was highlighted in Chapters 5 and 6, whereby teachers undertook their own subjective assessment of the situation. The table shows that this assessment comprised two processes: a situational analysis and a comparative analysis. It also shows that the purpose of engaging with these processes was to make sense of the situation through building knowledge and understanding of the local context. Teachers also used their interpretation of the situation and compared it to their experience in Australia as a way of determining equivalence.

As advanced in Chapter 3, in many models of curriculum development, such as the interactive and dynamic models, a situational analysis is used to examine factors (Print, 1993; Skilbeck, 1976). Typically, it is a foundational step that determines the feasibility of the curriculum proposal in a given situation. It also helps to identify and resolve any discrepancies between the situation and the curriculum intentions prior to implementation. However, a situational analysis of the learning environment is not a feature of the Training Package development process. Rather, the regulations expect Australian educational institutions to ensure that all the requirements listed in the syllabus are in place. However, it appears from the teachers' accounts that in many instances a proper analysis was not conducted, which may well have assisted the teachers' readiness to make decisions: the teachers took it upon themselves to analyse the factors and consider the implications for enactment.

Five common factors were identified in Chapter 5 as the most influential on curriculum implementation in the assessment phase: (a) information, (b) resource, (c) material, (d) institutional, and (e) student readiness. Rather than being a uniform set of factors, they manifested quite differently in each situation, which is not surprising given the diversity of countries in which the teachers were located. These factors were important because in combination they determined the readiness of: (a) teachers to enact the intended curriculum, (b) students to learn the intended curriculum, and (c) sponsors to support the intended curriculum. Thus, the key dilemma for teachers, as a result of their assessment, was whether or not they would be able to enact the curriculum with fidelity and in a way equivalent to how they would in Australia given the limitations of the supported curriculum. Thus, it is notable that at this phase of the curriculum development process, the teachers were primarily committed to the intentions of the curriculum and the regulations that governed them. 
As it turned out, the assessment of factors was the teachers' first step in the curriculum development process because, upon realising the extent of the dissonance between their expectations for curriculum implementation and the reality of their situations, teachers wanted to take practical action to resolve it (Schwab, 1983). Consequently, their initiative in the assessment phase had inadvertently set the wheels in motion for deliberation and curriculum remaking, as seen in Figure 8.2. What was of central concern to the teachers, at this stage, was their capacity to influence the factors associated with curriculum implementation. Thus, these teachers did not deliberately set out to adopt the role of developers in their enactment of the curriculum. Rather, it was related to the situational and temporal contexts of curriculum implementation.

\subsubsection{Deliberation phase}

Good curriculum implementation does not rely just on having the antecedents in place. It also relies on stakeholders to be in general agreement and to have a shared understanding of how to proceed with implementation (Helbowitsh, 2005). Hence, as reported in Chapter 6, teachers expected there would be opportunities for deliberation to ensure the factors were addressed (Schwab, 1983). In this same chapter, curriculum deliberation was revealed in the teachers' processes to negotiate with stakeholders and take practical action (Schwab, 1983; Walker, 1971). The process, purpose, and intended outcome of the deliberation phase are summarised in the second row of Table 8.2. It shows that the teachers' purpose for engaging in deliberation was to enlist support and take action to resolve problems in the here and now. The main focus of these efforts was to influence the resource, material, and institutional factors. The intended outcome was to achieve fidelity to the curriculum and equivalence with Australian settings by aligning their idealised version of the curriculum and the supported curriculum.

The deliberation phase, as represented in Figure 8.2, was characterised by the dynamics of the situation that comprised a complex set of interactions with Australian and local stakeholders. The teachers attempted to discuss and negotiate curriculum problems with actors they perceived as influential. In most instances, deliberation with local stakeholders took precedence as they were seen to have the greatest influence over many of the factors outside the teachers' control. Initially, these teachers reported being optimistic about deliberating with stakeholders and anticipated a reasonable level of support. Their expectations were premised on two taken-for-granted beliefs: Their first expectation was that stakeholders understood 
the theoretical and conceptual nature of the curriculum as well as the processes and requirements for implementation; the second was that they would be supported in their decisions to overcome the constraints. However, the findings reported in Chapter 6 indicated that these expectations were not met for all these teachers. While six of them reported deliberation as a relatively successful strategy for strengthening the supported curriculum, the other seven teachers reported it as less successful even though they tried and some persisted. They learnt that while the local decision-makers had the authority to make changes, they did not always have the capacity, understanding, or inclination to provide the conditions that were necessary for effective implementation (Fullan \& Pomfret, 1977). As a result, it was these teachers who were more likely to rely on their own resourcefulness and/or remake the curriculum to account for the negative influence of local factors.

It was during this phase that these teachers generated better understandings of the hidden curriculum, through learning about the rules they had to follow and the restrictions on their agency, as reported in Chapter 6. In some instances, following these rules meant that teachers could not meet the Australian requirements for fidelity and equivalence. However, breaking the rules could also lead to lamentable consequences. Thus, the key dilemma for some teachers, at this stage, was whether or not they would break these rules and resist the restrictions placed on them so they could meet the mandated requirements. It is notable that it was during the deliberation phase that, for some of these teachers, their commitment to the intentions of the curriculum and the regulations that governed them was challenged.

The phase of deliberation highlights the teachers' attempts to engage stakeholders and take practical action as the key problem-solving strategies for aligning the intended curriculum with the supported curriculum. Their actions revealed their commitment to deliberation as an essential phase of the curriculum development process. It also showed the initial willingness of teachers to take on the role of curriculum developer through negotiation and action to improve the situation rather than accept the status quo. However, it was also the process through which teachers came to understand their scope of influence over the local factors associated with curriculum implementation. Thus, it represented a significant turning point in the teachers' perspective as to whether they could achieve fidelity to the curriculum and equivalence with their practice in Australia, given the circumstances for enactment. Indeed, it became apparent to many teachers that the scope and complexity of enactment was not amenable to a rational and straightforward approach (Pinar et al., 1995; Schwab, 1983; Skilbeck, 1992; Walker, 1971). 


\subsubsection{Curriculum remaking phase}

It was advanced in Chapter 7 that when these teachers adopted the role of curriculum developer in enactment, they used their professional discretion to remake the curriculum to account for the specifics in their situation (Remillard, 1999; Stenhouse, 1993). The diagram presented in Figure 8.1 shows that the curriculum went through a process of remaking in enactment and, in many instances, based on the teachers' accounts, well beyond its intentions. This phase, discussed in Chapter 7 , and shown in the third row of Table 8.2, lists the six curriculum development strategies commonly used by teachers: (a) curriculum appraisal, (b) curriculum prioritisation, (c) curriculum change, (d) curriculum expansion, (e) curriculum design and experimentation, and (f) curriculum collaboration. Teachers were shown to use these strategies to remake the intended curriculum and develop teaching and learning materials to support it in enactment (teacher-intended curriculum).

Primarily, these teachers remade the curriculum for three reasons: (a) relevance, (b) learnability, and (c) achievability. Their initiatives in curriculum remaking were often an expression of their concern for the needs and interests of students. Thus, this third phase represented a shift in the teachers' priorities. Where once the mandates and interests of the Australian Government prevailed, teachers were no longer wedded to them (Clanindin \& Connelly, 1992). Consequently, at this point, the value of the intended curriculum became secondary to student achievement.

It is important to note, that while these teachers believed they should have a say in the curriculum development process, they did not start with the intention to remake the intended curriculum as much as they did. Rather, they decided that, based on their assessment and deliberations, trying to meet the criteria for fidelity and equivalence were neither achievable nor desirable. Thus, in many instances, teachers became "accidental developers" of the intended curriculum in response to the students' needs and interests.

It was also shown in Chapter 7 that 10 teachers found it challenging to create and use materials in another country with students who did not always respond to their teaching as they expected. Firstly, these teachers claimed there was little information or quality material provided to most of them to help them through the initial period. Secondly, they reported uncertainty about how to contextualise the content given their lack of local knowledge and experience. Thirdly, they reported that there was insufficient time made available to them to create and develop quality materials. For all these reasons, there were times that these teachers relied on 
students as co-constructers and teachers of the learned curriculum. Therefore, much of the learned curriculum was place and time sensitive (Mannion et al., 2011).

The phase of curriculum remaking highlights the teachers' efforts to develop the intended curriculum to align all the curricula types that were at work in their situation. Their actions show that while they had to remake the curriculum to account for factors outside of their control, they also exercised their discretion to cater for the students' needs and interests. In the process, their criteria for a quality curriculum shifted from fidelity and equivalence to relevancy, learnability, and achievability for the students, in that situation and at that specific point of time. These findings suggest that during the remaking phase teachers recognised the implications of imposing an Australia VET curriculum in situations for which it had not been designed.

\subsubsection{Recontextualisation of quality}

It is evident, from the preceding discussion, that the teachers' engagement in curriculum development was essential to align the different types of curricula and also informed their revision of what constituted quality in the situation. In this section, the conceptualisation is subjected to further analysis to understand how the teachers recontextualised their ideas of quality when they realised over time that they could not enact their idealised version of the curriculum because it was, to varying degrees, impractical, irrelevant, and unenforceable.

It is proposed that the teachers' recontextualisation of quality began in the assessment phase with their idealised version of the curriculum and continued through to the remaking phase when they developed the teacher-intended curriculum, as depicted in Figure 8.3. The figure depicts how the teachers started by prioritising the externally imposed quality objectives of fidelity and equivalence, marked at the start of the arrow, and over time shifted their priority to a situational version of quality that was based on the needs of students, shown at the end of the arrow.

Assessment phase Deliberation phase Remaking phase

Teacher-idealised curriculum Teacher-intended curriculum

Fidelity and equivalence Student needs

Figure 8.3. Teachers' recontextualisation of quality. 
Quality started for teachers, during the assessment phase, as an aspiration reflected in their idealised version of the curriculum, as depicted in Figure 8.3. Initially, the teachers' past experience set their benchmark for determining fidelity and equivalence. With these two mandated quality standards in mind, teachers had to make decisions about how they would enact the curriculum. So, as they engaged in a process of assessment to understand the supported curriculum, this also began the process of thinking about how they would meet the mandated requirements.

Initially, the teachers acted in ways that supported the mandated requirements. Their support was illustrated in the phase of deliberation, where teachers advocated for situational change. Their view at that stage was that the problems of implementation could be improved by aligning the supported curriculum with their idealised version of the curriculum. Hence, similar to one of the findings from Rahimi and Smith's (2017) case studies, at this stage teachers expected to enact Training Packages as a "technology of trust". In other words, they saw themselves as responsible for ensuring that Australian standards were upheld for transnational students.

However, during the deliberation phase, many teachers found that the mandated requirements for quality were contested. These teachers came to realise that their judgements about the context implied a state of preferences, values, and goals about the way curriculum implementation should proceed (Skilbeck, 1992) and they were not always in accord with the views of local stakeholders (Schwab, 1983). Thus, when they tried to attain their quality aspirations by aligning their idealised version of the curriculum with the supported curriculum through deliberation, many found it was contested (Ross, 1993). Hence, it was during the deliberation phase that many teachers' aspiration for quality was challenged and, as a consequence, their commitment to the construct of quality as codified in the Australian regulations was similarly challenged.

At the same time, an improved understanding of the situation also meant that all the teachers realised, to varying degrees, that enacting the curriculum with fidelity and equivalent to Australian provision was impractical, irrelevant, and unenforceable. Firstly, as reported in Chapters 5 and 6, these teachers found it impractical to enact the curriculum with fidelity and to an equivalent Australian standard because, in many instances, the local sponsors were unable to provide all of the standard resources, materials, and arrangements. As a result, and as reported by teachers in Chapter 7, that they had to appraise, prioritise, expand, and change the curriculum to account for these constraints. For example, without the appropriate resources some teachers could not teach many of the technical elements of a vocational curriculum. 
In another example, teachers in China had to change the assessments to meet the local requirements for exams. It was also impractical teaching students who did not have the foundational knowledge, skills, and language with which to engage with an Australian curriculum at the required level (i.e., at a certificate or diploma level). Thus, many teachers expanded the curriculum to supply the missing elements, changed the language, reduced standards, and extended the duration to accommodate these needs.

Teachers also started to change their minds about enacting the intended curriculum with fidelity when they realised that it was not always relevant because it was not aligned to the students' goals. Similarly to other findings, many teachers found that the taken-for-granted aspects of the curriculum did not apply (Dempsey, 2012; Dempsey \& Tao, 2017; Shi \& Woodley, 2008) and that it was overly focussed on Australian content (AEI, 2007; Anderson, 2006; Dempsey \& Tao, 2017; Moran \& Ryan, 2003; Shi \& Woodley, 2008; Woodley, 2007). In many cases, the relevance of the curriculum was undermined because the curriculum was not used for its primary purpose, which is to prepare students for working in Australian occupations. Indeed, in 11 instances the teachers reported that the students had no intention of working in Australia. Of these instances, seven teachers reported that the students did not even intend to work in a similar occupation in their own country of residence.

Consequently, as reported in Chapter 7, many teachers removed or substituted Australian content to suit the goals of the students who intended to work in their home country.

Teachers also reassessed their commitment to the mandated requirements of fidelity and equivalence when they realised that there was little enforcement of them by the Australian educational institution or the regulator. This finding supports Dempsey and Tao's (2017) claim that that there has been little effort on the part of the Australian federal government to address the difficulties that teachers face in trying to maintain Australian educational standards in other countries. Rather, it appeared to teachers that the application of the regulations was left to local managers and, therefore, subject to the way that they understood, implemented, and prioritised those requirements (Shams \& Huisman, 2012). However, teachers perceived that the local stakeholders did not always understand the mandated requirements or see them as priorities and so they were not always enforced. Notably, as reported in Chapter 6, teachers teaching in countries such as China, Kuwait, Iran, and UAE were of the opinion that the institutional priorities and rules took precedence over curriculum fidelity. For example, the scheduling and segregation of classes, the requirements for exams, the banning of the Internet, and 
limits on work placements were all in conflict with the curriculum intentions and requirements. Given that the teachers had little control over these institutional practices, they were not in a position to enforce the standards. At the same time, many of the usual external controls exerted by institutions and regulators over their own practice were also absent. Consequently, when the Australian stakeholders did not support or monitor them or help them to enforce the requirements, some of these teachers reported being less concerned with meeting the mandated requirements. As a result, they actively remade the curriculum.

As reported in Chapter 7, it was during the remaking phase that teachers reconsidered the achievability or desirability of enacting the curriculum as a technology of trust when it was not practical, relevant, or enforceable. Indeed, many teachers, notably in China and the Middle East, decided that, given the circumstances, it was simply not possible for them to take responsibility for ensuring that Australian standards were upheld for transnational students. The remade curriculum represents the teachers' recontextualisation of quality to focus on the needs and interests of students, rather than the mandated requirements, as depicted in Figure 8.3. While the teachers' commitment shifted away from the mandated requirements, it is important to note that they did not dismiss them entirely; rather, they learnt over time to assess whether they were practically or politically possible to achieve and/or relevant for students. Indeed, in many instances, teachers had considerable impact on improving the quality of the programs through their attempts to achieve Australian standards. For example, as shown in Chapter 7, Damien made notable efforts to create a real-life working restaurant for the hospitality students to practise authentic work activities in Fiji. In another example reported in Chapter 7 , Rachael organised for her event management students to attend events and evaluate them as part of the learning program. These examples are also an apt illustration of how, at times, teachers successfully resolved the tension between the mandated requirements of the curriculum and the needs and interests of their students.

Thus, it is held that teachers did not start with the intention to take on the role of curriculum developer to adapt and remake the curriculum and to recontextualise quality. Rather, they reported entering the situation with a sense of professional expertise and confidence in their capacity to adapt the intended curriculum for the local context but also uphold Australian standards. However, it did not take long for teachers to realise that their construct of quality was dissociated from the context. So, they recontextualised their idea of quality and remade the curriculum to make it more relevant, learnable, and attainable for specific cohorts of students in the 
situation rather than enact one that was exactly the same as Australia. It is proposed that their understanding of what constituted quality changed as they engaged in the curriculum development process and came to comprehend the implications of imposing the mandated quality requirements of an Australia VET curriculum in situations when it was not always practical, relevant, or enforceable.

\subsubsection{Summary}

Conceptualising curriculum implementation in Australian transnational VET through the synthesis of findings from Chapters 5, 6, and 7 provides an insight into the reasons that Training Packages are remade through their implementation in different ways, at different times, and in different situations. It also reveals the difficulties that teachers face when positioned between a "top-down" curriculum approach, where the curriculum was not developed with the local needs and conditions in mind, and the "bottom-up" pressures to conform to the institutional requirements and meet the needs of students (Billett, 2004; Fullan, 1994). It shows that over time the teachers' intentions changed as a consequence of new and different perspectives informed by their assessment of the situation and perceived scope of influence. Therefore, the conditions and relationships that constituted the embedded characteristics of the institution were critical elements in the re-ordering of their priorities through the remaking of the curriculum. Engaging in curriculum development throughout the enactment of the curriculum provided the teachers with a decision-making and problem-solving framework for strengthening the relevance and quality of the curriculum, often in less than ideal situations.

While curriculum development may have helped to improve the opportunities and experience for students, it is likely that such actions were insufficient in meeting all their needs. These findings suggest that the provision of Australian transnational VET should not only be confined to the intended curriculum as manifested in the syllabus; rather, there is also a need for active localised engagement to secure outcomes that do meet the needs and interests of students in every country. Consequently, teacher decision-making should not only be restricted to enacting the intended curriculum but should also be expanded to analyse, deliberate, and develop a relevant curriculum and measures of quality in collaboration with local stakeholders. Such efforts would not only increase the quality and relevance of the curriculum but would also make transparent the worth of the qualification obtained by transnational students. 


\subsection{A sustainable approach to Australian transnational VET provision}

As established in Chapters 2 and 3, the ability of Australia to remain competitive and educationally viable in the transnational VET market is partially premised on ensuring both the quality and relevance of the curriculum. However, the findings reported here and in Chapters 5, 6, and 7 prompt a reconsideration of the relevance and quality of exporting a national and standardised curriculum product in the global market. The findings suggest that if Australia is to continue exporting Training Packages internationally and engaging teachers to enact them, it needs to reconsider how the products are developed, implemented, monitored, and evaluated so they are responsive and sensitive to the various needs of those countries and what students want to learn and how. Further, it appears that many of the problems teachers faced in implementation could have been avoided through proper planning and communication amongst all stakeholders and teachers. It follows that the curriculum needs to be negotiated, planned, supported, and monitored in each situation to strengthen not only the relevance of the curriculum but also the quality of the students' experience. Consequently, teachers, as key experts of the curriculum and its enactment, need to play an active role as developers as well as implementers.

Drawing on the experiences of 13 teachers, this final section of the chapter considers five improvements for strengthening the relevance, quality, and sustainability of an exported curriculum product in the global VET market. These improvements specifically focus on improving the way that Training Packages are developed and implemented offshore, which might help teachers meet the different purposes and outcomes for students, their sponsors, and future workplaces. It is acknowledged that these improvements are not the only ones that could be made to potentially strengthen the relevance, quality, and sustainability of Training Packages in the international market. They are derived from the synthesis of findings presented in the previous section of the chapter. The intention is not to offer either a generalised or polarised view of how Australian transnational VET should be provided; rather, the intention is to elaborate on five improvements that would assist teachers to successfully develop and enact a vocational curriculum internationally. Thus, this section offers one perspective on how Training Packages might be better adapted and teachers better supported for implementation in transnational provision.

The five improvements that are considered are briefly summarised in Table 8.3 as: (a) curriculum negotiation, (b) material support, (c) teacher development, (d) implementation guidelines, and (e) monitoring implementation. It is suggested that 
this set of improvements offers Australian educational institutions and the teachers who work for them the opportunity to offer a curriculum that is: (a) ready and fit for purpose before implementation, (b) locally aligned and coherent, (c) relevant to the students' needs and interests, and (d) adequately supported in implementation. Each improvement is explained in greater detail in the remaining section of this chapter.

Table 8.3

Five Suggested Improvements

\begin{tabular}{ll}
\hline Improvement & Description \\
\hline Curriculum negotiation & $\begin{array}{l}\text { Opportunity to develop a locally aligned and coherent } \\
\text { curriculum that is fit for purpose and relevant to the needs, } \\
\text { goals, and interests of students. }\end{array}$ \\
& $\begin{array}{l}\text { Engagement with industry to align the occupational } \\
\text { standards, practices, and requirements. }\end{array}$ \\
& $\begin{array}{l}\text { Opportunity to provide transnational students with the } \\
\text { foundational knowledge and skills they need to } \\
\text { successfully engage with a vocational curriculum in } \\
\text { English. }\end{array}$ \\
\hline Material support & $\begin{array}{l}\text { Provision of accessible site-specific materials prior to } \\
\text { implementation. }\end{array}$ \\
& $\begin{array}{l}\text { Opportunities for teachers to collaborate with local experts } \\
\text { to further develop materials before and during } \\
\text { implementation. }\end{array}$ \\
\hline Teacher development & $\begin{array}{l}\text { Opportunity to play an active role in the curriculum } \\
\text { development phase. }\end{array}$ \\
Information and induction for the local site. \\
Professional development for creating materials and \\
teaching students with diverse learning approaches and \\
languages.
\end{tabular}




\subsubsection{Curriculum negotiation}

The first suggested improvement, as summarised in Table 8.4, is curriculum negotiation so that teachers can enact a vocational curriculum that is relevant to the goals, needs, and interests of students. The findings indicate that if Australian stakeholders were permitted to negotiate the endorsed curriculum with sponsors it would provide them with an opportunity to develop a locally aligned and coherent curriculum that was fit for purpose and relevant in context. Otherwise, it is held that the implementation of Training Packages offshore should be restricted to its main purpose, which is to prepare individuals for occupations in Australia. However, even in these instances, the findings suggest that the curriculum would still need to be supplemented with additional content so teachers can teach the foundational knowledge, literacy, and skills that transnational students need to successfully gain employment in Australia. For example, in Chapter 7 it was reported that Shiraz developed supplementary content so the Filipino students could learn about the cultural values and practices that underpin aged care practice in Australia. She also organised for the students to undertake voluntary work experience in Australia so they could learn about the work conditions and practices in context before they were employed. Shiraz's experience highlights the importance of supplementing the endorsed curriculum to ensure that transnational students are successfully prepared for gaining employment in Australia.

The findings also suggest that in some situations it is feasible that Training Packages could be used as basis for preparing individuals for occupations in their home country. For this to occur the current regulations would need to change so that Australian stakeholders were permitted to negotiate the intended curriculum with foreign partners. A negotiated curriculum would enable the development of locally aligned and coherent curricula that are fit for purpose and relevant to the students' needs, goals, and interests. It appears from the findings that this approach is more likely to work when there is compatibility between the occupational standards of the countries. For example, two teachers involved in work-based programs (i.e., an education program in a South Pacific country and a management program in PNG) reported that the curriculum content was highly applicable to the students' workplace but did require some adaptions to contextualise it. In comparison, the experiences of two other teachers show that the capacity to negotiate an electro-technology or architectural curriculum in countries that have different systems or safety regulations to Australia may not prove feasible. 
It is suggested that a negotiated curriculum would involve stakeholders, including teachers, in engaging with industry to align the Training Package with local occupational standards, practices, and requirements. It is also likely that the curriculum would need to be expanded to provide students with the opportunity to develop the foundational knowledge and skills (i.e., Australian values and culture, problem-solving, language proficiency) that they might need to successfully engage with a vocational curriculum in English.

In other situations, where students are interested in developing academic skills to prepare for a higher education program, the findings suggest that it is simply not desirable for teachers to enact a curriculum that does not meet these purposes. For example, similar to the findings of other studies (Woodley, 2007) in Chapter 5, it was reported that the teachers who taught business programs in China claimed that what they had to teach students was of little interest to them and what students wanted to learn was not covered in the curriculum. In these instances, a more viable alternative would involve stakeholders in negotiating and accrediting tertiary preparation programs for transnational provision. For all these reasons, it is contended that the opportunity for curriculum negotiation for Australian transnational VET provision curriculum would assist teachers to enact a curriculum that is fit for a range of purposes and relevant to students, sponsors, and future workplaces.

\subsubsection{Material support}

The second suggested improvement is to ensure teachers are provided with site-specific material for the non-endorsed components of Training Packages to assist them in providing a quality learning experience for students. Similarly to Dempsey and Tao's (2017) findings, teachers tried to develop local case studies and other contextualised materials, but often these proved unsatisfactory. These findings indicate that the quality of enactment would be considerably enhanced if teachers, especially those who are new to transnational teaching, were provided with predeveloped, site-specific materials. Additionally, the opportunity to collaborate with local experts to further develop these materials before and during implementation would also strengthen the means by which teachers could enact the curriculum. If the curriculum could be negotiated, then the content of the material would need to support it. Improving material support would assist the readiness of teachers to enact a quality and relevant vocational curriculum for transnational students. 


\subsubsection{Teacher development}

The third suggested improvement is teacher development. The findings indicate that even the most experienced teachers from Australia need to be provided with opportunities to develop new forms of knowledge and skills to develop and enact a vocational curriculum in another country. Similarly to other findings (Dempsey \& Tao, 2017; Leask, 2004), in this study teachers found it difficult to both develop relevant materials and teach students with diverse learning backgrounds and abilities. Other research has also shown that professional development programs are important in equipping teachers with the skills they need to teach in a foreign country (Dunn \& Wallace, 2004; Gribble \& Zigarus, 2003; Keevers et al., 2014; Tran \& Le, 2017).

The findings suggest that teachers would benefit from the: (a) opportunity to play an active role in curriculum negotiation, (b) provision of information and induction for the local site, and (c) provision of professional development for teaching students with diverse learning approaches and languages. Firstly, teachers benefit from playing an active role in the negotiation and development of the curriculum with local experts. For example, as was shown in Chapter 5, Steven was able to negotiate and develop the management program with the local sponsors in PNG.

Consequently, he reported a good understanding of the context for implementation, collaborative relationships with local stakeholders, and relevant curriculum materials with which students could engage. Secondly, the adequate preparation of teachers through the provision of a detailed induction program and ongoing professional development opportunities is important. Based on the findings it seems that a useful induction program for teachers would comprise (a) an initial pre-departure briefing, and (b) onsite orientation. The initial briefing would assist teachers to gain an understanding of what is expected of them in relation to their role and to build relationships with local stakeholders. Teachers would also benefit from learning about their students' backgrounds and motives for learning (Tran \& Le, 2017). The initial briefing would then need to be followed up on arrival so that teachers were successfully orientated to the teaching and learning environment and learnt more about the situation, students, and local workplaces. Thirdly, teachers need to develop the pedagogical expertise to teach students who do not respond to their teaching practice in the same way as domestic students (Dunn \& Wallace, 2006; Szkornik, 2017 ; Tran \& Le, 2017). It is contended that the quality of transnational provision would be strengthened through teacher development. 
The findings suggest that how professional development is provided is also important (Chin \& Benne, 1970; Clarke \& Hollingsworth, 2002; Penuel et al., 2007). While the capacity of Australian and foreign partners to provide ongoing opportunities for teacher learning is critical, these opportunities also need to be based on normative strategies that connect to teachers' values and respect their prior curriculum knowledge and teaching expertise (Coburn, 2004). Otherwise, as reported in Chapter 6, the use of power-coercive strategies, which was shown to be prevalent in some countries such as China, UAE, and Kuwait, is only likely to lead to covert resistance amongst teachers. It is held that the main problem with teacher resistance, in relation to quality in transnational education, is that it can reduce the transparency of curriculum adaption. Therefore, providing professional development that supports teachers to learn new skills and knowledge in a supportive environment is a critical component of ensuring the quality of Australian transnational VET provisions.

\subsubsection{Implementation guidelines}

The fourth suggested improvement is the provision of guidelines for the international implementation of each Training Package. If Training Package products are to be implemented with fidelity then teachers and other stakeholders need to understand what contextualisation and equivalence means in transnational provision.

Similarly to other studies (AEI, 2007; Shi \& Woodley, 2008; Woodley, 2008), teachers held different interpretations as to what equivalence and contextualisation meant in practice. Indeed, it was notable that most of the teachers made many, and sometimes significant, adaptions to the curriculum in their efforts to contextualise it, yet still maintained that they achieved fidelity most or all of the time. Moreover, many of them readily admitted that implementation was not equivalent to Australia because it was not achievable or desirable. So, if there is no consistency in interpretations of equivalence or information about its application, then it is unlikely there is uniformity in Australian VET provisions internationally.

It is proposed that all stakeholders, including teachers, would benefit from advice on how to achieve the balance between equivalence and contextualisation in relation to the: (a) provision of standard equipment, facilities, and supplies; (b) organisation of vocational experiences; (c) scheduling and duration of curriculum; and (d) assessment practices. For example, if female students are not allowed to participate in work placements because of cultural norms, what is an equivalent experience that teachers or the local sponsors can arrange? The provision of these 
implementation guidelines for transnational provision would ensure that there is an opportunity to understand what sort of contextualisation is and is not permitted and what equivalence actually means in transnational provision. Alternatively, if the curriculum can be negotiated then the guidelines would need to explain the rules that would govern this and how quality can be defined and measured in context. In either situation, it is important to ensure that stakeholders receive comprehensive guidance so they can develop an adequate understanding of how to achieve the required standards.

\subsubsection{Monitoring implementation}

The fifth suggestion for improvement is the monitoring of Training Package implementation by Australian stakeholders, so that teachers are supported in their decision-making, problem-solving and curriculum-remaking offshore. The findings suggest that the active involvement of the Australian partner is critical for enforcing standards and supporting teachers to align the intended, supported, and enacted curricula. As set out in Chapter 6, many teachers reported that the Australian stakeholders did not monitor curriculum implementation or respond to their requests for support. It was shown that, consequently, teachers were left to make their own decisions or raise implementation problems with local sponsors, which in some countries put them in a precarious position. Moreover, it was reported in Chapter 5 that many of the materials that teachers received were not subject to a quality review. Therefore, the teachers were not accountable for the adaptions they made in the remaking of the intended curriculum. Thus, it is contended that if Australian stakeholders were to effectively monitor implementation then problems are more likely to be identified and potentially resolved in a more transparent way, as both sponsors and teachers would be held accountable for the decisions they make.

\subsection{Conclusion}

The conceptualisation of curriculum implementation identified and explicated in this chapter advances an understanding of how Australian Training Packages are remade when they are implemented offshore. It shows the local factors that influence it and the cause and effect of different relationships and teacher roles, as well as depicting key processes. It suggests that Australia's approach to ensuring quality in transnational education through the impost of both national curricula and their associated quality systems onto other countries is unachievable for most teachers 
and can undermine the relevance and quality of those provisions for sponsors and their students. Subsequently, these findings question the sustainability of pursuing standardised curriculum implementation in Australian transnational VET.

At the same time, the synthesis of findings also illuminates the opportunities for strengthening the relevance, quality, and sustainability of Australian transnational VET provisions. It offers five improvements for supporting teachers to develop and enact a relevant vocational curriculum that can meet the specific purposes and goals of students, their sponsors, and future workplaces in different countries. These improvements offer opportunities for curriculum negotiation, teacher development, implementation guidelines, material support, and the monitoring of implementation by Australian stakeholders. It is contended that if these improvements had been put in place for this group of teachers, it would have improved their readiness and capacity to enact a relevant and quality vocational curriculum to meet the needs of their students offshore. 


\section{Chapter 9}

\section{Transnational vocational education: Conclusions and contributions}

This dissertation has explored the problem of transnational vocational education curriculum through an interrogation of the relevant literature to identify the factors that assist understanding this phenomenon and through a practical enquiry comprising detailed interviews with 13 teachers who have enacted standardised vocational curricula developed in one country transnationally. The review of the literature, in Chapters 2 and 3, identified key factors associated with transnational education and the practical inquiry subsequently elaborated those factors and identified the implications for enacting, in other countries, VET curricula designed for Australia. A qualitative orientation and phenomenological approach was used to collect and analyse data and to offer an explanatory account of transnational education through the lived experiences of these teachers. The findings offer a nuanced account of the local factors and relationships that influenced how these teachers enacted the intended curriculum and how they engaged in decision-making, problem-solving, and curriculum-making to overcome the constraints they encountered and to meet the needs and interests of their students. That is, in mediating these constraints and generating educational responses, they became the curriculum-makers. To elaborate these issues, a conceptualisation of curriculum implementation, influenced by theories of curriculum development and implementation, was derived from the review, and the synthesis of findings of the practical inquiry became the means by which to identify the implications for the relevance and quality of Australian transnational VET provisions. Also conceptualised were basic propositions for enabling a set of improvements that might contribute to more sustainable approaches to the provision of Australian transnational VET. These conceptualisations provide an alternative view to the current policy objective of international standardisation in the implementation of Training Packages.

In briefly explicating these outcomes, this final chapter comprises five sections. The first section provides a summary of six key findings, based on the analysis of the data presented in Chapters $5,6,7$, and 8 . The second section discusses four contributions to the field based on those findings. The third section draws on the findings to suggest five implications for policy and practice. The fourth section makes recommendations for future research areas while the concluding 
section highlights the importance of an extended scope of role for teachers to assess situations for curriculum implementation, and to be allowed the space and time to deliberate on and develop a relevant curriculum, and its measures of quality, in collaboration with local stakeholders. Such efforts would recognise the important role that teachers play in realising the benefits of transnational vocational education.

\subsection{Key findings}

The findings presented in Chapters 5, 6, and 7 highlighted the lived experiences of 13 teachers enacting Training Packages across nine countries. The inquiry explored the factors that emerged when these teachers were expected to enact a highly prescriptive, standardised, and regulated curriculum in countries for which it was not designed. The analyses of the data focused on how these factors influenced their decision-making, problem-solving, and curriculum-making which, through these processes, led to a transformation of the intended curriculum. Chapter 8 synthesised these findings to posit a conceptualisation that captured the situational and temporal nature of curriculum implementation offshore. This challenges assumptions that Training Packages can be and are implemented consistently across the world. The findings, offering key insights into the relevance, quality, and sustainability of Australian transnational VET, are summarised below.

\subsubsection{The influence of situational factors}

The first key finding is that situational factors were important determinants of curriculum implementation. As Chapter 5 shows, five localised factors had a key influence on the teachers' capacity to enact the curriculum as it was intended. Four factors related to the supported curriculum (i.e., the resources and arrangements that support implementation): (a) information, (b) resource, (c) material, and (d) institutional factors. The fifth factor, student readiness, relates to the learned curriculum (i.e., how students come to engage with and learn from what they experienced) that comprised four sub-factors: (a) goals and interests, (b) language proficiency, (c) prior knowledge and abilities, and (d) learning styles and preferences. This array of factors was important because it determined the quality of alignment amongst the intended, implemented, and experienced curricula in each situation.

Each of the five factors played a specific role in influencing the teachers' enactment of the curriculum. Access to quality information affected the teachers' understanding and learning about the situation and influenced their preparedness for 
enacting the intended curriculum transnationally. The resources that were made available, and their quality, determined the practical support teachers had to achieve the standards of a vocational curriculum. Material support influenced the readiness of teachers to plan and enact a quality vocational curriculum that was relevant in another country. The local institutional arrangements variously shaped what content could be taught and to what standard. Student readiness factors, which accounted for the majority of the teachers' concerns, influenced their capacity to (a) engage the students in learning the curriculum content, and (b) facilitate the students' achievement of the outcomes. All of these localised factors, taken in sum, shaped the potential and limits within which the intended curriculum could be enacted by teachers and learnt by students in different situations (S. J. Ball et al., 2012; Hlebowitsh, 2005; Lauder et al., 1998; Spillane et al., 2004).

These factors manifested quite differently in each of the nine situations, reflecting the findings of many other studies that show that there is significant diversity amongst the socio-cultural contexts for Training Package implementation nationally and transnationally (Agbola \& Lambert, 2010; Bailey, 2011; Bilboe, 2011; Guthrie, 2009; Guthrie et al., 2006; Hoeckal et al., 2008; Hua et al., 2011; Schofield \& McDonald, 2004; Woodley, 2007). In some of these situations, specific factors were constraining and in others they were enabling. Yet, regardless of whether their influence was positive or negative, this set of factors shaped the implementation of the curriculum according to the experiences of these teachers. It was the overall impact of these situational factors that contributed to a diverse range of unfamiliar problems and dilemmas that this group of teachers were forced to resolve in their enactment of the curriculum in transnational vocational education.

\subsubsection{Teachers' scope of influence}

The second key finding is that teachers cannot simply enact Training Packages in another country with fidelity unless they have: (a) support for an extended scope of role to learn about the factors in the situation before having to address them, and (b) the capacity to influence them through decision-making and problem-solving. Without the agency to address these factors, teacher facility to maintain Australian standards and fidelity to the curriculum can, at times, be compromised.

The quality of support afforded teachers through their interactions with local stakeholders largely determined their ability to learn about and address those situational factors most outside of their control. This was particularly the case given 
that most teachers reported that Australian stakeholders did not clearly articulate or prepare them for their role as transnational teachers or support their requests to help influence the standard of provision. Local relationships were predicated on the institutional stakeholders' understanding of the curriculum and their perceptions about the role of teachers in curriculum implementation, and these differed amongst countries. The efforts of many teachers to enact the mandated requirements in large institutions in countries such as China, Kuwait, and UAE were often contested. In comparison, the decisions of teachers involved with small-scale projects, working on their own or with one other colleague in other parts of Asia or in the South Pacific region, were usually supported within local conditions. The differences in the experiences of these two groups of teachers were significant because it was the latter group who made the most pervasive changes to the intended curriculum in their remaking of it. Thus, the difference in the teachers' scope of influence was subject to the cultural and social structures of the local institution and the power relationships within them (Priestley et al., 2012). Consequently, these teachers' scope of influence in enforcing curriculum standards was limited or enhanced by the level of support they received from local stakeholders to address the factors associated with curriculum implementation.

\subsubsection{Teachers as adaptive curriculum-makers}

The third key finding is that transnational vocational education provided teachers with the opportunity to play the role of adaptive curriculum-maker to positively influence student success. As a consequence of the situational factors, and within their scope of influence, teachers remade the intended curriculum to increase its relevancy, learnability, and attainability for students. To remake the intended curriculum teachers used five strategies: (a) curriculum appraisal, (b) curriculum prioritisation, (c) curriculum change, (d) curriculum expansion, and (e) curriculum collaboration. Also, the strategy of curriculum design and experimentation was used to plan, create, and use materials to support the curriculum they remade. Taken together, these strategies represent the teachers' efforts to align the intended, implemented, and experienced curricula to improve student achievement (Glatthorn, 2000; A. C. Porter \& Smithson, 2002; Squires, 2009).

Teachers, as adaptive curriculum-makers, reported both subtle and pervasive remaking of the intended curriculum. For example, teachers were shown to: (a) omit, substitute, and/or add content; (b) change the pace and sequence of learning; (c) increase the duration through additional classes and work placements; (d) change 
the language of instruction; and (e) lower the standards for learning and assessment. Many of these adaptions have not previously been located in the literature pertaining to the enactment of Training Packages in Australian transnational VET. While Dempsey and Tao (2017) have reported examples of teachers adapting the curriculum to suit the local context, their studies and others have not explicitly mentioned teachers lowering the curriculum standards. The extent of adaptions these teachers made to the intended curriculum reveals the high level of discretion exercised by this group as adaptive curriculum-makers. However, given the lack of both external monitoring of these adaptions and evaluation of the materials that teachers developed and used in enactment, it is not possible to discern whether the remaking of the intended curriculum led to an increase or a decrease in the relevance and quality of what was enacted by teachers and learnt by students in each situation.

\subsubsection{Curriculum development as a framework for teacher decision-making in enactment}

The fourth key finding is that curriculum development provided a framework of decision-making that enabled teachers to move from a reactive mode of decisionmaking to one that, over time, became more analytical, deliberative, and practical. Teachers engaged in three curriculum development phases: (a) assessment, (b) deliberation, and (c) remaking, to resolve the tension between the expectation to maintain fidelity to the intentions of an Australian VET curriculum and to meet the needs of their students. In the assessment phase, teachers made sense of the situation by analysing the factors and considering the implications for enactment. In the deliberation phase teachers negotiated with stakeholders and took practical action to resolve curriculum problems. In the remaking phase, teachers took their conceptualisation of the intended curriculum and constructed and enacted one that they believed could be implemented and learnt in the situation (Print, 1993).

Teachers reviewed their ideas of quality during the process of curriculum development when they realised, through direct experience, that they could not enact the intended curriculum because it was, to varying degrees, impractical, irrelevant, and unenforceable. Thus, their perspective of the quality and relevance of enacting an Australian vocational curriculum transnationally changed as they learnt to accommodate the contradictory interests and influences of stakeholders under different conditions. The decisions teachers made in the three phases of curriculum development were shown to support, challenge, and subvert the curriculum 
intentions at different times and under different conditions. Thus, by engaging in curriculum development, teachers made a decision about what constituted a relevant and quality vocational curriculum within the local constraints and their scope of influence in each situation.

\subsubsection{The limitations of the intended curriculum of Training Packages in transnational vocational education}

The fifth key finding is that many of the problems that teachers experienced were due to the limitations they encountered from using the highly regulated domestic curriculum of Training Packages in transnational education provision. Teachers found it challenging to engage students in a curriculum that was not developed to account for the students' specific goals, interests, abilities, and needs. In particular, the Australian-centric nature of the intended curriculum proved difficult to enact because, similarly to other findings, many teachers reported that: (a) those aspects of the curriculum that are taken for granted in Australia were not understood by overseas students (Dempsey, 2012; Dempsey \& Tao, 2017; Shi \& Woodley, 2008), (b) the curriculum was overly focussed on Australian content that was not relevant to many students who did not intend to work in Australia (AEI, 2007; Anderson, 2006b; Dempsey \& Tao, 2017; Moran \& Ryan, 2003; Shi \& Woodley, 2008; Woodley, 2007), and (c) the technical language and jargon typical of Australian industry settings were not used by students in their home country and local workplaces (Shi \& Woodley, 2008; Woodley, 2007). The failure of Training Packages to provide pedagogical guidance or teaching and learning materials was also a barrier to the teachers' ability to contextualise the curriculum and facilitate student engagement and achievement in a foreign country. Similarly to other findings (Shi \& Woodley, 2008; Woodley, 2008), teachers in this study reported finding it difficult to understand how to construct "equivalent" educational experiences for students given that neither Training Packages nor the regulations that govern their enactment provide specific guidelines for international implementation or advice on how to achieve equivalence with Australian provision. Thus, for these 13 teachers in nine countries, the intended curriculum of Training Packages did not always support relevant and quality transnational teaching or student achievement of standardised outcomes. 


\subsubsection{Localised knowledge is privileged}

The sixth key finding is that the opportunity to develop localised knowledge was critical to the quality of decision-making, problem-solving, and curriculummaking for this group of teachers. Extensive knowledge of and experience with the intended curriculum in Australia was not sufficient preparation for these teachers to enact it in another country. As other findings show (Dempsey \& Tao, 2017; Leask, 2004; Tran \& Le, 2017), teachers needed to develop localised forms of knowledge to: (a) understand the circumstances for enactment, (b) build relationships with institutional stakeholders, (c) create and use site-specific curriculum materials, and (d) develop a new set of pedagogical practices to meet the students' learning needs. Consequently, local knowledge was fundamental to the teachers' development of curriculum literacy (Ariav, 1988); that is, knowing how to enact a relevant and quality curriculum in specific situations.

\subsubsection{Summary}

In sum, it was problematic for teachers to enact a vocational curriculum designed for Australia transnationally as it was not always relevant or well supported by implementation guidelines, resources, site-specific materials, or institutional arrangements. The capacity of the teachers to resolve these problems relied on their scope of influence to address local factors and the extent of their local knowledge to understand how to enact the curriculum in their situation. Engaging in curriculum development assisted teachers to increase their local knowledge, exercise their scope of influence, and remake the intended curriculum to increase its relevancy, learnability, and attainability for students. However, given the lack of external monitoring of curriculum implementation, it is not possible to discern whether the teachers' decisions and actions improved the relevance and quality of what they enacted and what students subsequently learnt.

\subsection{Contributions to the field}

This dissertation explored the phenomenon of Australian transnational VET in nine countries. In doing so, it has investigated a phenomenon that is not well understood and it has highlighted the multifaceted and complex nature of implementing a vocational curriculum designed for one country, in another, based on the accounts of 13 teachers doing so in nine countries. The four main contributions to the knowledge in this particular field are identified as: (a) identifying the factors that 
shaped curriculum enactment in Australian transnational VET; (b) conceptualising the tension between the intended and enacted curricula in Australian transnational VET; (c) recognising the role that teachers play as curriculum-makers in Australian transnational VET; and (d) identifying tentative strategies for improving the relevance, quality, and sustainability of Australian transnational VET. These contributions are advanced below.

\subsubsection{Identifying factors shaping the enacted curriculum in Australian transnational VET}

This project sought to explore the factors surrounding curriculum implementation in Australian transnational VET from the perspective of 13 teachers. A complex set of local factors was identified in Chapter 5 that shaped these teachers' enactment of the intended curriculum in different ways. Five local factors were shown to have a profound effect on the teachers' capacity to enact the intended curriculum in a situation for which it was not designed. The five factors were presented in Table 5.1 as: (a) information, (b) resource, (c) material, (d) institutional, and (e) student readiness. The student readiness factor comprised four sub-factors: (a) goals and interests, (b) language proficiency, (c) prior knowledge and abilities, and (d) learning styles and preferences. It is held that the differences between the intended curriculum and what was enacted were greatest when it was neither adequately supported by the local institution nor aligned with the goals and learning needs of students.

All of these local factors were internal and were shown to have a greater influence on enactment than external factors such as regulatory requirements or Australian stakeholder support. While internal factors have been identified as influential in other curriculum implementation studies (Corbett \& Rossman, 1989; Fullan, 1982; House, 1996), the findings here differ because internal factors were more influential than external factors. However, the reasons these internal factors were the most important for these teachers were precisely for the same reason that external factors have been found important in other studies. That is, these factors were often outside of the teachers' control. Thus, it is proposed that Australian regulatory measures for fidelity and uniformity were, ultimately, a weak influence as situational factors shaped the degree to which the intentions of the curriculum were realised.

This first contribution illustrates that situational factors hold greater influence than mandatory regulations over whether the intentions of Training Packages are realised in Australian transnational VET. Furthermore, it elucidates that professional, 
practical, institutional, and material support for teachers are all key indicators of success in the enactment of a relevant and quality curriculum in transnational vocation education.

\subsubsection{Conceptualising the tension between the intended and enacted curricula in} Australian transnational VET

The conceptualisation of curriculum implementation presented in Chapter 8 advances an understanding of the tensions between the intended curriculum and the enacted curriculum in transnational vocational education. The explication of the conceptualisation is helpful as it provides a platform for understanding the relationships between the elements of curriculum implementation, and the influences on them, by mapping the terrain and revealing the tensions created by their interaction. Eight different types of curricula were identified, in Figure 8.1, as taking place in transnational settings: (a) intended curriculum, (b) teacher-idealised curriculum, (c) supported curriculum, (d) hidden curriculum, (e) null curriculum, (f) teacher-intended curriculum, (g) enacted curriculum (including what was taught and assessed), and ( $h$ ) learned curriculum. Outlining the distinctions between these different types of curricula and how they interacted demonstrates that the enacted curriculum is not informed only by the documented intentions of Training Packages, but also by the intentions and actions of teachers, sponsors and students. Therefore, the conceptualisation provides a broader perspective of curriculum in transnational vocational education as beyond that of the syllabus of an intended curriculum embedded in an Australian VET system, since it accounts for the planned and unplanned learning that occurs in different countries.

The tensions between the intended and enacted curricula are conceptualised as being the product of the processes, factors, and relationships that contributed to the transformation of the curriculum in every situation. Consequently, the second contribution made in this dissertation is that it advances a conceptual understanding of curriculum implementation in transnational vocational education as situational, interactional, and transformational.

\subsubsection{Recognising the role that teachers play as curriculum-makers in Australian transnational VET}

The role of these teachers was fundamental because, as curriculum-makers, their decisions determined what students learnt and how they learnt it. Based on the findings reported in Chapter 7, it is proposed that the extent of teachers' remaking of 
the intended curriculum provides insights into how they resolved the tension between fidelity to the intended curriculum and meeting the needs of their students. Six strategies that teachers used to remake the curriculum in different ways were identified. These strategies, presented in Table 7.1, were: (a) curriculum appraisal, (b) curriculum prioritisation, (c) curriculum change, (d) curriculum expansion, (e) curriculum design and experimentation, and (f) curriculum collaboration. It is held that all these strategies represent these teachers' efforts to remake a national curriculum that was not designed to be implemented transnationally, including accounting for the needs, capacities, and aspirations of students and their sponsors. This third contribution provides new knowledge about the level and types of adaptions teachers make to a vocational curriculum, based on their understanding of what is relevant, learnable, and achievable for transnational students.

\subsubsection{Identifying strategies for improving the relevance, quality, and sustainability of} Australian transnational VET

The conceptualisation of curriculum implementation explicated in Chapter 8 was used as a basis for informing tentative strategies for improving the relevance of the curriculum and the quality of teaching and learning provisions offshore. The five suggested improvements, as represented in Table 8.3, are: (a) curriculum negotiation, (b) teacher development, (c) implementation guidelines, (d) material support, and (e) monitoring implementation. It is proposed that these strategies would specifically focus on improving the way that vocational curricula are developed and implemented. Together, these also provide support to teachers for an extended scope of role in Australian transnational VET. It is acknowledged that these improvements are not the only ones that could potentially strengthen the relevance, quality, and sustainability of Training Packages in the international market. However, this set of improvements contributes new qualities that can assist teachers in enacting a vocational curriculum in transnational settings in ways that are responsive to the learning needs and interests of students so they can obtain the skills they need for their future employment. This fourth contribution offers five strategies that would enable a more dynamic and interactive model of curriculum that could be used to cater for a broader set of interests in Australian transnational VET.

\subsubsection{Summary}

This dissertation has advanced a new understanding of the key influences that shape curriculum implementation in Australian transnational VET. The four 
contributions to the field have provided new insights and much needed knowledge about how an Australian vocational curriculum can be developed and enacted in ways that are relevant and sensitive to the various needs of countries and students wanting to gain knowledge and skills for their future employment. The findings and the claims made are tentative, as they are based on the experiences and perspectives of 13 teachers who had experience in enacting Training Package products in nine countries.

\subsection{Implications for policy and practice}

Given that, for this group of teachers, the expectation to enact a Training Package product with fidelity in another country was not achievable or, in some cases, even desirable, the findings from this inquiry have implications for the relevance, quality, and sustainability of Australian transnational VET provisions. These findings also have implications for policymakers, curriculum developers, regulators, institutional decision-makers, and teachers as they suggest that Australia's current approach to the provision of transnational vocational educational programs needs to be reappraised. These implications are addressed as: (a) Australian transnational VET policy reappraisal, (b) support for an extended scope of role for transnational teacher guidelines, (c) provision of specific forms of professional development for transnational teachers, (d) improvement of Training Packages for international implementation, and (e) effective and regular monitoring by Australian stakeholders.

\subsubsection{Australian transnational VET policy reappraisal}

The capacity for Australian VET policy to adopt a more flexible approach to the development and implementation of a vocational curriculum would enable a broader set of interests to be considered for transnational education. The teachers' use of the three phases of curriculum development implies that this approach could follow a structured process of assessment, deliberation, and redevelopment of the curriculum. Firstly, an assessment would analyse the factors present in each situation. Secondly, various stakeholders, including sponsors, teachers, and industry representatives, could be brought together to discuss and deliberate on the factors before, thirdly, redeveloping the curriculum to cater for the specific needs of stakeholders in particular situations. It is recognised that the adoption of this approach would increase the relevance of the curriculum and facilitate a common 
understanding amongst stakeholders of how it would best be implemented (Fullan, 1982; Schwab, 1983). It would also necessitate a process of mutual recognition to determine the level of learning and where the qualifications would be pegged in relation to Australia's qualification framework. However, it is beyond the scope of this inquiry to suggest how this might best be achieved.

\subsubsection{Support for an extended scope of role for transnational teachers}

A more flexible approach to the development and implementation of a vocational curriculum, as proposed above, calls for an extended scope of role for transnational teachers. It appears that a paradox exists within Australian VET policy about the role a teacher must adopt in enactment overseas. On the one hand, the requirement for fidelity promotes the technical view of teachers as mere implementers of a national vocational curriculum imposed on other countries. On the other hand is the expectation for teachers to contextualise the curriculum so it is tailored to the specific requirements of the situation in which it is enacted. The findings from this inquiry suggest that both these expectations are unrealistic unless teachers have support for an extended scope of role to either: (a) influence the local factors associated with implementation to ensure fidelity, or (b) negotiate and develop a relevant curriculum with local stakeholders so it is contextualised locally. It is also important that Australian stakeholders negotiate the role of the teacher with local sponsors and actively support them in decision-making and problem-solving. This support is paramount if Australian standards are to be enforced transnationally.

\subsubsection{Provision of specific forms of professional development for transnational teachers}

To be effective in their role, transnational teachers must be provided with appropriate professional development. The findings showed that even the most experienced teachers needed to learn new skills and knowledge. It is inferred from these teachers' experiences that the preparation for teachers enacting the curriculum transnationally might best follow a structured process of a pre-departure briefing, an onsite orientation, and ongoing professional development opportunities. Teachers expressed a preference to learn from local professionals in industry and from other Australian and local teachers experienced in teaching transnational students. The types of knowledge and skills that might underpin these opportunities include: (a) information about their role, relationships, student characteristics, and local industry; (b) contextualising and developing site-specific curriculum materials; and (c) effective 
teaching practices to meet a variety of student learning needs and styles. How professional development is provided offshore is also important. It needs to be based on normative strategies that connect to teachers' values and respect their prior curriculum knowledge and teaching expertise. Additionally, there is a need to include specific competencies for transnational teaching in the mandatory qualification for VET teachers or, alternatively, develop a separate qualification.

\subsubsection{Improvement of Training Packages for international implementation}

The findings here suggest that there are two main improvements that developers could make to Training Packages for international implementation. The first is to provide guidance and advice to stakeholders on how to achieve equivalence and contextualisation in non-Australian contexts so that they can understand the level and type of adaptions they can make to the curriculum without compromising the curriculum standards.

The second improvement is the inclusion of foundational content in Training Packages for transnational students. The findings reported in Chapters 5, 6, and 7 reveal the difficulties teachers face in trying to enact Training Packages in another country, when the needs of transnational students have not been considered in their development. Consequently, there is a need for developers to include supplementary foundational content as it would assist teachers to facilitate the learning of the knowledge and skills that transnational students need to engage meaningfully with an Australian vocational curriculum, given that they do not have the same prerequisite knowledge and skills as students in Australia.

\subsubsection{Effective and regular monitoring by Australian stakeholders}

The findings also have implications for the role that Australian educational institutions and regulators must play in the quality assurance of transnational VET. Many teachers found it difficult to realise fidelity with the intended curriculum and equivalence with Australian provision when there was little monitoring undertaken by the Australian regulator or other stakeholders. Firstly, there is a need to ensure that the technical elements of the curriculum are adequately supported through the provision of resources and work-based learning programs. Secondly, there is a need to evaluate the quality of learning and teaching materials that are developed and used during enactment. As long as Australian legislation promises an equivalent standard of provision for all students, no matter where they are located, then deliberate efforts need to be made to ensure that that is the case. Otherwise, it is 
possible that Australia may be contributing to, rather than ameliorating, educational disadvantage.

\subsection{Recommendations for future research}

This inquiry focused on the contested realities of teachers within situated contexts to identify whether Australia's current models of VET curricula are suitable for international implementation. It has explored a less understood phenomenon and highlighted the multifaceted and complex nature of Training Package implementation for 13 teachers in nine countries. The findings lend support to the contention that Training Packages may not be the most suitable form of VET curricula to export in the global market. Indeed, it is likely that there are many products that could be offered in addition to these products. However, further research is warranted to consider the perspectives of other stakeholders such as sponsors, local teachers, and students, whose perspectives might be quite different from those of these teachers. For example, this inquiry highlights the influence of local management on the quality of curriculum implementation. It provides some useful insights into the complexity of implementation, but the perspective of local sponsors could illuminate these issues further. Similarly, the perspective of local teachers and the issues that confront them in trying to teach Australian content, or preparing students for occupations in Australia, might highlight a different set of constraining factors.

In particular, it is important to understand further whether the content that students learn from the enacted curriculum is relevant to their goals. Given the range of curriculum adaptions that were reported in Chapter 7 , including the lowering of standards, it appears that students may well be provided with different curricula, opportunities, and experiences based on their location. While the aim of Australian VET policy may be the provision of consistent outcomes, these findings suggest that this is not always the case. Thus, the implementation of Training Packages internationally is closely bound to issues of educational equity and social justice. Therefore, there is an urgent need to consider whether the knowledge and skills that transnational students learn will assist them to attain their goals.

Furthermore, there is a need for future research to focus on how teaching and learning materials can best be developed and applied for a range of cultural contexts. While this inquiry revealed the considerable effort that teachers put into developing or contextualising materials, it did not represent a quality approach to material development. Further research could provide insights into the way materials can be contextualised for different cultural settings and diverse student cohorts. 


\subsection{Conclusion}

To conclude, Australia has the capacity to assist other nation states to access vocational education and training to build workforce skills in their own country through transnational education. However, the exploration of the experiences of 13 teachers in enacting Training Packages in nine countries questions the feasibility of Australian VET policies and regulations that restrict this provision to the implementation of national curricula tied to Australian industry standards. Indeed, the teachers' experiences indicate that it is simply not possible to enact Training Package products without consideration of local factors. It is clear that these factors constrained these teachers' capacity to enact the intended curriculum with fidelity and to achieve equivalence with their practice in Australia. They engaged in curriculum development as the predominant approach to overcome these constraints and to meet the needs of their students. The differences in their individual responses were indicative of the situational nature of curriculum implementation in transnational VET provision. Given these findings, it is questionable as to how realistic it is for Australian VET policy to expect that Australian educational institutions, and the teachers who work for them, can achieve standardised outcomes for vocational education transnationally, or at least in the countries subject to this inquiry. There is also the question as to whether such a uniform approach to curriculum implementation is desirable for those countries that import the curriculum product.

All of this suggests that there is a case for negotiating the curriculum, particularly if it is to be used to assist students to gain employment in occupations outside Australia or to prepare them for entry into a higher education program. To achieve this, however, transnational teachers need support for an extended scope of role to analyse the situation for enactment and to deliberate with stakeholders in developing a relevant curriculum and its measures of quality. Such efforts would not only strengthen the quality, relevance, and sustainability of these provisions but would also make transparent the worth of Australian VET qualifications obtained by students in different countries. 


\section{References}

Abbott, A. (2017). Indonesian identity and cultural values. In A. Abbott (Ed.), Educational sovereignty and transnational exchanges in post-secondary Indonesian education (pp. 135-161). Switzerland: Springer.

Adams, S. (2001). Transnational education project: Report and recommendations. Paper presented at the Confederation of European Rectors' Conferences, Salamanca.

Agbola, F. W., \& Lambert, D. K. (2010). Skilling Australia for the future? A study of quality assurance in Australia's vocational education and training. Journal of Vocational Education and Training, 62(3), 327-349.

doi:10.1080/13636820.2010.509805

Akın, U., Aydın, İ., Erdoğan, Ç., \& Demirkasımoğlu, N. (2013). Emotional labor and burnout among Turkish primary school teachers. The Australian Educational Researcher, 41(2), 155-169.

Altbach, P. G. (2004). Globalisation and the university: Myths and realities in an unequal world. Tertiary Education and Management, 10(1), 3-25.

doi.org/10.1080/13583883.2004.9967114

Altbach, P. G. (2013). The International Imperative in Higher Education. Rotterdam: Springer Science.

Allen, A. (2002). Power, subjectivity, and agency: Between Arendt and Foucault. International Journal of Philosophical Studies, 10(2), 131-149. doi:10.1080/09672550210121432

Anderson, D. (2006a). Trading places: the impact and outcomes of market reform in vocational education and training. Adelaide: NCVER.

Anderson, D. L. (2006b). Globalisation, training packages and private providers: emerging tensions in national VET policy. Paper presented at the Australian Vocational Education and Training Research Association (AVETRA) 9th Annual Conference, Crows Nest.

Apple, M. W., \& Jungck, S. (1990). "You don't have to be a teacher to teach this unit": Teaching, technology, and gender in the classroom. American Educational Research Journal, 27(2), 227-251. 
Archbald, D. A., \& Porter, A. C. (1994). Curriculum control and teachers' perceptions of autonomy and satisfaction. Educational Evaluation and Policy Analysis, 16(1), 21-39.

Arends, L. (2005). Defining and assessing competencies for the development of a program for an international student assessment on vocational education and training: Challenges and opportunities. Paper presented at the 13th Annual International Conference on Post-Compulsory Education and Training, Brisbane.

Ariav, T. (1988). Growth in teachers' curriculum knowledge through the process of curriculum analysis. Paper presented at the Annual Meeting of the American Educational Research Association, New Orleans.

Ashton, D. N., \& Sung, J. (2002). Supporting workplace learning for high performance working. France: International Labour Organization.

Australian Education International. (2006). Outcomes of universities transnational education good practice projects. Canberra: Australian Government.

Australian Education International. (2007). Quality Assurance of offshore delivery in VET: Synthesis report. Canberra: Department of Education, Science and Training.

Australian Education International. (2012). Transnational education in the public and private VET sector. Canberra: Australian Government.

Australian Skills Quality Authority. (2016). Regulating offshore delivery of VET: ASQA's 2015 pilot audit program. Melbourne: ASQA.

Australian Skills Quality Authority. (2018). Australia's VET sector. Retrieved from https://www.asqa.gov.au/about/australias-vet-sector

Avis, J. (2012). Global reconstructions of vocational education and training.

Globalisation, Societies and Education, 10(1), 1-11. doi:10.1080/14767724.2012.646876

Bailey, A. (2011). Offshore teaching practice in the Australia-Pacific Technical College: A case study in the South Pacific. International Journal of Training Research, 9(1-2), 164-178. doi:10.5172/ijtr.9.1-2.164 
Baird, B. (2010). Stronger, simpler, smarter ESOS: Supporting international students: Review of the Education Services for Overseas Students (ESOS) Act 2000: Final report, February 2010 [Baird review]. Canberra: Commonwealth of Australia.

Ball, D. L., \& Cohen, D. K. (1996). Reform by the book: What is - or might be - the role of curriculum materials in teacher learning and instructional reform? Educational Researcher, 25(9), 6-15. doi:10.3102/0013189X025009006

Ball, D. L., \& Cohen, D. K. (1999). Developing practice, developing practitioners: Toward a practice-based theory of professional education. In G. Sykes \& L. Darling-Hammond (Eds.), Teaching as the learning profession: Handbook of policy and practice (pp. 3-32). San Francisco: Jossey Bass.

Ball, S. J., Maguire, M., \& Braun, A. (2012). How schools do policy: Policy enactments in secondary schools. New York: Taylor \& Francis.

Bannier, B. J. (2016). Global trends in transnational education. International Journal of Information and Education Technology, 6(1), 80-84.

Barrow, R. C. (2006). Flexibility and complexity: Opening the black box of training package implementation. Paper presented at the AVETRA 9th Annual Conference, Wollongong.

Bateman, A. (2007). Quality assurance of offshore delivery in VET: Synthesis report. Canberra: Australian Education International.

Beauchamp, G. A. (1972). Basic components of a curriculum theory. Curriculum Theory Network, 10, 16-22. doi:10.2307/1179213

Berman, P., McLaughlin, M., Bass, G., Pauly, E., \& Zellman, G. (1977). Federal programs supporting educational change. Vol. VII: Factors affecting implementation and continuation (ERIC Document Reproduction Service No. 140.432). Santa Monica, CA: RAND Corporation.

Biesta, G., \& Tedder, M. (2007). Agency and learning in the lifecourse: Towards an ecological perspective. Studies in the Education of Adults, 39(2), 132-149.

Bilboe, W. (2011). Vocational education and training in Kuwait: Vocational education versus values and viewpoints. International Journal of Training Research, 9(3), 256-260. doi:10.5172/ijtr.9.3.256 
Billett, S. (1995). Constructing the curriculum: National curriculum, teachers' practice \& change. New Horizons in Education, 92, 30-45.

Billett, S. (2004). From your business to our business: Industry and vocational education in Australia. Oxford Review of Education, 30(1), 13-35. doi:10.1080/0305498042000190041

Billett, S. (2011). Vocational education: Purposes, traditions and prospects. Queensland: Springer.

Billett, S., Henderson, A., Choy, S., Dymock, D., Beven, F., Kelly, A., \& Smith, R. (2012). Change, work and learning: Aligning continuing education and training - working paper. Adelaide: NCVER.

Black, S., \& Reich, A. (2010). The elephant in the room: Audit culture and TAFE teachers. Paper presented at the AVETRA 16th Annual Conference, Freemantle.

Bloom, D. E. (2004). Globalization and education: An economic perspective. In M. M. Suárez-Orozco \& D. B. Qin-Hilliard (Eds.), Globalization: Culture and education in the new millennium (pp. 56-77). Berkeley: University of California Press.

Brown, M. (2009). Toward a theory of curriculum design and use: Understanding the teacher-tool relationship. In J. Remillard, B. Herbel-Eisenman, \& G. Lloyd (Eds.), Mathematics teachers at work: Connecting curriculum materials and classroom instruction (pp. 17-37). New York: Routledge.

Boteju, D., \& Burnapp, D. (2011). Quality assurance in international collaborative courses. In D. Burnapp et al., The strategic implications of different forms of international collaboration in higher education (Ch. 3). Northampton: The University of Northampton.

Brown, J., Buttress, W., \& Matthews, M. (2018). Survey and Focus Groups of Students Enrolled in Australian Vocational Education and Training (VET) Offshore: Final Report. Canberra: Department of Education and Training.

Campbell, E. (2012). Teacher agency in curriculum contexts. Curriculum Inquiry, 42(2), 183-190. doi:10.1111/j.1467-873X.2012.00593.x 
Centre for International Economics. (2008). APEC and international education. Canberra: DEEWR.

Chakroun, B. (2010). National qualification frameworks: From policy borrowing to policy learning. European Journal of Education, 45(2), 199-216. doi:10.1111/j.1465-3435.2010.01425.x

Chapman, A., \& Pyvis, D. (2013). Enhancing Quality in Transnational Higher Education: Experiences of Teaching and Learning in Australian Offshore Programs. Lanham: Lexington Books.

Chappell, C., \& Johnston, R. (2001). Issues of teacher identity in a restructuring Australian vocational education and training (VET) system. Australian and New Zealand Journal of Vocational Education Research, 9(1), 21-39.

Retrieved from http://www.umanitoba.ca/unevoc/2002conference/text/papers/chappell.pdf

Chappell, C., \& Johnston, R. (2003). Changing work: Changing roles for vocational education and training teachers and trainers. Adelaide: NCVER.

Chappell, C., Solomon, N., Tennant, M., \& Yates, L. (2002). Researching the pedagogies of the new vocationalism. Sydney: UTS Research Centre for Vocational Education and Training.

Chin, R., \& Benne, K. (1970). General strategies for effecting changes in human systems. In W. Bennis, K. Benne, \& R. Chin (Eds.), The planning of change (pp. 32-59). London: Holt, Rinehart, and Winston.

Clandinin, D. J., \& Connelly, F. M. (1992). Teacher as curriculum maker. In P. W. Jackson (Ed.), Handbook of curriculum (pp. 363-461). Thousand Oaks, CA: Sage Publications.

Clarke, D., \& Hollingsworth, H. (2002). Elaborating a model of teacher professional growth. Teaching and Teacher Education, 18(8), 947-967. doi:10.1016/s0742-051x(02)00053-7

Clayton, B. (2009). Practitioner experiences and expectations with the Certificate IV in Training and Assessment (TAA40104): A discussion of the issues. Adelaide: NCVER. 
Coburn, C. E. (2004). Beyond decoupling: Rethinking the relationship between the institutional environment and the classroom. Sociology of Education, 77(3), 211-244. doi:10.1177/003804070407700302

Coleman, D. (2003). Quality assurance in transnational education. Journal of Studies in International Education, 7(4), 354-378. doi:10.1177/1028315303255597

Coles, M., (2006). A review of international and national developments in the use of qualifications frameworks. Luxembourg: Office for Official Publications of the European Communities.

Comyn, P. (2009). Vocational qualification frameworks in Asia-Pacific: A cresting wave of educational reform? Research in Post-Compulsory Education, 14(3), 251-268. doi:10.1080/13596740903139305

Connell, B., \& Yates, L. (2001). Renovating the 'public': The future of public education. Education Links, 63, 7-14.

Constantino, T. E. (2008). Constructivism. In L. M. Given (Ed.), The SAGE encyclopedia of qualitative research methods (pp. 116-119). Thousand Oaks, CA: Sage Publications.

Cooney, R., \& Long, M. (2010). Vocational education and training in Australia: The evolution of a segmented training system. In G. Bosch \& J. Charest (Eds.), Vocational training. International perspectives (pp. 27-57). New York: Routledge.

Corbett, H. D., \& Rossman, G. B. (1989). Three paths to implementing change: A research note. Curriculum Inquiry, 19(2), 163-190. doi:10.1080/03626784.1989.11075322

Cornford, I. R. (1999). Rediscovering the importance of learning and curriculum in vocational education and training in Australia. Journal of Vocational Education and Training: The Vocational Aspect of Education, 51(1), 93-113. doi:10.1080/13636829900200072

Cornford, I. R. (2000). Competency-based training: Evidence of a failed policy in training reform. Australian Journal of Education, 44(2), 135-154. doi:10.1177/000494410004400204 
Creswell, J. W. (2007). Qualitative inquiry and research design: Choosing among five approaches. Thousand Oaks, CA: Sage Publications.

Creswell, J. (2009). Research design: Qualitative, quantitative, and mixed methods approaches (3rd ed.). Thousand Oaks, CA: Sage.

Creswell, J. W. (2013). Qualitative inquiry \& research design: Choosing among five approaches ( $3^{\text {rd }}$ ed.). Thousand Oaks, CA: Sage.

Creswell, J. W. (2018). Qualitative inquiry and research design: Choosing among five approaches (4th ed.). Thousand Oaks, CA: Sage Publications.

Cuthbert, D., Smith, W., \& Boey, J. (2008). What do we really know about the outcomes of Australian international education? A critical review and prospectus for future research. Journal of Studies in International Education, 12(3), 255-275. doi:10.1177/1028315307308134

Dale, R. (2000). Globalisation and education: Demonstrating a 'common world education culture' or locating a 'globally structured educational agenda'. Educational Theory, 50(4), 427-448. doi:10.1111/j.1741-5446.2000.00427.x

Darwin, S. (2007). The changing contexts of vocational education: Implications for institutional vocational learning. International Journal of Training Research, 5(1), 55-71. doi:10.5172/ijtr.5.1.55

Davids, J. (2008). Have a heart: Challenges for lead vocational teachers in the changing VET landscape. Adelaide: NCVER.

Dempsey, K. (2012). Preparing staff to work offshore. Melbourne: Victorian TAFE International.

Dempsey, K., \& Tao, X. (2017). Australian VET in China: What has changed? In L. Tran \& K. Dempsey (Eds.), Internationalization in vocational education and training: Transnational perspectives (pp. 149-166). (Vol. 25 of the book series Technical and Vocational Education and Training: Issues, Concerns and Prospects). Cham: Springer.

Denzin, N. K. (2001). The reflexive interview and a performative social science. Qualitative Research, 1(1), 23-46. Retrieved from https://doi.org/10.1177/146879410100100102 
Denzin, N. K., \& Lincoln, Y. S. (2005). The SAGE handbook of qualitative research. Thousand Oaks, CA: Sage Publications.

Department of Education and Training. (2011). Annual national report of the Australian VET system. Canberra: Australian Government.

Department of Education and Training. (2012). Research snapshot: Transnational education in the public and private sector. Canberra: Australian Government.

Department of Education and Training. (2018). Research snapshot: Offshore course delivery in the VET sector, 2016. Canberra: Australian Government.

Dilley, P. (2000). Conducting successful interviews: Tips for intrepid research. Theory into Practice, 39(3), 131-137.

Down, C. (2002). Qualitative impact of Training Packages on vocational education and training clients. Melbourne: ANTA.

Down, C. M. (2003). The impact of training packages: What might we learn about substantial system-wide change processes? International Journal of Training Research, 1(2), 1-20. doi:10.5172/ijtr.1.2.1

Doyle, W. (1992). Constructing curriculum in the classroom. In F. K. Oser, A. Dick, \& J. Patry (Eds.), Effective and responsible teaching: The new syntheses (pp. 66-79). San Francisco: Jossey Bass.

Doyle, W. (1997). Heard any really good stories lately? A critique of the critics of narrative in educational research. Teaching and Teacher Education, 13(1), 93-99.

Doyle, W., \& Ponder, G. A. (1977). The practicality effort in teacher decision-making. Interchange, 8(3), 1-2.

Duncan-Andrade, J. M. R., \& Morrell, E. (2008). The art of critical pedagogy: Possibilities for moving from theory to practice in urban schools. New York: Peter Lang.

Dunn, L., \& Wallace, M. (2006). Australian academics and transnational teaching: An exploratory study of their preparedness and experiences. Higher Education Research \& Development, 25(4), 357-369. 
Dymock, D., \& Billett, S. (2009). Aligning VET policy and practice. Crows Nest: AVETRA.

EduWorld. (2013). International development research project. EduWorld and AFG Venture Group.

Eisner, E. W. (1985). The educational imagination: On the design and evaluation of school program. (2nd ed.). New York: Macmillan.

Eisner, E. W. (2002). The educational imagination: On the design and evaluation of school programs (3rd ed.). Upper Saddle River, N.J.: Prentice Hall.

Elbaz-Luwisch, F. (1997). Narrative research: Political issues and implications. Teaching and Teacher Education, 13(1), 75-83. doi:10.1016/s0742051x(96)00042-x

Emerson, R. M., Fretz, R. I., \& Shaw, L. L. (1995). Writing ethnographic fieldnotes. Chicago: The University of Chicago Press. doi.org/10.7208/chicago/9780226206851.001.0001

Englander, M. (2012). The interview: Data collection in descriptive phenomenological human scientific research. Journal of Phenomenological Psychology, 43(1), 13-35.

Epstein, E. H. (1987). The Peril of Paternalism: the Imposition of Education on Cuba by the United States. American Journal of Education, 96(1), 1-23.

Eraut, M. (1997). Professional knowledge in teacher education. In P. Nuutinen (Ed.), Inquiring teacher - From experience to pedagogy (pp. 1-27). Finland: University of Joensuu, Faculty of Education.

Eraut, M. (2000). Non-formal learning and tacit knowledge in professional work. British Journal of Educational Psychology, 70, 113-136. doi:10.1348/000709900158001

Finlay, L. (2008). A dance between the reduction and reflexivity: Explicating the "phenomenological psychological attitude". Journal of Phenomenological Psychology, 39(1), 1-32. doi:10.1163/156916208X311601

Flick, U. (2007). Sampling, selecting and access. In U. Flick. (Ed.), Designing qualitative research (pp. 25-35). London: SAGE Publications, Ltd. 
Flinders, D. J., Noddings, N., \& Thornton, S. J. (1986). The null curriculum: Its theoretical basis and practical implications. Curriculum Inquiry, 16(1), 33-42. doi:10.1080/03626784.1986.11075989

Friere, P. (1970). Pedagogy of the oppressed. Harmondsworth: Penguin.

Fullan, M. (1982). The meaning of educational change ( $1^{\text {st }}$ ed.). New York: Teachers College Press.

Fullan, M. (1991). The meaning of educational change ( $2^{\text {nd }}$ ed.). New York: Teachers College Press.

Fullan, M. (1994). Coordinating top-down and bottom-up strategies for educational reform. Systemic Reform: Perspectives on Personalizing Education, September. Retrieved from http://michaelfullan.ca/wpcontent/uploads/2016/06/13396035630.pdf

Fullan, M. (2001). The new meaning of educational change (3rd ed.). New York: Teachers College Press.

Fullan, M. (2007). The new meaning of educational change $\left(4^{\text {th }}\right.$ ed.). New York: Teachers College Press.

Fullan, M. (2008). Curriculum implementation and sustainability. In F. M. Connelly, M. F. He, \& J. Phillion (Eds.), The SAGE handbook of curriculum and instruction (pp. 113-122). Los Angeles: SAGE Publications.

Fullan, M., \& Pomfret, A. (1977). Research on curriculum and instruction implementation. Review of Educational Research, 47(2), 335-397.

Fullan, M., Rolheiser, C., Mascall, B., \& Edge, K. (2004). Accomplishing large scale reform: A tri-level proposition. In F. Hernandez \& I. F. Goodson (Eds.), Social geographies of educational change (pp. 1-13). Dordrecht: Springer.

Fullan, M., \& Stiegelbauer, S. (1991). The new meaning of educational change. New York: Teachers College Press.

Gallo, E., \& Tassinari, M. G. (2017). "Positive feelings about my work: I needed it!" Emotions and emotion self-regulation in language teachers. Apples-Journal of Applied Language Studies, 11(2), 55-84. 
Giorgi, A. (2010). Phenomenology and the practice of science. (Essay). Existential Analysis, 21(1), 3-22.

Glatthorn, A. A. (2000). The principal as curriculum leader: Shaping what is taught \& tested. Thousand Oaks, CA: Corwin Press.

Goodlad, J. I., Klein, M. F., \& Tye, K. A. (1979). The domains of curriculum and their study. In J. I. Goodlad (Ed.), Curriculum Inquiry: The study of curriculum practice (pp. 43-76). New York: McGraw-Hill.

Goodson, I. F. (1995). The story so far: Personal knowledge and the political. Qualitative Studies in Education, 8(1), 89-98.

Grace, L. (2005). Training packages and the AQTF: Freedom to move or components of a compliant-driven straightjacket? Paper presented at the 8th Annual Australian Vocational Education and Training Research Conference, Brisbane.

Green, A. (1999). Education and globalization in Europe and East Asia: Convergent and divergent trends. Journal of Education Policy, 14(1), 55-71. doi:10.1080/026809399286495

Gribble, K., \& Ziguras, C. (2003). Learning to teach offshore: Pre-departure training for lecturers in transnational programs. Higher Education: Research \& Development, 27(2), 206-216.

Guba, E. G., \& Lincoln, Y. S. (1994). Competing paradigms in qualitative research. In N. K. Denzin \& Y. S. Lincoln (Eds.), Handbook of qualitative research (pp. 105-117). London: Sage.

Gubrium, J. F., \& Holstein, J. A. (1997). The new language of qualitative method. New York: Oxford University Press.

Gubrium, J. F., \& Holstein, J. A. (2002). From the individual to the interview society. In J. F. Gubrium \& J. A. Holstein (Eds.), Handbook of interview research (pp. 3-32). Thousand Oaks, CA: Sage.

Guthrie, H. (2009). Competence and competency-based training: What the literature says. Adelaide: NCVER.

Guthrie, H. (2010). Vocational education and training workforce data: a compendium. Adelaide: NCVER. 
Guthrie, H., Perkins, K., \& Nguyen, N. (2006). VET teaching and learning: The future now 2006-10. Perth: Western Australia Department of Education and Training.

Hager, P. (2004). The competence affair, or why vocational education and training urgently needs a new understanding of learning. Journal of Vocational Education \& Training, 56(3), 409-433. doi:10.1080/13636820400200262

Hargreaves, A. (1994). Changing teachers, changing times: Teachers' work and culture in the postmodern age. London: Continuum.

Hargreaves, A. (2000). Four Ages of Professionalism and Professional Learning. Teachers and Teaching, 6(2), 151-182. doi: 10.1080/713698714

Hargreaves, A. (2004). Inclusive and exclusive educational change: Emotional responses of teachers and implications for leadership. School Leadership \& Management, 24(3), 287-309. doi:10.1080/1363243042000266936

Harman, G. (2005). Internationalization of Australian higher education: A critical review of literature and research. In P. Ninnes \& M. Hellsten (Eds.), Internationalizing higher education (pp. 119-140). CERC Studies in Comparative Education (Vol. 16). Dordrecht: Springer.

Harris, R., Simons, M., \& Clayton, B. (2005). Shifting mindsets: The changing work roles of vocational education and training practitioners. Adelaide: NCVER.

Hathaway, R. S. (1995). Assumptions underlying quantitative and qualitative research: Implications for institutional research. Research in Higher Education, 36(5), 535-562. doi:org/10.1007/BF02208830

Hawthorne, R. K. (1992). Curriculum in the making. New York: Teachers College Press.

Heffernan, T., Morrison, M., Basu, P., \& Sweeney, A. (2010). Cultural differences, learning styles and transnational education. Journal of Higher Education Policy and Management, 32(1), 27-39.

Helsby, G. (1998). Changing teachers' work. Buckingham: Open University Press.

Hammersley. M. \& Open Publishing in European Networks. (2013). What is qualitative research?. London: Bloomsbury Academic. 
Hickling-Hudson, A. R. (2003). Beyond schooling: Adult education in postcolonial societies. In R. F. Arnove \& C. A. Torres (Ed.), Comparative education: The dialectic of the global and the local (pp. 229-251). Maryland, USA: Rowman and Littlefield.

Hlebowitsh, P. S. (2005). Designing the school curriculum. Boston: Allyn and Bacon.

Hoeckel, F., Field, S., Justesen, T. R., \& Kim, M. (2008). Learning For Jobs: OECD Reviews of Vocational Education and Training. Australia: OECD.

Hopkins, R. M., Regehr, G., \& Pratt, D. D. (2017). A framework for negotiating positionality in phenomenological research. Medical Teacher, 39(1), 20-25. doi:10.1080/0142159X.2017.1245854

House, E. R. (1996). A framework for appraising educational reforms. Educational Researcher, 25(7), 6-14. doi:10.3102/0013189x025007006

Hua, Z., Harris, A., \& Ollin, R. (2011). Student autonomy and awareness: Vocational education and student-centred learning in China. Journal of Vocational Education \& Training, 63(2), 191-203. doi:10.1080/13636820.2011.566346

Hulme, R. (2005). Policy transfer and the internationalisation of social policy. Social Policy Society, 4(4), 417-425. doi:10.1017/s1474746405002605

Hurrell, A., \& Woods, N. (1995). Globalisation and inequality. Journal of International Studies, 24(3), 447-470. doi:10.1177/03058298950240031001

Husserl, E. (1970). The Crisis of European Sciences: An Introduction to Phenomenological Philosophy. (D. Carr, Trans.). Evanston: Northwestern University.

Hycner, R. H. (1999). Some guidelines for the phenomenological analysis of interview data. In A. Bryman \& R. G. Burgess (Eds.), Qualitative research (Vol. 3, pp. 143-164). London: Sage.

Jackson, P. W. (1968). Life in classrooms. New York: Holt, Rinehart \& Winston. Jisc. (2018). Transnational education data report. London: Jisc.

Johnson, M. (1967). Definitions and models in curriculum theory. Educational Theory, 17, 127-140. 
Karthigesu, S. (2007). Romancing transnational education and training. Adelaide: Department of Further Education, Employment, Science and Technology.

Katz, G., \& Raths, J. (1992). Six dilemmas in teacher education. Journal of Teacher Education, 43(1), 376-385. doi:doi.org/10.1177/0022487192043005007

Keating, J. (2008). Matching supply of and demand for skills: International perspectives. Adelaide: NCVER.

Keevers, L., Bell, M., Ganesharatnam, S., Dawood Sultan, F. K. P., See Yin Lim, J., Loh, V., \& Scholz, C. (2014). Transnational teaching teams: Professional development for quality enhancement of teaching and learning - Final Report. Sydney: Office for Learning and Teaching.

Kendell, T. (2004). Exporting Australian educational services to China. Journal of Higher Education Policy and Management, 26(1), 22-33. doi: $10.1080 / 1360080042000182519$

Knight, J., \& McNamara, J. (2017). Transnational education: A classification framework and data collection guidelines for international programme and provider mobility (IPPM). London: British Council and German Academic Exchange Service.

Lampert, M. (1985). How do teachers manage to teach? Perspectives on problems in practice. Harvard Educational Review, 55(2), 178-194.

Lasky, S. (2005). A sociocultural approach to understanding teacher identity, agency and professional vulnerability in a context of secondary school reform. Teaching and Teacher Education, 21, 899-916.

Lauder, H., Jamieson, I., \& Wikeley, F. (1998). Models of effective schools: Limits and capabilities. In R. Slee, G. Weiner\& S. Tomlinson (Eds.), School effectiveness for whom? (pp. 51-69). London: Falmer.

Leask, B. (2004). Transnational education and intercultural learning: Reconstructing the offshore teaching team to enhance internationalisation. Paper presented at the Australian Universities Quality Forum, Melbourne. 
Lim, C. B., Bentley, D., Henderson, F., Pan, S. Y., Balakrishnan, V. D., Balasingam, D.M., \& Teh, Y. Y. (2016). Equivalent or not?: Beyond measuring teaching and learning standards in a transnational education environment. Quality Assurance in Education, 24(4), 528-540. doi:doi:10.1108/QAE-01-2016-0001

Lincoln, Y. S., \& Guba, E. G. (2000). Paradigmatic controversies, contradictions, and emerging confluences. In N. K. Denzin \& Y. S. Lincoln (Eds.), The handbook of qualitative research (2nd ed., pp. 1065-1122). Thousand Oaks, CA: Sage Publications.

Little, A. W. (2000). Globalisation, qualifications and livelihoods: Towards a research agenda. Assessment in Education: Principles, Policy \& Practice, 7(3), 299312. doi:10.1080/09695940050201316

Luttrell, W. (2000). "Good enough" methods for ethnographic research. Harvard Educational Review, 70(4), 499-523. Retrieved from http://hepg.metapress.com/content/5333230502744141

Mahmud, S., \& Sanderson, G. (2011). Moderation for fair assessment in transnational learning and teaching: Final report. Sydney: Australian Learning \& Teaching Council.

Mannion, G., Fenwick, A., Nugent, C., \& l'anson, J. (2011). Teaching in nature: Commissioned by Scottish Natural Heritage: Report Contracted to University of Stirling.

Marginson, S. (1999). After globalization: Emerging politics of education. Journal of Education Policy, 14(1), 19-31. doi:10.1080/026809399286477

Marginson, S., \& McBurnie, G. (2004). Cross-Border Post-Secondary Education in the Asia-Pacific Region. In OECD (Ed.), Internationalisation and Trade in Higher Education (pp. 137-204). Paris: OECD.

Marland, P. W. (1987). Teachers personal knowledge: What counts as the personal. Journal of Curriculum Studies, 19, 503-505.

Marsh, C. J. (2009). Key concepts for understanding curriculum. New York: Routledge.

Marsh, C. J., \& Willis, G. (2007). Curriculum: Alternative approaches, ongoing issues. Upper Saddle River, NJ: Pearson. 
Marshall, C., \& Rossman, G. B. (2006). Designing qualitative research. Thousand Oaks, CA: Sage Publications.

Maurer, M., \& Gonon, P. (2014). The challenges of policy transfer in vocational skills development. In M. Maurer \& P. Gonon (Eds.), The challenges of policy transfer in vocational skills development. National Qualifications frameworks and the dual model of vocational education in international cooperation (pp. 15-35). Bern: Peter Lang.

Mayer, C. (2001). Transfer of concepts and practices of vocational education and training from the center to the peripheries: The case of Germany. Journal of Education and Work, 14(2), 189-208.

McBurnie, G., \& Ziguras, C. (2003). Remaking the world in our own image: Australia's efforts to liberalise trade in education services. Australian Journal of Education, 47(3), 217-234. Retrieved from https://doi.org/10.1177/000494410304700303

McBurnie, G., \& Ziguras, C. (2007). Transnational education: Issues and trends in offshore higher education. London and New York: Routledge.

McBurnie, G., \& Ziguras, C. (2009). Trends and Future Scenarios in Programme and Institution Mobility acRoss Borders. Higher Education to 2030, 2, 89-108. doi:10.1787/9789264075375-5-en.

McDonald, J. P. (1992). Teaching: Making sense of an uncertain craft. New York: Teachers College Press.

McGrath, S. (2002). Skills for development: A new approach to international cooperation in skills development? Journal of Vocational Education \& Training, 54(3), 413-430. doi:10.1080/13636820200200207

McGrath, S., \& Lugg, R. (2012). Knowing and doing vocational education and training reform: Evidence, learning and the policy process. International Journal of Educational Development, 32(5), 696-708.

Merriam, S. B. (2009). Qualitative research: A guide to design and implementation $\left(2^{\text {nd }}\right.$ ed. $)$. San Francisco: Jossey-Bass. 
Middlehurst, R., \& Woodfield, S. (2004). The role of transnational, private, and forprofit provision in meeting global demand for tertiary education: Mapping, regulation and impact. Vancouver: Commonwealth of Learning.

Miles, M. B., \& Huberman, A. M. (1994). Qualitative data analysis (2nd ed.). Thousand Oaks, CA: Sage Publications.

Misko, J. (2006). Vocational education and training in Australia, the United Kingdom and Germany. Adelaide: NCVER.

Mok, K. H., Han, X., Jiang., \& Zhang, X. (2018). International and transnational education for whose interests? A study on the career development of Chinese students. Higher Education Quarterly, 72(3), 208-223. doi:10.1111/hequ.12165

Moodie, G. (2002). Identifying vocational education and training. Journal of Vocational Education and Training, 54(2), 249-266. doi:10.1080/13636820200200197

Moore, A. (2000). Teaching and Learning Pedagogy: Curriculum and Culture. London: Routledge Falmer.

Moran, L., \& Ryan, Y. (2003). The Australian Quality Training Framework and globalisation of training markets. Brisbane: ANTA.

Morgan, D. (2008). Snowball sampling. In L. Given (Ed.), The SAGE encyclopedia of qualitative research methods (pp. 815-816). Thousand Oaks, CA: SAGE.

Moustakas, C. (1994). Phenomenological research methods. Thousand Oaks, CA: SAGE Publications.

Moutsios, S. (2010). Power, politics and transnational policy-making in education. Globalisation, Societies and Education, 8(1), 121-141. doi:10.1080/14767720903574124

Murphy, B. (2001). International NGOs and the challenge of modernity. In D. Eade \& E. Ligteringen (Eds.), Debating development: NGOs and the future (pp. 6085). Oxford: Oxfam.

National Centre for Vocational Education Research. (2010). Data collection on VET offshore by public and private providers 2009: Final report: December 2010. Melbourne: TVET Australia. 
National Centre for Vocational Education Research. (2015). Delivery of VET offshore by public providers, 2014. Canberra: Australian Government.

National Centre for Vocational Education Research. (2017). Glossary of VET. Adelaide: NCVER.

Nilsson, A. (2010). Vocational education and training - an engine for economic growth and a vehicle for social inclusion? International Journal of Training and Development, 14(4), 251-272.

Nuthall, G. (1997). Understanding student thinking and learning in the classroom. In B. Biddle, T. Good, \& I. Goodson (Eds.), The international handbook of teachers and teaching (pp. 1-90). Dordrecht: Kluwer.

OECD. (2004). Quality and recognition in higher education: The Cross-border challenge. Paris: Centre for Educational Research and Innovation.

OECD. (2012). Education at a Glance 2012: Highlights. Paris: OECD Publishing. doi: 10.1787/eag_highlights-2012-en

Oliva, P. F. (1997). Developing the curriculum. New York: Longman.

Oliver, D. G., Serovich, J. M., \& Mason, T. L. (2005). Constraints and opportunities with interview transcription: Towards reflection in qualitative research. Social Forces, 84(2). doi:10.1353/sof.2006.0023

Onwuegbuzie, A. J., Johnson, R. B., \& Collins, K. M. T. (2009). Call for mixed analysis: A philosophical framework for combining qualitative and quantitative approaches [online]. International Journal of Multiple Research Approaches, 3(2), 114-136.

Pence, K. L., Justice, L. M., \& Wiggins, A. K. (2008). Preschool teachers' fidelity in implementing a comprehensive language-rich curriculum. Language, Speech, and Hearing Services in Schools, 39(3), 329-341. doi:10.1044/0161$1461(2008 / 031)$

Penuel, W. R., Fishman, B. J., Yamaguchi, R., \& Gallagher, L. P. (2007). What makes professional development effective? Strategies that foster curriculum implementation. American Educational Research Journal, 44(4), 921-958. doi:10.3102/0002831207308221 
Perry, L. B., \& Tor, G. (2009). Understanding educational transfer: Theoretical perspectives and conceptual frameworks. Prospects, 38(4), 509-526. doi:10.1007/s11125-009-9092-3

Phillips, D. (2000). Learning from elsewhere in education: Some perennial problems revisited with reference to British interest in Germany. Comparative Education, 36(3), 297-307.

Phillips, D., \& Ochs, K. (2003). Processes of policy borrowing in education: Some explanatory and analytical devices. Comparative Education, 39(4), 451-461. doi:10.1080/0305006032000162020

Pinar, W., Reynolds, W., Slattery, P., \& Taubman, P. (1995). Understanding curriculum ( $1^{\text {st }}$ ed.). New York: Peter Lang.

Pinar, W., Reynolds, W. M., Slattery, P., \& Taubman, P. M. (2004). Understanding curriculum $\left(4^{\text {th }}\right.$ ed. $)$. New York: Peter Lang Publishing.

Poland, B. (2002). Transcription quality. In J. Gubrium \& J. Holstein (Eds.), Handbook of interview research (pp.629-650). Thousand Oaks, CA: Sage Publishing.

Polkinghorne, D. (1983). Methodology for the human sciences: Systems of inquiry. Albany: State University of New York Press.

Porter, A.C. (2002). Measuring the content of instruction: Uses in research and practice. Educational Researcher, 3(7), 3-14.

Porter, A. C., \& Smithson, J. L. (2001). Defining, developing, and using curriculum indicators. CPRE Research Report Series. Philadelphia: Consortium for Policy Research in Education.

Porter, P., \& Vidovich, L. (2000). Globalization and higher education policy. Educational Theory, 50(4), 449-465.

Priestley, M. (2010). Curriculum for excellence: Transformational change or business as usual? Scottish Educational Review, 42(1), 23-36.

Priestley, M., Biesta, G., \& Robinson, S. (2015). Teacher Agency: An Ecological Approach. London: Bloomsbury Academic. 
Priestley, M., Edwards, R., Priestley, A., \& Miller, K. (2012). Teacher agency in curriculum making: Agents of change and spaces for manoeuvre. Curriculum Inquiry, 42(2), 191-214. doi:10.1111/j.1467-873X.2012.00588.x

Print, M. (1993). Curriculum development and design (2nd ed.). Crows Nest: Allen \& Unwin.

Productivity Commission. (2011). Vocational education and training workforce. Research Report. Canberra: Author.

Productivity Commission. (2015). Report on Government Services 2015, Chapter 5 Volume B. Canberra: Australian Government.

Pyvis, D. (2011). The need for context-sensitive measures of educational quality in transnational higher education. Teaching in Higher Education, 16(6), 733744.

Qi, J. (2015). Knowledge hierarchies in transnational education: Staging dissensus. New York: Routledge.

Quiggin, J. (1999). Human capital theory and education policy in Australia. The Australian Economic Review, 32(2), 130-144. doi:10.1111/1467-8462.00100

Rahimi, M., \& Smith, H. (2017). Management of knowledge in international VET: Diversity of practice from Laos, Kuwait, and China. In L. Tran \& K. Dempsey (Eds.), Internationalization in vocational education and training: Transnational perspectives (pp. 117-134). (Vol. 25 of the book series Technical and Vocational Education and Training: Issues, Concerns and Prospects). Cham: Springer.

Rapley, T. (2004). Interviews. In C. Seale (Ed.), Qualitative research practice (pp. 1533). London: Sage Publications.

Reich, A. \& Ho, T. T. H. (2017). Adapting international influences and retaining 'Vietnamese Character' in VET in Vietnam. In L. Tran \& K. Dempsey (Eds.), Internationalization in vocational education and training: Transnational perspectives (pp. 135-147). (Vol. 25 of the book series Technical and Vocational Education and Training: Issues, Concerns and Prospects). Cham: Springer. 
Remillard, J. T. (1999). Curriculum materials in mathematics education reform: A framework for examining teachers' curriculum development. Curriculum Inquiry, 29(3), 315-342. doi:10.1111/0362-6784.00130

Remillard, J. T. (2000). Can curriculum materials support teachers' learning? Two fourth-grade teachers' use of a new mathematics text. Elementary School Journal, 100(4), 331-350. doi:10.1086/499645

Remillard, J. T. (2018). Mapping the relationship between written and enacted curriculum: Examining teachers' decision making. In G. Kaiser, $\mathrm{H}$. Forgasz, M. Graven, A. Kuzniak, E. Simmt, \& B. Xu (Eds.), Invited lectures from the 13th International Congress on Mathematical Education, ICME-13 Monographs (pp. 483-500). Cham: Springer.

Remillard, J. T., \& Heck, D. (2014). Conceptualizing the curriculum enactment process in mathematics education. The International Journal on Mathematics Education, 46(5), 705-718.

Rizvi, F. (2009). Global mobility and the challenges of educational research and policy. Yearbook of the National Society for the Study of Education, 108(2), 268-289. doi:10.1111/j.1744-7984.2009.01172.x

Rizvi, F., \& Walsh, L. (1998). Difference, globalisation and the internationalisation of curriculum. Australian Universities' Review, 41(2), 7-11.

Robertson, S. L. (2006). Globalisation, GATS and Trading in Education Services. Retrieved from https://susanleerobertson.com/publications/

Ross, E. W. (1993). Institutional Constraints on Curriculum Deliberation. Journal of Curriculum and Supervision, 8(2), 95-111.

Ross, H., \& Mannion, G. (2012). Curriculum Making as the Enactment of Dwelling in Places. Studies in Philosophy and Education, 31(3), 303-313. doi:10.1007/s11217-012-9295-6.

Rubin, H. J., \& Rubin, I. S. (2005). Qualitative interviewing: The art of hearing data (2nd ed.). Thousand Oaks, CA: SAGE Publications. doi:10.4135/9781452226651 
Sachs, J. (2001). Teacher professional identity: Competing discourses, competing outcomes. Journal of Education Policy, 16(2), 149-161.

doi:10.1080/02680930116819

Saumure, K., \& Given, L. M. (2008). Non-probability sampling. In L. M. Given (Ed.), The Sage encyclopedia of qualitative research methods (pp. 567). Thousand Oaks, CA: Sage Publications.

Schmidt, W. H., Jorde, D., Cogan, L., Barrier, E., Ganzalo, I., Moser,U., ... Wolfe, R. G. (1996). Characterizing pedagogical flow: An investigation of mathematics and science teaching in six countries. Dordrecht, The Netherlands: Kluwer.

Schofield, K., \& McDonald, R. (2004). Moving on: Report of the high level review of training packages. Melbourne: Australian National Training Authority.

Schwab, J. J. (1978). The practical: A language for curriculum. In I. Westbury \& N. J. Wilkof (Eds.), Science, curriculum, and liberal education: Selected essays (pp. 287-321). Chicago: University of Chicago Press.

Schwab, J. J. (1983). The practical 4: Something for curriculum professors to do. Curriculum Inquiry, 13(3), 239-265.

Scott, D., \& Usher, R. (2011). Researching education: Data methods and theory in educational enquiry. London: Continuum.

Scott, J. C. (1990). Domination and the arts of resistance: Hidden transcripts. New Haven: Yale University Press.

Seddon, T. (1983). The hidden curriculum: An overview. Curriculum Perspectives, 3(1), 1-6.

Seidman, I. (2013). Interviewing as qualitative research: $A$ guide for researchers in education and the social sciences. New York: Teachers College Press.

Shams, F., \& Huisman, J. (2012). Managing offshore branch campuses: An analytical framework for institutional strategies. Journal of Studies in International Education, 16(2), 106-127. doi:10.1177/1028315311413470

Shi, W., \& Woodley, C. (2008). Closing the gap between teaching and learning styles: An internationalised pedagogy for offshore VET. Paper presented at the 17th National Vocational Education and Training Research Conference, Adelaide. 
Simons, M., Harris, R., \& Smith, E. (2006). The Certificate IV in assessment and workplace training: Understanding learners and learning. Adelaide: NCVER.

Simons, M., Meyers, D., Harris, R., \& Blom, K. (2003). Implementing innovative approaches to learning and assessment through training packages. Adelaide: NCVER.

Skilbeck, M. (1976). School-based Curriculum Development and Teacher Education. Mimeograph, OECD.

Skilbeck, M. (1992). Curriculum implementation: Conflict or consensus? Education Research and Perspectives, 19(1), 1-12.

Slavin, R. E. (2002). Evidence-based education policies: Transforming educational practice and research. Educational Researcher, 31(7), 15-21. doi:10.3102/0013189X031007015

Smith, D. L., \& Lovat, T. J. (2003). Curriculum: Action on reflection (4th ed). Tuggerah, N.S.W.: Social Science Press.

Smith, E., \& Grace, L. (2011). Vocational educators' qualifications: A pedagogical poor relation? International Journal of Training Research, 9(30), 204-217.

Smith, E., \& Keating, J. (2003). From training reform to training packages. Tuggerah, N.S.W: Social Science Press.

Smith, J. A., Flower, P., \& Larkin, M. (2009). Interpretative phenomenological analysis: Theory, method and research. USA: Sage Publishing.

Smith, K. (2014). Exploring flying faculty teaching experiences: Motivations, challenges and opportunities. Studies in Higher Education, 39(1), 117-134. doi:10.1080/03075079.2011.646259

Smith, M. S., \& O'Day, J. (1991). Putting the pieces together: Systemic school reform. CPRE Policy Brief, RB-06-4/91. Brunswick, NJ: Consortium for Policy Research in Education.

Smylie, M. A. (1999). Teacher stress in a time of reform. In R. Vandenberghe \& A. M. Huberman (Eds.), Understanding and preventing teacher burnout: $A$ sourcebook of international research and practice (pp. 59-84). New York: Cambridge University Press. 
Snyder, J., Bolin, F., \& Zumwalt, K. (1992). Curriculum implementation. In P. W. Jackson (Ed.), Handbook of research on curriculum (pp. 402-435). New York: Macmillan.

Solomon, P.G. (2009). The curriculum bridge: From standards to actual classroom practice (3rd ed.). Thousand Oaks, CA: Corwin Press.

Sonu, D. (2012). Illusions of compliance: Performing the public and hidden transcripts of social justice education in neoliberal times. Curriculum Inquiry, 42(2), 240-259. doi:10.1111/j.1467-873X.2012.00592.x

Southren, M. (2015). Working with a competency-based Training Package: A contextual investigation from the perspective of a group of TAFE teachers. International Journal of Training Research, 13(3), 194-213. doi:10.1080/14480220.2015.1077722

Spillane, J. P., Halverson, R., \& Diamond, J. B. (2004). Towards a theory of leadership practice: A distributed perspective. Journal of Curriculum Studies, 36(1), 3-34. doi:10.1080/0022027032000106726

Squires, D. A. (2009). Curriculum alignment: Research-based strategies for increasing student achievement. Thousand Oaks, CA: Corwin Press.

Stake, R. E. (1977). The countenance of educational evaluation. In A. A. Bellack \& H. M. Kliebard (Eds.), Curriculum and evaluation (pp. 372-390). Berkeley: McCutchan.

Steiner-Khamsi, G. (2013). What is wrong with the 'what-went-right' approach in educational policy? European Educational Research Journal, 12(1), 20-33.

Stella, A. (2006). Quality Assurance of Cross-Border Higher Education. Quality in Higher Education, 12(3), 257-276. doi: 10.1080/13538320601072859

Stenhouse, L. (1983). Authority, education and emancipation. London: Heinemann.

Stevens, R. (2000). What counts as math? Emergent and assigned mathematics problems in a project-based classroom. In J. Boaler (Ed.), Multiple perspectives in mathematics teaching and learning (pp. 105-144). New York: Elsevier.

Strauss, A. L., \& Corbin, J. M. (1998). Basics of qualitative research: Techniques and procedures for developing grounded theory. Thousand Oaks, CA: Sage. 
Szkornik, K. (2017). Teaching and learning on a transnational educational programme: Opportunities and challenges for flying faculty in Geography and related disciplines. Journal of Geography in Higher Education, 41(4), 521531.

Taba, H., \& Spalding, W. B. (1962). Curriculum development: Theory and practice. New York: Harcourt, Brace \& World.

Taylor, S., \& Henry, M. (2000). Globalization and educational policymaking: A case study. Educational Theory, 50(4), 487-503. doi:10.1111/j.1741$5446.2000 .00487 . x$

Taylor, S., Rizvi, F., Lingard, B., \& Henry, M. (1997). Education policy and the politics of change. London: Routledge.

Tikly, L. (2013). Chapter 2. Education and the new imperialism. Counterpoints, 369, 23-45.

Tikly, L., \& Barrett, A. (2011). Social justice, capabilities and the quality of education in low income countries. International Journal of Educational Development, 31(1), 3-14. Retrieved from http://dx.doi.org/10.1016/j.ijedudev.2010.06.001

Tikly, L., \& Barrett, A. M. (2013). Education quality and social justice in the global South: Towards a conceptual framework. In L. Tickley \& A. M. Barrett (Eds.), Educational quality and social justice in the global South: Challenges for policy, practice and research (pp. 221-223). London: Routledge.

Tierney, W. G., \& Dilley, P. (2002). Interviewing in education. In J. F. Gubrium \& J. A. Holstein (Eds.), Handbook of interview research (pp. 453-472). Thousand Oaks, CA: Sage.

Tomlinson, B. (1998). Materials development in language teaching. Cambridge: Cambridge University Press.

Tomlinson, C. A., \& Jarvis, J. (2006). Teaching beyond the book. Educational Leadership, 64(1), 16-21.

Tran, L. T. (2013a). Internationalisation of vocational education and training: An adapting curve for teachers and learners. Journal of Studies in International Education, 17(4), 492-507. doi:10.1177/1028315312469987 
Tran, L. T. (2013b). International student adaptation to academic writing in higher education. Newcastle: Cambridge Scholar Publishing.

Tran, L. T. (2013c). Teachers' changing professional roles and identity under the impact of internationalization. Journal of Studies in International Education, 17(4), $492-507$.

Tran, L. T. (2013d). Teaching international students in vocational education and training: New pedagogical approaches. Melbourne: ACER Press.

Tran, L. T., \& Dempsey, K. (2017). Internationalization in VET: An overview. In L. Tran \& K. Dempsey (Eds.), Internationalization in vocational education and training: Transnational perspectives (pp. 1-15). (Vol. 25 of the book series Technical and Vocational Education and Training: Issues, Concerns and Prospects). Cham: Springer.

Tran, L. T., \& Le, T. T. T. (2017). Teacher professional development under the impact of internationalization in VET. In L. Tran \& K. Dempsey (Eds.), Internationalization in vocational education and training: Transnational perspectives (pp. 77-94). (Vol. 25 of the book series Technical and Vocational Education and Training: Issues, Concerns and Prospects). Cham: Springer.

Tran, L. T., \& Nyland, C. (2013). Competency-based training, global skills mobility and the teaching of international students in vocational education and training. Journal of Vocational Education \& Training, 65(1), 143-157. doi:10.1080/13636820.2012.755215

Troman, G., \& Woods, P. (2000). The social construction of teacher stress. London: Routledge Farmer.

Tyack, D., \& Cuban, L. (1995). Tinkering toward Utopia: A century of public school reform. USA: Harvard University Press.

Tyler, R. W. (1949). Basic principles of curriculum and instruction (6th ed.). Chicago: University of Chicago Press.

Van Der Linde, C. (2006). A new paradigm for evaluating TAFE graduate outcomes. International Journal of Training Research, 4(1), 17-29. doi:10.5172/ijtr.4.1.17

van Manen, M. (1984). Practicing phenomenological writing. Phenomenology \& Pedagogy, 2(1), 36-69. 
van Manen, M. (1990). Researching lived experience: Human science for an action sensitive pedagogy. Albany: State University of New York Press.

van Manen, M. (2014). Phenomenology of practice: Meaning-giving methods in phenomenological research and writing. Walnut Creek: Left Coast Press.

Walker, D. F. (1971). A naturalistic model for curriculum development. The School Review, 80(1), 51-65. doi:10.1086/443014

Wallace, C. S., \& Priestley, M. R. (2016). Secondary science teachers as curriculum makers: Mapping and designing Scotland's new Curriculum for Excellence. Journal of Research in Science Teaching, 54(3), 324-349.

Wallenborn, M. (2010). Vocational education and training and human capital development: Current practice and future options. European Journal of Education, Part I, 45(2), 181-198. doi:10.1111/j.1465-3435.2010.01424.x

Warren, C. A. B. (2002). Qualitative interviewing. Thousand Oaks, CA: Sage.

Wells, A. S., Carnochan, S., Slayton, J., Allen, R. L., \& Vasudeva, A. (1998). Globalization and Educational Change. In A. Hargreaves, A.Lieberman, M. Fullan, \& D. Hopkins (Eds.), International handbook of educational change (pp. 332-348). Dordrecht: Kluwer Academic.

Wheelahan, L., \& Moodie, G. (2011). The quality of teaching in VET: Final report and recommendations. Melbourne: LH Martin Institute.

Wilkins, S., \& Juusola, K. (2018). The benefits and drawbacks of transnational higher education: Myths and realities. Australian Universities' Review, 60(2), 68-76.

Windschitl, M. (2002). Framing constructivism in practice as the negotiation of dilemmas: An analysis of the conceptual, pedagogical, cultural, and political challenges facing teachers. Review of Educational Research, 72(2), 131-175. doi:10.3102/00346543072002131

Woodfield, S., \& Middlehurst, R. (2009). Universities and International Higher Education Partnerships: Making a difference (Project Report). London, UK: Million+.

Woodley, C. (2006). Quality matters: Promoting quality improvement for offshore VET programs: Final report. Adelaide: NCVER. 
Woodley, C. (2007). Quality matters offshore. Crows Nest: AVETRA.

Woodley, C. (2008). Equivalence and contextualisation in transnational education. Paper presented at the Australasian Vocational Education and Training Research Association (AVETRA) Conference, Adelaide.

Zembylas, M. (2005). Beyond teacher cognition and teacher beliefs: The value of the ethnography of emotions in teaching. International Journal of Qualitative Studies in Education, 18(4), 465-487.

Ziguras, C. (2003). The impact of the GATS on transnational tertiary education: Comparing experiences of New Zealand, Australia, Singapore and Malaysia. Australian Educational Researcher, 30(3), 89-109.

Ziguras, C., \& McBurnie, G. (2015). Governing cross-border higher education. London: Routledge. 


\section{Appendices}

\section{Appendix A: Participant recruitment advertisement}

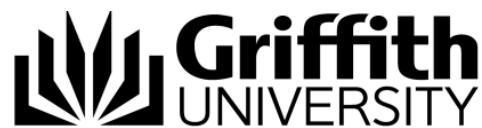

\section{Looking for VET Teachers with a story to tell about teaching Australian VET courses overseas}

We are seeking research participants for a research project titled: Australian transnational vocational education and training provisions: sustainability, quality and relevance. The purpose of this project is to identify and understand the factors that shape the roles and activities of those teaching Australian vocational education and training (VET) courses in transnational settings.

This practical inquiry will gather information about teachers' experiences in making decisions about what and how to teach in transnational settings. It is hoped that the collection of teachers' stories will provide important knowledge about the relevance and quality, and thus the sustainability, of exporting Australian VET provisions overseas. It should also provide much needed information about VET teachers' curriculum practices and how they negotiate between the imperatives of regulation and the needs of their students in diverse cultural settings.

\section{Who are we looking for?}

We are looking for VET teachers who have taught any Australian VET accredited or Training Package course overseas in the last ten years. You may be from anywhere in Australia and you may have taught in any discipline. What we are interested in is your experience and your story about teaching students overseas and how this compares to teaching in Australia.

\section{What would be required of participants?}

You are invited to contribute to this study by participating in three interviews over a two-month period. The first interview will be conducted face to face at a location of your choice. Subsequent interviews may also be face to face or via skype or videoconferencing - whatever is most convenient and practical for you. Each interview will take between one and two hours. The interviews will comprise some questions about your experiences as a VET teacher in a transnational setting.

Participation in these interviews is completely voluntary. You may withdraw at any time during or after each interview, without any adverse comment or consequences. You will have final control over your story. All information collected from participants will be confidential.

\section{Informed Consent}

If you are agreeable to taking part in this study, you will be asked to sign an Informed Consent Form.

\section{Questions/Further Information}

If you have any further questions about this study and/or would like to participate, please phone or text Louise King on 0411117427.

Thank you for your time and consideration of this project. 


\section{Contacts}

Student Researcher:

Louise King

Student, Doctorate of Education

School of Education and Professional Studies

Griffith University

0411117427

king.louise@hotmail.com

\section{Chief Investigators:}

Professor Stephen Billett

Associate Professor Sue Thomas

School of Education and

School of Education and

Professional Studies

Griffith University

Professional Studies

0737355855

Griffith University

s.billett@griffith.edu.au

0737355743

s.thomas@griffith.edu.au 


\title{
Appendix B: Information sheet
}

\section{\)」GNiffith}

\author{
Research Project \\ Australian transnational vocational education and training provisions: \\ sustainability, quality and relevance \\ Information Sheet for Participants
}

\section{Purpose}

The purpose of this project is to identify and understand the factors that shape the roles and activities of those teaching Australian vocational education and training (VET) courses in transnational settings. The practical inquiry will gather information about teachers' experiences of how these factors shape the decisions they make about what and how to teach in transnational settings. It is hoped that the collection of teachers' stories will provide important knowledge about the relevance and quality, and thus the sustainability, of exporting Australian VET provisions overseas. It should also provide much needed information about VET teachers' curriculum practices and how they negotiate between the imperatives of regulation and the needs of their students in diverse cultural settings.

\section{Outcomes}

At the end of the study, the findings will be presented as a thesis and papers published in educational journals.

What you are asked to do

You are invited to contribute to this study by participating in three interviews over a two-month period. The first interview will be conducted face to face at a location of your choice. Subsequent interviews may also be face to face or via skype or videoconferencing - whatever is most convenient and practical for you. Each interview will take between one and two hours. The interviews will comprise some questions about your experiences as a VET teacher in a transnational setting.

\section{Risks to you}

There is no foreseeable risk of harm or discomfort involved in this project. The most likely risk is that a third party may make inferences about the sources of information provided in interviews, even though it will not be attributed to any person. The risk of this will be minimised, as you will be able to amend any information that you feel may identify you.

\section{Privacy}

With your agreement, the interview will be audio-recorded. The recording will be held as a secure file until the interview is transcribed at which time it will be deleted. Your responses will only be used for the data analysis of this study.

This project will comply with the Information Privacy Act 2009. This includes your right of access to, and amendment of, personal information and that you are entitled to request access to any personal information you provide. The University's Privacy Plan can also be located at http://www.griffith.edu.au/about-griffith/planspublications/griffith-university-privacy-plan

\section{Participation is voluntary and all information is confidential}

Participation in these interviews is completely voluntary. You may withdraw at any time during or after each interview, without any adverse comment or consequences. All information collected from participants will be confidential. You will not be identified in the thesis or any publications. The information collected will not be disclosed to any third parties without your consent. Your anonymity will be safeguarded at all times. 


\title{
Ethical conduct
}

As a student of Griffith University this study must be conducted in accordance with the National Statement on Ethical Conduct in Human Research. If you have any concerns about the ethical conduct of this study you can discuss this with the researcher or supervisors. You may also phone the Manager, Research Ethics on 0737354855 or via email at: research-ethics@griffith.edu.au .

\section{Feedback to you}

You will be provided with the opportunity to read and provide feedback on all transcripts and summaries of the data. The final account of your story will be decided by you. The researcher will provide you with a summary of the research results at the conclusion of the project. You will also receive notification and access to copies of the final thesis and any published papers.

\section{Informed Consent}

If you are agreeable to taking part in this study, you will be asked to sign an Informed Consent Form to confirm that you have read and understood this Information Sheet and thus the particulars of your participation in the project.

\section{Questions/Further Information}

If you have any further questions about this study, please phone or text Louise King on 0411117427 . I can return your call to avoid any cost to you. Thank you for your time and consideration of this project.

\section{Contacts}

Student Researcher:

Louise King

Student, Doctorate of Education

School of Education and Professional Studies

Griffith University

0411117427

king.louise@hotmail.com

\section{Chief Investigators:}

Professor Stephen Billett

School of Education and

Professional Studies

Griffith University

0737355855

s.billett@griffith.edu.au

\author{
Associate Professor Sue Thomas \\ School of Education and \\ Professional Studies \\ Griffith University \\ 0737355743 \\ s.thomas@griffith.edu.au
}




\section{は凶」) Griffith}

Research Project

Australian transnational vocational education and training provisions: sustainability, quality and relevance Informed Consent Form

By signing this form below, I confirm that I have read and understood the Information Sheet provided, and in particular that:

My involvement in this research will include being asked questions in a series of three interviews about my experience teaching Australian VET courses in a transnational setting.

The conduct of this research involves the collection, access and/or use of my identified personal information. The information collected is confidential and will not be disclosed to third parties without your consent, except to meet government, legal or other regulatory authority requirements. A de-identified copy of this data may be used for other research purposes. However, my anonymity will at all times be safeguarded. For further information consult the University's Privacy Plan at http://www.griffith.edu.au/privacy-plan or telephone (07) 37354375.

I have had any questions about the study answered to my satisfaction.

I understand any risks involved.

I understand that my participation in this research is voluntary, and that I am free to withdraw at any time, without comment or penalty.

I understand the interview will be audio-recorded and that once the recording has been transcribed, it will be erased.

I understand the researcher will provide me with a summary of the research results at the conclusion of the project.

I understand that if I have any additional questions, I can contact the researcher or her supervisor.

I understand that I can contact the Manager, Research Ethics, at Griffith University, on 0737354855 or via email at: research-ethics@griffith.edu.au if I have any concerns about the ethical conduct of the project.

I agree to participate in the research project on as per the Information Sheet provided on the study titled, Australian transnational vocational education and training provisions: sustainability, quality and relevance.

Name (printed):

Signature:

Date:

For further information please contact:

Student Researcher:

Louise King

Student, Doctorate of Education

School of Education and Professional Studies

Griffith University

0411117427

king.louise@hotmail.com 
Chief Investigators:

Professor Stephen Billett

Associate Professor Sue Thomas

School of Education and

School of Education and

Professional Studies

Griffith University

0737355855

s.billett@griffith.edu.au

Professional Studies

Griffith University

0737355743

s.thomas@griffith.edu.au 
Appendix D: Semi-structured interview tool

Interview 1

\section{U/) Griffith L1] UNIVERSITY}

Australian transnational vocational education and training provisions:

sustainability, quality and relevance

\section{Interview Questions \\ Interview 1: Teaching Background, Preparation and Experience}

\section{Demographic Information}

1.1 Name:

NOTE: Names and personal details will not be shown in the research report.

1.2 Gender: Female or Male (please circle)

1.3 Age Group: [ ] 15-19 [ ] 20-29 [ ] 30-39 [ ] 40-49 [ ] 50-59 [ ] 60-69 [ ] 70+

1.4 Australian resident: Yes or No (please circle)

If no, what is your country of residence?

1.5 Country of birth:

\section{Teaching Experience}

Australian VET teaching experience:

2.1 How many years Australian VET teaching experience do you have in total?

\begin{tabular}{lll}
\hline Position (i.e. Hospitality & Place (i.e. Cairns, QLD) & Time period (i.e. May \\
Teacher) & & 2007-Sept 2008)
\end{tabular}


Transnational VET teaching experience:

2.2 How many years transnational VET teaching experience do you have in total?

\begin{tabular}{lll}
\hline $\begin{array}{l}\text { Position (i.e. Business } \\
\text { Teacher) }\end{array}$ & $\begin{array}{l}\text { Place (i.e. Abu Dhabi, } \\
\text { Emirates) }\end{array}$ & $\begin{array}{l}\text { Time period (i.e. May } \\
\text { 2009-Sept 2011) }\end{array}$ \\
\hline & & \\
\end{tabular}

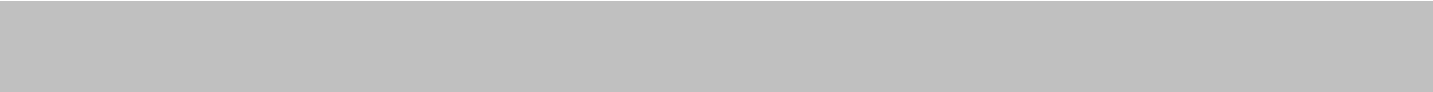

2.3 How would you rate your knowledge, skills and experience about each of the following in relation to the curriculum you were required to teach in place $x$ ? Please tick.

\begin{tabular}{|c|c|c|c|c|c|}
\hline & $\begin{array}{l}\text { Very } \\
\text { poor }\end{array}$ & Poor & Adequate & Good & Excellent \\
\hline $\begin{array}{l}\text { Competency based } \\
\text { training model }\end{array}$ & $\square$ & $\square$ & $\square$ & $\square$ & $\square$ \\
\hline Content knowledge & $\square$ & $\square$ & $\square$ & $\square$ & $\square$ \\
\hline Industry expertise & $\square$ & $\square$ & $\square$ & $\square$ & $\square$ \\
\hline $\begin{array}{l}\text { Classroom } \\
\text { management }\end{array}$ & $\square$ & $\square$ & $\square$ & $\square$ & $\square$ \\
\hline $\begin{array}{l}\text { Teaching } \\
\text { strategies and } \\
\text { methods }\end{array}$ & $\square$ & $\square$ & $\square$ & $\square$ & $\square$ \\
\hline $\begin{array}{l}\text { Implementing } \\
\text { curriculum to meet } \\
\text { standards }\end{array}$ & $\square$ & $\square$ & $\square$ & $\square$ & $\square$ \\
\hline $\begin{array}{l}\text { Teaching the } \\
\text { curriculum to the } \\
\text { same standard as } \\
\text { in Australia }\end{array}$ & $\square$ & $\square$ & $\square$ & $\square$ & $\square$ \\
\hline
\end{tabular}




\section{Qualifications}

3.1 What preparation did you have in becoming a teacher/educator?

\begin{tabular}{lllllll}
\hline $\begin{array}{l}\text { Non } \\
\mathbf{e} \text { at } \\
\text { all }\end{array}$ & $\begin{array}{l}\text { Cert IV } \\
\text { Training } \\
\text { and } \\
\text { Assessmen } \\
\mathbf{t}\end{array}$ & $\begin{array}{l}\text { Diploma of } \\
\text { Training } \\
\text { and } \\
\text { Assessmen } \\
\mathbf{t}\end{array}$ & $\begin{array}{l}\text { Undergraduat } \\
\text { e degree in } \\
\text { education }\end{array}$ & $\begin{array}{l}\text { Undergraduat } \\
\text { e degree in } \\
\text { vocational } \\
\text { education }\end{array}$ & $\begin{array}{l}\text { Postgraduat } \\
\text { e teaching } \\
\text { Diploma }\end{array}$ & $\begin{array}{l}\text { Master } \\
\text { som } \\
\text { degree }\end{array}$ \\
\hline$\square$ & $\square$ & $\square$ & $\square$ & $\square$ & $\square$ \\
\hline
\end{tabular}

3.2 Do you hold a CIV Training and Assessment or equivalent? Yes or No (please circle)

3.3 What other qualifications do you hold? Please list in the table below.

Qualification $\begin{aligned} & \text { Field of study (i.e.) } \\ & \text { Management }\end{aligned}$
Post graduate
or Certificate
Bachelor degree
Advanced Diploma
or Diploma
Certificate IV
Certificate I, II or III
Year 12 Certificate

Thank you for completing this Data Collection Sheet and providing this information about yourself. Now I would like to begin the interview by asking you to elaborate on your teaching background and experience both in Australia and overseas.

\section{Teachers' Background and Preparation}

4.1 Please describe your working life before you became a vocational teacher?

4.2 What were the parts of that working life that you enjoyed and with which you most closely identified?

4.3 Why did you decide to become a vocational teacher/educator?

4.4 What preparation did you undertake to become a vocational teacher/educator?

4.5 How useful was this preparation for teaching locally and internationally? 
4.6 What could have prepared you more adequately for teaching locally and overseas?

\section{Teaching Experiences}

5.1 What were your first teaching experiences?

5.2 What surprised you when you first began teaching in Australia?

5.3 What did/do you like and dislike about being a vocational teacher/educator in Australia?

5.4 How did you come to work as a VET teacher overseas?

5.5 What was the nature of the arrangement with the institution you worked at place $x ?$

5.6 What were your first impressions of the vocational education system in the country in which you taught internationally?

5.7 What did you find most different teaching internationally from what you were used to in Australia? 


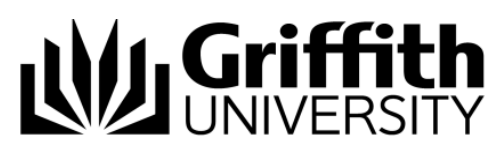

\section{Australian transnational vocational education and training provisions: sustainability, quality and relevance}

\section{Interview Questions \\ Interview 2: Factors Affecting Curriculum Implementation}

\section{Knowledge of Curriculum}

1.1 Below is a set of definitions of what might constitute curriculum. Using these definitions, could you indicate the degree by which (1-5: $1=$ no resemblance $5=$ strong resemblance) they describe curriculum as you understand it:

\begin{tabular}{|c|c|c|c|c|}
\hline $\begin{array}{l}1=\text { no } \\
\text { resemblance }\end{array}$ & $\begin{array}{l}2=\text { little } \\
\text { resemblance }\end{array}$ & $3=$ neutral & $\begin{array}{l}4=\text { some } \\
\text { resemblance }\end{array}$ & $\begin{array}{l}5=\text { strong } \\
\text { resemblance }\end{array}$ \\
\hline
\end{tabular}

\section{Definitions}

Resemblance

Curriculum is designed and mandated by government and industry

Curriculum is where all the learning for students is planned by and directed by the institution or college to meet its' educational goals.

Curriculum is a program of activities designed in a specific way so that students will attain by learning certain specifiable ends or objectives.

Curriculum is an attempt to communicate the essential principles and features of an educational proposal in such a form that that it is open to critical scrutiny and capable of effective translation into practice.

Curriculum is a course conceived as a series of planned events that are intended to have educational consequences for students.

Curriculum refers to the learning experiences of students, in so far as they are expressed or anticipated in educational goals and objectives, plans and designs for learning and the implementation of these plans and designs in educational environments.

1.2 Using the same definitions of curriculum indicate with a tick in the table below what you believe is the current provision of vocational education curriculum (i.e. what is currently happening) in Australia and how it should be ideally provided for in Australia (i.e. what should be happening)?

\begin{tabular}{|c|c|c|}
\hline Definitions & $\begin{array}{l}\text { What is the reality in } \\
\text { Australia }\end{array}$ & $\begin{array}{l}\text { What should } \\
\text { be the ideal in } \\
\text { Australia }\end{array}$ \\
\hline \multicolumn{3}{|l|}{$\begin{array}{l}\text { Curriculum is designed and mandated by government } \\
\text { and industry. }\end{array}$} \\
\hline $\begin{array}{l}\text { Curriculum is where all the learning for students is } \\
\text { planned by and directed by the institution or college to } \\
\text { meet its' educational goals. }\end{array}$ & & \\
\hline
\end{tabular}


Curriculum is a program of activities designed in a specific way so that students will attain by learning certain specifiable ends or objectives.

Curriculum is an attempt to communicate the essential principles and features of an educational proposal in such a form that that it is open to critical scrutiny and capable of effective translation into practice.

Curriculum is a course conceived as a series of planned events that are intended to have educational consequences for students.

Curriculum refers to the learning experiences of students, in so far as they are expressed or anticipated in educational goals and objectives, plans and designs for learning and the implementation of these plans and designs in school environments.

1.3 Using the same definitions of curriculum indicate with a tick in the table below what you believe is the current provision of vocational education curriculum (i.e. What is currently happening) in the place you taught overseas and how it should be ideally provided for there (i.e. what should be happening)?

$\begin{array}{lll}\text { Definitions } & \begin{array}{l}\text { What is the reality } \\ \text { overseas }\end{array} & \begin{array}{l}\text { What should } \\ \text { be the ideal } \\ \text { overseas }\end{array}\end{array}$

Curriculum is designed and mandated by government and industry.

Curriculum is where all the learning for students is planned by and directed by the institution or college to meet its' educational goals.

Curriculum is a program of activities designed in a specific way so that students will attain by learning certain specifiable ends or objectives.

Curriculum is an attempt to communicate the essential principles and features of an educational proposal in such a form that that it is open to critical scrutiny and capable of effective translation into practice.

Curriculum is a course conceived as a series of planned events that are intended to have educational consequences for students.

Curriculum refers to the learning experiences of students, in so far as they are expressed or anticipated in educational goals and objectives, plans and designs for learning and the implementation of these plans and designs in school environments.

1.4 What is the relative value you place upon the requirements of government, local industry and student needs in regard to curriculum development? That is, what emphasis of these interests needs to be expressed in the curriculum development process?

Please quantify these values out of 100 in the table below?

\begin{tabular}{lc}
\hline Stakeholder interest & Percentage \\
\hline Government/policy requirements & \\
Local industry/workplace requirements & Total $100 \%$ \\
Student needs and requirements & Tot \\
\hline
\end{tabular}


1.5 To what degree should teachers have a say in curriculum development? Please tick the statement that you most agree with.

\begin{tabular}{lllll}
\hline No say at all & $\begin{array}{l}\text { Adapting } \\
\text { pre-determined } \\
\text { curriculum to local } \\
\text { circumstances }\end{array}$ & $\begin{array}{l}\text { Planning and } \\
\text { organising the } \\
\text { curriculum to meet } \\
\text { local circumstances }\end{array}$ & $\begin{array}{l}\text { Developing parts of } \\
\text { the curriculum and } \\
\text { making decisions } \\
\text { about its } \\
\text { implementation }\end{array}$ & $\begin{array}{l}\text { Developing } \\
\text { the overall } \\
\text { curriculum }\end{array}$ \\
\hline$\square$ & $\square$ & $\square$ & $\square$ \\
\hline
\end{tabular}

1.6 What do you see as the most important roles VET teachers should uphold? Please tick the statement you most agree with.

\begin{tabular}{llll}
\hline $\begin{array}{l}\text { Implementers of } \\
\text { curriculum designed } \\
\text { elsewhere }\end{array}$ & $\begin{array}{l}\text { Adapters modifying } \\
\text { curriculum to meet local } \\
\text { needs }\end{array}$ & $\begin{array}{l}\text { Developers of the } \\
\text { curriculum and learning } \\
\text { and teaching materials }\end{array}$ & $\begin{array}{l}\text { Researchers } \\
\text { trialling new } \\
\text { approaches to } \\
\text { teaching and } \\
\text { evaluating the } \\
\text { curriculum }\end{array}$ \\
\hline$\square$ & $\square$ & $\square$ & $\square$ \\
\hline
\end{tabular}

1.7 Below is a set of definitions of what might constitute competency-based training (CBT) as a form of curriculum. Using these definitions, could you indicate the degree by which (1-5: $1=$ no resemblance $5=$ strong resemblance) they describe CBT as you understand it:

\begin{tabular}{|c|c|c|c|}
\hline $\begin{array}{l}1=\text { no } \\
\text { resemblance }\end{array}$ & $2=$ little resemblance $3=$ neutral & $\begin{array}{l}4=\text { some } \\
\text { resemblance }\end{array}$ & $\begin{array}{l}5=\text { strong } \\
\text { resemblance }\end{array}$ \\
\hline
\end{tabular}

\section{Definitions}

Resemblance

CBT is a form of training where the outcomes of the training are measured against specified industry standards in a given occupational setting.

$\mathrm{CBT}$ is a form of modularised delivery and assessment in a given context whereby students are deemed as either competent or not yet competent.

CBT is a holistic approach framed by the nature and context of industry and applicable to a wide range of contexts.

CBT fosters authentic learning within and beyond the workplace underpinned by the concept of learning to learn.

1.8 What did you perceive as the outcomes of the competency-based training model in the place you worked overseas?

\begin{tabular}{lllll}
\hline $\begin{array}{l}\text { Improving the } \\
\text { national economy }\end{array}$ & $\begin{array}{l}\text { Enhancing } \\
\text { student } \\
\text { employment } \\
\text { outcomes }\end{array}$ & $\begin{array}{l}\text { Reducing the } \\
\text { costs of training }\end{array}$ & $\begin{array}{l}\text { Preparing } \\
\text { students for into } \\
\text { onshore higher } \\
\text { education courses }\end{array}$ & $\begin{array}{l}\text { Other: } \\
\text { Please } \\
\text { describe }\end{array}$ \\
\hline$\square$ & $\square$ & $\square$ & $\square$ & $\square$ \\
\hline
\end{tabular}

1.9 What curriculum materials, if any did the institution you worked for provide to help you teach your course overseas? Please tick. 


\begin{tabular}{|c|c|c|c|c|}
\hline & $\begin{array}{l}\text { Available } \\
\text { Y or N }\end{array}$ & Unhelpful & Neutral & Helpful \\
\hline Syllabus & & $\square$ & $\square$ & $\square$ \\
\hline Unit outlines & & $\square$ & $\square$ & $\square$ \\
\hline Teacher Guides & & $\square$ & $\square$ & $\square$ \\
\hline Lesson plans & & $\square$ & $\square$ & $\square$ \\
\hline Assessment Tools & & $\square$ & $\square$ & $\square$ \\
\hline Marking Guides & & $\square$ & $\square$ & $\square$ \\
\hline Student materials & & $\square$ & $\square$ & $\square$ \\
\hline $\begin{array}{l}\text { Work Placement } \\
\text { Guides }\end{array}$ & & $\square$ & $\square$ & $\square$ \\
\hline Text books & & $\square$ & $\square$ & $\square$ \\
\hline $\begin{array}{l}\text { Other reference } \\
\text { material }\end{array}$ & & $\square$ & $\square$ & $\square$ \\
\hline $\begin{array}{l}\text { Other resources } \\
\text { Please name: }\end{array}$ & & & & \\
\hline
\end{tabular}

\section{Features of Transnational Teaching and Learning}

2.1 What percentage of your teaching was teacher and student centred in place $x$ ? How did this compare to teaching in Australia?

\begin{tabular}{|c|c|c|}
\hline ( & Teacher centred & Student centred \\
\hline Transnational setting & _\% & 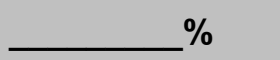 \\
\hline Australian setting & $\%$ & - $\%$ \\
\hline
\end{tabular}

2.2 What percentage of time did you spend teaching and assessing in place $x$ ? How did this compare to your teaching in Australia?

\begin{tabular}{lcc}
\hline & Teaching & Assessing \\
\hline Transnational setting & $\%$ & $\%$ \\
\cline { 2 - 3 } Australian setting & $\%$ & $\%$ \\
\hline
\end{tabular}

2.3 Which of the following were features of your provision of course/unit $x$ in place $x$ ? Online components

\begin{tabular}{lc}
\hline Recognition of prior learning (RPL) & $\square$ \\
Work based learning and assessment & $\square$ \\
Face to face teaching & $\square$ \\
Student choice (when, where and how) & $\square$
\end{tabular}


2.4 How much workplace learning was there in place $x$ ? How this compare to the amount of workplace learning available to students in Australia?

\begin{tabular}{lcc}
\hline & Classroom learning & Workplace learning \\
\hline Transnational setting & $\%$ & $\%$ \\
\cline { 2 - 3 } Australian setting & $\%$ & $\%$ \\
\hline
\end{tabular}

2.5 How would you describe the expectations of you as a teacher by your employer in place $x$ ?

\begin{tabular}{llll}
\hline $\begin{array}{l}\text { To focus on the } \\
\text { procedural aspects of } \\
\text { teaching to maintain } \\
\text { compliance }\end{array}$ & $\begin{array}{l}\text { To focus on corporate } \\
\text { goals and effectively } \\
\text { manage the students' } \\
\text { behaviour and } \\
\text { maintain records }\end{array}$ & $\begin{array}{l}\text { To hold a high level of } \\
\text { teaching expertise and } \\
\text { make decisions } \\
\text { autonomously within } \\
\text { guidelines }\end{array}$ & $\begin{array}{l}\text { To work } \\
\text { collaboratively } \\
\text { with others to } \\
\text { practice } \\
\text { reflexivity, } \\
\text { critical analysis } \\
\text { and transform } \\
\text { the student } \\
\text { experience }\end{array}$ \\
\hline$\square$ & & $\square$ & $\square$ \\
\hline
\end{tabular}

Thank you for completing this Data Collection Sheet and providing this information about yourself. Now I would like to begin the interview by asking you some questions about the factors which affected your teaching in place $\mathrm{x}$. These questions focus on the factors affecting the implementation of the curriculum in your international vocational education experiences.

However, before asking you questions about this, there are some issues that arose in the first interview that need to be clarified.

When we met last time you suggested that

\section{Cultural Factors}

I want to start by looking at the cultural context you were working in and some of the issues that arose from that setting.

3.1 Can you start by describing the cultural context of the classroom and the students in your classes at place $x$ (cultural, linguistic, socio-economic)?

3.2 What was/were the main learning style/s of students in place $x$ ?

3.3 What were some of the key language, literacy and communication issues you experienced with these students?

3.4 In your opinion, how well do you think the students understood the course requirements and what was expected of them in place $x$ ? 
3.5 Given your knowledge about the students' cultural backgrounds, how did you use this information to plan and conduct your lessons in place $x$ ?

3.6 What cultural factors or practices did you find the most difficult to adjust to in place $\mathrm{x}$ ?

3.5 How well do you think adapted to working with the culture in place $x$ ?

\section{Pedagogical Factors}

In this part of the interview I want to focus on your teaching more generally in place $x$ and some of the factors that affected your practice.

4.1 What did you find worked and did not work in the classroom with the students in place $x$ ?

4.2 When it came to implement the curriculum in place $x$, what type of adjustments did you have to make to teach the students and why did you make those adjustments?

4.3 What were the main factors which affected your teaching in place $x$ ?

4.4 How flexible could you be in your teaching practice in place $x$ ?

4.5 To what extent and how did your own values and interests influence what and how you taught in place $x$ ?

4.6 What were some of the administrative demands on your time that impacted on your teaching in place $x$ ?

\section{Conceptual/Curriculum Factors}

This part of the interview focuses on some of the issues as they related to the curriculum you had to teach.

5.1 What does the term curriculum mean for you?

5.2 What for you constitutes an effective curriculum?

5.3 To what extent was the curriculum contextualised for local conditions in place $x$ ?

5.4 How helpful were the curriculum materials provided to you in place $x$ ?

5.5 What additional teaching and learning resources did you have to develop to teach in place $x$ ?

5.6 Given what you have said - how effective do you think the curriculum and supporting materials were for you as a teacher in place $x$ ?

\section{Political Factors}

In this final part of the interview the questions focus on some of the political factors that affected the way you implemented the curriculum in place $x$. 
6.1 What were your responsibilities as a teacher for meeting Australia's regulatory requirements under the Standards for NVR Registered Training Organisations 2012 in place $x$ ?

6.2 How would you describe the expectations of you as a teacher by your employer in place $x$ ?

6.3 How was the quality of your teaching and the courses judged at place $x$ ?

6.4 How different was this from the way you judge the quality of your teaching and the courses at place $x$ ?

6.5 In what ways did your employer help you to develop the knowledge of the curriculum and skills you needed to teach course $\mathrm{x}$ in place $\mathrm{x}$ ?

6.6 In what ways did other people, places or things influence your decisions about what and how to teach in place $x$ ?

6.7 How relevant was your industry experience in place $x$ ?

6.8 How were you able/unable to make links with industry in place $x$ ?

6.9 Looking back, what support do you think you needed for the courses in place $\mathrm{x}$ to better meet the needs of students?

6.10 Knowing what you know now, how should the teaching have been better organised and enacted in place $\mathrm{x}$ and why?

Thank you for your contributions to this research 
Interview 3

\section{U) Griffith GNIVERSITY}

\section{Australian transnational vocational education and training provisions: sustainability, quality and relevance}

\section{Interview Questions}

\section{Interview 3: Teacher Decision-making and Autonomy}

\section{Teacher Discretion}

1.1 How important is teacher discretion (i.e. ability make decisions) to being an effective vocational educator/teacher?

\begin{tabular}{llll}
\hline Not at all & Important & Very important & $\begin{array}{l}\text { Essential for effective } \\
\text { teaching }\end{array}$ \\
\hline$\square$ & $\square$ & $\square$ \\
\hline
\end{tabular}

1.2 To what degree were you given the opportunity to make changes and bring about change in the place you worked overseas?

\begin{tabular}{lllll}
\hline $\begin{array}{l}\text { No opportunity } \\
\text { at all }\end{array}$ & $\begin{array}{l}\text { Minor changes } \\
\text { within the private } \\
\text { practice of the } \\
\text { classroom }\end{array}$ & $\begin{array}{l}\text { Ability to plan } \\
\text { semesters work } \\
\text { and individual } \\
\text { sessions }\end{array}$ & $\begin{array}{l}\text { Reorientate } \\
\text { parts of the } \\
\text { course to local } \\
\text { needs }\end{array}$ & $\begin{array}{l}\text { Make significant } \\
\text { changes to the } \\
\text { content, process } \\
\text { and assessment } \\
\text { student learning }\end{array}$ \\
\hline$\square$ & $\square$ & $\square$ & $\square$ \\
\hline
\end{tabular}

1.3 How does this compare to the degree in which you have been able to make changes and bring about change in Australia?

\begin{tabular}{lllll}
\hline $\begin{array}{l}\text { No opportunity } \\
\text { at all }\end{array}$ & $\begin{array}{l}\text { Minor changes } \\
\text { within the } \\
\text { private practice } \\
\text { of the classroom }\end{array}$ & $\begin{array}{l}\text { Ability to plan } \\
\text { semesters work } \\
\text { and individual } \\
\text { sessions }\end{array}$ & $\begin{array}{l}\text { Reorientate } \\
\text { parts of the } \\
\text { course to local } \\
\text { needs }\end{array}$ & $\begin{array}{l}\text { Make significant } \\
\text { changes to the } \\
\text { content, process } \\
\text { and assessment } \\
\text { student learning }\end{array}$ \\
\hline$\square$ & $\square$ & $\square$ & $\square$ \\
\hline
\end{tabular}

1.4 To what degree were you able to teach the way in which you wanted to in the place you worked overseas?

\begin{tabular}{lllll}
\hline $\begin{array}{l}\text { No opportunity } \\
\text { at all - had to } \\
\text { follow set }\end{array}$ & $\begin{array}{l}\text { Minor changes } \\
\text { within the } \\
\text { private practice } \\
\text { teacher guides }\end{array}$ & $\begin{array}{l}\text { Flexibility to teach } \\
\text { as required in } \\
\text { balance with } \\
\text { classroom }\end{array}$ & $\begin{array}{l}\text { Teach how you } \\
\text { wanted with } \\
\text { sollowing some } \\
\text { set teacher guides }\end{array}$ & $\begin{array}{l}\text { Teach how you } \\
\text { wanted to }\end{array}$ \\
\hline$\square$ & $\square$ & $\square$ & $\square$ & $\square$ \\
\hline
\end{tabular}


1.5 How does this compare to the degree you have been able to teach the way in which you wanted to in Australia?

\begin{tabular}{lllll}
\hline $\begin{array}{l}\text { No opportunity at } \\
\text { all - had to follow } \\
\text { set teacher guides }\end{array}$ & $\begin{array}{l}\text { Minor changes } \\
\text { within the } \\
\text { private } \\
\text { practice of the } \\
\text { classroom }\end{array}$ & $\begin{array}{l}\text { Flexibility to teach } \\
\text { as required in } \\
\text { balance with } \\
\text { following some } \\
\text { set teacher guides }\end{array}$ & $\begin{array}{l}\text { Teach how you } \\
\text { wanted with } \\
\text { some limitations }\end{array}$ & $\begin{array}{l}\text { Teach how you } \\
\text { wanted to }\end{array}$ \\
\hline$\square$ & $\square$ & $\square$ & $\square$ \\
\hline$\square$ & $\square$ & $\square$
\end{tabular}

1.6 To what degree did you implement the curriculum with fidelity in the place you worked overseas?

\begin{tabular}{llll}
\hline $\begin{array}{l}\text { Did not follow the } \\
\text { curriculum at all }\end{array}$ & $\begin{array}{l}\text { Followed the curriculum } \\
\text { some of the time }\end{array}$ & $\begin{array}{l}\text { Followed the } \\
\text { curriculum most of the } \\
\text { time }\end{array}$ & $\begin{array}{l}\text { Followed the } \\
\text { curriculum with } \\
\text { absolute fidelity }\end{array}$ \\
\hline$\square$ & $\square$ & $\square$ \\
\hline
\end{tabular}

1.7 How does this compare to when you implement the curriculum in Australia?

\begin{tabular}{llll}
\hline $\begin{array}{l}\text { Did not follow the } \\
\text { curriculum at all }\end{array}$ & $\begin{array}{l}\text { Followed the } \\
\text { curriculum some of } \\
\text { the time }\end{array}$ & $\begin{array}{l}\text { Followed the } \\
\text { curriculum most of the } \\
\text { time }\end{array}$ & $\begin{array}{l}\text { Followed the } \\
\text { curriculum with } \\
\text { absolute fidelity }\end{array}$ \\
\hline$\square$ & $\square$ & $\square$
\end{tabular}

1.8 When you decided to make changes to implementing the curriculum in the place you worked overseas did you? Please select.

\begin{tabular}{llll}
\hline $\begin{array}{l}\text { Seek permission } \\
\text { from Australian } \\
\text { institution }\end{array}$ & $\begin{array}{l}\text { Seek permission from } \\
\text { local } \\
\text { supervisor/authority }\end{array}$ & $\begin{array}{l}\text { Talk to other } \\
\text { teachers }\end{array}$ & $\begin{array}{l}\text { Make changes on } \\
\text { your own volition }\end{array}$ \\
\hline$\square$ & $\square$ & $\square$ & $\square$ \\
\hline
\end{tabular}

1.9 What type of changes did you make and to what extent the place you worked overseas? Please select.

\begin{tabular}{lllll}
\hline & $\begin{array}{l}\text { No } \\
\text { change }\end{array}$ & $\begin{array}{l}\text { Some } \\
\text { change }\end{array}$ & $\begin{array}{l}\text { Moderate } \\
\text { change }\end{array}$ & $\begin{array}{l}\text { Major } \\
\text { Change }\end{array}$ \\
\hline Pace & $\square$ & $\square$ & $\square$ & $\square$ \\
Emphasis & $\square$ & $\square$ & $\square$ & $\square$ \\
Sequence & $\square$ & $\square$ & $\square$ & $\square$ \\
Experience/activities & $\square$ & $\square$ & $\square$ & $\square$ \\
$\begin{array}{l}\text { Teaching and learning } \\
\text { materials }\end{array}$ & $\square$ & $\square$ & $\square$ & $\square$ \\
Assessment judgements & $\square$ & $\square$ & $\square$ & $\square$ \\
Standards/level/pitch & $\square$ & $\square$ & $\square$ & $\square$ \\
\hline
\end{tabular}


1.10 How uniform do you believe the curriculum was implemented in within the department/school/faculty in the place you worked overseas compared to places you have taught the same curriculum in Australia?

\begin{tabular}{lllll}
\hline & $\begin{array}{l}\text { No } \\
\text { uniformity }\end{array}$ & $\begin{array}{l}\text { Some } \\
\text { uniformity }\end{array}$ & $\begin{array}{l}\text { Mostly } \\
\text { uniform }\end{array}$ & Uniform \\
\hline Department/school/faculty & $\square$ & $\square$ & $\square$ & $\square$ \\
Australian settings & $\square$ & $\square$ & $\square$ & $\square$ \\
\hline
\end{tabular}

Thank you for completing this Data Collection Sheet and providing this information about yourself. Now I would like to begin the interview by asking you some questions more in depth questions about your decision making and autonomy as a teacher in place $x$.

This interview reflects on the factors that were discussed at the last interview and specifically focuses on teacher decision-making and professional autonomy in your international vocational education experiences.

However, before asking you questions about this, there are some issues that arose in the second interview that need to be clarified.

When we met last time you suggested that ...

\section{Teacher Decision-making}

2.1 On reflecting on our last interview what do you think were the three or four critical factors that had the biggest impact on your teaching at place $x$ ?

2.2 What were the scope of the changes you had to make to account for these factors and provide effective teaching experiences in place $x$ ?

2.3 How did you prioritise the competing demands on you in place $x$ ?

2.4 In what ways did these factors influence your decision-making in place $x$ ?

2.5 What else did you make decisions about and to what extent and what effect in place $x$ ?

2.6 Whose concerns and interests influenced you most when you made decisions in place $\mathrm{x}$ ?

2.7 How did you diversify or extend your methods of teaching to accommodate these interests in place $x$ ?

2.8 To what degree were you professionally and culturally prepared for making those changes in place $x$ ?

2.9 How was this process of decision making different from teaching in Australia?

2.10 In our second interview you indicated that the most important role for VET teachers was implementer/adapter/developer/researcher. Were you able to fulfil this role in place $x$ ? Yes or No. If no, what role did you play place $x$ ? Please elaborate. 
2.11 What were the specific site issues or cultural norms that influenced the construction of your role as a teacher in place $x$ ?

2.12 How could you have been better prepared to be more effective as an international vocational educator/teacher?

2.13 In retrospect how successful do you feel about meeting the demands of your role as a teacher in place $x$ ?

\section{Teacher Autonomy}

3.1 To what extent and how were able to exercise discretion in place $x$ ?

3.2 How does this compare to your ability to exercise discretion in Australia?

3.3 Were there any areas outside of the classroom where you had to discretion to act in place $x$ ?

3.4 What factors remained outside of your control as a teacher in place $x$ ?

3.5 What were the consequences of that for you as a teacher in place $x$ ?

3.6 What changes have you made to your teaching practice since your time in place $x ?$

3.7 Overall how do you feel about your teaching experience and the decisions you made in place $x$ ?

\section{Conclusion: Relevance, Quality and Sustainability of Transnational VET Provisions}

4.1 Upon reflecting, on the three interviews, how do you think your transnational teaching experience compares to your experience teaching course $\mathrm{x}$ in Australia or elsewhere?

4.2 How do you think the broader community in place $x$ perceived Australian VET provisions offered in place $x$ ?

4.3 How would you compare the standards of course $x$ in place $x$ compared to the same course in Australia?

4.4 What are your thoughts about whether it is better for countries such as $\mathrm{x}$ to import Australian VET provisions or develop their own VET curriculum and implement locally?

4.5 If Australia is going to continue to offer Australian VET provisions overseas what level of adaption do you think should be made to the curriculum to meet local needs?

\begin{tabular}{llll}
\hline No adaption & $\begin{array}{l}\text { Minor modifications to } \\
\text { contextualise to local } \\
\text { settings }\end{array}$ & $\begin{array}{l}\text { Major modifications to } \\
\text { contextualise for national } \\
\text { setting }\end{array}$ & $\begin{array}{l}\text { Internationalise the } \\
\text { curriculum for } \\
\text { global context }\end{array}$ \\
\hline$\square$ & $\square$ & $\square$ & $\square$ \\
\hline
\end{tabular}


4.6 In conclusion, based on your experience teaching overseas, can you rate the relevance, quality and sustainability of offering Australian VET provisions offshore?

\begin{tabular}{lccccc}
\hline & No & Low & Neutral & Moderate & High \\
\hline Relevance & $\square$ & $\square$ & $\square$ & $\square$ & $\square$ \\
Quality & $\square$ & $\square$ & $\square$ & $\square$ & $\square$ \\
Sustainability & $\square$ & $\square$ & $\square$ & $\square$ & $\square$ \\
\hline
\end{tabular}

Thank you for your contribution to this research 


\section{Appendix E: Ethical clearance}

\section{GRIFFITH UNIVERSITY HUMAN RESEARCH ETHICS COMMITTEE}

22-Feb-2013

\section{Dear Ms King}

I write further to the additional information provided in relation to the conditional approval granted to your application for ethical clearance for your project "NR: Australian transnational vocational education and training provisions: sustainability, quality and relevance" (GU Ref No: EDN/09/13/HREC).

This is to confirm receipt of the remaining required information, assurances or amendments to this protocol.

All conditions satisfied.

Consequently, I reconfirm my earlier advice that you are authorised to immediately commence this research on this basis.

The standard conditions of approval attached to our previous correspondence about this protocol continue to apply.

Regards

Ms Kristie Westerlaken

Policy Officer

Office for Research

Bray Centre, Nathan Campus

Griffith University

ph: $+61(0) 737358043$

fax: +61 (07) 37357994

email: k.westerlaken@griffith.edu.au

web:

Cc:

Researchers are reminded that the Griffith University Code for the Responsible Conduct of Research provides guidance to researchers in areas such as conflict of interest, authorship, storage of data, \& the training of research students.

You can find further information, resources and a link to the University's Code by visiting

http://policies.griffith.edu.au/pdf/Code $\% 20$ for $\% 20$ the $\% 20$ Responsible $\% 20$ Conduct $\%$ 20of\%20Research.pdf

PRIVILEGED, PRIVATE AND CONFIDENTIAL

This email and any files transmitted with it are intended solely for the use of the addressee(s) and may contain information which is confidential or privileged. If you receive this email and you are not the addressee(s) [or responsible for delivery of the email to the addressee(s)], please disregard the contents of the email, delete the email and notify the author immediately. 